Routledge Advances in Translation and Interpreting Studies

\title{
ENGLISH AND TRANSLATION IN THE EUROPEAN UNION
}

\section{UNITY AND MULTIPLICITY IN THE WAKE OF BREXIT}

\section{Alice Leal}

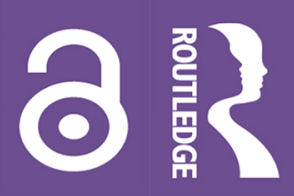




\section{English and Translation in the European Union}

This book explores the growing tension between multilingualism and monolingualism in the European Union in the wake of Brexit, underpinned by the interplay between the rise of English as a lingua franca and the effacement of translations in EU institutions, bodies and agencies.

English and Translation in the European Union draws on an interdisciplinary approach, highlighting insights from applied linguistics and sociolinguistics, translation studies, philosophy of language and political theory, while also looking at official documents and online resources, most of which are increasingly produced in English and not translated at all - and the ones which are translated into other languages are not labelled as translations. In analysing this data, Alice Leal explores issues around language hierarchy and the growing difficulty in reconciling the EU's approach to promoting multilingualism while fostering monolingualism in practice through the diffusion of English as a lingua franca, as well as questions around authenticity in the translation process and the boundaries between source and target texts. The volume also looks ahead to the implications of Brexit for this tension, while proposing potential ways forward, encapsulated in the language turn, the translation turn and the transcultural turn for the EU.

Offering unique insights into contemporary debates in the humanities, this book will be of interest to scholars in translation studies, applied linguistics and sociolinguistics, philosophy and political theory.

Alice Leal is Senior Lecturer at the Centre for Translation Studies of the University of Vienna, Austria. 


\section{Routledge Advances in Translation and Interpreting Studies}

Titles in this series include:

63 English and Translation in the European Union

Unity and Multiplicity in the Wake of Brexit

Alice Leal

64 The (Un)Translatability of Qur'anic Idiomatic Phrasal Verbs

A Contrastive Linguistic Study

Ali Yunis Aldahesh

65 The Qur'an, Translation and the Media

A Narrative Account

Ahmed S. Elimam and Alysia S. Fletcher

66 The Translation of Realia and Irrealia in Game Localization

Culture-Specificity between Realism and Fictionality

Silvia Pettini

67 Translation and the Global City

Bridges and Gateways

Edited by Judith Weisz Woodsworth

68 Gender and Translation: New Perspectives.

New Voices for Transnational Dialogues

Edited by Eleonora Federici and José Santaemilia

69 Global Insights into Public Service Interpreting

Theory, Practice and Training

Edited by Riccardo Moratto and Defeng Li

For more information about this series, please visit https://www.routledge.com/ Routledge-Advances-in-Translation-and-Interpreting-Studies/book-series/RTS 


\title{
English and Translation in the European Union \\ Unity and Multiplicity in the Wake of Brexit
}

\author{
Alice Leal
}


First published 2021

by Routledge

605 Third Avenue, New York, NY 10158

and by Routledge

2 Park Square, Milton Park, Abingdon, Oxon, OX14 4RN

Routledge is an imprint of the Taylor \& Francis Group, an informa business

(C) 2021 Taylor \& Francis

The right of Alice Leal to be identified as author of this work has been asserted by her in accordance with sections 77 and 78 of the Copyright, Designs and Patents Act 1988.

The Open Access version of this book, available at www.taylorfrancis.com, has been made available under a Creative Commons Attribution-Non Commercial-No Derivatives 4.0 license.

Trademark notice: Product or corporate names may be trademarks or registered trademarks, and are used only for identification and explanation without intent to infringe.

Library of Congress Cataloging-in-Publication Data

A catalog record for this title has been requested

ISBN: 978-0-367-24491-0 (hbk)

ISBN: 978-1-032-01975-8 (pbk)

ISBN: 978-0-429-28281-2 (ebk)

DOI: $10.4324 / 9780429282812$

Typeset in Sabon

by Taylor \& Francis Books 
To Amelia and Elliot, meus dois amores

in drei Sprachen 


\section{$\Longrightarrow$ Taylor \& Francis Taylor \& Francis Group http://taylorandfrancis.com}




\section{Contents}

List of Illustrations viii

Preface and Acknowledgements ix

Introduction $\quad 1$

1 Language, Meaning and Identity: From Mother Tongue to Lingua $\begin{array}{ll}\text { Franca } & 7\end{array}$

2 The EU and English as a "Lingua Franca": De Jure

Multilingualism Versus De Facto Monolingualism 45

3 Translation and the EU: The Tension between Unity Versus $\begin{array}{ll}\text { Multiplicity } & 90\end{array}$

4 The EU as a Community in Formation in the Wake of Brexit: For $\begin{array}{ll}\text { a New Linguistic Regime } & 127\end{array}$

5 The Future of Language and Translation in the EU: The Language Turn, the Translation Turn and the Transcultural Turn 181

$\begin{array}{ll}\text { Final Remarks } & 204\end{array}$

$\begin{array}{ll}\text { Appendix } & 207\end{array}$

$\begin{array}{ll}\text { Index } & 215\end{array}$ 


\section{Illustrations}

\section{Figure}

2.1 Some key terms in language policy

\section{Tables}

2.1 EU member states and national languages 46

2.2 The four dimensions of minority languages spoken in EU territory 55

3.1 The EU's translation regimes 95

4.1 Dahl's democracy criteria in the EU 134

4.2 Kraus's demos problem 135

4.3 Transfers enjoyed by native speakers of English 148

4.4 The future of English, according to Graddol 154

4.5 Official EU languages by language family and percentage of EU population 162

4.6 The impact of intercomprehension on linguistic justice 167

5.1 The language turn, the translation turn and the transcultural turn 182 


\section{Preface and Acknowledgements}

This book was gestated and born with my second child. As the unexpected invitation to write it arrived, I was pregnant. I wrote the book proposal in the final weeks before giving birth, alternating between the kitchen counter, which is high enough for me to write standing, and an exercise ball which doubled as a chair in those final months. I'd like to thank my editor Elysse Preposi for reaching out to me, the anonymous peer reviewers, as well as my beloved partner Daniel Stirrat, my cherished friend Philip Wilson and my dear colleague Hanna Risku, for convincing me that the timing was not that bad after all.

Prefaces and acknowledgements are usually about the support and the accomplishments involved in the making of a book. No one wants to know about the difficulties and the dark hours, like when a senior (male) colleague advises you to "use" your maternity leave to write it - "how else do you think mothers in academia get books published?" No one needs to know that whole sections were written while nursing a baby or after having nursed it all night long. It is irrelevant whether key insights came to you while your partner was bathing the children and you finally had seven or eight minutes to think. When, during a talk about gender ethics in academia - while I was visiting the University of East Anglia in 2019 - Jo Drugan asked, "Who has the luxury of time to think?", the penny dropped. Career prospects are dictated by gender roles and stereotypes - you have to write your book despite only rarely having the luxury of time to think, and no one needs to learn about the hurdles you've had to overcome.

So I have to begin by thanking the carers at both my children's nursery schools, an invisible army without whom the world as we know it would pretty much stop - much like translators. I'm also very grateful to the staff of the Equality and Diversity Unit at the University of Vienna for their support and for their post-doc mentoring programme - and to my peers, trainers, coach and mentor from the programme.

My wordcount is going through the roof, so I can't write all my friends' and colleagues' names here who took part in my pools, and/or read and discussed this book with me - though three - Leonardo Schneider, Melanie Strasser and Camila Verzenhassi - earned a special nomination. The same goes for all the English teachers - my former colleagues and supervisors - who 
agreed to be interviewed for this book. My special thanks to dozens of EU staff who had either direct or indirect contact with me, be it in an interview, an email query or an informal chat - from the Parliament, the Court of Auditors, the Commission Representation in Austria, the Legal Service of the Commission and the Directorate-General for Translation. From the latter, I'd like to thank in particular Ivana Zeljković for coordinating our communications.

Many thanks to the senior diplomats, most notably the current Ambassador to Brazil in Austria, José Antônio Marcondes, and the Deputy Head of Mission of the Embassy of Ireland in Austria, Seán Ó Riain; the economists at the International Monetary Fund and the European Central Bank; along with the scholars in different disciplines, especially Peter A. Kraus, who kindly shared their insights with me on sections of this book. I also owe a huge debt to Susan Dunsmore for her careful reading and insightful comments.

Last but not least, without my mother's support, meals and care during those precious months which she spent in Austria, this book would not have been possible. Maria Aparecida Borges Leal, this book is yours as much as it is mine. Obrigada!

Vienna, 4 November 2021 


\section{Introduction}

My children were born in Austria, where they, my partner and I live. Yet none of us are Austrian. The children are registered here as Germans, because my British partner's grandparents were German; so my partner is both German and British, as both his parents and he were born in the United Kingdom. Hence my children are British, too. In addition to German and British, they are Brazilian and Italian as well, because I was born in Brazil to a family whose maternal grandparents had come from Italy. I do not speak any Italian, nor do my children. They have never been to Italy. Yet they are Italian citizens. At home we speak mostly Portuguese and English, but also German. The children speak German at nursery. When they started talking, they spoke all three languages to the same extent - and often at the same time. Trilingual sentences are everyday occurrences in our home. The kids are German, even though they have never been to Germany. (Their German paternal greatgrandparents had never been to Germany either, but that is a different story.) What will my children answer when asked where they come from? Or what their mother tongue is? Will these questions no longer matter as much when they come of age? Will Europe have moved on from the "one nation, one language" notion of citizenship?

Families such as mine are no exception in the European Union. A lot of our friends and acquaintances in Austria have similar multilingual, multicultural backgrounds, and those rare few who do not apologetically explain that despite their monolingualism (or because of it), they have hired an - almost invariably English-speaking - nanny or enrolled the children in an - almost invariably English-speaking - international nursery. (Some even take it upon themselves to socialise their children in English, although they themselves are not proficient in it.) As of 2017, out of 8,772,865 inhabitants in Austria, 1,341,930 (just over 15 per cent) were not Austrian citizens, and 1,656,266 (nearly 19 per cent) had been born abroad. There are almost 665,000 EU citizens living here; 370,000 had been born in the former Yugoslavia, along with another 153,000 second-generation former Yugoslavians. In the schoolyear 2015-2016, over 30 per cent of children enrolled in public nurseries did not speak German at home. Every year, the proportion of school children in the city of Vienna, whose first language is not German, hovers around 50 per cent. 


\section{Introduction}

According to a 2001 census by Statistik Austria, 250 languages are spoken in Austria in addition to German - Serbo-Croatian being the most widely spoken with 308,627 speakers, followed by Turkish with 183,445. English comes next with 58,582 speakers.

The fact that English was the third most spoken language in Austria in 2001 may come as a bit of a surprise, considering that there were only 5,744 Brits, 533 Irish, 39 Maltese, 1,076 Australians, 1,126 Canadians and 6,224 US citizens living here - and the number of citizens from other nations in which English is a (de facto spoken) official language barely reached 12,000. These nearly 60,000 English speakers in Austria were probably second or foreign-language speakers but feel attached to it to the extent that they put it down as their main language. Why is that? And how fast is this cohort growing?

$x * *$

This book is written in English, although I am not an inner- or an outercircle speaker of English, to use Braj Kachru's terminology. Although I started learning English as a child growing up in Brazil, I have never lived in an English-speaking country or been socialised in it by inner-circle speakers. What is my English then? Should it be associated with "standard" British English because of my choice of spelling? Should it rather be classified as international English? Or global English? Or English as a lingua franca? Or some hybrid form of world English? What is the status of this language you are reading now and what is my status as its speaker - and yours, as its reader?

There are 24 official and working languages in the EU, which means that 24 languages have exactly the same status enshrined in legislation. This entails having all legally binding documents available in all 24 , as well as allowing communications with the EU to take place in any of these languages. This is thanks to monumental efforts by the EU's language services, an army of translators, interpreters and language experts working around the clock to keep the output flowing into 24 languages. But there are dozens more languages spoken in the EU's territory, both by autochthonous (such as Basque) and allochthonous (such as Tamil), both by territorial (such as Galician) and non-territorial communities (such as Sámi languages). These communities enjoy no such reverence for their languages, even though some of these communities of speakers are significantly larger than official EU language communities.

Non-binding documents are increasingly found in a single language, though: English. English is by far the most used drafting language across all EU institutions, bodies and agencies, having overtaken French in the 1990s and proceeded to supersede it almost completely. It is estimated, for instance, that 95 per cent of legal drafting takes place in English, 5 per cent in French. However, translations and originals are granted the same status in EU law as equally authentic texts, which means that while most originals are probably in English and most texts in other languages are probably translations, we never know for sure. Equality of status merges into equality of meaning, and the boundaries between translations 
and originals disappear, shrouding the underlying language hierarchies in a thick fog.

No official decision was taken to adopt English as the EU's working language, procedural language or lingua franca -23 other languages are classed as working languages and, informally, English, French and German are procedural languages. In fact, the EU has continuously spoken against the adoption of a lingua franca, since officially raising the status of a single language would constitute a breach of its own legislation. Yet English is the EU's de facto lingua franca of sorts - some 95 per cent of EU staff, for instance, reported in 2016 that English was the most used language in performing their duties. Why is that? Is settling on a common language always the best - and only - solution in multilingual settings? And if so, why not implement it officially?

$* * *$

Dieter Grimm once wrote that "the European Union represents the most significant political innovation of the twentieth century" because it "does not dissolve the national states with their otherwise irreplaceable resources of legitimacy and solidarity" while "provid[ing] solutions for those kinds of problems that can overtax national powers” (2005, 101). The European Union was erected around a common market, initially for coal and steel, which gradually expanded into the European Economic Community and then into the EU of the four freedoms as we know it today: (1) free movement of goods; (2) free movement of capital; (3) freedom to establish and provide services; and (4) free movement of people. These freedoms are predicated on exclusive, shared and supporting areas of competence which were slowly added to the EU's remit, such as the customs union, the internal market and industry, respectively. These areas of competence (26 in total) rely on language and translation to materialise - talks, negotiations, documents, guidelines, products, labels and signs exist in and through language (and translation). Yet language policy is not an EU area of exclusive, shared or supporting competence, even though diversity and multilingualism are hailed as the cornerstones of the European project. National language policies vary greatly, ranging from a no-policy policy to a few articles establishing national and sometimes regional languages. Glaring discrepancies emerge as we cross invisible borders.

The border-free Schengen Area and the free movement of people, compounded by the recent migration flows from outside the EU, have added significantly to the EU's local linguistic diversity (say, in a given member state) and inter-local linguistic diversity (in the EU as a whole). At the same time, the push for monolingualism in the member states' national languages, on the one hand, and bilingualism with English, on the other, have been steadily on the rise. Language tests have become a requirement for citizenship in most EU member states, and education systems are geared towards "integrating" (often "assimilating") children whose mother tongue is not the national language(s). Subsidies for foreign language teaching are almost entirely allocated to English, which is now taught across the EU, often as the main 


\section{Introduction}

(or the only) foreign language, often from primary school to the end of secondary education.

If the EU is a union of peoples with different languages, why is language policy not an EU area of competence? If linguistic diversity is at the heart of the EU, why is it explicitly reduced to monolingualism in a national language and/or bilingualism with English? Would European integration profit from adopting a single language? And what would the consequences be for speakers of other languages? Are languages (and the ligatures they imply) discardable, easily replaceable?

$* * *$

This book weaves many threads from different disciplines together - notably from philosophy of language, applied linguistics and sociolinguistics, translation studies and political theory. Hence, it is transdisciplinary, as it not only combines academic disciplines but also pushes their boundaries and challenges their convictions. Roland Barthes once wrote that this kind of work cannot be a "peaceful operation" since "the solidarity of the old disciplines [must] brea $[\mathrm{k}]$ down" in order for a "new object and a new language" to emerge, "neither of which is in the domain of those branches of knowledge that one commonly sought to confront" $(1979,73)$. Or, as Doris Bachmann-Medick suggests, let us replace "the 'smoother' category of interdisciplinarity" with the "translation category", which "has the advantage of explicitly addressing the differences, tensions and antagonisms between disciplines or schools of thought" (2009, 12). This is how I ask the reader to understand the transdisciplinarity of this volume, bearing in mind that my look into these disciplines is often an outsider's look - except perhaps for translations studies, which I have to call "my" discipline, albeit reluctantly.

My objective is to shed light on the questions asked in this introduction, which can be summarised as follows: what does the EU's ad hoc use of English and effacement of translations say about its underpinning notion of language and translation? And how will Brexit impact the EU's use of language and translation? "Shedding light" is not the same as answering outright - we will spend more time unpicking paradoxes, deconstructing their premises and revealing the aporias of the disciplines that converge (or diverge) in this book than answering straightforward questions. Indeed, the "movements of deconstruction", as Jacques Derrida once wrote, will operate "from inside" and across these disciplines and their "structures" (1997, 24). However, to appease the more pragmatic readers, concrete suggestions will feature throughout and particularly in Chapter 5 .

Why should we care about the EU's language and translation regime? For those of us living in the EU, the more it expands and interacts with our local governments, the more we look to its institutions as an object of identification and as the embodiment of the EU in our identity repertoires. As a unique and multifaceted community of communication emerges in the EU, the spillover effects particularly of the EU's language 
regime - itself a spillover of market forces - become evident. Translation and multilingualism remind us of the Union's ineluctable multiplicity. How much unity does this Union require and what role should language and translation play in it?

For those of us who do not live here, let us remember that the EU "is more than just one case study among others of the future of democracy", as Peter Ives notes. Thanks to its unique nature, the EU is a "crucial site of investigation" and reflection for anyone interested in interpersonal relationships in general (Ives 2004, 43).

You can read this book from cover to cover, or you can choose to skip to the chapters that interest you the most. In Chapter 1, insights from philosophy of language and linguistics will shed light on such notions as language, identity, mother tongue and lingua franca. Chapter 2 is dedicated to the EU's de jure and de facto language policy, whereas the EU's translation regime features in Chapter 3. Chapter 4 looks at the political underpinnings of EU language and translation, with emphasis on the impact of Brexit. A language turn, a translation turn and a transcultural turn will be woven through these four chapters; in Chapter 5, they will be presented in detail. In the Appendix, the reader will find an interview with the Directorate-General for Translation of the European Commission, the EU's main translation body and the unit currently responsible for multilingualism in the bloc.

This is a theorist's and commentator's book rather than the work of an empiricist. I am interested in the epistemological, theoretical and normative implications of the issues surrounding EU multilingualism and translation. I do nonetheless include empirical data wherever possible - mostly collected by the EU, with the exception of interviews and polls which I conducted myself. In the end, I spoke with dozens of EU staff, people in international organisations, diplomacy, academia, language schools and among my circle of friends and acquaintances to gather insight and information for this book, but their input will feature rather as complementary remarks to an otherwise theoretical debate.

\section{References}

Bachmann-Medick, Doris (ed.). 2009. Special issue. Translation Studies 2(1).

Barthes, Roland. 1979. "From work to text". In Textual strategies: Perspectives in poststructuralist criticism, edited and translated by Josué V. Harari, 73-81. Ithaca, NY: Cornell University Press.

Derrida, Jacques. 1997. Of grammatology. Translated by Gayatri Chakravorty Spivak. Baltimore, MD: Johns Hopkins University Press.

Grimm, Dieter. 2005. "A great innovation of our times: As a worldwide recognized role model, Europe does not need a constitution". In Old Europe, new Europe, core 


\section{Introduction}

Europe: Transatlantic relations after the Iraq War, edited by Daniel Levy, Max Pensky and John Torpey, 95-102. New York: Verso.

Ives, Peter. 2004. "Language, representation and suprastate democracy: Questions facing the European Union". In Representation and democratic theory, edited by David Laycock, 23-47. Vancouver: UBC Press. 


\section{Language, Meaning and Identity \\ From Mother Tongue to Lingua Franca}

\subsection{Introduction}

Different estimates set the number of living languages between 4,000 and 6,000 (Steiner 1998, 53; Crystal 2007, 69; Juaristi et al. 2008, 47). Why so many?

Why does homo sapiens, whose digestive tract has evolved and functions in precisely the same complicated ways the world over, whose biochemical fabric and genetic potential are ... essentially common, the delicate runnels of whose cortex are wholly akin in all peoples at every stage of social evolution - why does this unified, though individually unique mammalian species not use one common language?

(Steiner 1998, 52)

George Steiner's own answer lies in the "looseness" and "messiness" of natural languages: they cannot be fully systematised, codified or reduced to their strictly informative content. This profusion of human languages is, for him, an evolutionary advantage "crucial to the creative functions of internalized and outward speech", so that "new worlds are born between the lines" (ibid., 239). It follows that different languages engender and reflect different world-views in ways that relate intimately with their speakers' reality and psyche. From this perspective, we speak different languages because we - notwithstanding our biological similarities - are different, with different communicative needs, different (individual and collective) identities. And we are also different because we speak different languages.

In After Babel (ibid., first published in 1975), Steiner groups theories of language into two categories, though not categorically, as most theories will present traces of both simultaneously. The first group puts forth that "the underlying structure of language is universal and common to all men", whereas for the second group, "universal deep structures are either fathomless to logical and psychological investigation or of an order so abstract, so generalized as to be well-nigh trivial" (ibid., 76-77). Steiner calls them "universalist" and "relativistic" theories of language, respectively. For universalists, "however singular and bizarre [the] superficial forms" of individual languages, 


\section{Language, Meaning and Identity}

they still trace back to "deep-seated universals ... from which all grammars derive"; relativists, in turn, see between different languages no more than "approximate analogies, a rough-cast similitude" (ibid., 77).

Most theories of language can be investigated through Steiner's universalist-relativistic prism. This chapter opens with a cursory examination of a small selection of all-time notions of language, from the classical paradigm to more contemporary views (Sections 1.2-1.6). The main questions that permeate these initial reflections are the following: do we need to speak so many languages and do these different languages trace back to the same source of meaning - in other words, do we all convey the same meanings in different languages? At issue here is not the pre-history of natural tongues; instead, we want to focus on different conceptions of language and its functions. We will then analyse how these different notions of language underpin the concepts of "mother tongue" and "lingua franca" (Section 1.7). And thus we will arrive at the main object of this book, namely "the" English language, to which two sections are dedicated (Sections 1.8 and 1.9). How does it fit into the definitions of language outlined in the previous sections? How does it differ from a "mother tongue" and in which epistemological framework can it be embedded?

This chapter will draw together multiple threads from several disciplines: philosophy of language, applied linguistics and sociolinguistics, anthropological linguistics, as well as, to a lesser extent, translation studies, political theory, history and language policy. This is not the place for a thorough review of these disciplines' respective literatures, so I shall have to paint with a broad brush. In the end, we will have a clearer picture of the dialectics between language and identity, along with their impact on "lingua franca" uses of English.

Steiner's universalist-relativistic categories do not directly tackle the crux of our question here, namely the need for different languages and whether these different languages engender different meanings. However, we could argue that, if the underlying structure of all languages is the same, as universalist theories of language postulate in one way or another, surely there is no need for multiple tongues. After all, all they do is articulate the same, pre-existing meanings and grammatical features in different ways. Relativistic theories, on the other hand, hold that each language conjures up its own meanings; hence there is a human need for multiple tongues. This is of course a generalisation; let us see below how different classic theories of language fit into these categories and shed light on our core questions in this chapter.

\subsection{The Classical Paradigm and Its Legacy: Logos and Affections of the Soul}

The classical paradigm is permeated by an all-embracing logos [from Greek, both "word" and "reason"], i.e. the place where word matches reality univocally. The logos remains constant and is universal; thanks to it we are first 
able to think and then to speak. Speech is the direct representation of thought; speech is hence secondary, derivative of thought. Different tongues simply articulate the same meanings in different ways. This view of language can be traced back to the sixth and fifth centuries BC, particularly to Heraclitus and Parmenides. A corollary of this tradition is the reduction of the function of language to one of reference, of representation of reality - an instrumental function, as it were (Braun 1996, 7; Hoffmann 2003, 27).

Both Plato and Aristotle confirm this view in the fourth century BC. In Cratylus, Plato adds the important caveat that language does not match reality perfectly; therefore, it should not be trusted. This is because individuals corrupted the original words which a primeval "name-giver" had naturally attributed to things $(1921,436)$. This original language is irrecoverable, but the nature and essence [from Greek, ovóí ] on which it rested remain constant and universal. For Plato, "[m]inor differences in sounds and syllables count for little; the languages of different countries point to a common truth"; also, "[i]f the meaning or essence remains the same, we can alter freely a few syllables or individual sounds" (Partee 1972, 120, 122).

A similar view is found in Aristotle's De Interpretatione, though his point is rather that all individuals possess the same universal prelinguistic, mental impressions in their minds - called "affections of the soul". These affections or mental impressions correspond to reality in a natural way; put differently, signs do not refer directly to reality but to these mental impressions, and the equivalence between them is established conventionally, traditionally. There is a "likeness" between meaning and reality (see Braun 1996, 10-11; Modrak 2001, 13-14, 20-21). In Aristotle's words, translated by John Ackrill,

just as written letters are not the same for all humans neither are spoken words. But what these are in the first place signs of, the affections of the soul, are the same for all; and what these affections are likenesses of, actual things, are also the same.

(De Interpretatione, 2002, 16a3)

This much-quoted passage summarises not only Aristotle's theory of language but also the concept of language generally attributed to the classical paradigm.

Generalising somewhat, the classical paradigm is therefore commonly associated with the idea that thought comes first and is not only universal but also independent from language, whereas language is secondary to thought. And although these views tend to be dismissed as simplistic, they have left a permanent imprint on our mainstream notions of language and, consequently, translation. ${ }^{1}$ The very concept of equivalence, every translator's good old friend and worst foe, is an offshoot of this classical conception of language (more in Section 3.4).

In these classical theories, language is thus seen as referential and universal. And, decisively for our purposes here, they place the source of meaning outside language. In Cratylus (Plato 1921, 439b), Plato even cautions us to seek 
knowledge outside language, here in Harold Fowler's translation: "realities are to be learned or discovered ... not from names but much better through themselves".

Therefore, within the classical paradigm, there was no need for multiple languages - we might as well say that there was no linguistic diversity as we understand it today. For the Greeks, the only true language was Greek - nonGreek-speakers were barbarians [from ancient Greek $\beta \alpha \alpha \beta \beta \alpha \rho \varsigma_{\text {, }}$ an onomatopoeic representation of dissonant, meaningless sounds]. For Romans, initially there were only Greek and Latin; later, only Latin. And although there was significant diglossia ${ }^{2}$ for the learned, with a vernacular being used at home and Latin in "higher" domains of society, Latin was perceived as universal, the only true language (Trabant 2010, 883-884). Greek, and then Latin, were seen as an instrument to articulate meanings which stemmed from a universal source. This linguistic monocentrism prevailed in Europe until the late Middle Ages.

Later theories of language went on relentlessly trying to pinpoint this universal source of meaning, with some attributing it to God, others to a "third realm" between our subjective ideas and reality, yet others to a universal language underneath all natural tongues. There have been numerous attempts both to systematise natural languages, thus ridding them of their "messiness", and to devise fully logical artificial languages or metalanguages. Underpinning these projects is the belief that speaking multiple languages is a nuisance, a murk that obfuscates true meaning, a pointless enterprise, for surely there is no need to employ multiple instruments to represent the same meanings. We will investigate some of these projects in the coming sections.

The legacy of the classical paradigm finds its most influential and lasting expression in Ferdinand de Saussure's theory of language - though it must be noted that Saussure broke away from these universalist traditions of direct association between language and reality. In fact, he emphasised that languages are not mere lists of terms, and that there is no reality, no pre-established ideas before and outside language; put differently, for Saussure, each language articulates its own meanings. This notwithstanding, he retained two key binary oppositions, which in turn might explain the lasting influence of universalist ideas on our mainstream notion of language (Rodrigues 1999, 187; Lages 2007, 211). The first is form versus substance, whereby "form" can be understood as languages or words, whereas "substance" refers to meaning. The second dichotomy is speech versus thought, along with the idea that speech is the direct representation of thought (see Saussure 1986, 115-117). Both dichotomies are crucial to any universalist notion of language (and translation; see Section 3.4), as we will see in what follows.

\subsection{A Historical Note on the Rise of Vernaculars: Cuius Regio, Eius Lingua}

Dante's De vulgari eloquentia, written at the beginning of the fourteenth century but kept under wraps for about two centuries, is perceived as the first 
scholarly work in which a vernacular is considered on a par with Latin. It took a few centuries for this shift to take hold in Europe: at the beginning of the seventeenth century, Galileo Galilei started writing in "Italian”, René Descartes in "French" and Francis Bacon in "English". The trend culminates in the eighteenth century, when the interest in languages and in the differences between peoples grows exponentially, leading to the establishment of anthropology, as Jürgen Trabant points out (2010, 885-886). He notes, nevertheless, that this diversity is not perceived positively at first, and that the developments that followed were in fact attempts to tame it (ibid., 887).

We must bear in mind that "the equation of language and nation is not a natural fact but rather a historical, ideological construct" of the eighteenth century (Woolard 1998, 16). The classical paradigm unfolded long before the notion of nation, nationality and national language had been established. These are relatively new constructs:

In the early 19th century Bucharest was still a Greek town, in 1848 Prague, Plzeň [Pilsen] and Ljubljana had German majorities, and as late as the second half of the nineteenth century, the most important towns in Finland were mainly Swedish, Riga and Tartu (Worpat) were German, the towns of Bulgaria mostly Greek and those of the Dalmatian coast, Italian.

(Kolarz, quoted in Fishman 1972, 19)

Notwithstanding the differences between canonical views on the emergence of nationhood in Europe, the following points hold sway in contemporary history. The nation state, i.e. a sovereign state in which one people (perceived as) fairly homogeneous in ethnical and/or cultural terms predominates, is a Western European creation that began to spread after the French Revolution in 1789 - initially in Europe and then beyond, due to colonialism. The nation and its offshoots (nationalities, national languages) are hence state-driven constructions. It is as Eric Hobsbawm (1990) puts it: nationalism follows the state and not the other way around; nations (and national languages) can only be recognised a posteriori.

In an attempt to create unity, not least for warfare purposes, states actively sought to homogenise their vernaculars and the cultural practices performed in their territories. "In the making of modern Europe," Peter A. Kraus reminds us, "the norm cuius regio, eius religio often found its 'natural' continuation in the politics of cuius regio, eius lingua" (2008, 86). The newly founded education systems, aided by the advent of print capitalism, played a pivotal role in this enterprise. Their key task was to spread the "national language", the "mother tongue", as it were, which in turn first had to be created - i.e. standardised, codified. Jan Blommaert calls it "linguistic items with a name" or a "set of decontextualized rules and norms ... confined to national spaces within which they could become the emblems of national identity" $(2006,242)$.

National languages led to the "discovery" or "invention" of national literatures, which helped create a sense of local differentiation and uniqueness in 
relation to other nations. There certainly were places in which integrative bonds were tighter to begin with, thus facilitating the construction of "national identity", while others struggled to forge these ties. In both, however, national cohesion was not a natural result of ethnocultural similarity, not least because ethnocultural similarity has never been the main basis for political integration (Blommaert \& Verschueren 1998). These perceived similarities within states aspiring to nationhood amounted more to common political, economic or religious values than to ethnocultural homogeneity (see Fishman 1972; Hobsbawm 1990; Bayly 2004; Kraus 2018, 89-93). ${ }^{3}$

\subsection{The Enlightenment and Its Legacy: Language as an Instrument for Communication, as Divine Logos and as a Nation's Genius}

To come back to philosophy of language, the legacy left by the classical paradigm means that later theories of language invariably returned to the themes at its heart. In the seventeenth and eighteenth centuries, two streams of reaction to the classical paradigm paved the way for the establishment of a fully-fledged philosophy of language in the nineteenth century, namely nominalism and rationalism.

Nominalism held that language does not reduce to the logos and is not secondary to it (Braun 1996, 11-12). A key thinker for our purposes here is John Locke, who was the first to wonder how communication is possible when ideas are private entities available only to individual speakers, and when meaning is established conventionally, through language use, and not naturally, as Plato would have it. Locke also pondered whether language creates or reflects reality, without arriving at definitive answers (Nye 1998, 3-4). His denial of metaphysical forms, i.e. a stable and external source of meaning, undermines the thesis that different languages articulate the same meanings, hence sowing the seed of relativism ${ }^{4}$ (Rorty 2000, 23). Yet Locke's philosophy came to be linked with an instrumental view of language as a mere tool for communication, which in turn is crucial for the notion of lingua franca. $\mathrm{He}$ avers, for instance, that "language [is] the great conduit, whereby men convey their discoveries, reasonings, and knowledge, from one to another ..." and warns that language is a "mist before our eyes" (Locke 1999, 500, 483). To clear the mist and promote the instrumentality particularly of philosophical language - which had to be strictly truth-speaking - he proposed a separation between popular and scientific language - not unlike the diglossic division of previous times with Latin and local vernaculars (see Trabant 2010, 887).

Rationalist thinkers, too, sought to protect and foster the instrumentality of language, though in different ways. Gottfried W. Leibniz, for example, stressed the intersubjectivity of language; in other words, for him, communication was possible because beneath the surface of every tongue lies a universal language shared by all and governed by strict logical-mathematical principles, the socalled characteristica universalis (Braun 1996, 14; Steiner 1998, 73). With rationalism, the dreams both of a universal language and of a strictly logical 
way to systematise natural languages are born. However, unlike Locke, Leibniz perceived different languages (and language uses) as a source of wealth rather than as obfuscations of philosophical thought. His celebration of linguistic diversity, particularly in his 1765 Nouveaux essais, can be seen as the dawn of linguistics (Steiner 1998, 78; Trabant 2010, 888).

Another development from the Enlightenment that sheds light on the question of linguistic diversity is encapsulated in Jakob Böhme's and, later, in Johann G. Hamann's writings, which are predicated on a mystical, divine logos. In other words, speaking and understanding (and translating) were tasks that involved recovering God's word hidden in every natural language, i.e. the Ursprache [from German, "original language"] (Braun 1996, 22, 24-26; Steiner 1998, 80). Linguistic diversity obscured these divine meanings, which in turn remained stable across different tongues. This view dovetails with mainstream interpretations of the biblical myth of Babel - which I trust the reader knows according to which linguistic diversity amounts to a divine punishment for humankind's audacity.

Yet many Bible specialists see the myth in a more benign light, rather as a divine push for humanity to spread across the globe (see e.g. Sarna 1974; Grossman 2017). The newly imposed plurality of languages simply meant that we were less likely to remain gathered in a single spot. One of the Akkadian etymologies of "Babel" is indeed to channel, to move. It is known that Babylon was irrigated by numerous channels from nearby rivers, which brought wealth and fertility to the city. According to this interpretation, the etymology of "Babylon" points to the notion of "redistribution of water" and "redistribution of humanity" (Grossman 2017, 372). Babylon is thus not necessarily (and definitely not only) the site of chaos and corruption of the Ursprache, but rather the point from which humanity spread. Umberto Eco opportunely reminds us that the existence of multilingualism is actually mentioned as a fact in Genesis before the infamous episode of the Tower of Babel (1997, 10). For Paul Ricoeur, the myth is tantamount to "the non-judgemental acknowledgement of an original separation", here in Eileen Brennan's translation $(2006,18)$. Still, the fact that we speak multiple tongues has been persistently seen through a negative light, as an obstacle to communication, in philosophy as in Christianity (see Trabant 2010, 881).

However, it was from a place of faith in the divine logos that an out-andout relativistic notion of language was born, namely in Johann G. Herder's writings (Hamann's student - see Braun 1996, 26; Steiner 1998, 81). Herder swam against the tide by asserting that thought is not secondary to language (as both the classical paradigm and the Enlightenment held) and that different languages conjure up different patterns of thought. For the first time, the expressive rather than the instrumental function of language was in the spotlight, as each language was seen as the quintessential symbol of a people's "genius" [Genie, from German, both from Latin genius, "guardian deity" or "natural inclinations"]; in other words, each language "contain[ed] its own particular vision of the world" (Eco 1997, 110). For Fishman, all instances of 
celebration of vernaculars witnessed in the past two centuries stem from Herder (1972, 46; see also Schieffelin et al. 1998). German Romanticism as a whole, of which Herder was a key precursor, is seen as having replaced "the uniformitarianism of the Enlightenment" with "diversitarianism" (Schlesinger 1991, 13).

More controversially, Herder is associated with a Blut und Boden ideology ["blood and land", from German], i.e. the belief in a tight-knit link between nation and ethnicity which eventually came to form Nazi ideology.

Herder's relativism infused philosophy of language in the eighteenth and nineteenth centuries, finding perhaps its most enduring form in Wilhelm von Humboldt's writings. Humboldt developed Herder's proposition that language was not secondary to thought by claiming that language was not the finished "product" of thought either; it was rather the "thought-forming organ" [ das bildende Organ des Gedanken; Humboldt 1836, 50]. Put differently, language was not Ergon [from Greek, "work"] but rather Energeia [from Greek, "activity"]; not the means to an objective, but the objective itself (Humboldt 1963, 418; Braun 1996, 27). Through this expressive light, language was portrayed as inseparable from the Weltanschauung, culture and history of its speakers - these factors fed into language and language fed into them in a circular motion.

About a century later, Humboldt's relativism was put to the test empirically by Edward Sapir and Benjamin Lee Whorf. ${ }^{5}$ Steiner even names this joint enterprise the "Humboldt-Sapir-Whorf Hypothesis" (1998, 98). In Sapir's words, “[n]o two languages are ever sufficiently similar to be considered as representing the same social reality" $(1985,162)$. Similarly, Whorf suggests that

[a person's] thinking itself is in a language ... And every language is a vast pattern-system ... in which are culturally ordained the forms and categories by which the personality not only communicates, but also analyses culture, notices or neglects types of relationship and phenomena, channels his reasoning, and builds the house of his consciousness.

(1956, 252; see also Formigari 2004, 133)

Like Humboldt's, Sapir and Whorf's understanding of language was circular, as the influence of language was seen as bidirectional: from culture to language and from language to culture (Schlesinger 1991, 17). In a nutshell, the SapirWhorf hypothesis postulates that thoughts or utterances in one language are not (fully) comprehensible beyond that individual's language community. It follows that linguistic diversity is a necessity, a reality to be celebrated. From this out-and-out relativistic perspective, say, Western thought is merely a "specialization of the Western Indo-European type of language" (Whorf 1956, 247), thus suggesting that only by stepping into different language circles can we broaden our horizons (see Formigari 2004, 133; Wierzbicka 2013).

The Sapir-Whorf hypothesis plays a pivotal role in our discussions here because it encapsulates a series of ideas about language and its dialectics with 
such concepts as identity, meaning and Weltanschauung. Its main corollary is that speaking different languages amounts to far more than simply articulating the same meanings with different words. Particularly with Whorf, what we take home is a steadfast commitment to linguistic diversity (John-Steiner 1991, 62). Attempts at testing and systematising the hypothesis galore, from linguistic anthropology, linguistics, psycholinguistics and psychology, and with varying degrees of success (see Fishman 1960; 1985; Schlesinger 1991). The more radical strains of relativism culminated in linguistic determinism, i.e. the view that cognition depends on language. These radical views have been thoroughly rejected; after all, if they were right, Whorf himself would not have been able to work among the Hopi as he would have been incapable of understanding their language and their corresponding world-views (Schlesinger 1991, 16). Both Ricoeur and Steiner concur with this opinion: if the SapirWhorf hypothesis were entirely correct, interlingual communication and foreign language acquisition would be impossible tasks - in which case, bilinguals would be schizophrenics (Steiner 1998, 98; Ricoeur 2006, 15). For Ricoeur, the hypothesis amounts to a "theory of the untranslatable" (ibid., 14-15 - more in Section 3.5).

There are enough indications that even Sapir and Whorf's textbook relativism was not entirely without universalist traits, thus dispelling claims of linguistic determinism (see Whorf 1956, 239; Macnamara 1991). Further, the link between language and ethnicity or ethnic identity, inherited from Herder, is pretty much undone with Sapir and Whorf. Sapir emphasises that a language creates the race to which the mystical origins of that language are later attributed, and not vice versa. The link is hence "man-made" (Fishman 1972, 47). Still, Sapir and Whorf's (often interpreted as ethnical) linguistic relativism has come to constitute our contemporary notion of language (see Macnamara 1991; Schlesinger 1991; Steiner 1998, 97-114; Wierzbicka 2013, 1-51; Leal 2019). Witness, for example, the new marketing campaign of Vienna's Volkshochschulen [community colleges]: "die Welt verstehen, Sprachen lernen", or "understand the world: learn languages". It is a truism that learning a new language broadens our horizons - just as it is a truism to say that there is equivalence among different languages. Indeed, our mainstream notion of language merges universalism and relativism, too.

The legacy of the Sapir-Whorf hypothesis is less about what we can say, for we can say anything in any language; it is rather about what we must say, what we say with relative ease, and how our languages determine how we express ourselves. The reception of Herder's, Humboldt's, Sapir's and Whorf's works in the past several decades teaches us this much: we are all influenced by the language(s) we speak, and we also influence these languages (or linguacultures - Risager 2012) in a self-perpetuating cycle. Linguistic diversity is not a hurdle to be overcome but a trait as human as humanity itself. This realisation is disconcerting, as it removes language both from the logical framework envisioned by Leibniz and from the supra-human framework proposed by Böhme and Hamann, to throw it into the more abstract and volatile 
realm of human subjectivity. Little wonder that a lot of effort has been put into framing language according to logic, as we will see in Section 1.5.

\subsection{The Linguistic Turn and the Pragmatic Turn: The Enduring Appeal of Universalism}

Philosophy of language blossomed in the nineteenth and twentieth centuries and this is no coincidence, as a so-called linguistic turn swept through philosophy. Language went from being one possible object of philosophical inquiry to the pivotal element in any philosophical investigation. However plural the theories developed in this period may be, they concur that language and thought cannot be separated and, more importantly, that all philosophical problems are, first and foremost, linguistic problems - i.e. problems in language and about language (see Braun 1996, 29).

Analytic philosophy, one of the "most influential [currents] in modern philosophy" (Steiner 1998, 212), was born out of a radicalisation of the characteristica universalis predicated on the Platonic notion that natural tongues are deceptive and treacherous. Analytic philosophy is important for our reflections here because it encapsulates the quest for an ideal language or metalanguage above and beyond natural languages; put differently, it typifies the will to push language back into a strictly logical framework, which in turn would render multilingualism pointless - at least theoretically - and lead to perfect machine translation. Both turned out to be a tall order, but hope lives on until this day (see Rorty 2000, 22; Trabant 2010, 892).

One of its main precursors, Gottlob Frege, argued that there is a "third realm" [in German, drittes Reich] between our subjective ideas and the objective world, which is common to all languages (Nye 1998, 4; Soames 2010, 20). Following Frege, Bertrand Russell and the early Ludwig Wittgenstein set out to develop a "correspondence theory" in which "language is ... a one-to-one picture of the world [and] propositions 'are like' the things they are about" (Steiner 1998, 219-220). Indeed, in Wittgenstein's Tractatus Logico-Philosophicus $(1922,3.343)$ we read that "[d]efinitions are rules for the translation of one language into another. Every correct symbolism must be translated into every other according to such rules. It is this which all have in common" here in Charles K. Ogden's translation.

As a reaction to this current, known as ideal language philosophy, ordinary language philosophy emerged from a pragmatic turn in philosophy, which has arguably been brought about in part by the later Wittgenstein (see Trabant 2010, 893-894). Although both currents agreed that philosophical problems stemmed from the elusive character of natural languages, ordinary language philosophers thought it better to describe the features of everyday discourse than to devise an ideal language (see Steiner 1998, 217-218). John L. Austin's and John Searle's speech act theory epitomises this endeavour as it rests upon the idea that meaning lies in the rules that govern everyday language. At first sight, its pragmatic character generally speaks against universalism: if language 
is action and amounts to ordinary use by speakers, it is impossible to determine "the" meaning of a given utterance. On the other hand, Austin and especially Searle rely heavily on the notion of intentionally and literal (as opposed to metaphorical) meaning. If languages possess an inventory of literal meanings which are publicly available to everyone, arguably different languages articulate roughly the same meanings - at least the ones perceived as literal (see Searle 1979; Austin 1998; Arrojo \& Rajagopalan 2003; Leal 2014).

Speech act theory paved the way to Jürgen Habermas's theory of communicative action and universal pragmatics, one of the most influential currents in philosophy of language from the latter half of the twentieth century (Braun 1996, 44). Unlike Searle and Paul Grice, for example, Habermas does not tie his notion of meaning to intention but to the acceptability of speech acts (2003, 232-233). There is an important shift from the perspective of the speaker (Grice's "intention") to a more global, intersubjective perspective. Habermas, in his theory of truth and knowledge (1999), avoids the age-old problem of the referential character of language by stating that a proposition is true if it accurately represents the reality to which it refers in the real world, though not in a metaphysical but in a pragmatic way (Habermas 2003, 343-381). Habermas's pragmatics is universal in the sense that it attempts to stipulate universal conditions for mutual understanding. He does not defend any form of universal language but does push for English as the "second first language" of the $\mathrm{EU}$, which to him is a prerequisite for the formation of a European public sphere, "so that citizens can have an opportunity to relate simultaneously to the same issues in similar terms" (Habermas 2006, 104; translated by Ciaran Cronin and Max Pensky; see Kraus 2008, 141-142). This suggests an instrumental view of language, at least as far as the English language is concerned. We will come back to Habermas's stance on EU multilingualism in Section 4.3. Let us now turn to the last section on philosophy of language before introducing the notion of lingua franca.

\subsection{Postmodernism, Poststructuralism, Deconstruction: Beyond the Dichotomy Universalism Versus Relativism}

Contemporary philosophy has refined and challenged the notions of language discussed thus far in different ways. Poststructuralism can be seen as an attack on the scientistic aspirations of some of the theories of language outlined in the previous sections, which not only "attempted to create a scientific basis for the study of culture [and language]" but also "strove for the standard modern goals of foundation, truth, objectivity, certainty and system" (Best \& Kellner 1991, 20; Leal 2014, 24-28). In many ways, the struggle against scientism is ongoing (see Rorty 2000).

Poststructuralism is a current within postmodernism; while postmodern theory encompasses a broad range of discourses, poststructuralist theory refers directly to our models of subjectivity, writing and thinking (Leal 2014, 24-28). Poststructuralist discourse has made pivotal contributions to philosophy of 
language, though not as a unified front - the notions of difference, disagreement and heterogeneity are key in poststructuralist discourse (Lyotard 2003, 6; Leal 2014, 302-310).

One of the most controversial poststructuralist thinkers who left a permanent imprint on philosophy of language is Jacques Derrida, the founder of deconstruction (see Sarup 1993; Norris 2002). In the 1960s, Derrida radicalised the linguistic turn by claiming that "there is nothing outside of the text", here in Gayatri Chakravorty Spivak's translation (1997, 158). So not only did he acknowledge that all philosophical questions are, first and foremost, questions about language and in language, but he also attributed our entire existence to language, to a "system of writing" from which there is no escape (ibid., 30-44). With poststructuralist discourse and particularly with deconstruction, language began dominating the philosophical debate because meaning could no longer be taken for granted as the unproblematic, direct representation or reflection of external - or internal - realities, nor as a straightforward entity that could be instrumentally conveyed in different languages (Glendinning 2004, 6; Leal 2019, 236).

Because the word "meaning" is charged with different connotations that link it with a transcendental source, Derrida avoids it altogether, choosing instead the Saussurean dichotomy "signified" (concept or meaning) and "signifier" (acoustic image or word). For him, all Western philosophers defend some form of transcendental meaning, in the sense of a source of meaning outside language. In other words, Western philosophy is, on Derrida's account, logocentric, i.e. obsessed with the logos [word or reason]. As we have seen in the previous sections, both more relativistic and more universalist thinkers sought to find or establish a transcendental source of meaning, or simply took it for granted that there was one. This source has been located in different places: in the all-embracing logos, the divine logos, Aristotle's affections of the soul, a third realm of objective thoughts, social conventions, culture, a nation's genius and language use. However diverse the notions of language reviewed in earlier sections may be, they all concur with the thesis that meaning either transcends language or lies outside its domains (Goldgaber 2019; see Leal 2019). These logocentric views permeate our mainstream notion of language (and translation - more in Section 3.4).

Assuming that there is nothing outside the text or outside language, Derrida boldly outlines the fallacy of logocentrism as follows: to presuppose that there is a system of meaning beyond or beneath/above language to which each sign in each language refers. Signs are self-referential - they refer only to themselves and to each other, and not to external entities in the real world or internal entities in our consciousness. Here, two concepts are key to illuminate our main questions in this chapter, namely différance and "trace/track". Différance, the purposefully misspelt French word, refers to meaning as a process of both deferring (one sign leads to another sign ad infinitum) and differentiating (signs are told apart by their differences to other signs) (Derrida 1967, 297-305). "Trace/track" plays a central role in the process of différance, as signs refer to 
what they are not, to an absence made present; they "carry" with themselves the traces of other signs, not references to anything else. Put differently, signs are but traces of other signs, irrespective of the language to which they belong, for différance takes place across languages (see Derrida 1997, 66-67). Languages do not exist in some pure state, isolated from one another, but rather "bleed" into one another (see Foran 2012, 79). From this perspective, the origin or source to which signs refer is a non-origin. There is no "outside-language" or "outside-text" to which to anchor signs.

Translation plays a pivotal part in deconstruction - Derrida argues that the possibility of philosophy is contingent on translatability (more in Section 3.4). Translation is, after all, a task traditionally associated with recovering meaning - or the transcendental signified - and then transferring it into another language. As noted earlier, linguistic determinism entails full untranslatability, whereas universalist approaches tend to see translation as a matter-of-fact transaction. In deconstruction, a double bind comes into play: understanding, and hence translating, entails translatability and untranslatability simultaneously. We cannot help but establish a relation with others, translate them, make them our own, but at the same time we cannot help but maintain their otherness, their alterity - they are, after all, untranslatable. Accordingly, Derrida sees translation as "regulated transformation" rather than as "some 'transport' of pure signifieds from one language to another", here in Alan Bass's translation (Derrida 1981, 20). Indeed, for Derrida, each "language must be unique and self-referential in that it cannot be totally subsumed into another language, yet it must also be able to reach beyond itself to another linguistic entity" (Foran 2012, 81).

What we have here is the suspension of the dichotomy universalism-relativism - in fact, the suspension of dichotomies in general, as we are always pushed to look beyond them. Because language is self-referential, because there are no "closed circuits in natural language, no self-consistent axiomatic sets" (Steiner 1998, 428), it is superfluous to speak either of a universal source of meaning or of a relativistic source of meaning. There is no "outside language"; thus, the boundaries between different languages are blurred, as are the boundaries between language and reality. Language is no longer seen as a reflection of external - be they social, cultural or political - or internal factors - be they subjective ideas or objective thoughts, to use some of the categories mentioned in the previous sections. In other words, language, discourse, ideology and culture - themselves tricky constructs - do not reflect or portray the world; rather, they are the "primary sites of how the world is organized and understood" (Pennycook 2006, 61).

In postmodern theory, the notion of individual natural languages as ontological, monolithic units is often replaced with the less positivistic and inevitably localised term "discourse", understood here as a means of talking, writing and acting that is simultaneously a representation and a new creation of social practices within multiple circles (see Candlin 1997). But even when the word "language" is used, it is not understood as a bounded entity, but 
rather as discourse, which is neither universal (for knowledge is always particular, always situated) nor relativistic (since the boundaries between languages, peoples, ethnicities, cultures and nation states are nothing but taken-for-granted, modernist, often colonial, constructs) (see Pennycook 2006; Shohamy 2006).

This anti-foundationalist view of language is the first that is non-logocentric, at least from a deconstructive perspective. To give up the logos means to abandon the quest for a source of meaning - a "demonstrable identity of meaning” in Ricoeur's words $(2006,22)$. One such abandonment entails the rejection of the search for a verifiable link between language and identity, culture and ideology, too. Identity, culture and ideology are language. As Alastair Pennycook puts it:

[1] anguages are not so much ontological systems that precede the utterance as the products of language use sedimented through acts of identity. As we perform identity with words (rather than reflect identities in language), we also perform languages with words.

$(2006,71)$

Through this prism, language is reinscribed into a complex multimodal framework which encompasses, for instance, body language, music, clothes, along with any other identity-related practices. Within this multimodal framework, linguistic diversity is approached in more fluid, mobile and especially contextual ways. The idea of ethnic identity, so dear to early relativistic theories of language, thus pales into insignificance as the notion of multiple identifications across and beyond individual languages and their associated ethnicities takes centre stage.

If we embrace this poststructuralist conception of language, can we still address the issue of "the" English language in this book? Yes, we can, for two main reasons. First, even though postmodernism seeks to dis-invent the constructs that shape any debate around language (such as "language"6 itself, but also "ethnic identity", "nation state", "culture", among many others), as long as entire societies and their institutions are based on these constructs, we have no choice but to engage with them (Johnson 2013, 42-43). If we wish to critique a sign, we have to use it, to "inhabit" it and "its old structures" - while "respect[ing] all its classical exigencies" but, at the same time, striving to open a "new reading" (Derrida 1997, 24, 158). To come back to "the" English language, or any language, for that matter: abandoning named languages altogether - because they are constructs and because multilingual individuals perform their languages in a continuum (and not as separate entities) - seems an unnecessary step that does a disservice to linguistic minorities, for example, who need their languages to remain visible (more in Section 3.7).

Second, the study of multilingualism, in fact, the study of anything, is first and foremost a study of a discourse about multilingualism - again, there is no outside-text. However, even as a study (itself a discourse) of a discourse about multilingualism, a text can and should also be able to stop problematising its 
own epistemological grounds and moments of aporia to reach out to the processes which shape its discourse. Derrida himself did this numerous times: one of his last publications, the renowned 2003 paper signed with Habermas and originally entitled "Unsere Erneuerung - Nach dem Krieg: Die Wiedergeburt Europas" (Habermas \& Derrida 2005), is an obvious attempt to "halt deconstruction", as it were, and to produce what Kraus and François Grin would call an "explanation and interpretation of the actual processes themselves" instead of deconstructing the discourse upon which these processes rest (2018, 9-10). Derrida would probably remind us that deconstruction cannot be halted anyway, for it always happens as soon as there is language, whenever there is text - and there is always language, there is always text. To be honest, he would probably - as ever paradoxically - also reject the notion that we can reach out to the "actual processes themselves" for there is no outside-text. ${ }^{7}$

So I ask the reader to bear with me and enact the first of many double injunctions or double binds that this book will require. Let us be willing simultaneously to deconstruct the pillars of our discussion here - language, meaning, identity - while also moving away from their moments of aporia to try to reach out to the "actual processes themselves".

\subsection{Introducing a Lingua Franca}

How do these ideas about language apply to the notion of lingua franca? Does a lingua franca constitute a different object altogether? This is not the place to offer a thorough review of the history of lingua franca uses across the globe (see e.g. Dakhlia 2008; Ostler 2010), so a few cursory remarks will have to suffice. The ever-increasing use of the term "lingua franca" in the past few decades in numerous disciplines, notably linguistics, translation studies and political theory, has turned this area into a terminological minefield, so we shall have to tread carefully.

Today, a lingua franca is often a national language used as the common denominator among speakers of different languages. Traditionally, however, a lingua franca was a vehicular language made up of bits of multiple contact languages in a restricted geographical area - remember "the" lingua franca of the Mediterranean, Sabir, a mixture of what we would today call Arabic, Berber, Catalan, French, Greek, Italian, Occitan, Portuguese, Spanish and Turkish (see Wansbrough 2013). Note the key differences between these two definitions: the former has no native speakers and "represents" no nation state, whereas the latter does. Focussing on the first definition, if any language can play the role of lingua franca depending on the context, how do we distinguish between a mother tongue, a second language, a foreign language and a lingua franca? There is no consensus in linguistics when it comes to this thorny question, but a few general terminological tendencies can be identified, and I will lay them out with extreme caution in the next few paragraphs, hoping to avoid most mines. 


\section{Language, Meaning and Identity}

In our postmodern times, many linguists eschew the terms "mother tongue" or "native speaker", as they convey an idealised notion of a monolithic language optimally acquired by an equally optimal individual. Christopher Hutton (1999) reminds us of the controversial role played by linguistics in establishing notions such as these, which, in his view, fuelled nineteenth-century nationalism, race theory and Nazi ideology - the latter being not so "conceptual[ly] distan[t]" from modern linguistics, as Hutton sees it (ibid., 2; see Eco 1997, especially his Chapter 5). Elana Shohamy concurs with Hutton and adds that the notion of language "as a closed and finite system" dovetails with "the idea of the nationstate as a closed and finite society to which only certain people had the legitimacy to belong", which means that those "who had the right blood" were the "native-speakers" (2006, 31-32). ${ }^{8}$

Traditionally, however, a "mother tongue" is viewed as any language into which one is socialised early on - though late "acquirers" may also be promoted to the exclusive group of "native speakers". Einar Haugen (1991) traces the origin of the expression "mother tongue" to the early Middle Ages, when it was a pejorative term used to describe the less prestigious language of women and children, usually in contrast with the "father tongue", i.e. Latin (and Hebrew). In the Renaissance, the "mother tongue" started gaining ground as a legitimate language mostly thanks to the advent of Bible translations into vernaculars. But it was not until the nineteenth century that the "mother tongue" achieved its fully-fledged glory as the pillar of national identity. From that point onwards, the "reverence for the mother tongue reached at points mystical levels", reminding us of the biological bond implied in the epithet (Hutton 1999, 6). After all, a child's primary socialisation happens at the mother's knee; hence the mainstream notion of "mother tongue" as an organic, blood-related entity.

A "native speaker" of a "mother tongue" can then go on to learn a "second language". The ordinal number here points to the fact that the language in question enjoys some kind of official status in the institutions where the individual in question is socialised. Imagine, for example, someone who speaks Portuguese at home in Germany - her second language will be German, and by many standards she may be officially considered a native speaker of German as well.

A “foreign language", in turn, usually denotes a language with no special status in the region where it happens to be "acquired". If that same Portuguese native speaker growing up in Germany went on to learn Arabic, then Arabic would class as a foreign language. Both "second" and "foreign" languages rely heavily on the symbolic and concrete value of the "mother tongue". In other words, second and foreign language teaching revolves around the adoption of mother tongue norms with the purpose of (potentially) integrating the learner into the target culture (see Graddol 2006, 80-91; Seidlhofer 2011, 18).

Within this terminological framework, a lingua franca speaker is most likely a foreign language speaker, though there is a rather thin line (if at all, depending on the context) between a second and a foreign language speaker. 
Think of all the territories in which English is an official or co-official language - David Crystal lists as many as 75 (2003, 62-65). In many of these, English is as little widespread as - or even less widespread than - in countries and territories where it enjoys no official status. The difference between a second and a foreign language speaker is thus political rather than linguistic (which is obvious). Moreover, the very presumption that one can objectively assess someone's language proficiency against "mother tongue" norms and decide whether they are native, second language or foreign language speakers is at best problematic, but that is a different discussion.

Multiple languages have played the role of lingua franca in different corners of the globe, most notably Latin, Greek, Sanskrit, Arabic, Persian, Turkish, French, Russian and English, on Nicholas Ostler's (2010) account. These languages were all well established in a certain area, as the mother tongue of large populations, before they were - mostly but not exclusively - forcefully introduced into newly conquered territories. Incidentally, Ostler and others make no distinction between a second or foreign language and a lingua franca, which he defines as "large-scale languages used internationally" (ibid., 7; see Van Parijs 2011, 9).

Through a postmodern lens, we can see the continuity between these different language uses, along with their overlapping functions as fluid, localised and mobile components of more complex multimodal frameworks. When does a second or foreign language become a mother tongue or a lingua franca? Can a lingua franca speaker be "upgraded" to mother tongue status after, say, having spoken the language daily for a long time? What about the other way around: can a native speaker who has not spoken her mother tongue for most of her life be "downgraded" to lingua franca speaker? And who gets to make these decisions?

More important than the status of individual speakers, however, is the notion of language that underpins these value judgements. Particularly regarding the use of English as a lingua franca, an instrumental notion of language is often implied, whereby meaning in one's mother tongue(s) can be mechanically conveyed in English, without any spillover effects or ideological implications (more in Section 1.8). Generalising somewhat, this view of lingua franca implies that one's mother tongue is reserved for identification, (national) identity building and expressive functions, whereas the lingua franca is a mere instrument for communication, devoid of any national, cultural or ideological attachment. This drastic separation is seldom problematised and constitutes another pernicious construct which - albeit handy - requires a deconstructive effort on our part.

Postmodernism may have unveiled the construed character of some mystical, intrinsic connection between "national" language and identity; the very notions of a fixed "national language" and an equally fixed "national identity" are untenable today. Nevertheless, the link between language and identity remains, not least because there is no such thing as purely linguistic and purely identity-related elements in language. Language is certainly a contingent 


\section{Language, Meaning and Identity}

marker of identity, which does not mean to say that language is not constitutive of identity - along with many other factors (see Blommaert \& Verschueren 1998, 2; Holmes \& Dervin 2016, 3). Let us remember Derrida again: there is no outside-text. However hybrid and fluid these concepts may be, both our social and our individual identity repertoires are permeated, conveyed, constructed by and in language and vice versa (May 2004, 43-45; see Pennycook 2006, 70). As Kraus puts it:

[We] tend to experience language as something that belongs to [us] in a unique way, i.e., as an asset that establishes critical links between [our] immediate life-world and the realm of institutionalised collective practices ... thereby constituting a core element of [our] identity.

$(2018,94)$

To propose a binary opposition between the instrumental and the expressive or identity-shaping function of language is not only incompatible with contemporary views on language, but also highly controversial because of the ensuing linguistic hierarchy. The pecking order of languages with instrumental value (usually majority languages and/or international languages associated with usefulness, upward mobility and cosmopolitanism) and languages with expressive value (often minority languages spoken in more localised contexts, such as the home) has proven detrimental and, at times, fatal, to minority languages. ${ }^{9}$ As the early history of language policy reveals, in the mid-twentieth century the focus of language policy lay on "establishing stable diglossic language contexts in which majority languages (usually, ex-colonial languages, and most often English and French) were promoted as public languages of wider communication". In these colonial contexts, local languages were relegated to "private, familial language domains" (May 2006, 256), leading to, for example, English "replac[ing] $90 \%$ of the languages it has come into contact with in what is now called the English-speaking world" (Johnson 2013, 17, based on Kraus).

This is the reason why many also avoid the term "lingua franca" when referring to international languages, for it is too firmly bound up with strict instrumentality - this Lockean notion of language. Moreover, "lingua franca" often conveys a sense of fairness and neutrality, of nobody's language and, precisely for this reason, potentially everybody's language. But when the "lingua franca" in question is an international language with hundreds of millions of native speakers worldwide, then it is hardly nobody's language (see e.g. Phillipson 2009, especially his Chapter 7 - more in Section 1.8).

And so new terminologies emerge, tied to specific disciplines and ideological orientations, making the terminological minefield even more perilous. For example, any of the following epithets could be employed to refer to uses of English among speakers not primarily socialised in it:

- English as a foreign language

- English as a lingua franca 
- lingua franca English

- English for speakers of other languages

- international English

- English as an international language

- English as a (universal) auxiliary language

- Global English

- Global Englishes

- English as a global language

- English as a world language

- English as a World language

- English around the World

- world English

- World English

- $\quad$ world Englishes

- World Englishes

- World Standard Spoken English

- Englishes

- Post-imperial English

- Open English

- English as a language of wider communication (see Rajagopalan 2012, 377).

I suspect this list is not exhaustive. Change the word order or the distribution of capital letters and a mine is sure to blow up. Fittingly, Kanavillil Rajagopalan suggests calling the use of English in international settings "whatever-one-wants-to-call-it" (ibid., 375).

In this book, I have chosen neither to propose new terminology nor to fully adopt any one terminological framework, and the terminology I use in relation to language "proficiency" is not due its purported superiority. I trust the reader is capable of reading the words "mother tongue" or "native speaker" and not necessarily imagining an "ideal" monolingual individual; we can speak of "lingua franca" uses of English without picturing a neutral instrument for communication. When all definitions are constructs, I would rather keep the ones that are most familiar to the reader - "mother tongue", "native speaker" and "lingua franca" - while at the same time demanding a critical, deconstructive stance towards their meanings hallowed by custom.

But again: more important than these terminological issues is the notion of language that underpins the concept of lingua franca. When the lingua franca is a natural and national language, then it cannot escape the dynamics of différance and trace/track, noted earlier. Put differently, we cannot draw a line in our minds and in our communicative practices between those uses of language which communicate with who we are and which communicate with each other, from those uses which are (allegedly) strictly referential, instrumental. Différance does not respect language boundaries; traces/tracks of signs in one language cannot be contained in that one language, not least because the idea of a language as a discrete unit no longer holds. In Section 1.8, let us see how 
this notion of lingua franca fits into the picture of the multiple Englishes spoken in the world today.

\subsection{Multiples Englishes: Competing Paradigms in Liberation Linguistics}

The past few decades have witnessed an intense debate - mostly in applied linguistics and sociolinguistics, but also in the humanities and social sciences as a whole - concerning the status of the different Englishes that coexist in the world today. In particular, English language teaching has been in the spotlight. New paradigms have emerged and have reframed, reshaped and dis-invented a lot of those epithets discussed in Section 1.7, notably "mother tongue", "native speaker" and "foreign language". Notwithstanding the differences among these new perspectives and their complex ramifications, one major trait unites them: the shift from a one-language-one-model to a more plural approach to "the" English language. In other words, English is no longer seen as belonging to and measured against native-speaker norms. ${ }^{10}$

This rupture with more traditional, monocentric approaches to English has given rise to "liberation linguistics", which spans new paradigms in the study and teaching of Englishes across the globe. The most influential of these paradigms is that of World Englishes, inaugurated by Braj Kachru in the 1980s. Kachru's (1985) much-quoted image of the three concentric circles in the spread of English worldwide has become a staple in any discussion of the role of Shakespeare's language today. The inner circle consists of "norm-providing" countries where English is spoken as a first language, typically in Great Britain and Ireland, North America, Australia and New Zealand. Some include many more countries and territories in this list, such as Jamaica and Trinidad and Tobago (Ostler 2010, 33). Immediately after the inner circle comes the outer circle with "norm-developing" countries, i.e. places where English has been institutionalised as one of the official languages, as is the case in most former British colonies. The third and outermost circle is the expanding circle of "norm-dependent" countries, i.e. places where English enjoys no special status and is thus a foreign language, such as most of the EU or Brazil. We have to imagine these circles as ripples in a pond, overlapping and in constant motion (McArthur, cited in Kachru 2005, 13).

Kachru's framework has been criticised from various angles but remains influential because it neatly traces the spread of English historically and geographically, in addition to empowering and legitimising the Englishes outside the inner circle. Maintaining the notion of individual "varieties" of English and laying them out in a seemingly hierarchised framework might look like a step in the wrong direction, at least from a postmodern perspective. Yet at the time, Kachru's model pushed linguistics and especially English language teaching radically away from the native-speaker centrism that had long defined it. The adverb "seemingly" is key, for Kachru always emphasised that the word "inner" is not meant to imply "superior" but simply to capture "the historical source of the English language" (Kachru 2005, 218-220). 
To return to the image of the ripples in a pond, the blurred boundaries between Kachru's circles, though intentional, have been the target of criticism. Ostler, for instance, points out that Kachru's differentiation between the inner and outer circles is about "political differences" instead of linguistic ones, and this is indisputable $(2010,35)$. Yet, Ostler would probably agree that there are no strictly linguistic questions anyway, completely devoid of politics. Jennifer Jenkins voices a similar concern regarding the boundaries between the outer and expanding circles, where the status of English as a "foreign" or "second" language is not clear-cut - something about which Kachru had warned back in 1985: the "outer and expanding circles cannot be viewed as clearly demarcated from each other; ... the status of English in the language policies of such countries changes from time to time" (Kachru 1985, 13-14; see Kachru 2005, 214). In a similar vein, Ricento expresses the more general concern that Kachru's framework is "limited in accounting for the myriad contexts in which English is used ... between native and non-native English speakers", while recognising the model's "useful[ness] in legitimizing the status of English in outer-circle countries" $(2015,280)$.

In this book, Kachru's model will be used particularly to distinguish between inner- and outer-circle nations and peoples - for whom English tends to be the first or one of the first languages in which they are socialised, as well as the language or one of the languages pervading most realms of their lives and the expanding circle - where English is not as institutionalised or widespread and usually acquired at a later point. These categories should be taken with a pinch of salt, though, as noted earlier.

The lower status accorded to expanding-circle members as mere "normdependent" speakers is perceived as one of the main flaws of the Kachruvian model by proponents of a competing paradigm to that of World Englishes, namely that of "English as a lingua franca" (ELF; see Seidlhofer 2011, 60). Barbara Seidlhofer, one of the protagonists of the ELF paradigm, argues that this downgrading is unfair and unjustified, considering not only that expanding-circle speakers are very much "norm-developing", as their inventive uses of English demonstrate, but also that "native" speakers are dramatically outnumbered by "non-natives". Some estimates set the ratio to one to three (Crystal 2003, 69); others to one to four (Graddol 1997, 10). As many as 74 per cent of all "face-toface communications" that took place in English in international tourism in 2004 were among "non-English speakers" (Graddol 2006, 29).

How we choose to interpret "norm-dependent" versus "norm-developing" or indeed "norm-providing" is up for debate. Expanding-circle Englishes do not enjoy any special status in the countries where they are spoken, so there are hardly any, if any, dictionaries or grammar books laying down their norms. And little or no effort is put into codifying these expanding-circle Englishes precisely because of their lack of officialdom in their respective communities. After all, which state is going to subsidise reference work on English when English is not one of its national languages, and inner-circle nations have already taken the trouble of doing it? These Englishes are "norm- 
dependent" in the sense that they do not officially "provide" or "develop" norms, and their peculiarities are often classed as errors.

ELF advocates, in turn, argue that these peculiarities are not errors but systematic language uses which are just as legitimate as inner- or outer-circle uses. In a large-scale corpus study of (oral) ELF entitled VOICE (ViennaOxford International Corpus of English), ${ }^{11}$ Seidlhofer and her team came across creative formulations, for example, on the level of morphology, which stem from inner-circle norms and yet would be considered deviant. Take, for instance, the verb "examinate" or the nouns "increasement" and "approvement" - all three, along with numerous analogous examples at different levels, were documented in Seidlhofer's study $(2011,108)$. Their coiners were clearly aware of verb and noun formation patterns with the suffixes "-ate" and "-ment", but extended their use in unconventional ways, much like children when experimenting with language. For Seidlhofer, English outside inner-circle contexts is hence not adopted but adapted (ibid., 111). When similar adaptation processes are in place within inner-circle communities, these newly coined words, albeit deviant, gradually make their way into dictionaries - these Englishes are therefore officially "norm-providing". ${ }^{12}$ When they take place outside inner-circle communities, they are frowned upon.

Witness all the pejorative epithets that have emerged in the past few decades to designate lingua franca uses of English - "Globish American/British" (GAB) or simply "Globish”, “McLanguage”, "Bad Simple English” (BSE), "English as an interlanguage", among others (House 2010, 365; 2013, 285; 2014, 264; see Snell-Hornby 2010). Though in slightly different ways, these epithets highlight the deficiencies of English speakers outside the inner circle vis-à-vis inner-circle norms, while remaining completely oblivious to the fact that ELF speakers are multilingual individuals using English outside inner-circle contexts.

ELF arose as an alternative to this. One of its founding members, Alan Firth, defines it as "a contact language between persons who share neither a common native tongue nor a common national culture, and for whom English is the chosen foreign language of communication" (cited in House 2010, 365). ELF is also described as a "vehicular language", i.e. a "mere tool bereft of collective cultural capital" (House 2013, 287; see also 2003, 560). It emerges wherever and whenever non-native speakers of English need to communicate and their only shared language is English. It is "NOT a fixed code, and cannot be defined by its formal characteristics" (House 2014, 364); it is rather "an open source phenomenon", an "ad hoc" instrument that varies depending on "context, speaker group and communicative purpose", for each ELF speaker helps shape it afresh in each new communicative situation (ibid., 364). Innercircle speakers may and do participate in ELF interactions, but in order for communication to run smoothly despite their presence, they have to "acquire" ELF as a different language system instead of simply speaking their mother tongue as they usually would (Cogo \& Jenkins 2010, 275, 289-290). It is as though the idea of a lingua franca like Sabir or Esperanto - made up of bits and pieces from various languages - were applied directly to English; put 
differently, English is removed from its inner-circle embedment and placed in a changeable framework based on the other languages in ELF speakers' repertoires at any given moment.

According to ELF proponents, because ELF speakers often share no or few cultural values, accommodation is one of its pillars. In other words, in ELF, meaning is constantly co-constructed in a cooperative fashion, as speakers dynamically adjust their speech on all levels (pronunciation, word choice, etc.) to ensure intelligibility. Indeed, the "let it pass" principle has been widely documented in ELF empirical research: ELF speakers are willing to let ambiguous or even unintelligible utterances pass in the hope that they will be clarified or become irrelevant in the course of the conversation (see Smit 2010 and Mackenzie 2014 for examples of accommodation in ELF empirical studies). Of course, language use in general is characterised by accommodation (think of Grice's cooperative maxims); but ELF scholars argue that this trait is much more present in lingua franca communications. Interestingly, studies on ELF reveal that inner-circle speakers are seldom accommodating in lingua franca interactions; often, when serious intelligibility issues arise in ELF interactions, it is because of native speakers and their "unilateral idiomaticity" (see Seidlhofer 2011, especially her Chapter 6). ${ }^{13}$

This idea of ELF as a vehicular language or a language as an instrument for communication might seem to imply it is restricted to a few simple contexts, making it suited to nothing beyond small talk or giving instructions to tourists. ELF proponents stress, however, that it can be used in a range of contexts, including more formal or complex ones (ibid.; House 2014). ${ }^{14}$ Seen in this light, ELF cuts across the entire Kachruvian model as a widespread phenomenon in all three circles. For this reason, ELF has rendered the Kachruvian framework obsolete in the eyes of ELF advocates - though they still use it for convenience's sake (House 2010, 363; Seidlhofer 2011, 81).

To come back to the question of norms, where do we draw the line between inner-circle and ELF norms? ELF scholars argue that both tap into "virtual English", an admittedly (mental) construct that represents all "underlying encoding possibilities" of the language (House 2010; 2014; Seidlhofer 2011, 111). ${ }^{15}$ So inner-circle and ELF speakers alike resort to "virtual English" but accomplish rather different language uses, not least because inner-circle speakers are often monolingual, whereas ELF speakers have a minimum of two languages in their repertoire, and features of these linguacultures surface in their use of English. Inner-circle and ELF uses of English also differ in that the former remains closer to the conventions that regulate English grammar and use, while the latter "exploit the possibilities of the virtual language to their own ends", often combining these possibilities with those offered by their other languages (ibid., 120; see Cogo \& Jenkins 2010, 277).

Another example, this time by Cornelia Hülmbauer. She proposes that "false friends", such as "actually" and aktuell ["currently" in German], should actually (no pun intended) be called "true friends" because of the widespread use of "actually" meaning "currently" in European ELF (ibid., 277). Would 
this use be understood beyond EU circles? How would we handle less widespread but equally legitimate "true friends", such as "become" and "bekommen" [to get/ receive in German, both from Old High German biqueman, "to come about"]? The utterance "I became a bicycle on Christmas Day" would be perfectly intelligible in the German-speaking world, but what about beyond it? How much "let it pass" is still admissible before intelligibility is seriously compromised? ELF advocates emphasise that there is no "anything-goes-principle" in place in ELF, that its variability is not random and follows the encoding possibilities of virtual English. Still, the number of possible variations considering all potential ELF speakers and the specificities of their language repertoires would certainly exceed any target of intelligibility, however loose (see Seidlhofer 2011, 185, 201). As Colin Sowden puts it in relation to ELF, it is impossible to distinguish "between authentic non-standard alternatives and persistent error" (2012, 92).

ELF proponents insist on the unique character of ELF in comparison with inner-circle uses of English and with uses of language in general. Seidlhofer concedes that the creative mechanisms to which ELF speakers resort are present whenever we use any language in any context, but ELF speakers do it "unabashedly", pushing the boundaries further than observed in inner-circle interactions - as the examples quoted above ("examinate", "approvement" and "increasement") illustrate (Seidlhofer 2011, 98-99, 120). For this reason, ELF researchers are against codifying the surface features of ELF, for one of its cornerstones is variability. ELF is understood as a unique case of accelerated language contact and change.

In this book, both the World Englishes and the ELF paradigm will feature throughout - the former as a general guiding principle to the different Englishes worldwide and the latter more specifically in relation to the role of the English language in the EU. The body of research on ELF is crucial to us here because our main focus lies on the dominance of English in the EU, and the ELF paradigm proposes that "English" is not simply English, but rather "English as a lingua franca", i.e. an entirely different matter - an idea we will investigate (and challenge) in what follows.

\subsection{English as Lingua Franca: A Neutral Instrument for Communication?}

Because ELF is perceived as a neutral instrument for communication, its advocates suggest that "European ELF" should be recognised as a language (or "language use"; ibid., 153) in its own right in the European Union, quite apart from the inner-circle Englishes spoken in its territory today (Cogo \& Jenkins 2010; see Modiano 2009; 2017, for a similar proposition from within the World Englishes paradigm). And lest we forget, Brexit has reduced these innercircle uses of English in EU institutions - or rather will in the future, once those UK nationals working in EU institutions retire or leave.

ELF scholars nevertheless also emphasise that "variety counting" is passé and that ELF cannot be established as a fixed, standardised variety of English 
because of its variability (Cogo \& Jenkins 2010, 278; Seidlhofer 2011, 77). Yet some insist that ELF can and should become the sole official lingua franca of the EU, provided that a new understanding of linguistic competence as an invariably multilingual multicompetence emerges (Cogo \& Jenkins 2010, 290). In Robert Phillipson's words, "ELF protagonists readily admit that they are in for the long haul” (2009, 167).

It is clear that ELF is predicated on an instrumental notion of language, as a mere vehicle for communication. But is its use really so different to other language uses? ELF uses strike one as more creative largely because ELF speakers draw from their entire linguistic repertoire when speaking English. Anyone who has taught and/or learnt foreign languages would probably agree this phenomenon is typical of multilingual settings and not exclusive to ELF. Anyone who has contact with children knows that they practise this unabashedly, also within "one" language. And we are all invariably socialised in more than one language use (language variety, dialect, sociolect, register, other languages) and hence systematically tap into our entire linguistic repertoire. Différance respects no language boundaries. One could argue that ELF is simply more widespread than any language used as lingua franca, which nevertheless does not imply that the mechanisms of ELF are exclusive to it, nor that it requires new epistemological tools and a new paradigm for its study (see e.g. Ricento 2015, 285-288).

The purportedly exclusive variability of ELF is also questionable, for language in general is highly variable. Through monumental efforts of codification, standardisation and dissemination of vernaculars, we create an illusion of stability, permanent norms and linguistic standards. Herein lies the paradox of ELF: the same efforts would defeat the very objective of ELF as a distinctive phenomenon because its value lies in its contextual character. Keeping its cherished variability and alleged "neutrality" entails resisting standardisation and, consequently, institutionalisation and officialdom. On the other hand, giving up its variability would place it alongside all "other" natural languages, in this case, at best as a variety of English very much tied to inner-circle nations.

Both terms of the ELF paradox are riddled with aporias. Taking the concrete example of English in the EU today, even if ELF became its exclusive lingua franca, speakers would be exposed to far more (audio, visual and audio-visual) material in American English than in, say, "European ELF" - not to mention dictionaries, grammar books and teaching materials. Contact with inner-circle English would not cease after one such "elevation" of ELF, just as contact with inner-circle Englishes will not cease after Brexit. On the other hand, if ELF were codified and established as a "fixed" code to set it apart from inner-circle Englishes, its ties with "virtual English" would gradually become looser. Straightforward (and ideologically neutral, identity-free) intelligibility, one of the pillars of the ELF movement, would suffer. ELF would become ever more localised once officially tied to a territory, a scenario we will project in Section 4.6. 
ELF's promise of liberation rests on shaky foundations, not least because the vast majority of its corpora consist of oral exchanges. Even ELFA, the corpus of English as a lingua franca in academic settings, is solely oral. In speaking, we can resort to endless circumlocutions, assess our interlocutors' response and adjust our speech accordingly; we can go back, correct our utterances and ask our interlocutors for clarification - none of which applies in writing (see Sowden 2012, 94). Granted, the divide between spoken and written language is probably an issue in every codified language. Yet what makes this divide particularly problematic in the context of ELF is - again - the scale of variability welcome in speech but detrimental in writing. Of course, ELF is still based on "virtual English", which in turn has norms and standards, but the hybridity of ELF allows for virtually infinite new creations. Whereas the "let it pass" principle may work well in informal, oral interactions, it would be significantly less efficient - if not downright unfeasible - say, in EU legislation or academic papers.

Helder De Schutter, for instance, asks whether an "ELF professional" would suggest "dropping [the] use of third personal ' $\mathrm{s}$ "” or "create new verbs such as 'forsify' or 'levelize'" when editing one of his speeches (2018, 188-189). In his view, this "norm-free appraisal of non-standardised forms of speaking English" is not liberating but restraining, because although non-native speakers may be numerically more significant, native speakers "have a clear set of codified sources and a native self-confidence that is, in part, based on it" (ibid., 190, 183). Indeed, a wealth of studies reveals that neither English teachers nor learners want to adopt ELF, and that inner-circle norms remain very much the be-all and end-all in rating proficiency in English (see e.g. Jenkins 2007; Fiedler 2010, 211; Sowden 2012, 92-93).

Moreover, the rosy, cooperative character of ELF is not without its limitations. It is all very well when the interactions take place among peers in academic or other work and study-related settings - little wonder that these are the typical environments of ELF corpora (Seidlhofer 2011, 207; see also Ricento 2015, 285 and Grzega 2010, 796). However, when ELF interactions are charged with a power imbalance, its speakers are not nearly as cooperative (see Guido 2012 for examples of exchanges between African asylum seekers and Western immigration officials; see also O’Regan 2014, especially 539-543; 2016).

What is more important for our purposes here is the dynamic between ELF, identity and ideology. ELF is considered neutral by its protagonists, for it "represents" no specific nation, people(s), national or cultural values. According to this view, ELF speakers' emotional ligatures, identity markers and ideological allegiances lie exclusively with their mother tongue(s). Put differently, the only expressive values that surface in ELF are those connected with the speakers' mother tongue(s), because the processes of "de-culturalisation" (i.e. the removal of obviously culturally or ideologically-charged linguistic elements) and "re-culturalisation" (i.e. the reinsertion of these same elements derived from the speakers' mother tongues) kick in as soon as one starts using ELF (see De Schutter 2018, 187). 
ELF proponents thus take it for granted that the following twofold, clearcut separation occurs in speakers' minds: first, between ELF and their other language(s), and, second, between identity-related or ideologically charged elements of language and purely content-related elements. They seem to suggest that ELF speakers do not even come across these inner-circle expressive patterns and, even if they did, it would not matter anyway as their "original" life-worlds ${ }^{16}$ would remain inexorably bound to their mother tongue(s). English remains an empty vessel "carrying" those meanings and values that "belong" to ELF speakers' mother tongue(s). Yet the "colonisation of nonEnglish[-speaking] life-worlds" by "Anglo-American culture" can never be overstated (ibid., 175). Anyone with access to English will take advantage of English-language goods, and these goods can "easily maintain a privileged role in shaping the cultural life-world of non-native speakers" (ibid., 187).

The notion of language that undergirds the ELF paradigm rests upon the instrumental, referential function of ELF, which in turn is anathema to the postmodern theories to which key ELF proponents openly subscribe (see e.g. Seidlhofer 2011). As noted earlier, lingua franca uses of national languages cannot be set apart from other language uses; the interplay between language, identity and ideology cannot be halted. Within the ELF paradigm, questions of power are often pushed out of the debate due to the purported neutrality of ELF: while "English" or any other dominant language may well be used to perpetrate social injustice and perpetuate power imbalances, ELF remains innocuous because it is detached from any specific English varieties. ${ }^{17}$ As John O'Regan notes, ELF “seems wedded to a politics of knowledge in which ideology, discourse and power are separated out and neatly located within a rationalist, positivist and objectivist epistemology" (2014, 547).

A ramification of this identity issue manifests itself on the phenomenon of ELF as a mother tongue. In ELF literature, ELF is always distinguished from mother tongues; its use is contingent on one's mother tongue(s) and one's mother tongues remain the "carriers" of identity (House 2010, 365). "[N]obody is a native speaker of ELF", declares Jenkins repeatedly $(2014,11,38)$. There are nevertheless increasingly more ELF speakers who pass it on to their children, either because ELF is the common denominator in the home or because parents or carers feel that learning English early is just as important as - or even more important than - learning their mother tongue. The instrumental value of English is perceived as much higher, a trend confirmed by the last special Eurobarometer report on this issue: 79 per cent of respondents see English as "the most useful [language] for the future of their children" (European Commission 2012, 141).

What happens when a child is socialised in ELF, at its mother's knee, as it were? Statistics in this field are hard to come by and long overdue in areas where English is the dominant additional language, such as the EU. English is gradually entering people's homes and displacing home languages, even when parents are not proficient in it or have no ties with the inner or outer circle. ${ }^{18}$ Convincing indicators of this phenomenon are emerging slowly, especially in 
Europe. It has recently been found, for example, that Norwegian boys, whose literacy skills in Norwegian are poor, are excellent readers of English as a result of gaming (and communicating with other gamers across the globe) from an early age (Brevik 2016). In Vienna, teachers in public bilingual schools report that the lion's share of English-speaking pupils have nothing to do with the inner or outer circle, as suggested in the Introduction (see e.g. Reif-Breitwieser 2011, 11).

The phenomenon of English spoken as a mother tongue outside the inner circle seems to escape both the World Englishes and the ELF paradigm. As the uses of English become more widespread and multifaceted across the globe, our epistemological tools become limited. The EU is the one place in which this plethora of Englishes possibly reaches its apex. Here there are inner-circle, outer-circle and expanding-circle speakers; the geographical proximity between linguistically diverse countries, the free movement of people and the concentration of international organisations and multinational corporations result in intense lingua franca uses, particularly in English; the ubiquity of English in all EU education systems reinforces this trend (more in Section 2.7). Clearly, English is not a neutral instrument for communication, and its dominance in the EU raises thorny political questions, particularly in light of Brexit.

\subsection{Final Remarks}

The promotion of a healthy distance from native speaker-centrism unites the ELF and World Englishes paradigms in their quest for liberation. The World Englishes paradigm sees different Englishes as endonormative and exonormative varieties (depending on the status of English in the place in question) in their own right and on a par with each other, with their own particular cultural, ideological and identity markers and worthy of recognition. The ELF paradigm, in turn, perceives all English uses outside inner-circle settings as unique chameleons and waives all claims to variety status.

A lot of liberation linguistics is about changing the English language teaching canon, as already noted. Learning English as a foreign language is not the same as learning ELF, as the former implies the wish to integrate into innerand/or outer-circle groups, whereas the latter is intended for international settings, in which there is little need for, say, idiomatic expressions or even certain phonological traits proven to be superfluous regarding intelligibility (such as the "th" sounds in "bath" or "that" - see Jenkins 2007).

In any case, this is not the place to assess the pedagogical value of these two paradigms. The question that concerns us here pertains rather to the status and function of these different Englishes in the EU today. Within the World Englishes paradigm, Modiano (2009; 2017) sees what he calls "Euro-English" as an outer-circle variety of English and defends its adoption as the EU's sole lingua franca. From the ELF paradigm, Cogo and Jenkins (2010) propose a revision of the EU's notions of language and multilingualism, along with the 
adoption of "European ELF" as its exclusive lingua franca. Similar calls have come from other fronts, as we will see in Chapter 4.

Their differences notwithstanding, these calls for English to become the EU's official lingua franca share some premises, notably (1) the belief in the (at least predominantly) instrumental function of English uses outside the inner circle; (2) the idea that, since Brexit, uses of English in the EU have become detached from the UK (not to mention the USA), thus turning it into nobody's language; and (3) the notion that cultural, ideological and identity markers are relevant only in one's mother tongue(s), an idealised, "complete" language which is not threatened by English. As we will continue to see throughout the book, all three points are questionable.

Chapter 2 will reveal that EU member states cling to their precious national languages, on a Herderian/Humboldtian quest to maintain their unique genius through language. Citizenship is increasingly tied to language knowledge - if you want to belong, you have to speak "the" language. The member states' logos is hence the nation: the source of meaning is to be "found" in each member state's collection of linguistic and cultural practices. Accordingly, they try to insulate their national language(s) from foreign influences like guards at the nation's gates, while casually ignoring their own minority languages. Paradoxically, they remain largely oblivious to the ever-growing reach of English in the EU and help entrench it further by increasing its presence in their education systems. This same paradoxical stance is found in EU institutions, bodies and agencies, as the EU pays constant lip service to multilingualism as one of its cornerstones while unofficially - albeit in plain sight nurturing an instrumental, Lockean notion of language in its internal workings, which are increasingly carried out in English only.

This paradox is complicated further by the high hopes, entertained by the EU and different scholars, that machine translation will greatly and rapidly improve, allowing communication to run smoothly without the "burdens" of translation and interpreting (see e.g. Graddol 1997; Spolsky 2004, 91; Ostler 2010, 261 and the Appendix in this book). In other words, the missing link of language, one hopes, will finally be unveiled; a perfect and "demonstrable identity of meaning" (Ricoeur 2006, 22) will be established, allowing computers to reduce texts to their purely instrumental, referential content and to transfer it instantly into another language - a venture not unlike that of rationalist and analytic philosophers. Translation software would therefore hold the key to the new Ursprache, no longer Babylonian but equally universal. $^{19}$

In contemporary thought, this firm belief in some kind of logos or unequivocal source of meaning has largely been replaced with the conviction of the fallacy of logocentrism. Put differently, meaning is not to be "found" anywhere as it is the result - or rather the perennial journey - of past, present and future transactions in increasingly complex multimodal frameworks. We might as well say that meaning is not; it is an absence made present. Yet the search for the logos is ongoing. 
If contradictory views of language exist side by side seemingly harmoniously - as they always have, as noted in earlier sections - what broad, language-related development would be welcome, especially in the context of the EU? The linguistic turn in philosophy placed language in the spotlight as an all-pervasive phenomenon without which no other phenomena can be conceivable. A similar development could have a positive impact on our societies and institutions, including the EU. Language is still perceived as a separate "entity", distinguishable from, say, maths and geography in our education systems, and from economic policy and customs regulations in the EU. Yet these areas, to focus on the EU, do not exist in some essentialist, pure state: they exist in and through language. As we will see in what follows, it is not the EU's language policy that raises concern, but the lack thereof. A language turn in the EU, i.e. the acknowledgement of the pivotal role of language in every domain - as an expressive and ideologically charged component of our identities - would be very welcome (more in Chapter 5).

\section{Acknowledgements}

An earlier version of this chapter was published in Leal (2019).

\section{Notes}

1 Newer readings, particularly of Aristotle's works, reveal that there are significantly more intricacies to the classical paradigm than meet the eye (see e.g. Modrak 2001).

2 The notion of diglossia will emerge again in Section 4.4 in relation to English in the EU today and refers to the simultaneous use of two languages (or language varieties) in the same community.

3 In this latter work, Kraus reminds us that the process of linguistic homogenisation for purposes of nation-building was not solely top-down: the embracing of the French language as a prerequisite for emancipation, on the part of the Jacobins, is a hugely significant embodiment of bottom-up initiatives of linguistic homogenisation.

4 Nominalism comprises widely different approaches into which I cannot go here (see Leal 2019, 229).

5 For other theories of language put forth in this interstice, such as Ernst Cassirer's and Jost Trier's, and for theories which anticipated Humboldt's, including Madame de Staël's, Friedrich Schlegel's and Étienne de Condillac's, see Steiner (1998, 76-97) and Schlesinger (1991).

6 See Davidson (2005) and Begby (2016) for an interesting development in analytic philosophy about the illusory character of what we call "language".

7 This issue is going to emerge throughout this book. Embracing deconstruction must not entail the rejection of everything we know about language; it must not be a nihilistic project that stops short each time it encounters objects whose construed character undermine the possibility of any meaningful reflection. Christopher Norris puts this point very aptly:

[Deconstruction] makes manifest the fact that any radical shift of interpretative thought must always come up against the limits of seeming absurdity. Philosophers have long had to recognize that thinking may lead them inescapably into regions of scepticism such that life could scarcely carry on if people were to act on their conclusions ... Deconstruction works at the same giddy limit, 
suspending all that we take for granted about language, experience and the 'normal' possibilities of human communication. Yet ... [d] econstruction is ... an activity of thought which cannot be consistently acted on - that way madness lies - but which yet possesses an inescapable rigour of its own.

(2002, xii)

8 Shohamy denounces further terminology currently used in linguistics, such as "codemixing" and "code-switching", which, in her view, appear to suggest that the "weaving and moving freely and smoothly among genres, registers, codes and languages ... beyond fixed boundaries" are not "a natural phenomenon". Although I agree with her, the alternatives she proposes, namely "hybrids" and "fusions", may just as well connote the existence of monolithic units which became fused (Shohamy 2006, 14). As argued earlier, a critical stance towards such well-established and controversial constructs as "mother tongue", "foreign language", "codeswitching", and even "language" and "English", is imperative, but new constructs might turn out to be just as controversial. Thomas Ricento, for example, successfully deconstructs the notion of English as the global lingua franca while still using the terms "lingua franca" and "English" in the senses that he means to dis-invent (Ricento 2018). The attempts to show the moments of aporia of the traditional terminology of the disciplines that converge in this book push the boundaries of our epistemologies to such an extreme that unveils the limits of any epistemology.

9 The contrast between instrumental and expressive value will appear repeatedly here and should not be confused with "instrumental" and "intrinsic approaches" in the debate on linguistic justice, according to which languages either possess intrinsic value or serve as instruments to obtain something. "Expressive value" rather means that members of a certain language community attach value to it because it forms a key link to their life-world. "Instrumental value" means that languages can be stripped of these expressive traits and simply convey information without interacting with one's life-world (see e.g. De Schutter \& Robichaud 2015).

10 This applies to other languages as well, of course. In Brazilian Portuguese, for instance, there has been a growing movement in the past few decades to combat linguistic prejudice - or linguicism - and celebrate the different varieties of Portuguese (Bagno 2002).

11 See www.univie.ac.at/voice/page/index.php. All electronic sources quoted here were last accessed in December 2020.

12 The Oxford English Dictionary incorporated as many as 157 new words in 2019 alone - in addition to 212 new word senses (full list available at https://public.oed. com/updates/new-words-list-march-2019/).

13 Sue Wright $(2007,153)$ provides an interesting example of this phenomenon derived from research among members of the European Parliament:

Very telling evidence of how difficult non-native speakers of English find such practice [of not making a conscious effort to meet the linguistic needs of those using English as a second language] came in a meeting where a German MEP spoke first, using English. His delivery was slow, with heavy emphasis, his sentences were short and mostly SVO [subject, verb, object] and his lexis plain. Only a dozen of the one hundred and twenty or so members of the audience (with a mixture of first languages) put on headphones. An Irish MEP then gave an address, in English. After a few sentences, 55 more people had put on their headphones.

14 Many beg to disagree (see e.g. Snell-Hornby 2010).

15 Jenkins (2007) uses the term "lingua franca core" in a similar fashion, though her focus lies on phonology. 
16 In the Habermasian sense of a "set of assumptions that the average adult takes for granted; it involves shared common understandings, shared assumptions about the world, about who we are, what we believe, what shocks and offends us, what we desire, and so on" (De Schutter 2018, 173).

17 I trust it is obvious to the reader that the point is not to vilify English and its speakers - languages can never be blamed for anything anyway. Moreover, English is the most widespread additional language worldwide today, but the same remarks would apply if it were Norwegian or Yoruba.

18 I know a lot of so-called Erasmus babies' parents, i.e. couples who met while spending time abroad through the EU's Erasmus exchange programme. The European Commission estimates that around one million Erasmus babies were born between 1987 and 2014. Many of these couples spoke English initially as their lingua franca and then never went on to learn each other's languages, making English their home language. In extreme cases, English is the only home language; in others, it is spoken alongside the parents' mother tongue(s) (more in Section 4.4).

19 See Schuster et al. (2016) for Google's "multilingual neural machine translation system" and the quest for a perfect interlingua.

\section{Further Reading}

Derrida, Jacques. 1997. Of grammatology. Translated by Gayatri Chakravorty Spivak. Baltimore, MD: Johns Hopkins University Press.

Kachru, Braj B., Yamuna Kachru and Cecil L. Nelson (eds). 2006. The handbook of World Englishes. Oxford: Blackwell.

Leal, Alice. 2019. "Equivalence". In The Routledge handbook of translation and philosophy, edited by Piers Rawling and Philip Wilson, 224-242. London: Routledge.

Steiner, George. 1998. After Babel: Aspects of language and translation. Oxford: Oxford University Press.

\section{References}

Aristotle. 2002. Categories and De Interpretatione. Translated by John L. Ackrill. Oxford: Clarendon Press.

Arrojo, Rosemary and Kanavillil Rajagopalan. 2003. "A crise da metalinguagem: Uma perspectiva interdisciplinar”. In O signo desconstruído: Implicações para a tradução, a leitura e o ensino, edited by Rosemary Arrojo, 57-62. Campinas: Pontes.

Austin, John L. 1998. "Performative utterances". In Philosophy of language: The big questions, edited by Andrea Nye, 126-131. Oxford: Blackwell.

Bagno, Marcos. 2002. Preconceito linguístico: O que é, como se faz. São Paulo, Brazil: Loyola.

Bayly, Christopher A. 2004. The birth of the modern world, 1780-1914. Oxford: Blackwell Publishing.

Begby, Endre. 2016. "Deranging the mental lexicon”. Inquiry 59 (1): 33-55.

Best, Steven and Douglas Kellner. 1991. Postmodern theory: Critical interrogations. New York: The Guilford Press.

Blommaert, Jan. 2006. "Language policy and national identity". In An introduction to language policy: Theory and method, edited by Thomas Ricento, 238-254. Oxford: Blackwell Publishing.

Blommaert, Jan and Jef Verschueren. 1998. "The role of language in European nationalist ideologies". In Language ideologies: Practice and theory, edited by Bambi B. 
Schieffelin, Kathryn Ann Woolard and Paul V. Kroskrity, 189-210. Oxford: Oxford University Press.

Braun, Edmund. 1996. Der Paradigmenwechsel in der Sprachphilosophie. Darmstadt: Wissenschaftliche Buchgesellschaft.

Brevik, Lisbeth M. 2016. "The gaming outliers: Does out-of-school gaming improve boys' reading skills in English as a second language?" In Educational technology and polycontextual bridging, edited by Eyvind Elstad, 39-61. Rotterdam: Sense Publishers.

Candlin, Christopher N. 1997. "General editor's preface”. In The construction of professional discourse, edited by Britt-Louise Gunnarsson, Per Linell and Nordberg Bengt, viii-xiv. Harlow: Addison-Wesley Longman.

Cogo, Alessia and Jenkins, Jennifer. 2010. "English as a lingua franca in Europe: A mismatch between policy and practice". European Journal of Language Policy 2 (2): 271-294.

Crystal, David. 2003. English as a global language. Cambridge: Cambridge University Press.

Crystal, David. 2007. Language death. Cambridge: Cambridge University Press.

Dakhlia, Jocelyne. 2008. Lingua franca: Histoire d'une langue métisse en Méditerranée. Paris: Actes Sud.

Davidson, Donald. 2005. “A nice derangement of epitaphs". In Truth, language, and history: Philosophical papers, vol. 5, by Donald Davidson, 90-108. Oxford: Clarendon Press.

Derrida, Jacques. 1967. L'écriture et la différence. Paris: Éditions du Seuil.

Derrida, Jacques. 1981. Positions. Translated by Alan Bass. Chicago: University of Chicago Press.

Derrida, Jacques. 1997. Of grammatology. Translated by Gayatri Chakravorty Spivak. Baltimore, MD: Johns Hopkins University Press.

De Schutter, Helder. 2018. "Linguistic justice and English as a lingua franca". In The politics of multilingualism: Europeanisation, globalisation and linguistic governance, edited by François Grin and Peter A. Kraus, 167-199. Philadelphia, PA: John Benjamins.

De Schutter, Helder and David Robichaud. 2015. "Van Parijsian linguistic justice: Context, analysis and critiques". Critical Review of International Social and Political Philosophy 18 (2): 87-112.

Eco, Umberto. 1997. The search for the perfect language. Translated by James Fentress. Oxford: Blackwell Publishing.

European Commission. 2012. "Special Eurobarometer 386: Europeans and their languages". Available at: https://ec.europa.eu/commfrontoffice/publicopinion/archives/ ebs/ebs_386_en.pdf.

Fiedler, Sabine. 2010. "The English-as-a-lingua-franca approach: Linguistic fair play?" Language Problems \& Language Planning 34 (3): 201-221.

Fishman, Joshua A. 1960. "A systematization of the Whorfian hypothesis". Behavioral Science 5: 323-339.

Fishman, Joshua A. 1972. Language and nationalism: Two integrative essays. Rowley, MA: Newbury House.

Fishman, Joshua A. 1985. "The Whorfian hypothesis: Varieties of valuation, confirmation and disconfirmation". In The rise and fall of the ethnic revival: Perspectives of language and ethnicity, edited by Joshua A. Fishman, 457-471. Berlin: Mouton de Gruyter. 
Foran, Lisa. 2012. "Translation as a path to the other: Derrida and Ricoeur". In Translation and philosophy, edited by Lisa Foran, 75-87. Bern: Peter Lang.

Formigari, Lia. 2004. A history of language philosophies. Translated by Gabriel Poole. Philadelphia, PA: John Benjamins.

Glendinning, Simon. 2004. "Language”. In Understanding Jacques Derrida, edited by Jack Reynolds and Jonathan Roffe, 5-13. London: Continuum.

Goldgaber, Deborah. 2019. "Derrida". In The Routledge handbook of translation and philosophy, edited by Piers Rawling and Philip Wilson, 141-156. London: Routledge.

Graddol, David. 1997. The future of English? A guide to forecasting the popularity of the English language in the 21st century. London: The British Council.

Graddol, David. 2006. English next: Why global English may mean the end of 'English as a Foreign Language'. London: The British Council.

Grossman, Jonathan. 2017. "The double etymology of Babel in Genesis 11". Zeitschrift für die alttestamentliche Wissenschaft 129 (3): 362-375.

Grzega, Joachim. 2010. "Mehrsprachigkeitskonzepte in Europa und Global Englisch". In Handbuch der Eurolinguistik, edited by Uwe Hinrichs, 795-804. Wiesbaden: Harrassowitz.

Guido, Maria. 2012. "ELF authentication and accommodation strategies in crosscultural immigration encounters". Journal of English as a Lingua Franca 1 (2): 219-240.

Habermas, Jürgen. 1999. Wahrheit und Rechtfertigung. Berlin: Suhrkamp.

Habermas, Jürgen. 2003. On the pragmatics of communication. Translated by Thomas McCarthy, Jeremy Gaines, Doris L. Joneset al. Cambridge: Polity Press.

Habermas, Jürgen. 2006. Time of transitions. Translated by Ciaran Cronin and Max Pensky. Cambridge: Polity.

Habermas, Jürgen and Jacques Derrida. 2005. "February 15, or, what binds us together: Plea for a common foreign policy, beginning in core Europe”. In Old Europe, new Europe, core Europe: Transatlantic relations after the Iraq War, edited by Daniel Levy, Max Pensky and John Torpey, translated by Max Pensky, 3-13. London: Verso.

Haugen, Einar. 1991. "The 'mother tongue". In The influence of language on culture and thought: Essays in honor of Joshua A. Fishman's sixty-fifth birthday, edited by Robert L. Cooper and Bernard Spolsky, 75-84. Berlin: Mouton de Gruyter.

Hobsbawm, Eric J. 1990. Nations and nationalism since 1780: Programme, myth, reality. Cambridge: Cambridge University Press.

Hoffmann, David. 2003. "Logos as composition”. Rhetoric Society Quarterly 33 (3): 27-53.

Holmes, Prue and Fred Dervin. 2016. "Introduction - English as a lingua franca and interculturality: Beyond orthodoxies". In The cultural and intercultural dimensions of English as a lingua franca, edited by Prue Holmes and Fred Dervin, 1-30. Bristol: Multilingual Matters.

House, Juliane. 2003. "English as a lingua franca: A threat to multilingualism?” Journal of Sociolinguistics 7 (4): 556-578.

House, Juliane. 2010. "The pragmatics of English as a lingua franca”. In Pragmatics across languages and cultures: Handbook of pragmatics, vol. 7, edited by Anna Trosborg, 363-387. Berlin: Mouton de Gruyter.

House, Juliane. 2013. "English as a lingua franca and translation”. The Interpreter and Translator Trainer 7 (2): 279-298.

House, Juliane. 2014. "English as a global lingua franca: A threat to multilingual communication and translation?" Language Teaching 47 (3): 363-376. 
Humboldt, Wilhelm von. 1836. Über die Verschiedenheit des menschlichen Sprachbaues und ibren Einfluss auf die geistige Entwickelung des Menschengeschlechts. Berlin: Dümmler.

Humboldt, Wilhelm von. 1963. Schriften zur Sprachphilosophie. Edited by Andreas Flitner. Darmstadt: Wissenschaftliche Buchgesellschaft.

Hutton, Christopher. 1999. Linguistics and the Third Reich: Mother-tongue fascism, race and the science of language. London: Routledge.

Jenkins, Jennifer. 2007. English as a lingua franca: Attitude and identity. Oxford: Oxford University Press.

Jenkins, Jennifer. 2014. English as a lingua franca in the international university: The politics of academic English language policy. London: Routledge.

Johnson, David Cassels. 2013. Language policy. London: Palgrave Macmillan.

John-Steiner, Vera. 1991. "Cognitive pluralism: A Whorfian analysis". In The influence of language on culture and thought: Essays in honor of Joshua A. Fishman's sixtyfifth birthday, edited by Robert L. Cooper and Bernard J. Spolsky, 61-74. Berlin: Mouton de Gruyter.

Juaristi, Patxi, Timothy Reagan and Humphrey Tonkin. 2008. "Linguistic diversity in the European Union: An overview". In Respecting linguistic diversity in the European Union, edited by Xabier Arzoz, 47-72. Philadelphia, PA: John Benjamins.

Kachru, Braj B. 1985. "Standards, codification and sociolinguistic realism: The English language in the outer circle". In English in the world: Teaching and learning the language and literatures, edited by Randolph Quirk and Henry G. Widdowson, 1130. Cambridge: Cambridge University Press.

Kachru, Braj B. 2005. Asian Englishes: Beyond the canon. Hong Kong: Hong Kong University Press.

Kraus, Peter A. 2008. A union of diversity: Language, identity and polity-building in Europe. Cambridge: Cambridge University Press.

Kraus, Peter A. 2018. "From glossophagic hegemony to multilingual pluralism?: Reassessing the politics of linguistic identity in Europe". In The politics of multilingualism: Europeanisation, globalisation and linguistic governance, edited by François Grin and Peter A. Kraus, 89-109. Philadelphia, PA: John Benjamins.

Kraus, Peter A. and François Grin. 2018. "The politics of multilingualism: General introduction and overview". In The politics of multilingualism: Europeanisation, globalisation and linguistic governance, edited by François Grin and Peter A. Kraus, 1-16. Philadelphia, PA: John Benjamins.

Lages, Susana Kampff. 2007. Walter Benjamin: Tradução e melancolia. São Paulo, Brazil: Editora UNESP.

Leal, Alice. 2014. Is the glass half empty or half full? Reflections on translation theory and practice in Brazil. Berlin: Frank \& Timme.

Leal, Alice. 2019. "Equivalence". In The Routledge handbook of translation and philosophy, edited by Piers Rawling and Philip Wilson, 224-242. London: Routledge.

Locke, John. 1999. An essay concerning human understanding. Pennsylvania, PA: Pennsylvania State University Press.

Lyotard, Jean-François. 2003. Postmodern fables. Translated by Georges Van Den Abbeele. Minneapolis, MN: Minnesota University Press.

Mackenzie, Ian. 2014. English as a lingua franca: Theorizing and teaching English. London: Routledge.

Macnamara, John. 1991. "Linguistic relativity revisited". In The influence of language on culture and thought: Essays in honor of Joshua A. Fishman's sixty-fifth birthday, 


\section{Language, Meaning and Identity}

edited by Robert L. Cooper and Bernard J. Spolsky, 45-60. Berlin: Mouton de Gruyter.

May, Stephen. 2004. "Rethinking linguistic human rights: Answering questions of identity, essentialism and mobility". In Language rights and language survival, edited by Jane Freeland and Donna Patrick, 35-53. Manchester: St. Jerome Publishing.

May, Stephen. 2006. "Language policy and minority rights". In An introduction to language policy: Theory and method, edited by Thomas Ricento, 255-272. Malden, MA: Blackwell Publishing.

Modiano, Marko. 2009. "Inclusive/exclusive? English as a lingua franca in the European Union”. World Englishes 28 (2): 208-223.

Modiano, Marko. 2017. "English in a post-Brexit European Union”. World Englishes 36 (3): 313-327.

Modrak, Deborah K. W. 2001. Aristotle's theory of language and meaning. Cambridge: Cambridge University Press.

Norris, Christopher. 2002. Deconstruction: Theory and practice. London: Routledge.

Nye, Andrea. 1998. Philosophy of language: The big questions. Oxford: Blackwell Publishining.

O’Regan, John. 2014. "English as a lingua franca: An immanent critique". Applied Linguistics 35 (5): 533-552.

O'Regan, John. 2016. "Intercultural communication and the possibility of English as lingua franca". In The cultural and intercultural dimensions of English as a lingua franca, edited by Prue Holmes and Fred Dervin, 203-217. Bristol: Multilingual Matters.

Ostler, Nicholas. 2010. The last lingua franca: The rise and fall of world languages. London: Penguin.

Partee, Morris. 1972. "Plato's theory of language". Foundations of Language 8 (1): 113132.

Pennycook, Alastair. 2006. "Postmodernism in language policy". In An introduction to language policy: Theory and method, edited by Thomas Ricento, 60-76. Malden, MA: Blackwell Publishing.

Phillipson, Robert. 2009. Linguistic imperialism continued. London: Routledge.

Plato. 1921. Cratylus/Sophist: Plato in twelve volumes. Translated by Harold N. Fowler, vol. 12. Cambridge, MA: Harvard University Press.

Rajagopalan, Kanavillil. 2012. “'World English' or 'World Englishes'? Does it make any difference?” International Journal of Applied Linguistics 22 (3): 374-391.

Reif-Breitwieser, Susanne. 2011. Wir sprechen zehn Sprachen!Vienna: Bundesministerium für Unterricht, Kunst und Kultur.

Ricento, Thomas. 2015. “'English,' the global lingua franca?” In Language policy and political economy: English in a global context, edited by Thomas Ricento, 276-304. Oxford: Oxford University Press.

Ricento, Thomas. 2018. "The promise and pitfalls of global English". In The politics of multilingualism: Europeanisation, globalisation and linguistic governance, edited by François Grin and Peter A. Kraus, 201-222. Philadelphia, PA: John Benjamins.

Ricoeur, Paul. 2006. On translation. Translated by Eileen Brennan. London: Routledge. Risager, Karen. 2012. "Linguaculture and transnationality: The cultural dimensions of language". In The Routledge handbook of language and culture, edited by Jane Jackson, 101-114. London: Routledge.

Rodrigues, Cristina Carneiro. 1999. Tradução e diferença. São Paulo, Brazil: Editora UNESP. 
Rorty, Richard. 2000. "Being that can be understood is language". London Review of Books 22 (6): 21-29.

Sapir, Edward. 1985. Selected writings of Edward Sapir in language, culture and personality. Edited by David G. Mandelbaum. Berkeley, CA: University of California Press.

Sarna, Nahum. 1974. Understanding Genesis: The heritage of Biblical Israel. New York: Schocken Books.

Sarup, Madan. 1993. An introductory guide to post-structuralism and postmodernism. Harlow: Pearson Education Ltd.

Saussure, Ferdinand de. 1986. Course in general linguistics. Edited by Charles Bally, Albert Sechehaye and Albert Riedlinger. Translated by Roy Harris. Illinois: Open Court.

Schieffelin, Bambi B., Kathryn A. Woolard and Paul V. Kroskrity. 1998. Language ideologies: Practice and theory. Oxford: Oxford University Press.

Schlesinger, Izchak M. 1991. "The wax and wane of Whorfian views". In The influence of language on culture and thought: Essays in honor of Joshua A. Fishman's sixtyfifth birthday, edited by Robert L. Cooper and Bernard J. Spolsky, 7-44. Berlin: Mouton de Gruyter.

Schuster, Mike, Melvin Johnson and Nikhil Thorat. 2016. "Zero-shot translation with Google's multilingual neural machine translation system”. Google AI Blog: The latest news from Google AI, 22 November. Available at: https://ai.googleblog.com/ 2016/11/zero-shot-translation-with-googles.html.

Searle, John. 1979. Expression and meaning. Cambridge: Cambridge University Press.

Seidlhofer, Barbara. 2011. Understanding English as a lingua franca. Oxford: Oxford University Press.

Shohamy, Elana. 2006. Language policy: Hidden agendas and new approaches. London: Routledge.

Smit, Ute. 2010. English as a lingua franca in higher education: A longitudinal study of classroom discourse. Berlin: Mouton de Gruyter.

Snell-Hornby, Mary. 2010. "Mind the GAB! The hazards of a global language in translation studies". The Linguist 3: 18-19.

Soames, Scott. 2010. Philosophy of language. Princeton, NJ: Princeton University Press.

Sowden, Colin. 2012. "ELF on a mushroom: The overnight growth in English as a lingua franca”. ELT Journal 66 (1): 89-96.

Spolsky, Bernard. 2004. Language policy. Cambridge: Cambridge University Press.

Steiner, George. 1998. After Babel: Aspects of language and translation. Oxford: Oxford University Press.

Trabant, Jürgen. 2010. "Europäisches Sprachdenken”. In Handbuch der Eurolinguistik, edited by Uwe Hinrichs, 881-898. Wiesbaden: Harrassowitz.

Van Parijs, Philippe. 2011. Linguistic justice for Europe and for the world. Oxford: Oxford University Press.

Wansbrough, John Edward. 2013. Lingua franca in the Mediterranean. London: Routledge.

Whorf, Benjamin Lee. 1956. Language, thought, and reality: Selected writings of Benjamin Lee Whorf. Edited by John B. Carroll. Cambridge, MA: The MIT Press.

Wierzbicka, Anna. 2013. Imprisoned in English: The hazards of English as a default language. Oxford: Oxford University Press.

Wittgenstein, Ludwig. 1922. Tractatus Logico-Philosophicus. Translated by Charles K. Ogden. London: Kegan Paul, Trench, Trubner \& Co. Ltd/New York: Harcourt, Brace \& Company, Inc. 


\section{Language, Meaning and Identity}

Woolard, Kathryn A. 1998. "Introduction: Language ideology as a field of inquiry". In Language ideologies: Practice and theory, edited by Bambi B. Schieffelin, Kathryn A. Woolard and Paul V. Kroskrity, 3-48. Oxford: Oxford University Press.

Wright, Sue. 2007. "English in the European Parliament: MEPs and their language repertoires". Sociolinguistica Jahrbuch 21: 151-165. 


\section{The EU and English as a "Lingua Franca"

\author{
De Jure Multilingualism Versus De Facto \\ Monolingualism
}

\subsection{Introduction}

Europe is one of the least linguistically diverse parts of the globe. Only 200 languages are European, roughly 3 per cent of the world's languages. Africa and Asia each host around 32 per cent; 18 per cent are Pacific and Oceanic, while 15 per cent are American. The European Union, where about 7 per cent of the world's population lives, is home to only 1 per cent of the world's languages (Juaristi et al. 2008).

Still, the EU is one of the most multilingual bodies of institutions in the world as the unparalleled economic and political union of 27 countries and their 24 respective languages. Table 2.1 shows all current (and former) EU member states along with their respective national official languages which are also official EU languages, ordered chronologically (per accession year) and alphabetically (in English).

Each of the items marked with an asterisk in Table 2.1 requires a brief note. Luxembourgish, one of the national languages of the founding member Luxemburg, and Turkish, one of Cyprus's national languages, are the only ones that are not official EU languages as well. Luxembourgish had dialect status until 1984, when it became a national official language alongside German and French. Negotiations are ongoing between Luxembourg and the EU to raise its status, though not as a fully-fledged official language (see EURACTIV 2018). As for the Republic of Cyprus, despite being de facto divided, with over a third of its territory administered by the self-declared Turkish Republic of Northern Cyprus, the entire island is EU territory. EU law is nevertheless only valid in those areas where the Government of the Republic exercises effective control (see European Union n.d.a). Similar to Luxembourgish, there have been calls to raise the status of Turkish in the EU, ideally as an official language (see Morgan 2016; 2017).

It should be added that Malta's accession in 2004 has fuelled the debate on the recognition of the additional national languages of current member states. Malta, a former British colony in which English remains a national language, requested that Maltese be adopted as its official EU language. The EU conceded, though Maltese was placed in a three-year derogation period, in which 
46 The EU and English as a "Lingua Franca"

Table 2.1 EU member states and national languages

\begin{tabular}{|c|c|}
\hline Member state & National and official EU language(s) \\
\hline \multicolumn{2}{|c|}{ Founding members (1957) } \\
\hline Belgium & $\begin{array}{l}\text { Dutch } \\
\text { French } \\
\text { German }\end{array}$ \\
\hline Germany & German \\
\hline France & French \\
\hline Italy & Italian \\
\hline Luxemburg* & $\begin{array}{l}\text { French } \\
\text { German }\end{array}$ \\
\hline the Netherlands & Dutch \\
\hline \multicolumn{2}{|c|}{ First enlargement (1973) } \\
\hline Denmark & Danish \\
\hline Ireland* & $\begin{array}{l}\text { English } \\
\text { Irish }\end{array}$ \\
\hline United Kingdom & English \\
\hline \multicolumn{2}{|c|}{ Second enlargement (1981) } \\
\hline Greece & Greek \\
\hline \multicolumn{2}{|c|}{ Third enlargement (1986) } \\
\hline Portugal & Portuguese \\
\hline Spain & Spanish \\
\hline \multicolumn{2}{|c|}{ Fourth enlargement (1995) } \\
\hline Austria & German \\
\hline Finland & $\begin{array}{l}\text { Finnish } \\
\text { Swedish }\end{array}$ \\
\hline Sweden & $\begin{array}{l}\text { Danish } \\
\text { Swedish }\end{array}$ \\
\hline \multicolumn{2}{|c|}{ Fifth enlargement (2004) } \\
\hline Cyprus* & Greek \\
\hline Czech Republic & Czech \\
\hline Estonia & Estonian \\
\hline Hungary & Hungarian \\
\hline Latvia & Latvian \\
\hline Lithuania & Lithuanian \\
\hline Malta* & $\begin{array}{l}\text { English } \\
\text { Maltese }\end{array}$ \\
\hline Poland & Polish \\
\hline Slovakia & Slovak \\
\hline Slovenia & Slovenian \\
\hline \multicolumn{2}{|c|}{ Sixth enlargement (2007) } \\
\hline Bulgaria & Bulgarian \\
\hline Romania & Romanian \\
\hline
\end{tabular}


Table 2.1 (Cont.)

\begin{tabular}{ll}
\hline Member state & National and official EU language(s) \\
\hline Seventh enlargement (2013) & \\
Croatia & Croatian \\
First contraction (2020) & \\
United Kingdom & \\
\hline
\end{tabular}

Acts did not have to be drafted and published in Maltese in the Official Journal of the European Union (European Union 2011, 117). This situation with Maltese triggered a series of motions from other member states to raise the status of their languages.

Among them was Ireland, which had been a member since 1973 - although at that point English was the only Irish national language among official EU languages. The status of Irish was that of "treaty language", i.e. a language in which only primary law is drafted and published. In November 2004, Ireland launched a proposal to include Irish as an official EU language, which was granted from 1 January 2007 (Shuibhne 2008). Initially, however, it was placed under derogation ${ }^{1}$ as Maltese had been, a state of affairs due to be phased out by 31 December 2021 (ibid., 116).

Leaving these intricacies aside for now, diversity constitutes one of the cornerstones of the EU, as enshrined in its legislation and conveyed in its motto, "united in diversity". But how is linguistic diversity made viable in EU institutions? Mostly through mammoth translation and interpreting services coupled with the ad hoc, unofficial use of English as the EU's lingua franca. Ironically, therefore, the EU's de jure multilingualism is enabled by its de facto monolingualism or use of English. Abram De Swaan very fittingly suggests that, in the EU, "the more languages, the more English" (2001). Against the backdrop of the largely unquestioned dominance of English, the member states' efforts to obtain official status for their national languages seems perplexing. Does the combination of Herderian pride of national languages with Lockean instrumentality for English constitute a paradox in the EU today? And what does this potential paradox look like in terms of language policy? These are the main questions that permeate this chapter - let us analyse them from different angles.

First, we will scrutinise the EU's de jure linguistic regime and language policy (Section 2.2), with Section 2.3 dedicated to EU languages deprived of officialdom. Section 2.4 will examine the EU's de facto internal language policies and practices, which amount to a lot of English with a little bit of French. The question of whether there is a paradox between the EU's de jure and de facto language policies will be addressed in Section 2.5. The longer Section 2.6 will offer an overview of some of the key aspects of recent literature in language policy, which will then be illustrated in Section 2.7 through the EU's education language policies on foreign language teaching. 
It will become clear in this chapter that, even though the English language is the focus of this book, we cannot approach it without considering not only its effect on other languages spoken in EU territory but also the overall dynamic among these languages. EU minority languages, which can be understood sensu lato as all languages except English, will feature heavily in this chapter for this reason.

One last terminological clarification: "multilingualism", "linguistic diversity" and the less frequently used "plurilingualism" are quasi-equivalent in this book. "Multilingualism" and "plurilingualism" can be understood as both individual and societal, i.e. certain individuals may speak more than one language, while certain territories and/or communities may have more than one official language. Let us bear in mind that a geographical area may well be multilingual and its citizens, monolingual - and vice versa: a geographical area populated by multilingual individuals may well have a single official language (see e.g. Edwards 2013; Cardinal \& Léger 2018, 21).

From a postmodern perspective, without languages as discrete units, there can be no "mono", "multi" or "plurilingualism" either. Each "language" is already multilingual on different levels - it is an intricate web of "languages", past and present, encompassing myriad language uses, registers, dialects, sociolects, idiolects, discourses etc. Still, for reasons of readability, I will use these terms to refer to individuals and (mostly national and supranational) groupings associated with more than "one" language. "Linguistic diversity", in turn, refers not so much to the use of multiple languages as to its resulting multifariousness; hence, it will usually appear in relation to larger groupings rather than to individuals.

\subsection{De Jure Multilingualism: Herder Would Be Proud}

When the European Economic Community (EEC), the forerunner of the EU, was founded in 1957, Article 217 of the Treaty of Rome (today Article 342 of the Treaty on the Functioning of the European Union (TFEU)) stated that the "rules governing the languages of the institutions of the Union shall ... be determined by the Council [of the European Union, where all members states are represented], acting unanimously by means of regulations". 2 And indeed the very first EEC regulation, of 15 April 1958, stipulated that "each of the four languages in which the Treaty is drafted is recognised as an official language in one or more of the Member States of the Community", and went on to establish, in Article 1, that "[t]he official languages and the working languages of the institutions of the Community shall be Dutch, French, German and Italian”. This article has been repeatedly updated since then, most recently upon Croatia's accession in 2013. It is thus up to each member state to appoint one official language which, usually upon admission to the Union (except in the case of Ireland and possibly Cyprus ${ }^{3}$ in the future), automatically becomes an official and working language in all EU institutions. No official distinction is made between "official" and "working languages" - all languages in Table 2.1 class as both. 
Lest this point escape the readers' attention, let me emphasise it here: this multilingual regime of 24 languages is valid within EU institutions ${ }^{4}$ only and pertains to communications between citizens and EU institutions, not between institutions and EU officials (including job applicants). This notwithstanding, institutions enjoy some flexibility in their linguistic regime "in specific cases", as Article 6 of Regulation No. 1 lays out: "The institutions of the Community may stipulate in their rules of procedure which of the languages are to be used in specific cases." Unlike institutions, EU bodies and agencies have free rein to choose their own linguistic scheme - the majority stick to English only or a combination of English and French. Different court cases reveal that these vague legal statements quoted thus far do not imply any hard language rights - notably Kik v OHMI (case C-361/01P; see note 2), whereby the Court of Justice of the EU ruled that EU treaties "cannot be regarded as evidencing a general principle of community law that confers a right on every citizen to have a version of anything that might affect his interests drawn up in his language in all circumstances" (see Section 3.2).

Still, one of the main perks of being an "official EU language", as laid down in Article 24 of the TFEU, is that "[e]very citizen of the Union may write to any of the institutions or bodies ... in one of the languages mentioned in Article 55(1) of the Treaty on European Union (TEU) and have an answer in the same language". Article 55(1) lists the 24 official languages of the EU, whereas Article 165(2) states that "the Union shall be aimed at developing the European dimension in education, particularly through the teaching and dissemination of the languages of the Member States". In a similar vein, Article 2 of the TEU declares that " $[\mathrm{t}]$ he Union is founded on the values of respect for human dignity, freedom, democracy, equality, the rule of law and respect for human rights, including the rights of persons belonging to minorities", adding that " $[\mathrm{t}]$ hese values are common to the Member States in a society in which pluralism, non-discrimination, tolerance, justice, solidarity and equality between women and men prevail". In Article 3, we read that the EU "shall respect its rich cultural and linguistic diversity, and shall ensure that Europe's cultural heritage is safeguarded and enhanced".

Further, the Charter of Fundamental Rights of the EU, which was made legally binding by the Treaty of Lisbon, also covers questions of linguistic diversity in several articles (see de Witte 2008). Explicitly, however, only in Articles 21 ("Any discrimination based on any ground such as sex, race, colour, ethnic or social origin, genetic features, language, religion or belief, political or any other opinion, membership of a national minority, property, birth, disability, age or sexual orientation shall be prohibited") and 22 ("The Union shall respect cultural, religious and linguistic diversity").

In terms of primary law, this is the EU's entire language policy (more on legislation about translation in Chapter 3). Primary law consists of the treaties and the Charter of Fundamental Rights; they are legally binding and set out the objectives and ground rules for the functioning of the Union. But how do they translate into action? Their formulation is often vague, as we have seen in 
the previous paragraphs. How exactly does the Union respect its "rich cultural and linguistic diversity"? The articles in these treaties give rise to the body of legislation known as "secondary law", which lays specific actions for the goals sketched out in the treaties to be achieved. Secondary law forms the legal acts of the Union, comprising regulations, directives, decisions, recommendations and opinions.

Regulations are the only ones that are legally binding and mandatory to all member states, resulting in supranational actions. Consequently, in terms of EU-wide language policy, regulations are the most relevant pieces of secondary law. They must be translated into national law within a given deadline. Take, for instance, Regulation 2015/478 of 11 March 2015: it is a lengthy document, comprising 27 articles that painstakingly lay down common safeguards to be taken on goods imported from outside the EU.

Decisions and directives are also legally binding, but the former apply solely to one or more member states, thus having no full supranational effect, whereas the latter leaves it up to national authorities to decide how to achieve the desired goal. Recommendations and opinions are not legally binding (see TFEU $\$ 288$, see note 2). As far as EU language policy is concerned, we have several articles in EU treaties and in the Charter of Fundamental Rights that emphasise the importance of multilingualism in the EU without, however, giving rise to specific language policies in secondary law. The only supranational, legally binding pieces of secondary law currently in force regarding language and culture are Regulations 1295/2013 and 1288/2013, both of 11 December 2013, which established the Creative Europe Programme (from 2014 to 2020) and the Erasmus+ programme, respectively (more on these below).

If we nevertheless look for non-legally binding statements by EU institutions about multilingualism, such as recommendations, special reports and general information on their multiple portals, we find a plethora of examples in which diversity is univocally celebrated. Here is a small sample: "Languages are an integral part of European identity and the most direct expression of culture", "In an EU founded on the motto 'United in diversity', the ability to communicate in several languages is an important asset for individuals, organisations and companies", "Languages not only play a key role in the everyday life of the European Union, but are also fundamental for respecting cultural and linguistic diversity in the EU" (European Parliament n.d.); "Languages unite people, render other countries and their cultures accessible, and strengthen intercultural understanding" (European Commission n.d.); "The EU ... is committed to safeguarding ... linguistic diversity and promoting knowledge of languages, for reasons of cultural identity and social integration and cohesion" (European Commission 2012, 2); "Everyone in the Union is entitled to contribute to the discussion [on EU legislation] in the official language of his or her choice. It is a question of transparency and democracy" (European Commission 2009, 1); "language is not only a means of communication but the expression of the inner world of its speakers. We are all intrinsically different, and our languages express our differences of thought and meaning” (Martikonis \& Viola 2017). 
The right to use one's own language(s) is thus portrayed as a basic right in the EU, one that dovetails with the notions of identity and democracy. The EU's discourse on language is out-and-out relativistic: Herder would be proud (see Section 1.4). This point raises the following questions: (1) Are all EU official languages equal in terms of status?; (2) What does the EU actually do to foster and protect multilingualism not only in its member states but also within its institutions, bodies and agencies?; and (3) What about other languages spoken in EU territory that are not deemed official (such as Catalan or Turkish)?

The answer to the first question is a straight "no". Although officially all 24 languages enjoy the same status, informally (and in breach of its own legislation), the EU makes a distinction between official and procedural languages, the latter being English, French and German, with English being by far the most used drafting language across EU institutions, bodies and agencies. This distinction, along with the special status of the English language, has not been implemented by treaties or legal acts and is often only mentioned in passing in different EU sources. In a 2009 booklet, for instance, “procedural languages" are defined as "English, French and German - i.e. ... those [languages] in which the Commission conducts its internal business" (European Commission 2009, 3). Statistics and further information on the EU's de facto monolingualism will follow in Section 2.4.

How about question (2), the EU's concrete actions to foster and protect multilingualism in its member states and within its institutions, bodies and agencies? Can the EU realistically achieve that and, if so, how? Here the answer is not as straightforward and must be viewed from at least two angles, namely the EU's internal language policies and the member states' language policies. Regarding the latter, language policy does not fall within the competences of the EU, so "the EU ... has limited influence because educational and language policies are the responsibility of individual Member States" (European Commission 2012, 2). In short, as stipulated in Article 5(2) of the TEU common provisions, "the Union shall act only within the limits of the competences conferred upon it by the Member States". This is known as the "principle of conferral", which hampers any supranational initiatives regarding language policy (see Phillipson 2003, 9).

However, this principle is complemented by the principles of subsidiarity and proportionality, also laid down in Article 5 of the TEU. "Subsidiarity" means that the EU is allowed to act only in those areas which fall outside its exclusive competence (such as language policy) when its action will be more effective than action taken locally. "Proportionality" means that any such actions taken by the EU on grounds of subsidiarity may not go beyond what is strictly necessary to achieve the objectives of the treaties. This means that, by default, the EU's jurisdiction regarding language policy is limited to the symbolic level. ${ }^{5}$

Nevertheless, legally speaking, if it resorted to the principle of subsidiarity and conformed to the principle of proportionality (as it did, for instance, when 
implementing the regulations mentioned above for Erasmus+ and Creative Europe), the EU could try to take legally binding steps to engender a more robust supranational language policy. However, any draft legislative acts proposed in the area of language policy would have to be approved by each national parliament; if at least one third of the national parliaments decided that the draft legislative act in question did not comply with the principle of subsidiarity, the proposal would have to be reviewed. If 55 per cent of the ministers in the Council of the European Union or a simple majority in the European Parliament confirmed this non-compliance, the draft would have to be withdrawn altogether. ${ }^{6}$ The legal mechanisms to introduce supranational language policy are thus in place, but as they currently stand, they by no means facilitate any initiatives. The adoption of concrete EU-wide language policies would require not only a bold step on the part of the EU, potentially encroaching upon member states' areas of competence, but also an almost utopian willingness to comply on the part of the member states. To complicate matters further, the EU may not harmonise legislation currently in force in the member states in areas outside its competences. ${ }^{7}$

Increasing the competences of the EU to include, for example, language policy, would of course be an imaginable solution to this deadlock, but doing so would probably turn out to be more impossible [let us hang on to the notion of impossibility for a moment, for it will gradually gain importance in this book], than passing the odd draft legislative act. To increase or decrease the EU's competences, any of the EU countries' national governments, the European Parliament or the Commission must submit a proposal to amend the treaties to the Council of the European Union, which would then forward it to the European Council (i.e. to the heads of state and government of all 27 member states). If the European Council accepted the proposal, a convention would be arranged with the representatives of the national parliaments, the member states' heads of state or government, the European Parliament and the Commission. All potential amendments would have to be agreed upon by consensus. The president of the European Council would then call a second conference with the representatives of the governments of all member states. The amendments to the treaties would come into force only after having been ratified by all EU member states. ${ }^{8}$

Even if the EU cannot harmonise national education language policies, for example, it does promote numerous programmes to encourage multilingualism and language learning, such as the two mentioned above: the Creative Europe Programme, through which funding is provided for the translation of, for example, books into European languages, and Erasmus+, a comprehensive exchange programme whose main objective is to promote language learning. There are others as well, such as the European Day of Languages, the European Language Label and Juvenes Translatores. These initiatives do contribute to multilingualism in the member states, but the level on which they operate and their scope are modest, if not because of the hurdles of jurisdiction mentioned earlier, then for budgetary reasons. 
Let us take the 2018 budget as an example: out of $€ 157.9$ billion, just under $€ 400$ million ( 0.25 per cent) was allocated to the Commission's language services (Official Journal of the European Union 2018). Different estimates set the total amount invested in language services across the EU at less than 1 per cent of the budget (Phillipson 2003, 114; Kraus 2011, 123; European Commission 2013). Also, all programmes under the umbrella "education and culture" (such as Erasmus+ and Creative Europe) took up just over 2 per cent of the 2018 budget.

The second angle suggested earlier, from which we must view the issue of concrete EU actions on behalf of multilingualism, pertains to the EU's internal language policy. The articles listed at the beginning of this section say little about the EU's de facto internal language practices. All we learn from them is that 24 official languages enjoy the same status within EU institutions (which we know, in practice, is an illusion) and that linguistic diversity must be respected - but "respect" is not "actionable, does not confer rights [or] duties on the EU" (Phillipson 2018, 290). If the EU wished to introduce internal language policies, it would most likely have to amend the treaties through the cumbersome procedure described earlier in this section. That would also be the case it if wished to introduce any changes to its current linguistic regime for example, adding or withdrawing a language in the wake of Brexit (more on this in Chapter 4).

The key questions that emerge from this discussion are whether language policy should remain a national prerogative in the EU and whether the EU should make it easier to enact supranational legislation, thus moving it closer to a federation. ${ }^{9}$ These issues will be addressed in Chapters 4 and 5. In Section 2.3, let us turn to the last question asked earlier about the status of the other languages spoken in EU territory, beyond the official 24.

\subsection{The Pecking Order of EU Languages: English, the Other 23, European Languages with No EU Status, Non-Territorial and Migrant Languages}

It is estimated that around 60 indigenous regional and minority languages are spoken by some 40 to 50 million people in the EU (European Commission 2012, 2; European Commission/EACEA/Eurydice 2017, 48). ${ }^{10}$ Three of these regional languages, namely Galician, Catalan and Basque, are semi-official (or co-official) EU languages. ${ }^{11}$ This means that they can be officially used under a special administrative arrangement, whereby any translation and interpreting costs are borne by Spain. ${ }^{12}$ It is further estimated that "at least 175 nationalities are now present within the EU's borders" - and surely a similar number of migrant languages, too (European Union 2018). As of 2018, there were 22.3 million non-EU citizens living in the EU - and these numbers do not include all those speakers of non-official EU languages who might have acquired EU citizenship (Eurostat 2019, 9). 
As noted earlier, language policy is not an EU area of competence, so the EU may not enact new - or harmonise existing - legislation when it comes to protecting these indigenous, regional, minority and/or migrant languages. As a member of the Commission explained on 7 November 2013 in her reply to Written Question E-006204/2013, for example, the EU "has no general powers as regards minorities" due to the principle of conferral outlined in Section 2.2. She goes on to state:

the Commission has no competence over the definition and recognition of national minorities, their self-determination and autonomy or the use of regional or minority languages, which fall under the responsibility of the Member States. In such cases the Commission does not make recommendations to Member States.

This is not the place to address the pressing issue of minority languages at length - see the works quoted in this section for more detailed studies. Generalising somewhat, this problematic encompasses four main dimensions (Table 2.2). The first is that of the official EU languages: increasingly, they can be seen as minority languages in relation to English (see Craith 2006, 67; Shuibhne 2008, 124). Next, there is the dimension of the approximately 60 European "autochthonous", or indigenous, languages, such as Frisian, which may or may not enjoy official status in the regions of the countries where they are spoken. The third dimension is that of non-territorial European languages, such as the Sámi and Romani languages. Finally, the fourth dimension comprises "allochthonous" languages, i.e. non-indigenous, migrant languages, such as Arabic. ${ }^{13}$

At the heart of this book is the first dimension suggested above - arguably the least pressing in terms of language survival (more below). Due to space constraints, I will limit myself to making a few brief remarks on the other dimensions. Suffice to say that, at first glance, what looks like an inclusive community in which state boundaries are lifted and the notion of national, state-bound citizenship is taken to the supranational level, can also be seen as a mechanism of internal exclusion on historical and ethnic grounds (see e.g. Balibar 2004; Craith 2006).

European languages grouped under the second dimension suggested above may enjoy official regional status in some member states - such as Basque in Euskadi (Spain) and West Frisian in Friesland (the Netherlands). Across the border to a neighbouring country, however, these languages may enjoy no official status whatsoever - for instance, Basque in France. Some of these languages have official status in non-EU countries, such as Turkish in Turkey and Albanian in Albania, Kosovo and North Macedonia. A few of these language communities are larger than those of some official EU languages. The classic examples here are the giants, albeit deprived of official EU status, Catalan, with more than five million native speakers, and Turkish, ${ }^{14}$ with around seven million (Dirim 2011, 132; Laçiner 2016, 2-3). By contrast, the official EU languages Irish and Maltese have less than $100,000^{15}$ and about 500,000, respectively. 
Table 2.2 The four dimensions of minority languages spoken in EU territory

Official EU languages minus English

1 Bulgarian $\bullet$ Croatian $\bullet$ Czech $\bullet$ Danish $\bullet$ Dutch $\bullet$ Estonian $\bullet$ Finnish

- French • German • Greek • Hungarian • Irish • Italian • Latvian

- Lithuanian • Maltese • Polish • Portuguese • Romanian • Slovak

- Slovenian • Spanish • Swedish

\section{European territorial languages}

2 Albanian $\bullet$ Arabic, Cypriot Maronite $\bullet$ Aragonese $\bullet$ Aranese $\bullet$ Armenian

- Aromanian (Vlach) • Asturian $\bullet$ Basque • Belarusian $\bullet$ Bosnian $\bullet$ Breton

$\bullet$ Catalan $\bullet$ Corsican $\bullet$ Faroese $\bullet$ Frisian $\bullet$ Frisian, North $\bullet$ Frisian, Sater

$\bullet$ Frisian, West $\bullet$ Friulian $\bullet$ Galician $\bullet$ German, Low $\bullet$ Greenlandic $\bullet$ Hebrew

$\bullet$ Istro-Romanian • Karaim • Kashubian $\bullet$ Ladin $\bullet$ Latgalian $\bullet$ Lemko

$\bullet$ Leonese • Limburgish $\bullet$ Livonian $^{1} \bullet$ Macedonian $\bullet$ Meänkieli $\bullet$ Mirandese

- Montenegrin $\bullet$ Occitan $\bullet$ Russian $\bullet$ Ruthenian $\bullet$ Sardinian $\bullet$ Saxon, Lower

- Scanian $\bullet$ Serbian $\bullet$ Sorbian, Lower $\bullet$ Sorbian, Upper $\bullet$ Tamazight (Berber) ${ }^{2}$

- Tatar • Tatar, Crimean • Turkish• Ukrainian • Valencian

European non-territorial languages

3 Beás • Karelian • Romani (Romany, Romanes, Romani Chib) • Sámi, Eastern/Skolt • Sámi, Inari • Sámi, Lule • Sámi, North • Sámi, South - Yiddish

Migrant languages

4 Arabic, Algerian $\bullet$ Berber, Kabyle $\bullet$ Chinese $\bullet$ Gujarati $\bullet$ Hindi /Urdu

- Punjabi • Russian • Tunisian

Sources: For dimensions 2 and 3: the list of languages included in the European Charter for Regional or Minority Languages (ECRML) (of January 2018; see www.coe.int/en/web/europea $\mathrm{n}$-charter-regional-or-minority-languages) and the European Commission's interactive map of regional and minority languages (of December 2019; see www.map.language-diversity.eu/). Dimensions 2 and 3 feature a comprehensive, though not exhaustive, list of languages; dimension 4 includes a small sample of languages.

${ }^{1}$ The last native speaker of Livonian is reported to have died in 2013 in Canada (Charter 2013). However, the European Commission's interactive map of regional and minority languages lists 135 speakers in Western Latvia. The language does not feature in the ECRML because Latvia is not among the signatories (more below).

${ }^{2}$ Tamazight, a variety of Berber, is only listed in the European Commission's interactive map of regional and minority languages because of Melilla, the Spanish autonomous city in the Northwest coast of Africa. Berber varieties are spoken by millions of people with Moroccan and Algerian background in Belgium, France, Germany, Italy, the Netherlands and Spain, but are not included in either maps as they are not considered indigenous to Europe.

Because there is no concrete EU language policy, there are no common criteria to treat these 60-something languages in an equitable fashion. Each member state has free rein to decide how to approach them, leading to glaring discrepancies across the EU. Máiréad Nic Craith, for example, reports that Basque-speaking Spanish nationals were allowed to speak Basque in a particular court case, whereas Basque-speaking French nationals involved in the same incident were not $(2006,98)$.

The same cross-border disparities apply to the languages grouped under the third dimension above, i.e. that of non-territorial languages. It is estimated 
that 10-12 million Romani minorities alone live in Europe (European Commission 2020a, 1). There are official EU reports of rampant discrimination against them, and although they may enjoy a few linguistic rights in parts of Austria, the Czech Republic, Finland, Germany, Hungary, the Netherlands, Poland, Romania, Slovakia, Slovenia and Sweden, there are still significant "gaps in legislation and policy" in these countries, not to mention in member states where they enjoy no specific rights, such as Bulgaria, France and Ireland (Chopin et al. 2017, 7). Attempts to push EU member states to grant rights to their linguistic minorities, be they territorial or non-territorial, have been largely constrained to the realm of symbolic politics. A new 10-year Roma strategic framework was launched by the EU in 2020; alas, it is limited to a proposal for a recommendation (which, even if passed, would not be legally binding) and language policy is virtually absent from the plan.

One of the most acclaimed initiatives so far in terms of protecting these European languages has been the European Charter for Regional or Minority Languages (ECRML) by the Council of Europe, which came into force in March 1998. The ECRML ${ }^{16}$ outlines concrete measures to promote the use of minority languages in public life. It defines "minority languages" as languages "traditionally used within a given territory of a State by nationals of that State who form a group numerically smaller than the rest of the State's population", as well as languages "different from the official language(s) of the State" - thus excluding the fourth dimension of migrant languages suggested earlier. In principle, the ECRML excludes non-territorial languages as well, since a lot of its provisions require a territorial base. Yet the Charter does recommend that all languages spoken by citizens of a given state be included, at least on a limited basis. In 2018, the ECRML pertained to 79 languages, spoken across Europe, including a few non-territorial ones. Although the ECRML was an initiative by the Council of Europe, the EU has officially endorsed it, for example, through the Killilea Resolution of 1994, which urged all member states to ratify it and to transpose it into national legislation (see Craith 2006, 75-76).

Now, more than 20 years after its launch, the ECRML has 33 signatories though eight of them never actually ratified the Charter, which would entail choosing a minimum of 35 measures from a list of 68 and enacting legislation accordingly within a given deadline. As for EU member states, 19 have signed the ECRML, but three, namely France, Italy and Malta, have never ratified it. Belgium, Bulgaria, Estonia, Greece, Ireland, Latvia, Lithuania and Portugal have not signed it. Signing and ratifying the ECRML do not by any means guarantee equity to all linguistic minorities within a given territory, not least because each signatory may choose freely which languages to recognise, along with the scope of rights granted. Moreover, there is no effective control system in place, nor are there consequences if states do not abide by the articles they chose to ratify (see e.g. Cichon 2003; Schjerve 2003). Still, the Charter has been an important step in two key directions, namely in establishing a dialogue with 
the signatories about linguistic minorities and in laying down benchmarks to assess the legal landscape of candidate countries to EU accession in terms of linguistic minorities (see Craith 2006; Paulston \& Heidemann 2006, 298; de Witte 2008). ${ }^{17}$

Initiatives such as the ECRML apply to historical minorities of Europe only, thus excluding recent migrants, as already pointed out. The majority of efforts towards linguistic equity in the EU have systematically left out the fourth dimension suggested earlier of "allochthonous", non-indigenous or migrant languages, both on a political and on a scholarly level. The ECRML is a significant example of exclusion of migrant languages on a political level. As Joshua A. Fishman bitterly notes, the EU "has [not] made any effort whatsoever to extend any rights or courtesies to [its] manifold immigrant languages" (2006, 314).

On a scholarly level, one of the most influential contemporary political theorists, Will Kymlicka, for instance, draws a distinction between "multination" and "polyethnic" states, the former having "national minorities" (i.e. "forcibly incorporated indigenous populations" or "cultures" in a "more or less voluntary federation") and the latter having "ethnic minorities" (a direct result of "individual or familial immigration") (Kymlicka 1995, especially his Chapter 2). Kymlicka's ethnic minorities thus coincide with our fourth dimension here. In his view, they need not be accorded any special language rights in the public space - all they need is the right to continue to use their language in private and resources to learn the national language, to ensure proper integration. Though this approach has been widely criticised - particularly for its patent individualistic neoliberalism - it remains influential and certainly holds sway in EU policy (see May 2006; Schmidt 2006; SkutnabbKangas 2006; Wee 2011, especially his Chapter 2; Ives 2015).

In short, the EU's de jure linguistic landscape encompasses 24 official and working languages whose status in all $\mathrm{EU}$ institutions is the same, along with three semi-official languages (Basque, Catalan and Galician), to which translation and interpreting services may be allocated as long as Spain foots the bill. The other languages spoken in EU territory, be they indigenous or nonindigenous, territorial or non-territorial, have no EU status. ${ }^{18}$ And since language policy lies outside the EU's competences, speakers of these languages are at the mercy of the national governments of the states in which they are spoken. As already noted at the end of Section 2.1, we must ask ourselves whether language policy should not fall within the EU's competences, so that supranational legislation could be enacted to oversee the use of these languages, combat discrimination on grounds of language and ensure these languages' survival.

The latest edition of the UNESCO Atlas of the World's Languages in Danger (Moseley 2010) lists 2,500 languages, 128 of which are in Europe. In the EU, there are 109 languages whose vitality is under threat, the majority of which are in Italy (32) and France (26), along with three languages that have become extinct since the 1950s, namely Dalmatian in Croatia, Guanche in Spain and Slovincian in Poland (ibid.). ${ }^{19}$ 
The history of humanity has been the history of language death. It is roughly estimated that there were 12,000 languages in use 10,000 years ago (Crystal 2007, 90; Johnson 2013, 16). It is equally roughly estimated that half of the remaining 6,000 languages will die in the next 100 years (Arzoz 2008, 3). The processes that lead to language death are too multifaceted and localised to be outlined here; yet it is clear that the "current situation is without precedent" because "the world has never had so many people in it, globalization processes have never been so marked; communication and transport technologies have never been so omnipresent; there has never been so much language contact", and crucially for us here, "no language has ever exercised so much international influence as English" (Crystal 2007, 92; see also Laponce 2001, 179-181).

In any case, why should we care that language death is happening at an unprecedented pace - also within the EU? Both the UN and the EU subscribe to the theory of ecology of language, proposed by Einar Haugen in 1972. "Ecology" in the sense that loss of linguistic diversity is tantamount to loss of biodiversity. Like organisms in an ecosystem, certain languages will need support from time to time to retain their vitality - often in the form of language policy (see Johnson 2013, 51-53). The UN's Universal Declaration on Cultural Diversity (2001), for example, states that safeguarding cultural (and, by extension, linguistic) diversity is an "ethical imperative, inseparable from respect for human dignity" (quoted in Arzoz 2008, 1).

This "ecology-of-languages paradigm" is often opposed to the "diffusion-ofEnglish paradigm” (based on Yukio Tsuda's work; see e.g. Grin 2004; Spolsky 2004, 78-80; Pennycook 2006, 67-68; Ricento 2015). Tove Skutnabb-Kangas's theory of linguicism, defined as "ideologies, structures and practices which are used to legitimate, effectuate, regulate and reproduce an unequal division of power and resources ... between groups which are defined on the basis of language", encapsulates the clash between the two paradigms (cited in Phillipson 2017, 317). Based on the UN International Convention on the Prevention and Punishment of the Crime of Genocide (1948), she coins the term "linguistic genocide" to describe the "forcible transfer of children from a linguistic group to another linguistic group, or serious mental harm caused to children through submersion education" (Skutnabb-Kangas 2006, 278). Through this prism, most speakers of the languages in the second, third and fourth dimensions in Table 2.2 are victims of linguistic genocide in the EU - and so are many speakers of languages in the first dimension who happen to move to another member state.

The "ecology-of-languages paradigm" often overlaps with the "universal linguistic human rights paradigm", because of their focus on collective linguistic rights. Both are also linked with the "linguistic imperialism paradigm", after Robert Phillipson's polemical notion of "linguistic imperialism", which he defines as

inequality, absence of a level linguistic playing-field, unfair privileging of the use of one language ..., the uncritical acceptance of English having a 'natural' right to be the default language, and a blind belief in English as a 'lingua franca' of Europe.

(Phillipson 2006, 357) 
It is indisputable that there is an "absence of a level linguistic playing-field" in the EU today, which is damaging the vitality of dozens of languages. The three paradigms of ecology-of-languages, universal linguistic human rights and linguistic imperialism have played a pivotal role in unveiling the intricacies and ramifications of linguistic inequality in the world, and some of their contributions will permeate this book.

We should, however, not lose sight of their moments of aporia, structured around two clusters of issues, namely (1) a postmodern theory, as particularly the linguistic imperialism paradigm claims to be, cannot uncritically rely on terminology derived from the natural sciences; and (2) the ecological metaphor suggests the survival of the fittest, meaning that any ecosystem must have both predators and prey (Pennycook 2004, 232; Spolsky 2004, 80, 128; Johnson 2013, 52; Ricento 2015, 29).

Attempts to create the so-called "European Agency for Linguistic Diversity and Language Learning" in the EU have been blocked either in plenary sessions of the European Parliament or directly by the Commission (Phillipson 2016, 145-152; more in Section 5.2). This leaves dozens of vulnerable languages in the hands of individual member states, which cling to their Herderian notion of national language while at the same time depriving their minority communities of the privileges reserved to the national language(s). The contradiction between some member states' outcry for more space in the EU for their national language(s), on the one hand, and their simultaneous rejection of their own linguistic minorities, on the other, is scandalous (see e.g. Cichon 2003; Arzoz 2008, 7-8; Jablonka 2011, 121-127). ${ }^{20}$ As Peter A. Kraus notes, from the perspective of the member states, diversity is nothing more than "a guarantee of the persistence of their identities in the Union" $(2011,24)$ - bearing in mind here that these "identities" are perceived as mostly monolingual in their respective official EU language(s). Moreover, the EU's flowery discourse on multilingualism flies in the face of its actions to protect and foster multilingualism, not only because it does very little for its regional and minority languages, but also because of its predilection for English, as we will see in Section 2.4.

\subsection{De Facto Monolingualism: Lockean Instrumentality and the EU's "Lingua Franca"}

The EU's de jure multilingualism and de facto monolingualism or use of English have become the elephant in the room, so to speak: whereas most EU researchers mention it as a hard fact (to be celebrated, accepted or regretted), the EU sweeps it under the rug. Officially, the EU sees language as a crucial element of one's identity, culture and Weltanschauung, a view akin to Herder's and Humboldt's. Yet its use of language reveals the very opposite: that languages can be mere vehicles for communication, a view in line with Locke's (Ives 2004, 28-29; Leal 2016, 5-6). The compartmentalisation of languages with "instrumental value" (mostly English) and languages with "expressive 
value" (all other languages), mentioned in Section 1.7, is very much in place in the EU, chiefly through the distinction between official and procedural languages [from Latin procedere, to go forward], i.e. English, French and German. $^{21}$ The distinction is nonetheless informal, hence it is not precise - at times only English and French are considered procedural languages, the latter probably more for historical reasons and because of its role as the language of the Court of Justice than because of its overall presence in the EU. As for German, among EU translation and drafting resources, for example, practical tips on clear writing are offered in English and French only, which is telling of the current status of German in EU institutions.

The use of English as a drafting language rose from 45.4 per cent in 1997 to 62 per cent in 2007, 72.5 per cent in 2008 and then 85.5 per cent in 2020 (European Commission 2009; 2020b; see also Sandrelli 2018, 64; Cliffe 2019), whereas the percentage of EU law originally drafted in English reaches 95 per cent (5 per cent in French; Barbier 2018, 337). A 2009 survey of staff in the European Commission found that 90 per cent use English as their main drafting language (see Robinson 2014, 194), whereas 95 per cent considered English the most used language in performing their duties in 2016 (see e.g. recruitment notices PE/219/S and PE/200/S).

There is an abundance of evidence, coming from various fronts, of the dominant role of English in the EU as a whole - from academics, politicians, Brussels correspondents and members of the European Parliament all the way to senior EU officials. ${ }^{22}$ Dissenting voices do not so much deny the EU's monolingualism as perceive it as a natural - often unavoidable and at times harmless - state of affairs (see e.g. Van Parijs 2011). Former Italian prime minister and European Commissioner, Mario Monti, for example, is an ardent defender of the adoption of English as the EU's sole official lingua franca ("with a bit of French") (quoted in Dallison 2017).

As noted earlier, the EU's efforts to foster multilingualism are tantamount to symbolic politics, and its language policy in its institutions is very much non-existent, so the adoption of English as a lingua franca of sorts is the ad hoc, unofficial "solution" to the "problem" of multilingualism. In the interview in the Appendix with the Commission's Directorate-General for Translation, English is portrayed merely as the language which most EU employees happen to speak for instrumental purposes alongside their mother tongue(s). This compartmentalisation is controversial because any natural, living language used as lingua franca in the EU cannot have its instrumental and vehicular character detached from its expressive value, as noted in Chapter 1.

Moreover, this state of affairs unveils a discrepancy between the current status of English as the EU's lingua franca of sorts and the EU's linguistic reality. Before Brexit, English was spoken as a first language by 13 per cent of the population - a number which has now fallen to around 1 per cent (Ginsburgh et al. 2018). As a second language, it is spoken by 38 per cent of EU citizens - though "spoken" does not mean spoken well, as only 21 per cent of these EU English-speakers rate their English proficiency as "very good". 
Combining these two percentages, the number of competent non-native speakers of English amounts to 8 per cent of the EU's population - roughly 9 per cent if we include all Irish and Maltese citizens. Only 25 per cent of EU citizens claim to be able to follow radio or television news in English, whereas 26 per cent consider themselves able to communicate online in English (European Commission 2012, 6; see also Barbier 2018). As Kraus put it in relation to the number of proficient English speakers in the EU back in 2008, "English may be a reliable medium for asking directions for many Europeans when they are abroad, but that does not make it the linguistic cement of a transnational political community." Indeed, although it may have established itself as the EU's "first second language", English is in no way the EU's "second first language", as Jürgen Habermas would have it (Kraus 2008, 155, 156).

English is thus neither a neutral language - nobody's language, as it were nor is it a widely spoken language in the EU - at least not yet (more in Section 2.7). Brexit has simply reduced the percentage of English native speakers from 13 to 1 per cent of the EU's population, and of proficient speakers from 21 per cent to 9 per cent. Language-related, post-Brexit developments will be addressed in Chapter 4. For now, we must ask ourselves whether there is a paradox in the EU between its de jure multilingualism - deeply-rooted in ethnic strands of linguistic relativism - and its de facto monolingualism or use of English permeated by Platonic essentialism, Lockean instrumentality and a logocentric will to compartmentalise languages according to instrumental and expressive value.

\subsection{One Language for Communication, Many for Identification: Pernicious Paradox or Harmonic Reality?}

Though an oversimplification of more complex theories of language (addressed in Chapter 1), the opposition between a Lockean and a Herderian/Humboldtian notion of language encapsulates the conundrum of the EU's de facto monolingualism versus de jure multilingualism. In political theory, Peter Ives, for example, sees it as a pernicious paradox, particularly because no measures have been taken to introduce English as the EU's "lingua franca"; instead, its use appears to be "driven by a sense of inevitability or pragmatic concern over the cost of multilingualism" which is the result not of "some conscious public debate" but simply a "default" choice (Ives 2004, 43; see also 28, 29; Leal 2012, 50; 2013, 64).

Others, like Catherine Frost, find that "high support for a language as a cultural object" is not necessarily at odds with "low support for day-to-day bilingualism", as is the case with the Irish language (2004, 52). Her conclusion is that maybe there is no paradox between "language attachment" and "language use" in the EU after all, and that we need to rethink such categories as Herder's or Locke's notion of language because "language use does not lend itself to neat categories of intrinsic or instrumental value" (ibid., 52; see also Spolsky 2004, 192; Leal 2013, 68). 
Though via a different route, the English as a lingua franca (ELF) paradigm, spearheaded in this case by Juliane House, maintains an analogous distinction between "languages for identification" and "languages for communication". For House, "Using ELF for instrumental purposes does not necessarily displace national or local languages, as they are used for different purposes" (2003, 560). In the EU, despite the "illusion of multilingualism" and "the lip-service paid to the ideal of a multiplicity of languages", she sees English strictly as a "language for communication", which "strength[ens] the complementary need for native local languages that are rooted in their speakers' shared history, cultural tradition, practices, conventions and values as identificatory potential" (ibid., 561-562). As noted in Chapter 1, it is taken for granted that "languages for communication" and "for identification" remain shielded from each other - hence the LockeanHerderian unlikely alliance constitutes no paradox in this paradigm.

Jan Blommaert brings Locke and Herder together from yet another perspective. He attributes our mainstream notion of national identity - as some sort of straightforward national affiliation - to an actual alliance of these philosophers' writings. Relying on Bauman and Briggs's work, Blommaert avers that Locke "developed a highly elitist view on language" whereby "the vernacular stories and anecdotes told by the common people [oral folk]" were considered antirational, emotional and chaotic, and were thus gradually replaced by standard written language. Yet this same oral folk tradition "was rescued by Herder ... and elevated to the level of 'national character"”. This tradition had nevertheless already been rationalised through the "transparent, standard language ${ }^{23}$ promulgated by Locke". Blommaert concludes that "it is the combination of tradition seen as national identity and rationalist perceptions of standard speech that offered the launching platform for national (standard) languages as we now know them" (2006, 243).

Interestingly, a combination of these conflicting theories of language is also found in EU citizens' opinions on language, albeit along different lines. The 2012 special Eurobarometer report on "Europeans and their languages" reveals that while 81 per cent of respondents agree that all EU languages "should be treated equally", 69 per cent believe that Europeans should "be able to speak a common language", with over half (53 per cent) suggesting that "a single language" should be adopted by EU institutions to facilitate communication. And although the question of "which single language" was not part of this survey, 67 per cent of respondents consider English "one of the two most useful languages for themselves", while 79 per cent see it as "the most useful [language] for the future of their children” (European Commission 2012, 141).

Similar to the EU as a body of institutions, EU citizens seem torn between a conception of language as a vehicle for communication and as an important element in one's culture and identity. Therefore, and following Frost and House, we could argue that there is no paradox on a practical level - at least not in the sense of a disruptive and paralysing contradiction that renders the coexistence of multiple languages and cultures impossible [here it is again: the notion of impossibility]. 
However, if this model were indeed so harmonic, why not officially introduce it in the EU or at the very least acknowledge it is in place? The European Commission flatly denies that English is favoured in its internal language practices (see Appendix). And it is easy to guess why: questions of linguistic affiliation, even the most practical and everyday ones (such as ticking one's preferred language in a form), are underpinned by far-reaching, deeply-rooted "political processes and ideologies of state-formation", which in turn could challenge the EU's very existence (Ricento 2006, 15). In Gramsci's words, "the question of language" is ineluctably about "the formation and enlargement of the governing class, the need to establish a more intimate and secure relationship between the governing groups and the nation-popular mass, in other words to reorganize the cultural hegemony" (quoted in Ives 2015, 66).

Any tensions in the realm of language, any reluctance on the part of the EU to acknowledge its monolingualism and its favouritism of English (in the wake of Brexit), amount to far more than simply questions about language - as in discrete units hermetically sealed from one another, each with its own sets of cultural values, ideologies and affiliation criteria. If we understand language as a part of a comprehensive multimodal framework, then there are no purely linguistic questions. As argued in Chapter 1, our social and individual identities are permeated, conveyed, constructed by and in language and vice versa, so that multiple identifications across and beyond individual languages are not to be avoided.

On a practical and superficial level, therefore, there is no urgent paradox in the EU's de jure multilingualism and de facto monolingualism. However, on an epistemological level, it is a pernicious paradox that needs to be addressed by the EU. If multilingualism is one of the pillars of the European project, and if language equality is enshrined in EU law, the EU cannot allow it to be undermined in its institutions by the ad hoc, seemingly unescapable and especially unofficial use of English. Informally adopting any one language as the main procedural language in its institutions goes against the very raison d'être of the EU. English has not become the world's lingua franca of sorts by accident, nor is this simply a natural result of economic prowess. The role played in the spread of English by Britain's (and America's) colonial past can never be overstated (Phillipson 2003; 2017). Moreover, the idea that one can use a language purely for communication purposes, neatly detached from any such issues of ideology and power, is an illusion. The fact that English is the global language in science, academia, diplomacy, entertainment, and so many other areas entails the imposition of world-views and thought patterns, and this imposition happens to the detriment of other languages and cultures (see Phillipson 2003; Fiedler 2010, 208; Wierzbicka 2013 - more on epistemicide in Section 3.7).

Can this epistemological paradox be resolved? The EU certainly cannot (and need not) directly curb the use of English in its institutions and member states. What it can do is be more open regarding its internal language use and hierarchy, acknowledge that there is a paradox in place and seek ways to remedy 
it without, however, fully resolving it. As Helder De Schutter and David Robichaud put it, "We do not have a choice between freedom and regulation, or between neutrality and engagement. Rather we must choose between different forms of regulation and engagement, between different language policies" (2015, 89). Language policy is everywhere, albeit often as tacit, unspoken rules: in the home, in schools, universities, small and large corporations, in cities and portions of countries, in states and supranational institutions. What is language policy, why should we take it seriously and how does it work?

\subsection{Language Policy: What, Why, How?}

Language policy often comes to mind when we think about multilingual states such as Belgium and Canada, as a set of rules governing the use of multiple languages within various institutional frameworks. I have referred to language policy so far in this sense in relation to the EU. However, as Bernard Spolsky reminds us, language policy encompasses "language practices, language beliefs and ideology, and the explicit policies and plans resulting from languagemanagement or planning activities that attempt to modify the practices and ideologies of a community" $(2004,39)$. In this sense, language policy is present in every social domain, starting in families, schools, religious organisations and workplaces, all the way to local governments, nations and states and, finally, supranational groupings (see ibid., 39-56).

In the EU's case, language discourse complements Spolsky's tripartite picture of language ideologies, practices and policies. The EU's de jure multilingualism pervades its (abundant) language discourse and is undergirded by (scarce) language policies, whereas its language practices amount to de facto monolingualism. We have to assume that the EU's (institutional and individual) language ideologies are torn between these two sides.

"Ideology" has become a buzzword pretty much everywhere. For our purposes here, language ideology is not a neutral concept, encompassing "all cultural systems of representation", but rather a construct embedding "strategies for maintaining social power", whose potentially hegemonic character should never be understated (Woolard \& Schieffelin, quoted in Johnson 2013, 112; see also Woolard 1998). Ideologies often amount to "unconscious beliefs and assumptions", which in turn can become "natural" through "hegemonic practices", thus reinforcing "privilege" (Tollefson 2006, 47, based on Fairclough and Bourdieu). From James W. Tollefson's “critical language policy”, a strand of language policy research with tight-knit links to critical theory (Foucault) and critical discourse analysis (Fairclough), we particularly take its avoidance of apolitical approaches, its acknowledgement of the role of policymakers in "promoting the interests of dominant social groups" and its intention to bring about more democratic language policies that further minority languages (Johnson 2013, 40; see Tollefson 2006).

Though amalgamated into one another, there is no "cause-effect relationship" between language ideology and language policy, at least not a priori, as 
they often feed into each other mutually (Johnson 2013, 113). The same is valid in relation to the pair policy and practice: "[l]anguage practices are influenced by, products of, producers of, and instantiations of language policies" (ibid., 8). The EU illustrates that language discourse does not necessarily match practices, policies and ideologies, either. As Elana Shohamy notes, despite - and often in breach of - "declared policy statements", "a variety of devices [can be] used to perpetuate language practices, often in covert and implicit ways" (2006, xvi). Here, Harold Schiffman's much-quoted differentiation between overt ("explicit, formalized, de jure, codified and manifest") and covert ("implicit, informal, unstated, de facto, grass-roots and latent") language policies is crucial (quoted in Shohamy 2006, 50). In the context of the EU's de jure multilingualism and de facto monolingualism, the former is underpinned by overt, formal language policies; the latter, by covert, informal language policies.

To complement the picture of covert and overt language policies, Robert L. Cooper adds that "[m]icrolevel, face-to-face interactional circles can both implement decisions initiated from above [top-down] and initiate [bottom-up] language planning which snowballs to the societal or governmental level" (quoted in Johnson 2013, 37; see also ibid., 10, for a discussion on "bottomup" and "top-down"). In other words, though often perceived hierarchically, each of the different layers involved in language policy plays an equally (at least potentially) decisive role in initiating and/or implementing, appropriating and instantiating policies. To implement a policy means to enact it; policy appropriation, on the other hand, suggests "taking ... policy and making it one's own" (Levinson \& Sutton, quoted in Johnson 2013, 96). Finally, instantiation refers to "the patterns of language use that emerge [as a result of language policy] based on a broader set of social, political, and cultural influences within a given context" (ibid., 107). In other words, looking at policy text is just as important as investigating policy implementation (i.e. to what extent it is appropriated) and instantiation.

Here, postmodern approaches to language policy, pioneered, for example, by Alastair Pennycook, add the dimension of "language governmentality", derived from Michel Foucault's notion of governmentality. Language governmentality refers to the impact that multiple decisions about language - taken in all layers of society and promulgated through official and nonofficial means - have on language practices. It moves emphasis away from governance in the sense of government authorities, focussing instead on more microlevel processes and discourses on language, along with their individual agents - such as educators and other local actors (Pennycook 2006, 65). ${ }^{24}$

Language policy usually goes hand in hand with language planning, which in turn is "deliberate language change ... that [is] planned by organizations established for such purposes" (Rubin, quoted in Johnson 2013, 27). Many simply use the acronym LPP, "language policy and planning" (see e.g. Canagarajah 2006, 153; Hornberger 2006, 25). In this book, "language policy" may at times mean "language policy and planning", though usually it will have less 
to do with planning particular vernaculars than with the distribution of languages, notably in EU institutions and schools. Also, here "language policy" is often used as an umbrella term for ideologies, practices, discourses and policies about language. Therefore, there cannot be a "no-policy language policy", because these four elements are ubiquitous, and decisions about them are always made. Any mention of a "no-policy policy" here should be understood strictly as overt, often a top-down policy - as in the EU's case.

One of the key questions in language policy research for our purposes here is how the dynamic between macrolevel language policy and actual language practices works. In other words, if the EU introduced overt, top-down language policies, would they translate into renewed practices? And is language policy even necessary to bring about new language practices (and ideologies)? Johnson reviews eight language policy studies and arrives at an interesting conclusion: some individuals simply choose to exercise agency, often quite apart from overt policies, whereas others do not, indicating that the phenomenon is too localised and particular (often personal) to be generalised (Johnson 2013, especially his Chapter 3). His findings include the following (paraphrased from Johnson 2013, his Chapter 4):

- "National [and local] multilingual language policies can and do open spaces for multilingual education and minority languages" - Multilingual language policies that see multilingualism as a resource create ideological space for multilingualism, but this space must be filled with actual practices, thus requiring the active involvement of all actors. Here, Richard Ruiz's celebrated framework of orientations towards language, first proposed in 1984, is of utmost importance. He defines language orientation as "a complex set of dispositions toward language and its role, and toward languages and their role in society" and identifies three such orientations (Ruiz 2016, 14). The first is called "language-as-problem", whereby minority languages are seen as hurdles in the acquisition of the majority language(s). Linguistic assimilation and cultural assimilation are the ultimate goal of the "language-as-problem" orientation. The second, "language-asright" orientation, is inherent to the universal linguistic human rights movement and usually leads to policies that allow linguistic minorities to learn the majority language while maintaining their mother tongue. Finally, the "language-as-resource" orientation perceives multilingualism as an asset for all, resulting in multilingual education for minority and majority language speakers alike (ibid.; see also Johnson 2013, 36).

- "Macro multilingual language policies are not necessarily enough" Particularly regarding minorities, speakers may suspect that their language is being encouraged simply to keep their communities subjugated, and/or they may prefer their children to acquire the majority language. As long as language ideologies remain intact, language practices are unlikely to change through language policies. As Nancy Hornberger explains, officialdom, for instance, is not enough; "incentive" and "opportunity" to use these languages 
are more important $(2006,32)$. Moreover, multilingual language policies and "incentive and opportunity" together might not suffice either without economic planning as well. In Ireland, for example, Irish started being taught across the country as a result of language policy, but no financial measures were adopted to foster the economy of the Gaeltacht, the traditionally Irishspeaking areas of the country, leading to heavy emigration flows of Irish speakers to English-speaking countries. When the policy was at long last expanded to encompass economic planning, those emigrants and their families did return to Ireland, but as resolute English speakers (see Spolsky 2004, 191).

- "Meso-level language policies matter" - Sometimes a regional language policy leads to rights being granted at the national or supranational level the co-official EU status of Basque, Catalan and Galician is a case in point.

In short, Johnson's meta-study results underline the importance both of microlevel processes and actors, and of the state as an "obvious locus of power, with a constitutionally established authority of governments over their citizens" (ibid., 40). Official language policies promulgated by the state and by supra-state organisations remain an important research object and will take centre stage in this book, not least due to a lack of data on EU-wide language practices and ideologies (see Tollefson 2006, 51).

This is not the place to thoroughly review the models of language policy and planning in place in the world today, so a few cursory remarks will have to suffice. The nineteenth century saw a lot of language planning underpinned by nationalism, or a will to establish nationhood rooted in national identity and national language (see Section 1.3; this process is ongoing today, as Konstantin Zamyatin (2018) argues apropos of Russia). This planning entailed first selecting certain linguistic forms (status planning) and, second, codifying, standardising and purifying them of alien influences, along with elaborating them in terms of terminology and stylistics (corpus planning). It also involved implementation, i.e. ensuring that everyone acquired this particular, idealised "national" language (see Spolsky 2004, 60; Johnson 2013, 28). Through colonialism, this dynamic between language and territory was imposed on various communities outside Europe. Colonial language policies were mostly out-and-out restrictive, for it was believed that acquiring the colonial language and obliterating local languages were prerequisites for obedient citizenship and for Christianity to take hold (Johnson 2013, 17-19).

It was not until after the First World War that the need to provide protection for linguistic minorities started gaining ground (see Spolsky 2004, 57). Today, there are various instances of language policies that portray linguistic diversity in a positive light and seek to actively foster it - if only ritualistically at times, as in the case of the EU. Accordingly, language policy research has moved from a positivistic to a more critical framework (see Hornberger 2006, 26-27; Ricento 2006, 12-16). 
Still, the ways in which states manage their languages vary widely and depend on their sociolinguistic set-up. Within Richard D. Lambert's muchquoted model (based largely on Joshua A. Fishman's writings), there are three basic types of countries: (1) monolingual (or monoethnic), such as Japan; (2) dyadic (or triadic), such as Switzerland; and (3) mosaic (or multi-ethnic), such as India - the majority fall into this category (see Spolsky 2004, 58). ${ }^{25}$ Yet the most widespread language policy system is a "no-policy policy", which invariably "works in favor of the stronger party" (Fishman 2006, 318). Among those states in categories two and three in which there is at least some overt language policy, two types predominate, namely policies based on territory (i.e. a single language and concomitant language rights are assigned to a particular geographical area, as, for instance, in Belgium and Switzerland) and policies based on personality (i.e. language rights may be granted upon demand regardless of territory, as is the case in South Africa and Canada) (see e.g. Cartwright 2006, 202-203; Edwards 2013, 6).

To come back to the title of this section, why should we take language policy seriously? Regarding overt language policy, a few factors certainly speak against any attempt to plan, control, change or interfere with people's language use. If a "no-policy policy" helps perpetrate social injustices, overt policies that favour dominant groups and marginalises minority communities are even more nefarious. Had there been no language policy and planning in the nineteenth century, for example, it is unlikely that the dangerous ties between territory, language and ethnicity, which dominate the West and Westernised countries today, would have been established the way they were. Language policy and planning are used by governing bodies to exert control over the population - for good or for ill (Johnson 2013, 102-103). ${ }^{26}$ Critical language policy emerged as a reaction to the power imbalances engendered, perpetuated and/or exacerbated by language policy. However, its aim has been to change the course of language policy to promote social justice, and not to do away with language policy altogether, not least because of the dangers of a no-policy policy.

Many of the voices against state interference in language affairs are wary of the implications of the linguistic human rights movement mentioned in Section 2.3. Spolsky, for example, contends that collective language rights are at odds with individual language rights, especially when we are looking at a "language-as-resource" orientation. Put differently, if speakers of the dominant language do not wish to learn or have contact with other languages, they should have a choice. Spolsky places the responsibility for linguistic diversity in the hands of linguistic minorities, taking the onus away from governing bodies. States, he claims, can and should be expected to make it possible for certain languages to be used, not to promote or facilitate their use (Spolsky 2004, 130). In a more or less overt attack on Skutnabb-Kangas, Spolsky declares that "the loss of linguistic diversity results less from linguistic genocide than from linguistic suicide" (ibid., 218).

In Spolsky's view, language policy is only ever realistic if it matches the communities' language practices and language ideologies; otherwise "the 
explicit policy written in the constitution and laws is likely to have no more effect ... than the activities of generations of schoolteachers vainly urging the choice of correct language" (ibid., 222). Furthermore, he stresses that circumstances lying outside the realms of language policy play a bigger part in the revitalisation and maintenance of minority languages. Based on Crystal's work, Spolsky formulates the six following factors (ibid., 215-216): (1) "increased prestige"; (2) "increased legitimate power" and (3) "increase in wealth" in the "dominant community for speakers of the language"; (4) "a strong presence in the educational system"; (5) "a writing system"; and (6) "access to electronic technology". Only factor five can be placed under the umbrella of language policy, on Spolsky's account. The others are social, economic, political and technological.

It is indisputable that language policy is unlikely to bring any results without a change in language practices and ideologies. However, language policy would be pointless if it only ever worked when it went hand in glove with existing language ideologies and practices. Moreover, it seems unrealistic to expect linguistic minorities, which are often in a subordinate position in their respective communities, to take full responsibility for the maintenance of linguistic diversity, without state provisions and without proper, state-sanctioned "incentive and opportunity" to use their languages (Hornberger 2006, 32). Particularly regarding migrant subordinate groups, ${ }^{27}$ the full loss of their mother tongue usually occurs by the third generation, as Spolsky himself reports $(2004,44)$.

While Crystal's and Spolsky's six factors quoted earlier may not pertain directly to language policy, it is unimaginable that the linguistic minorities of the EU, for example, could ever obtain increased prestige, wealth, legitimate power, presence in the education system and access to technology without the assistance of comprehensive language policies undergirded by a language-asresource orientation. To unpick only the first of these factors for want of space, it is unclear how a linguistic minority should be in a position to accrue prestige in the eyes of the dominant community without policies that carve out both physical and ideological space for that minority language. If the subordinate group is to obtain prestige by acquiring the majority language and losing any obvious associations with the minority linguaculture, then what is expected is assimilation within a language-as-problem orientation.

Language policies which foster minority languages can also be construed as mechanisms to highlight and hence perpetuate their minority status. This view is prevalent among postmodern researchers, who are concerned that the notion of "minority" remains "caught within the same paradigm" that established it in the first place (Pennycook 2006, 70). This point takes us back to the issue of embracing a postmodern notion of language while at the same time trying to bring about social justice. Even if minority-oriented language policy does contribute to the perpetuation of the categories underpinning social injustice, its long-term benefits outweigh its potential drawbacks because it can help shape new language ideologies and practices. ${ }^{28}$ Also, policies that aim at transcultural competence 
further minority languages without depicting them as a "weak David" (more in Section 4.8). Moreover, if we believe that the majority-minority logic is so detrimental that minority-oriented language policies have to go, accordingly we have to believe that policies against, say, racism, sexism and homophobia are ultimately harmful because they reify the oppressions they wish to combat (see Bale 2015, 75). Nevertheless, the validity of Pennycook's deconstructionist exercises is of course not in question - there is always a place and a need for deconstruction.

Besides the social justice agenda, another factor that speaks in favour of promoting multilingualism through overt language policies lies in the economic value of linguistic diversity. Linguistic diversity (and literacy) are known to boost foreign trade, for example (see Ricento 2018, 205-206). Further, links have been found between language skills and wage premiums of 10-18 per cent in certain sectors of the market, "holding the main determinants of income (typically, education and work experience) constant" (Grin 2015, 125-126).

Moreover, when left to market forces, language practices can become increasingly restrictive (see e.g. Johnson 2013, 23). From the perspective of the economics of language, any one form of market failure justifies state intervention; yet nearly all kinds of market failure documented to date take place in relation to language. François Grin stresses “positive or negative externalities”, which means that "a person's language learning (or non-learning) behavior affects the value of another person's language skills" (2006, 83-84; see also Wickström et al. 2018).

Furthermore, when regulated by market forces, language practices hugely benefit the native speakers of given dominant languages financially, as Grin convincingly shows. In the EU, for instance, the preference for English "amounts to a massive transfer in the direction of native speakers of English, paid for by everybody else", estimated at $€ 17$ billion in the EU alone back in 2005 - and this is a "conservative" estimate (Grin 2006, 86-87; 2008, 80; more in Section 4.5). The message from the economics of language is that these injustices, along with the market failures reported in relation to language, justify state intervention through language policy.

From the perspective of the global political economy, one could of course argue that language is such a small player, subjected as it is to more palpable and crucial forces, such as economic investment. Looking at foreign direct investment statistics, Jeff Bale explains that capital is the real shaper of social power, not language. Yet "formal language rights" remain "relevant and indeed urgent" in this scenario, precisely because "neoliberalism continues to reproduce nation-state structures that are used in part to regulate the linguistic lives of migrants and other minoritized linguistic communities" (Bale 2015, 93), often through a no-policy policy and/or through a language-as-problem orientation. Bale argues in favour of a global political economy framework to "understand the contradictory connections between neoliberal capitalism and its negative consequences for linguistic justice" and to design language policies "not as an end unto themselves but rather as a way to exploit those contradictory connections ... toward more liberatory ends" (ibid., 93). 
Another factor that speaks in favour of overt language-as-resource policies lies in the symbolic value of linguistic diversity. Some see it as "a social asset, like clean air" (Tollefson 2006, 52). Others emphasise the nonmarket value of linguistic diversity which, although impossible to pin down, should not be overlooked, as countless examples suggest (see Grin 2015, 125). The 1979 student riots in Soweto that culminated in the end of apartheid in South Africa were triggered by the introduction of Afrikaans into the curriculum. The introduction of Latvian as the sole national language of Latvia in 2004 led to mass protests in Riga by Russian-speaking Latvians (Paulston \& Heidemann 2006, 298). Increasingly restrictive, monolingual language policies introduced in the 1980s under the rule of Slobodan Miloševic in the former Yugoslavia played a part in the socio-political context that led to the infamous "trial of the four" Slovene journalists for treason in 1988 (Huszka 2014, 39). The trial, which was unlawfully conducted in Serbo-Croatian only, became a symbol of the end of a pluralistic Yugoslavia, foreshadowing the civil war that ensued (Johnson 2013, 102-103; see Kraus 2018, 90-91, for further examples of similar mobilisations on grounds of language).

Little wonder that the Organization for Security and Co-operation in Europe (OSCE) - whose chief aim is to mitigate potential conflict in its 57 participating states - has a "High Commissioner on National Minorities". They know from experience that issues of inequality in multilingual societies tend to mushroom into full-blown conflicts. Their "Oslo Recommendations Regarding the Linguistic Rights of National Minorities" (1998), albeit not legally binding, endorse minority-oriented language policies - not as an end unto themselves, but as alleviating measures since linguistic minorities are almost always socially and economically marginalised, and their languages promptly reveal and bolster their disadvantaged status. In this context, linguistic rights work as a palliative against conflict (see Spolsky 2004, 127; www.osce.org).

The last and most decisive argument for overt language policies for the EU lies in the fact that language pervades all domains of society, including those deemed more relevant and powerful when it comes, for example, to social justice. Everything takes place in and through language, so decisions about language are constantly made, whether or not there are overt policies to guide them. In Chapter 5, we will see how the EU can take a more active stance in this regard without encroaching upon citizens' individual rights and member states' sovereignty.

In this book, language policy constitutes one of several prisms through which to understand the dominance of English in the EU (see Figure 2.1, for some key terms). In Section 2.7, foreign language teaching in the EU will feature as an example from the field of education language policy which impacts the status of English in the member states. Together with the EU's overt and covert language policies, sketched in the previous sections, the issue of education language policies plays a pivotal part in establishing, perpetuating and potentially changing language practices and ideologies in and beyond the classroom. 


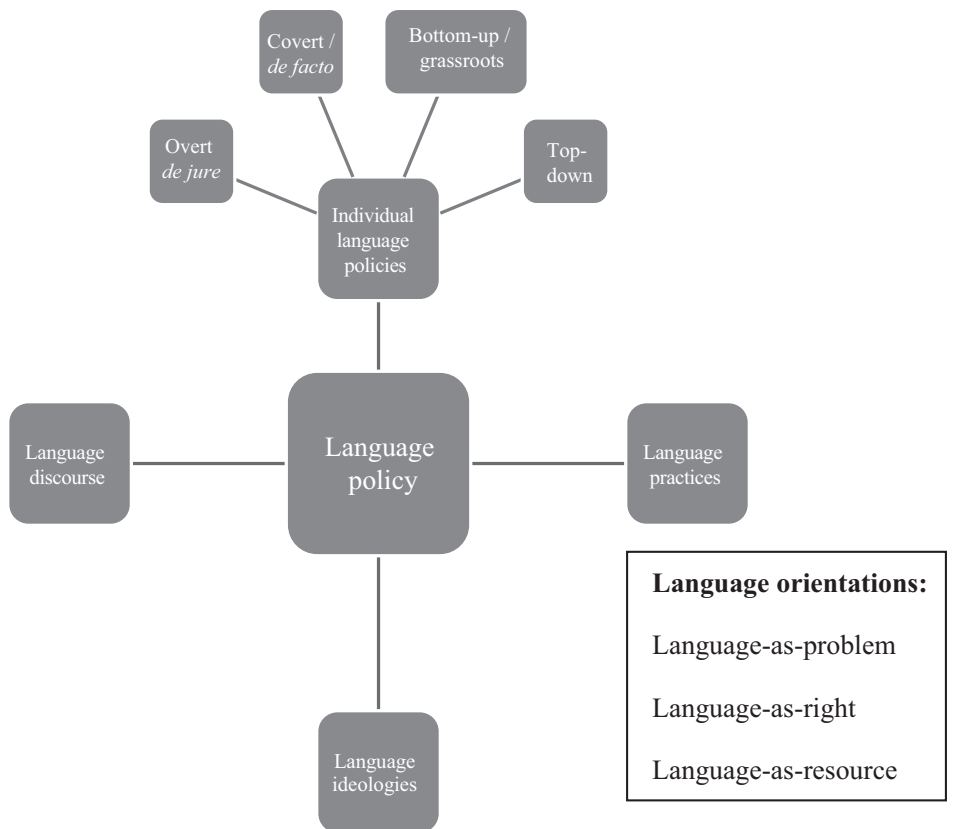

Figure 2.1 Some key terms in language policy

\subsection{Education Language Policies: Foreign Language Teaching in the EU}

In this book, "education language policies" are understood as "the official and unofficial policies that are created across multiple layers and institutional contexts (from national organizations to classrooms) that impact language use in classrooms and schools" (Johnson 2013, 54). They are a key mechanism through which linguistic diversity vis-à-vis the dominance of English can be diminished, maintained or fostered. Fishman names three factors that make the education system "a very useful and highly irreversible language-shift mechanism", namely: (1) education is usually mandatory; (2) it starts at an early age; and (3) it takes place over many consecutive years - leaving a permanent imprint on pupils well beyond their school years. He argues that the postmodern focus on the grassroots, spontaneous level of language policy "misses the boat completely in connection with formal and educated language" (Fishman 2006, 320).

This interplay between macro-level (mostly top-down) and micro-level (mainly bottom-up) language policy is particularly intriguing when it comes to the education system. There are abundant reports on pedagogical success despite policy failure and pedagogical failure despite policy success (see e.g. Canagarajah 2006, 161). To be successful, a policy must either (1) match dominant ideologies and practices, or (2) persuade those against it to change their ideologies and practices, or (3) change the factors behind the 
disagreement (Baker 2006, 211). As regards points 2 and 3, bringing teachers, parents and pupils actively on board contributes to the success of education policies that seek to change current language practices and ideologies.

Policy success also requires data on language practices, ideologies and (covert) policies. While it is true that language-related surveys are limited, particularly because they rely on respondents' self-assessment, there are interesting alternatives available today (see ibid., 216; Johnson 2013, especially his Chapters 5 and 6, for a range of methods to collect data on language policy). Education language policies that reflect the needs of their target populations, take the pupils' socioeconomic contexts into account and seek social justice can only be designed with the help of detailed data and by everyone involved not only policymakers. Yet the chronic lack of data in relation to language use bedevils the field of language policy (see e.g. Grin 2015, 123-124; Ricento 2015, 295). Even in the EU, the last special Eurobarometer report on "Europeans and their languages" was published in 2012 (European Commission 2012) and hardly included any information on multilingualism as the dynamic and ubiquitous phenomenon it is today. Its results give the impression that respondents are "ideal" monolingual individuals whose single mother tongue is also the national language, and that foreign language learning may or may not take place after "the" mother tongue has been "fully acquired". ${ }^{29}$

Perhaps it is no coincidence that education language policies are still by and large underpinned by the monolingual ideal, at least in the EU. Multilingual pupils are often segregated from these "ideal monolinguals" to learn the majority language. Lessons and exams take place solely in the dominant language, increasing the performance gap between "natives" and "non-natives" even after controlling for socioeconomic factors (see e.g. Flisi et al. 2016). Yet the cognitive advantages of multilingualism have been widely documented (see e.g. Edwards 2013, 16; Fürst \& Grin 2018), and research on testing conclusively reveals that migrant pupils do significantly better in bilingual than in monolingual exams (Shohamy 2006, 81-84). ${ }^{30}$ Although studies on multilingualism and literacy consistently endorse mother-tongue tuition, ${ }^{31}$ it remains an exception, even in the EU - this despite Directive 77/486/EEC of 1977 , which obliges member states to offer it to children coming from other member states. EU reports and official documents often insist on the importance of having migrant children learn the dominant language, failing to acknowledge the role of mother-tongue tuition in this context (see e.g. European Commission 2016; Flisi et al. 2016).

Turning specifically to education language policies pertaining to foreign language teaching in the EU, the 2017 Eurydice report, "Key data on teaching languages at school in Europe" maps the distribution of foreign languages in classrooms across EU and EEA (European Economic Area) member states, along with candidate countries. These data, which combine international survey results from 2013-2016 by Eurydice, Eurostat and the OECD's PISA and TALIS, offer a glimpse of the grip of English in EU education systems today and will undergird some of the recommendations made in Chapter 5. Its 
main findings for our purposes here include the following (paraphrased from European Commission/EACEA/Eurydice 2017, pp. 11-16).

- More students in primary education are learning a foreign language: Some 83.8 per cent of primary school pupils were learning a foreign language in 2014, a rise of 16.5 per cent in relation to 2005. However, instruction time allocated to foreign language teaching has remained low: on average, it takes up 5-10 per cent of total instruction time in primary school. It must be added that while the number of hours allocated to foreign languages increased in primary school curricula, they decreased in secondary education (ibid., 109-110), suggesting that foreign languages are being introduced earlier at the expense of foreign language tuition in secondary education.

- More pupils are learning two foreign languages in lower secondary school: Some 59.7 per cent in 2014 compared to 46.7 per cent in 2005. This seems to be a result of the agreement, reached by EU heads of state and government at the 2002 Barcelona European Council, that "teaching at least two foreign languages from a very early age" is important (ibid., 59). Instruction time allocated to foreign language teaching has nonetheless often remained the same, meaning that today more pupils learn two languages in the same number of hours in which they used to learn a single language (ibid., 108). Moreover, the largest share of instruction time devoted to foreign languages - on average about two-thirds, though there are significant variations among the member states - is taken up by the first foreign language (usually English).

- English is the most studied foreign language: In 2014, 79.4 per cent of primary school pupils, "virtually all" pupils in lower secondary education and 85.2 per cent of students in upper secondary school learned English. ${ }^{32}$ The authors of the report add that "[s]tudent participation in foreign language learning is strongly influenced by the curriculum requirements in place in individual countries and the predominance of specific languages is, in turn, largely dependent of whether they are compulsory or optional" (ibid., 71). Additional data indicate that "English is studied in all countries regardless of its status (mandatory, recommended or free choice)", but the authors also stress that "other foreign languages are studied more in those countries where education authorities make them mandatory" (ibid., 44). The largest shift in the dominance of English happened in primary education: an 18.7 per cent increase (ibid., 76). In several countries, including Austria, Italy and Spain, between 90 per cent to virtually all primary school pupils learned English both in 2005 and in 2014. In several more, such as Poland, Romania and Slovakia, the proportion rose by more than 33 per cent in this period, while in others (such as Croatia, Cyprus and Germany) by more than 10 per cent. In some of these countries, the number of English learners could 
not have risen any further anyway as it reached 100 per cent in 2014 (ibid., 76-77, 168). In seven countries, more than 90 per cent of pupils "learn English from the first grade until their school graduation" (ibid., 73). ${ }^{33}$

- French, German and Spanish are the most studied second foreign languages: French and German remain popular optional foreign languages in EU schools (28.5 per cent and 21 per cent of pupils in secondary education, respectively), albeit only in Luxembourg as mandatory subjects across all levels. The presence of both in school curricula is decreasing gradually, with German having sustained the greatest loss in upper secondary education (11 per cent between 2005 and 2014). In contrast, the popularity of Spanish increased 5.6 per cent in lower secondary education. The only other foreign languages learned by at least 10 per cent of pupils in primary or secondary school in any given member state are Italian (in Austria and Croatia), Dutch (in Belgium), Russian (in Bulgaria, the Czech Republic, Estonia, Latvia, Lithuania and Slovakia) and Swedish (in Finland) (ibid., 76). Yet schools could offer additional languages if they wanted to. Two-thirds of EU education systems provide lists of languages from which schools must and/or may choose to include in their curricula (ibid., 46). In all the countries which provide lists but Finland (13 in total), English features as a language that all schools must offer, sometimes alongside French (in 6 countries) and German (in 4). Education systems whose central authorities do not provide lists may choose freely which languages to teach at which levels (ibid., 46-48). Regardless of whether central authorities issue language lists or not, "schools in a great number of countries enjoy some autonomy ... to offer additional teaching of foreign languages" (ibid., 39).

- Some support for newly arrived immigrant students is offered in most countries, but only in two do prospective teachers receive specific integration-related training: This "support" amounts to "additional classes in the language of schooling", which take place instead of other classes, i.e. during school hours, often in separate groups. Nine countries offer teaching assistants for this purpose. Only six EU member states provide mother-tongue tuition: Austria, the Czech Republic, Finland, Germany, Slovenia and Sweden. These classes are nevertheless mostly optional, limited (in terms of hours) and often take place outside school hours. ${ }^{34}$ Further, only in Austria and Denmark does general teacher training include subjects on the integration of migrant pupils, whereas in another five countries (Belgium, Cyprus, France, Italy and Hungary) there are central recommendations for teachers working with pupils who do not speak the language of instruction (more in Section 5.4).

- Another interesting finding: "half of the 15-year-old students whose parents were born abroad ... speak the language of schooling at home" (ibid., 24), suggesting that mother tongues are probably being displaced more quickly than typically estimated (see Section 2.6). ${ }^{35}$ The role that education language policies play in this process of language shift is pivotal: 
when pupils' mother tongues are not in the curriculum and students are expected to attend lessons and take exams in the dominant language only, it is not surprising that mother tongues are quickly being displaced.

- Another relevant finding for our purposes here refers to "Content and language integrated learning" (CLIL), i.e. "all types of provision in which a language different to the language of schooling is used to teach certain curriculum subjects other than languages themselves" (ibid., 55). The term was coined in 1994 to combine "language learning" and "subject learning" (Coyle et al. 2010, 4), an approach that was endorsed by the EU and recommended to all member states back in the 1990s (see e.g. Council Resolution OJ C 320). In the 2017 Eurydice report, CLIL lessons were not considered as they are not foreign language lessons as such, but rather "regular" subjects taught through a different language than that of instruction. The report reveals that "English, French and German ... are the most widespread target languages for CLIL", adding, however, that only in Austria, Cyprus, Italy, Luxembourg and Malta "is CLIL provision available in all schools at some stage" (though often for one or two years only) (European Commission/EACEA/Eurydice 2017, 57).

In sum, the report reveals that most education language policies in the EU stem from central education authorities, and that EU recommendations do have some impact on these policies. "Some" because the increase in the number of foreign languages offered seems to correlate with the decisions taken at the 2002 Barcelona European Council. Still, this “increase" rather amounts to the same number of tuition hours being allocated mostly to English, and the rest to another major language. Relatively few education systems have officially adopted CLIL, even after decades of official EU endorsement. Moreover, the EU's appeal for schools to offer mother-tongue tuition to migrant pupils - a plea already made by UNESCO back in 1953 (see e.g. Paulston \& Heidemann 2006, 298) - has been largely ignored, as already noted. These discrepancies between the EU's advice on education language policies and the member states' actual policies indicate that there are more deeply-rooted disparities in language ideologies preventing EU countries from, for instance, investing in mother-tongue tuition or effectively expanding the repertoire of foreign languages included in their school curricula.

The data in the report also show that central education authorities have the upper hand when it comes to the range of foreign languages offered by schools. Also, even when schools have free rein in this respect, they largely follow the same pattern discernible all across Europe: a lot of English and a little French, at times alongside even less of other languages. The correlation between the ubiquity of English in EU schools both as language policy and practice suggests the underlying and the resulting ideology is that English is perceived as a necessity - more so than any other language(s). Indeed, as noted in Section 2.5, 79 per cent of EU citizens see English as the most useful language for their children (European Commission 2012, 141). It seems that parents and 
educators alike share this view, both because language policy and practices in EU schools promote this ideology, and because this ideology gives rise to language practices and policies that favour English.

To come back to the issue, raised at the beginning of this section, of whether current EU education language policies help diminish, maintain or foster linguistic diversity, the answer is probably "none of the above". EU education systems strive to integrate those pupils who do not speak the majority language by having them learn the majority language, frequently through sudden and total immersion. This is their priority - not to maintain the linguistic diversity that these pupils bring into the school. Beneath the surface is hence a "language-as-problem" orientation, whereby states can be seen as largely "glossophagic", in Kraus's terms, i.e. "state[s] that devou[r] minority languages in order to establish a strict monolingual regime in the public realm" (2018, 92, referring to Calvet). One could reasonably protest that these education systems are, therefore, by no means fostering linguistic diversity but rather diminishing it.

I argue that EU schools are fostering linguistic diversity with English which, in the end - when nearly all pupils all across the EU are learning English - is no longer diversity. CLIL is a case in point: the EU recommends allocating CLIL provisions to neighbouring and minority languages, which can be seen as policy success. However, when schools with large numbers of pupils who do not speak the language of instruction use CLIL almost exclusively for English instruction, then this is a pedagogical failure - thus a policy with potential for multilingualism becomes another policy for English.

Despite that, grassroots multilingual language policies remain a promising alternative to open physical and ideological space for linguistic diversity. The fact that most EU education systems allow for some autonomy on the part of individual schools to offer additional language programmes means that a lot can be achieved without major changes to national language policies, particularly when schools and educators take a "language-as-resource" orientation. This has to do with the two aspects of language policy mentioned earlier, namely "language governmentality" and the fact that some actors choose to exercise agency.

A remarkable example from Vienna in this respect is the project Wir sprechen zehn Sprachen! [We speak ten languages!], which started in June 2002 in one of the city's bilingual schools (German and English). Most students in Susanne Reif-Breitwieser's first primary school year spoke another language in addition to the two languages of instruction - 10 different languages in total. The teacher spontaneously decided to ask each pupil to play the teacher and teach the others about their language. Slowly, the project gained impetus and a clearer frame. By the end of primary school, all pupils had learned the basics of those 10 languages, largely within the regular curriculum. In the words of some of the pupils, the most valuable aspect of this project was not learning the languages per se but broadening their horizons and raising their awareness of racism (see Reif-Breitwieser 2011). ${ }^{36}$ Projects such as this are often entirely 
up to individual schools and educators to be implemented and can go a long way both in fostering transcultural awareness and in changing language ideologies (more in Section 4.8).

Both the nativism of the EU's education systems and their excessive focus on English call for a comprehensive reform of top-down, overt education language policies - one that encompasses the education of teachers in relation to language policies and includes teachers, parents and pupils in the process of designing these policies (see Shohamy 2006, 80; Dannerer et al. 2013; Erkurt 2020). However, initiatives like Reif-Breitwieser's show that grassroots education language policies can engender a shift in the dominant ideologies and practices, opening new avenues for language policy to counteract social injustice (see Johnson 2013, 51).

\subsection{Final Remarks}

The EU is torn between two notions of language, namely as an identity-shaping element and as a neutral instrument for communication; between linguistic diversity as a legally sanctioned, symbolic asset and as a hurdle to be overcome through the ad hoc use of English. EU member states are equally torn between a Herderian pride in their national language(s) - the repository of their history, culture and identity which must be defended at all costs - and a view of (migrant) language(s) as disposable items, easily discarded, with no further implications for the speakers. Similarly, EU citizens seem torn between their attachment to their mother tongue(s) and to the symbolic value of linguistic diversity, on the one hand, and the conviction that "diversity" with English is enough and ideal, on the other.

These paradoxes reveal themselves in the disparities between the EU's de jure multilingualism and de facto monolingualism; between the EU's passionate discourse on language rights for European minorities and its silence regarding immigrant minorities; between the EU's official recommendations on language policy and the member states' actual policies; between the EU's discourse on the value of diversity and the education systems' and the citizens' "English-is-enough" ideology. What linguistic diversity is possible [the notion of impossibility remains crucial in this book] is this scenario? Tentative answers will feature in Chapters 4 and 5. First, we will look into the role of translation in EU multilingualism in Chapter 3.

A few questions should stay with us through the coming chapters. What does diversity mean in the EU today? Does it mean that each member state gets to be largely monolingual, suppressing the languages of their minorities but entrenching English as by far the largest - sometimes the only - statesanctioned additional language? In this linguistic landscape, the monolingualism of the member states is revered by the EU under the guise of its celebration of linguistic diversity, while the EU's institutions themselves remain largely monolingual in English. EU multilingualism amounts to many "monolingualisms" which, combined, make up the official linguistic diversity 
of the EU - which in turn is unofficially, for pragmatic reasons, reduced to monolingualism in English. Can linguistic diversity be tantamount to a collection of disconnected uniformities? And how much "connection" would homogenise these singular uniformities, bringing them closer together and, hence, diminishing diversity? Is linguistic diversity an obstacle to the establishment of a "European identity"? Should English be officially adopted as the "second first language" of the EU, as Habermas and others propose (2006, 104; see Section 1.5)?

\section{Acknowledgements}

An earlier version of this chapter was published in Leal (2021).

\section{Notes}

1 One of the key reasons behind the need for such derogation periods was the lack of translators, interpreters and other language experts from/into Maltese and Irish.

2 All EU legislation mentioned throughout this book, including court cases, was taken from the EUR-Lex portal: (C) European Union, available at: https://eur-lex. europa.eu/. All electronic sources quoted here were last accessed in December 2020.

3 I asked the European Commission Representation in Cyprus for a statement regarding the future status of Turkish in the EU but obtained no response.

4 There are three main institutions involved in EU legislation, as follows: (1) the European Parliament, a directly elected body of 705 members of the European Parliament (MEPs) with legislative, supervisory and budgetary responsibilities; (2) the European Commission, the politically independent executive branch of the EU, in which a team or college of 27 commissioners (one for each member state) proposes and enforces legislation, carries out policies and implements the budget; and (3) the Council of the European Union, in which the relevant government ministers from each EU country adopt EU laws and coordinate EU policies. The Council of the European Union is not to be confused with the European Council, in which the heads of state or government of all 27 member states, along with the European Council president and the European Commission president, define the general political direction of the EU, and in which most decisions are taken by consensus. Other EU institutions include the Court of Justice of the European Union (whose working language is French), the European Central Bank and the European Court of Auditors (European Union n.d.b).

5 For the development of the principle of subsidiarity in the West, see Kraus (2008, 183-188).

6 This is only a snapshot of the process, which in reality has a few additional intricacies - see "Protocol No. 2 on the Application of the Principles of Subsidiarity and Proportionality" in the TFEU.

7 See Barbier $(2018,351,352)$ for an appraisal of subsidiarity as an "illusory protection" to "placate the concerns of the Member States".

8 The procedure is described in detail in the section on the Revision of EU Treaties of the EUR-Lex platform.

9 The latter question has been at the heart of the EU from the outset. It emerged during the 2021-2027 budget negotiations in summer 2020, as the bloc wanted to tie the disbursement of the coronavirus recovery fund to compliance to the rule law, a clear attempt to penalise Hungary and Poland. 
The European Council underlines the importance of the respect of the rule of law. Based on this background, a regime of conditionality to protect the budget and Next Generation EU [the recovery fund] will be introduced. In this context, the Commission will propose measures in case of breaches for adoption by the Council by qualified majority.

See Herszenhorn et al. (2020). This (allegedly deliberately) vague clause in the EU leaders' conclusions leaves a lot of room for interpretation but could mean that a mere qualified majority might suffice to pass sanctions. This would represent an unprecedented move towards a more federative system and could lead to further easing in the EU's collective decision-making (see also Written Question E-004430/2020).

10 Due to space constraints and my own limitations, this section leaves out one of the most vulnerable groups of languages worldwide, namely that of sign languages (see e.g. Craith 2006; Skutnabb-Kangas 2006).

11 Before Brexit, Welsh and Scottish Gaelic enjoyed the same status.

12 See e.g. Resolution (EU) 2018/1347 of the European Parliament of 18 April 2018.

13 The terminology hallowed by custom here ("autochthonous" versus "allochthonous" languages) was borrowed from biology and is unfortunate because it suggests an original, primeval link between these languages and the territories where they are spoken. The next link, namely with ethnicities, is only a short step away. We must also ask ourselves how long a language has to be present in how large a portion of a territory in order for it to be considered "indigenous" (see e.g. Edwards 2013, 9).

14 The thorny issue of whether Turkish should be added to the EU's official languages remains as pressing as ever. Whereas the EU has made repeated nods to the need to include Turkish as an official EU language - not least because of potentially positive developments towards Cyprus's reunification - no concrete actions have been taken on the part of the EU. An official request was put forward in February 2016 by the Greek-Cypriot President Nicos Anastasiades (Morgan 2016; 2017). So far, however, in the words of the EU, "[ $\mathrm{t}]$ he introduction of Turkish as an official language ... has not been discussed by the Council" (see Written Question E-002783/2019).

15 In the 2010 edition of the UNESCO Atlas of the World's Languages in Danger, Irish was listed as having 44,000 native-speakers in 2007. It also mentions that, according to the 2011 Irish census, there are 77,185 daily speakers of Irish outside the education system (see www.unesco.org/languages-atlas). The 2016 census lists 73,803 daily Irish speakers outside school, along with 1,761,420 Irish speakers.

16 For more on the ECRML, see www.coe.int/en/web/european-charter-regional-or-m inority-languages/.

17 I wonder whether those countries notorious for their lack of recognition and provisions to minority language speakers, such as France, would fulfil the EU's current accession criteria as regards language rights.

$18 \mathrm{My}$ intention is not to overestimate the value of "officialdom" when it comes to language. The world is not short of examples of languages which, despite enjoying official status, are in a position of severe subjugation in the country in question. Witness, for example, the low societal status of - albeit official - Arabic in Israel in relation to the prestige of - albeit nonofficial - English in the same country (Shohamy 2006, 72). Officialdom does, however, frequently entail the allocation of resources to these languages, which is turn has the potential of raising their status and prestige in their respective communities. In the EU, official status also presents an opportunity for lesser-used languages to be further developed, as their corpora are expanded in a range of written instruments whose production is subsidised by the EU (Arzoz 2008, 6).

19 Very little research of any breadth had been carried out before then (see e.g. Crystal 2007, 4). 
20 Catalonia is an interesting example in this respect because it is notorious both for its dogged campaign for everything Catalan in Spain and in the EU, on the one hand, and its exclusion of immigrants from the "linguistically and ethnically defined Catalan 'nation'", on the other (Henders 2004, 126).

21 Nevertheless, the treaties stipulate that official and working languages are on an equal footing, and that all 24 EU languages class as both. The notion of "procedural languages" is key to the internal workings of the EU institutions but enjoys no legal basis whatsoever (see e.g. European Commission 2010, 56).

22 Modiano (2017, 316), Gill \& Parrock (2019), Wright (2007) and Stolton (2018), respectively.

23 A "standard language", in this sense, "has a normative orthography, grammar, and dictionary, arrived at through processes of selection, codification, expansion, and acceptance of some linguistic variety or other" (Paulston \& Heidemann 2006, 301, based on Haugen). We can also think of Gramsci's notion of "normative grammar" here, as

made up of the reciprocal monitoring, reciprocal teaching and the 'censorship' expressed in such questions as 'What did you mean to say?' ... This whole complex of interactions come together to create a grammatical conformism, to establish 'norms' or judgments of correctness or incorrectness.

(quoted in Ives 2015, 64)

24 Tollefson's and Pennycook's approaches are not always perceived as complementary. While Tollefson seeks to foster minority languages, Pennycook aims at the dis-invention of the parameters that permeate language policy today, starting from "minority" and "majority languages" and even "languages" as monolithic units (Johnson 2013, 41). I chose to combine them here because the controversial notions of "language", "majority" and "minority" can be duly deconstructed while simultaneously pursuing more democratic language policies. In Thomas Ricento's words, language policy "is not just an exercise in philosophical inquiry; it is interested in addressing social problems which often involve language, ... and in proposing realistic remedies" $(2006,11)$.

25 Strictly speaking, there are no entirely monolingual or monoethnic countries - Iceland would probably be a strong contender, but official statistics set the proportion of immigrants at around 15 per cent, most of whom are from Poland (see https://sta tice.is/). It is not that the nations that typically fall under this category, such as the USA and France, are monolingual and monoethnic; they simply perceive their minorities as insignificant (see Spolsky 2004, 58; Kraus 2008, 93).

26 In Brazil, for instance, a succession of local laws regulating the use of foreign words in Portuguese has been passed in several states since the millennium. They stipulate that foreign words must be followed either by a Portuguese translation or a gloss of the term. The aim is to promote the use of Portuguese and to curb foreign (mostly anglophone) influences, which can be interpreted as a legitimate attempt to prevent language use from becoming unnecessarily arcane, excluding those who do not understand the foreign language in question. It can also be interpreted as an inadmissible infringement on a person's individual right to choose how to communicate.

27 The following categories, devised by Lieberson et al. in 1975, shed light on the phenomenon of language shift in migrant communities: “(1) indigenous superordinate, (2) migrant superordinate, (3) indigenous subordinate, and (4) migrant subordinate" (quoted in Paulston \& Heidemann 2006, 296). According to them, a lower rate of mother-tongue shift takes place among the first two groups, whereas the others are more vulnerable. Fortunately, there are success stories among the latter categories, too. For example, a small group of Basque parents organised a language pre-school in the 1960 s, initially financed through fund-raisers. At first 


\section{The EU and English as a "Lingua Franca"}

they had eight students; by the end of the 1970s, 400. By the year 2000, there were two dozen Basque-medium schools ranging from pre-school to high-school with almost 2,000 students (ibid., 303-304).

28 This discussion resonates with the debate surrounding quotas at Brazilian public universities for underprivileged students and/or students of colour. In a nutshell, admission to public universities - the most prestigious in the country and free of charge - takes place through comprehensive exams, which until recently, before the introduction of the quota system, restricted the access of underprivileged students, most of whom are of colour. The key argument against these measures is that they perpetuate social injustice by depicting these groups as vulnerable. This may be correct to a certain extent, but having no quotas at all would simply keep these disadvantaged students from obtaining higher education, feeding the vicious circle of poverty and lack of qualifications. Of course it would be preferable to end inequality outright, but quotas are a more viable solution that brings immediate socioeconomic results and helps, in the medium term, change the dominant groups' perception of these underprivileged individuals. Once those who obtain access to higher education through quotas finish their studies, they become doctors, lawyers, engineers, academics, etc., thus gradually reversing the social stigma associated with quota students in the first place.

29 Interestingly, in 2001, 2005 and 2006 the same Special Eurobarometer surveys ("Europeans and Languages" or "Europeans and their languages") were conducted and included a few - however superficial - questions about the respondents' mother tongues, specifically on whether they coincided with the official language(s) of their countries of residence. It is unclear why these questions were dropped altogether in the 2012 survey, as well as why these surveys were discontinued (at least to my knowledge).

30 Most EU countries offer a range of testing languages in their final secondary education exam, typically including English, French, German, along with Italian, Russian and/or Spanish (European Commission/EACEA/Eurydice 2017, 128-129). These languages are, however, tested as foreign languages; content subjects are tested exclusively in the dominant language. In some member states, special agreements may allow for these tests to be conducted in foreign languages, which in turn are generally restricted to the same large European languages.

31 See Romaine (2015) and Ricento (2018) for the negative impact of the introduction of European languages as mediums of instruction in Africa.

32 The percentage is lower in upper secondary education because VET (vocational education and training) is also considered, and in these courses foreign languages feature less prominently than in "regular" upper secondary curricula.

33 The Republic of North Macedonia, though not an EU member, is particularly noteworthy in this respect: in 2004, only one in five primary school pupils learned English; in 2014, all did (European Commission/EACEA/Eurydice 2017, 76). This shows not only the power of education language policies in terms of changing a nation's language practices and ideologies, but also the extent of the dominance of the English language. One could speculate about the reasons behind this colossal shift. Is it because the country is a candidate for EU accession and English is the EU's lingua franca of sorts? It is a well-known fact that communications between the EU and candidate countries take place exclusively in English, sending a clear message to these countries about the status of English in the EU. Or is it because of the link between English and upward mobility that culminated, for example, in the rush for English in Africa and Asia (see Romaine 2015)? More research would be needed to answer these questions, but most likely both factors played a role in this shift in North Macedonia.

34 Austria, for instance, offers two to six weekly lessons (50 minutes) in two systems, namely "team teaching", when mother tongue lessons are integrated into German- 
speaking classes, and the more widespread "course teaching", when pupils attend mother tongue lessons outside school hours, often in a different school. In the school year 2017-2018, over 420 teachers and nearly 33,000 pupils (14.5 per cent of all students enrolled in Austrian schools) worked in 26 languages: Albanian, Arabic, Bosnian/ Croatian/Serbian, Bulgarian, Chechen, Chinese, Czech, Dari, French, Hungarian, Igbo, Italian, Kurdish/Kurmanci, Nepali, Pashto, Persian, Polish, Portuguese, Romani, Romanian, Russian, Slovak, Slovenian, Somali, Spanish and Turkish (European Commission/EACEA/Eurydice 2017, 139; Garnitschnig 2019, 9; 37).

35 This particular statistic was taken from the OECD's PISA 2015. In order to assess the displacement of mother tongues more accurately, we would have to compare this with, say, the proportion of primary school pupils who spoke a different language at home. However, PISA 2015 surveyed 15-year-old students only.

36 See Grin and Civico (2018) for a similar example in pre-schools in Geneva.

\section{Further Reading}

Craith, Máiréad Nic. 2006. Europe and the politics of language: Citizens, migrants and outsiders. New York: Palgrave Macmillan.

Grin, François and Peter A. Kraus (eds). 2018. The politics of multilingualism: Europeanisation, globalisation and linguistic governance. Philadelphia, PA: John Benjamins.

Johnson, David Cassels. 2013. Language policy. London: Palgrave Macmillan.

\section{References}

Arzoz, Xabier. 2008. "Introduction”. In Respecting linguistic diversity in the European Union, edited by Xabier Arzoz, 1-13. Philadelphia, PA: John Benjamins.

Baker, Colin. 2006. "Psycho-sociological analysis in language policy". In An introduction to language policy: Theory and method, edited by Thomas Ricento, 210-228. Malden, MA: Blackwell.

Bale, Jeff. 2015. "Language policy and global political economy". In Language policy and political economy: English in a global context, edited by Thomas Ricento, 72-96. Oxford: Oxford University Press.

Balibar, Étienne. 2004. We, the people of Europe: Reflections on transnational citizenship. Translated by James Ingram. Princeton, NJ: Princeton University Press.

Barbier, Jean-Claude. 2018. "European integration and the variety of languages: An awkward co-existence". In The politics of multilingualism: Europeanisation, globalisation and linguistic governance, edited by François Grin and Peter A. Kraus, 333357. Philadelphia, PA: John Benjamins.

Blommaert, Jan. 2006. "Language policy and national identity". In An introduction to language policy: Theory and method, edited by Thomas Ricento, 238-254. Malden, MA: Blackwell Publishing.

Canagarajah, Suresh. 2006. "Ethnographic methods in language policy". In An introduction to language policy: Theory and method, edited by Thomas Ricento, 153-169. Malden, MA: Blackwell Publishing.

Cardinal, Linda and Rémi Léger. 2018. "The politics of multilingualism in Canada: A neo-institutional approach". In The politics of multilingualism: Europeanisation, globalisation and linguistic governance, edited by François Grin and Peter A. Kraus, 19-37. Philadelphia, PA: John Benjamins. 
Cartwright, Don. 2006. "Geolinguistic analysis in language policy”. In An introduction to language policy: Theory and method, edited by Thomas Ricento, 194-209. Malden, MA: Blackwell Publishing.

Charter, David. 2013. "Death of a language: Last ever speaker of Livonian passes away aged 103". The Times, 5 June.

Chopin, Isabelle, Catharina Germaine and Judit Tanczos. 2017. Roma and the enforcement of anti-discrimination law. Luxembourg: Publications Office of the European Union.

Cichon, Peter. 2003. "Sprachenpolitik im heutigen Frankreich: Schwieriger Umgang mit einem reichen sprachlich-kulturellen Erbe". In Sprachenvielfalt: Babylonische Sprachverwirrung oder Mehrsprachigkeit als Chance?, edited by Hans-Jürgen Krumm, 137-146. Innsbruck: Studien Verlag.

Cliffe, Jeremy. 2019. "Brexit is the ideal moment to make English the EU's common language”. The Economist, 15 June.

Coyle, Don, Philip Hood and David Marsh. 2010. Content and language integrated learning. Cambridge: Cambridge University Press.

Craith, Máiréad Nic. 2006. Europe and the politics of language: Citizens, migrants and outsiders. New York: Palgrave Macmillan.

Crystal, David. 2007. Language death. Cambridge: Cambridge University Press.

Dallison, Paul. 2017. "Mario Monti: EU should adopt English post Brexit". Politico, 21 November. Available at: www.politico.eu/article/brexit-mario-monti-eu-should-adop t-english/.

Dannerer, Monika, Magdalena Knappik and Birgit Springsits. 2013. "Pädagoginnenbildung in einer mehrsprachigen Gesellschaft: Deutsch als Zweitsprache und Mehrsprachigkeitsdidaktik in der Aus- und Weiterbildung von Lehrerinnen und Kindergarten-Pädagoginnen in Österreich”. In Sprachenpolitik in Österreich, edited by Rudolf de Cillia and Eva Vetter, 29-47. Frankfurt a.M.: Peter Lang.

De Schutter, Helder and David Robichaud. 2015. "Van Parijsian linguistic justice: Context, analysis and critiques". Critical Review of International Social and Political Philosophy 18 (2): 87-112.

De Swaan, Abram. 2001. Words of the world: The global language system. Cambridge: Polity Press.

de Witte, Bruno. 2008. "The protection of linguistic diversity through provisions of the EU Charter other than Article 22". In Respecting linguistic diversity in the European Union, edited by Xabier Arzoz, 175-190. Philadelphia, PA: John Benjamins.

Dirim, İnci. 2011. "Europasprache Türkisch". In Europasprachen, edited by Peter Cichon and Michael Mitterauer, 131-144. Vienna: Böhlau Verlag.

Edwards, John. 2013. "Bilingualism and multilingualism: Some central concepts". In The handbook of bilingualism and multilingualism, edited by Tej K. Bhatia and William C. Ritchie, 6-25. Malden. MA: Blackwell Publishing.

Erkurt, Melisa. 2020. Generation Haram: Warum Schule lernen muss, allen eine Stimme $z u$ geben. Vienna: Zsolnay.

EURACTIV. 2018. "Luxembourgish makes comeback, bid for EU approval". 15 February. Available at: www.euractiv.com/section/languages-culture/news/luxembour gish-makes-comeback-bid-for-eu-approval/.

European Commission. 2009. Translating for a multilingual community. Luxembourg: Office for Official Publications of the European Communities.

European Commission. 2010. Translation at the European Commission: A history. Luxembourg: Office for Official Publications of the European Communities. 
European Commission. 2012. "Special Eurobarometer 386: Europeans and their languages”. Available at: https://ec.europa.eu/commfrontoffice/publicopinion/archives/ ebs/ebs_386_en.pdf.

European Commission. 2013. "Frequently asked questions on languages in Europe". Available at: http://europa.eu/rapid/press-release_MEMO-13-825_en.htm.

European Commission. 2016. “COM(2016) 3772”. 7 June. Available at: https://ec. europa.eu/home-affairs/sites/homeaffairs/files/what-we-do/policies/european-agendamigration/proposal-implementation-package/docs/20160607/communication_action_ plan_integration_third-country_nationals_en.pdf.

European Commission. 2020a. "EU Roma strategic framework for equality, inclusion and participation for 2020-2030". Available at: https:/ec.europa.eu/info/sites/info/ files/union_of_equality_eu_roma_strategic_framework_for_equality_inclusion_and_ participation_en.pdf.

European Commission. 2020b. “Translation in figures 2020”. Luxembourg: Publications Office of the European Union. Available at: https://op.europa.eu/en/publicationdetail/-/publication/c29be934-9588-11ea-aac4-01aa75ed71a1/language-en/format-PDF/ source-128980315.

European Commission. n.d. "About multilingualism policy”. Available at: https://ec. europa.eu/education/policies/multilingualism/about-multilingualism-policy_en.

European Commission/EACEA/Eurydice. 2017. Key data on teaching languages at school in Europe, 2017 edition. Luxembourg: Publications Office of the European Union.

European Parliament. n.d. "Language policy". Available at: www.europarl.europa.eu/fa ctsheets/en/sheet/142/language-policy.

European Union. 2011. Interinstitutional style guide 2011. Luxembourg: Publications Office of the European Union.

European Union. 2018. "European days of languages 2018". Available at: https:// europa.eu/cultural-heritage/node/699_en.html.

European Union. n.d.a. “About the EU: Countries”. Available at: https://europa.eu/ european-union/about-eu/countries.

European Union. n.d.b. "Institutions and bodies”. Available at: https://europa.eu/europ ean-union/about-eu/institutions-bodies_en.

Eurostat. 2019. "Migration and migrant population statistics". Available at: https://ec. europa.eu/eurostat/statistics-explained/pdfscache/1275.pdf.

Fiedler, Sabine. 2010. "The English-as-a-lingua-franca approach: Linguistic fair play?” Language Problems \& Language Planning 34 (3): 201-221.

Fishman, Joshua. 2006. "Language policy and language shift". In An introduction to language policy: Theory and method, edited by Thomas Ricento, 311-328. Malden, MA: Blackwell Publishing.

Flisi, Sara, Elena Claudia Meroni and Esperanza Vera-Toscano. 2016. Educational outcomes and immigrant background: EUR 28195 EN. Luxembourg: Publications Office of the European Union.

Frost, Catherine. 2004. "Getting to yes: People, practices and the paradox of multicultural democracy". In Representation and democratic theory, edited by David Laycock, 48-64. Vancouver: UBC Press.

Fürst, Guillaume and François Grin. 2018. "Are multilingual individuals more creative?" In The MIME Vademecum: Mobility and inclusion in multilingual Europe, edited by François Grin et al., 170-171. Grandson, Switzerland: Artgraphic Cavin. 
Garnitschnig, Ines. 2019. Der muttersprachliche Unterricht in Österreich: Statistische Auswertung für das Schuljahr 2017/18. Vienna: Bundesministerium für Bildung, Wissenschaft und Forschung.

Gill, Joanna and Jack Parrock. 2019. "Polyglot or mono: The word wars in Brussels". Euronews, 30 September. Available at: www.euronews.com/2019/09/30/polyglot-or-m ono-the-word-wars-in-brussels.

Ginsburgh, Victor, Juan Moreno-Ternero and Shlomo Weber. 2018. "The fate of English in the EU after Brexit: Expected and unexpected twists". VOX CEPR Policy Portal. Available at: https://voxeu.org/article/english-language-eu-after-brexit.

Grin, François. 2004. "Book review: 'ROBERT PHILLIPSON. English-only Europe? Challenging language policy. London: Routledge, 2003. Pp. $240+$ x. Pb $\$ 29.95$ ””. Language Policy 3: 67-93.

Grin, François. 2006. "Economic considerations in language policy". In An introduction to language policy: Theory and method, edited by Thomas Ricento, 75-94. Malden, MA: Blackwell Publishing.

Grin, François. 2008. "Principles of policy evaluation and their application to multilingualism in the European Union". In Respecting linguistic diversity in the European Union, edited by Xabier Arzoz, 73-83. Philadelphia, PA: John Benjamins.

Grin, François. 2015. "The economics of English in Europe”. In Language policy and political economy: English in a global context, edited by Thomas Ricento, 119-144. Oxford: Oxford University Press.

Grin, François and Marco Civico. 2018. "Why is a good typology helpful for language policy selection and design?" In The MIME Vademecum: Mobility and inclusion in multilingual Europe, edited by François Grin et al., 36-37. Grandon, Switzerland: Artgraphic Cavin.

Habermas, Jürgen. 2006. Time of transitions. Translated by Ciaran Cronin and Max Pensky. Cambridge: Polity.

Henders, Susan J. 2004. "The self-government of unbounded communities: Emancipatory minority autonomy in China and Western Europe". In Representation and democratic theory, edited by David Laycock, 119-140. Vancouver: UBC Press.

Herszenhorn, David M., Lili Bayer and Rym Momtaz. 2020. "Takeaways from the EU budget and recovery deal”. Politico, 21 July. Available at: www.politico.eu/article/ 5-takeaways-from-the-eu-budget-mff-and-recovery-deal-coronavirus/.

Hornberger, Nancy H. 2006. "Frameworks and models in language policy and planning". In An introduction to language policy: Theory and method, edited by Thomas Ricento, 24-41. Malden, MA: Blackwell Publishing.

House, Juliane. 2003. "English as a lingua franca: A threat to multilingualism?" Journal of Sociolinguistics 7 (4): 556-578.

Huszka, Beáta. 2014. Secessionist movements and ethnic conflict: Debate-framing and rhetoric in independence campaigns. New York: Routledge.

Ives, Peter. 2004. "Language, representation and suprastate democracy: Questions facing the European Union”. In Representation and democratic theory, edited by David Laycock, 23-47. Vancouver: UBC Press.

Ives, Peter. 2015. "Global English and the limits of liberalism: Confronting global capitalism and challenges to the nation-state". In Language policy and political economy: English in a global context, 48-71. Oxford: Oxford University Press.

Jablonka, Frank. 2011. “Ist das Arabische eine Europasprache?” In Europasprachen, edited by Peter Cichon and Michael Mitterauer, 113-129. Vienna: Böhlau Verlag.

Johnson, David Cassels. 2013. Language policy. London: Palgrave Macmillan. 
Juaristi, Patxi, Timothy Reagan and Humphrey Tonkin. 2008. "Linguistic diversity in the European Union: An overview". In Respecting linguistic diversity in the European Union, edited by Xabier Arzoz, 47-72. Philadelphia, PA: John Benjamins.

Kraus, Peter A. 2008. A union of diversity: Language, identity and polity-building in Europe. Cambridge: Cambridge University Press.

Kraus, Peter A. 2011. "Neither united nor diverse? The language issue and political legitimation in the European Union". In Linguistic diversity and European democracy, edited by Anne Lise Kjaer and Silvia Adamo, 17-34. Farnham: Ashgate.

Kraus, Peter A. 2018. "From glossophagic hegemony to multilingual pluralism? Reassessing the politics of linguistic identity in Europe". In The politics of multilingualism: Europeanisation, globalisation and linguistic governance, edited by François Grin and Peter A. Kraus, 89-109. Philadelphia, PA: John Benjamins.

Kymlicka, Will. 1995. Multicultural citizenship: A liberal theory of minority rights. Oxford: Oxford University Press.

Laçiner, Sedat. 2016. “The European Union's language policy and Turkish”. The Turkish Sun, 18 April, 1-4. Available at: www.academia.edu/24531603/The_Europea n_Union_s_Language_Policy_And_Turkish.

Laponce, Jean. 2001. "Politics and the law of Babel". Social Science Information 40 (2): 179-194.

Leal, Alice. 2012. "Mehrsprachigkeit: Brasilien, Österreich und die Europäische Union”. In Die Multiminoritätengesellschaft, edited by Mary Snell-Hornby and Mira Kadrić, 45-53. Berlin: SAXA Verlag.

Leal, Alice. 2013. "The European Union and translation studies: Unity, multiplicity and English as a lingua franca". Translation Spaces 2: 63-80.

Leal, Alice. 2016. "Translation at the European Union and English as a lingua franca: Can erasing language hierarchy foster multilingualism?" New Voices in Translation Studies 14: 1-22.

Leal, Alice. 2021. "Multilingualism and translation in the European Union". In The Routledge handbook of translation and globalisation, edited by Esperança Bielsa and Dionysios Kapsaskis, 483-497. New York: Routledge.

Martikonis, Rytis and Roberto Viola. 2017. "Digital single market blog”. Multilingualism in the digital age: A barrier or an opportunity?10 May. Available at: https://ec.europa. eu/digital-single-market/en/blog/multilingualism-digital-age-barrier-or-opportunity.

May, Stephen. 2006. "Language policy and minority rights". In An introduction to language policy: Theory and method, edited by Thomas Ricento, 255-272. Malden, MA: Blackwell Publishing.

Modiano, Marko. 2017. "English in a post-Brexit European Union". World Englishes 36 (3): 313-327.

Morgan, Sam. 2016. “Cyprus: Make Turkish an official EU language”. EURACTIV, 16 September. Available at: www.euractiv.com/section/enlargement/news/make-tur kish-an-official-eu-language-cyprus-tells-eu/.

Morgan, Sam. 2017. "Turkish language still far away from official EU status”. EURACTIV, 11 April. Available at: www.euractiv.com/section/languages-culture/news/ official-eu-language-status-evades-turkish/.

Moseley, Christopher (ed.). 2010. Atlas of the world's languages in danger. Paris: UNESCO Publishing.

Official Journal of the European Union. 2018. DEFINITIVE ADOPTION 2018/251 of the European Union's general budget for the financial year 2018. Available at: 
http://publications.europa.eu/resource/cellar/3a0cb847-1c55-11e8-ac7301aa75ed71a1. 0006.03/ DOC_1.

Paulston, Christina B. and Kai Heidemann. 2006. "Language policies and the education of linguistic minorities". In An introduction to language policy: Theory and method, edited by Thomas Ricento, 292-310. Malden, MA: Blackwell Publishing.

Pennycook, Alastair. 2004. "Language policy and the ecological turn". Language Policy 3: 213-239.

Pennycook, Alastair. 2006. "Postmodernism in language policy". In An introduction to language policy: Theory and method, edited by Thomas Ricento, 60-76. Malden, MA: Blackwell Publishing.

Phillipson, Robert. 2003. English-only Europe? Challenging language policy. London: Routledge.

Phillipson, Robert. 2006. "Language policy and linguistic imperialism". In An introduction to language policy: Theory and method, edited by Thomas Ricento, 346-360. Malden, MA: Blackwell Publishing.

Phillipson, Robert. 2016. "Linguistic imperialism of and in the European Union". In Revisiting the European Union as empire, edited by Hartmut Behr and Yannis A. Stivachtis, 134-163. New York: Routledge.

Phillipson, Robert. 2017. "Myths and realities of 'global' English". Language Policy 16 (3): 313-331.

Phillipson, Robert. 2018. "English, the Lingua Nullius of global hegemony". In The politics of multilingualism: Europeanisation, globalisation and linguistic governance, edited by François Grin and Peter A. Kraus, 275-303. Philadelphia, PA: John Benjamins.

Reif-Breitwieser, Susanne. 2011. Wir sprechen zehn Sprachen!Vienna: Bundesministerium für Unterricht, Kunst und Kultur.

Ricento, Thomas. 2006. "Language policy: Theory and practice - An introduction”. In An introduction to language policy: Theory and method, edited by Thomas Ricento, 10-23. Malden, MA: Blackwell Publishing.

Ricento, Thomas. 2015. "Political economy and English as a 'global' language". In Language policy and political economy: English in a global context, edited by Thomas Ricento, 27-47. Oxford: Oxford University Press.

Ricento, Thomas. 2018. "The promise and pitfalls of global English". In The politics of multilingualism: Europeanisation, globalisation and linguistic governance, edited by François Grin and Peter A. Kraus, 201-222. Philadelphia, PA: John Benjamins.

Robinson, William. 2014. “Translating legislation: The European Union”. The Theory and Practice of Legislation 2 (2): 185-210.

Romaine, Suzanne. 2015. "Linguistic diversity and global English: The Pushmi-pullyu of language policy and political economy". In Language policy and political economy: English in a global context, edited by Thomas Ricento, 252-275. Oxford: Oxford University Press.

Ruiz, Richard. 2016. “Orientations in language planning”. In Honoring Richard Ruiz and his work on language planning and bilingual education, edited by Nancy $\mathrm{H}$. Hornberger, 13-32. Bristol: Multilingual Matters.

Sandrelli, Annalisa. 2018. "Observing Eurolects: The case of English". In Observing Eurolects: Corpus analysis of linguistic variation in EU law, edited by Laura Mori, 63-92. Philadelphia, PA: John Benjamins.

Saragosa, Manuela. 2019. "Podcast: How 'cheap' English is conquering the world". Business daily from the BBC. 5 December. Available at: www.bbc.co.uk/sounds/play/ w3csy78p. 
Schjerve, Rosita Rindler. 2003. "Europäische Sprachenpolitik und Minderheiten". In Sprachenvielfalt: Babylonische Sprachverwirrung oder Mehrsprachigkeit als Chance?, edited by Hans-Jürgen Krumm, 49-60. Innsbruck: Studien Verlag.

Schmidt, Ronald. 2006. "Political theory and language policy". In An introduction to language policy: Theory and method, edited by Thomas Ricento, 95-110. Malden, MA: Blackwell Publishing.

Shohamy, Elana. 2006. Language policy: Hidden agendas and new approaches. London: Routledge.

Shuibhne, Niamh Nic. 2008. "EC law and minority language policy: Some recent developments". In Respecting linguistic diversity in the European Union, edited by Xabier Arzoz, 123-143. Philadelphia, PA: John Benjamins.

Skutnabb-Kangas, Tove. 2006. "Language policy and linguistic human rights". In An introduction to language policy: Theory and method, edited by Thomas Ricento, 273-291. Malden, MA: Blackwell Publishing.

Spolsky, Bernard. 2004. Language policy. Cambridge: Cambridge University Press.

Stolton, Samuel. 2018. “Juncker: We are not 'under the rule' of English”. EURACTIV, 18 September. Available at: www.euractiv.com/section/english-language/news/junck er-we-are-not-under-the-rule-of-english/.

Tollefson, James W. 2006. "Critical theory in language policy". In An introduction to language policy: Theory and method, edited by Thomas Ricento, 42-59. Malden, MA: Blackwell Publishing.

Van Parijs, Philippe. 2011. Linguistic justice for Europe and for the world. Oxford: Oxford University Press.

Wee, Lionel. 2011. Language without rights. Oxford: Oxford University Press.

Wickström, Bengt-Arne, Michele Gazzola and Torsten Templin. 2018. "Can the 'free market' manage language diversity?" In The MIME Vademecum: Mobility and inclusion in multilingual Europe, edited by François Grin et al., 34-35. Grandson, Switzerland: Artgraphic Cavin.

Wierzbicka, Anna. 2013. Imprisoned in English: The hazards of English as a default language. Oxford: Oxford University Press.

Woolard, Kathryn A. 1998. "Introduction: Language ideology as a field of inquiry". In Language ideologies: Practice and theory, edited by Bambi B. Schieffelin, Kathryn A. Woolard and Paul V. Kroskrity, 3-50. Oxford: Oxford University Press.

Wright, Sue. 2007. "English in the European Parliament: MEPs and their language repertoires”. Sociolinguistica Jahrbuch 21: 151-165.

Zamyatin, Konstantin. 2018. "A Russian-speaking nation? The promotion of the Russian language and its significance for ongoing efforts at Russian nation-building”. In The politics of multilingualism: Europeanisation, globalisation and linguistic governance, edited by François Grin and Peter A. Kraus, 39-64. Philadelphia, PA: John Benjamins. 


\section{Translation and the EU \\ The Tension between Unity Versus Multiplicity}

\subsection{Introduction}

Language was in the spotlight in the previous chapters - its mechanisms, its value, its function in our lives, in Chapter 1, along with the weight given to multilingualism and the status of individual languages in the EU, in Chapter 2. It seems clear thus far that the EU is steadfast on the need to maintain status equality for all official languages, while simultaneously using English most of the time for pragmatic reasons. In other words, in terms of language, the imperative of unity has the upper hand at the expense of multiplicity - which, nevertheless, has a fixed symbolic place close to the EU's heart. How does this paradox ${ }^{1}$ manifest itself in relation to translation? And can/should it be resolved? If so, how? These are the main questions that permeate this chapter.

Section 3.2 will offer an overview of the EU's language services, followed by an analysis of the EU's translation policy in Section 3.3. In Section 3.4, the issues of translatability, equivalence between different texts and the status of originals versus translations will be approached from the perspective of translation studies, whereas in Section 3.5, they will be embedded in a fresh debate on (un)translatability which has recently taken translation studies by storm. In Section 3.6, I will inscribe the trends identified in relation to EU translation into a framework of unity versus multiplicity. This framework will then give rise to new strategies and a new ethos as regards the EU's language services in Section 3.7.

\subsection{EU Language Services: Set-Up, Numbers and Language Regimes}

In Section 2.2, we saw how status equality to 24 official languages and every EU citizen's right to communicate with the EU in one of these languages are enshrined in EU primary law. Thousands of speakers of dozens of languages work side by side in the EU, communicating with hundreds of millions of speakers of these (and many more) languages. In this scenario, it is easy to understand why language services, understood here as translation and interpreting, ${ }^{2}$ are so fundamental in the EU. It will thus come as no surprise to the reader that a rough estimate of the number of internal translators, interpreters

DOI: $10.4324 / 9780429282812-4$ 
and other language experts currently employed in EU bodies, agencies and institutions surpasses 5,000, and that the number of freelancers used yearly is probably just as high. Excluding external staff, nevertheless, 5,000 is still nearly 10 per cent of the EU's total staff.

As of 2018, the EU's Directorate-General for Translation (DG Translation) employed 1,600 translators and 700 support staff, with an output of over two million translated pages every year - a quarter of which are produced by external translators. The Directorate-General for Interpretation (DG Interpretation) employed 530 interpreters along with freelance interpreters, who account for half of the interpreted output. Both DGs are part of the European Commission and act as the key suppliers of language services in the EU. Besides these two DGs, nine other language units are spread throughout EU institutions, bodies and agencies, employing thousands of translators, interpreters, language assistants and terminologists (European Union 2018).

An important note here: the DG Translation is currently in charge of the multilingualism portfolio in the EU, enjoying "the status of a DirectorateGeneral with a role in European policy-making, in which it is now an essential element as the representative of languages and the guarantor of multilingualism in the European Union” (European Commission 2010, 57). The creation of the short-lived Directorate-General for Multilingualism, in 2006, was riddled with controversy as it was perceived by some as a stratagem to produce commissioner's portfolios for the newly acceded member states Romania and Bulgaria. Although the whole business was painted by the EU as an indication of the ever-growing importance of multilingualism in the bloc (see e.g. ibid., 55-56), it looked more like "a reflection of Romania's [low] standing in Brussels" (Buck 2006). Once that term of office ended in October 2007, the multilingualism portfolio was returned to the commissioner for Education, Culture, Multilingualism and Youth. Under Jean-Claude Juncker, "multilingualism" was replaced with "sport": "Commissioner for Education, Culture, Youth and Sport". Today, the post is called "Commissioner for Innovation, Research, Culture, Education and Youth", and the multilingualism portfolio belongs to the DG Translation.

What exactly do these thousands of translators translate - and into which languages? According to the language policy section of the EU website, few texts get to be translated into all official languages - usually legally binding information only, such as legislation and other official documents, along with some general information in the EU's multiple online portals. Legislation must be available in all languages, as the absence of translations renders it unenforceable. The Skoma-Lux case (C-161/06) ${ }^{3}$ illustrates this point: in December 2007, the Court of Justice of the EU deemed the imposition of fines by the Czech authorities on the company Skoma-Lux (due to customs infringements) unlawful, since legislation regarding customs regulations had not yet been fully translated into Czech (see Bobek 2011, 124).

Non-binding documents, however, are often available in English only sometimes French and, more rarely, German. These three languages, it will be 
remembered, are the unofficial "procedural languages" of the EU. Urgent or short-lived information, specialised information (technical information, information about campaigns and calls for tender), news and information about events are often available in a single language (guess which one), though at a later point translations may be added (European Union 2019).

I have been monitoring the calls for tenders, grants and expressions of interest for three years now: they have been available exclusively in English, even though a message underneath the heading announces that French and German translations will be "available soon" ("disponible prochainement" and "bald verfügbar"; European Commission n.d.a). The exact proportion of content published on EU websites in English only is not known, though some estimates set it at 88 per cent back in 2008 (see e.g. Küchler 2008). The fact that not everything gets translated is confirmed by the DG Translation and regretted by everyone who has tried to navigate beyond the initial pages of the EU's multiple websites or to access documents in languages other than English (see e.g. European Commission 2010; Wagner et al. 2014, 9). With an ever-expanding EU and growing charges of democratic deficit, one might expect the DG Translation to want to up its translation output; yet the opposite applies, as revealed in the interview in the Appendix (more in Section 5.3).

In Chapter 2, we saw that English is the EU's most used language: 85.5 per cent of pages translated by the DG Translation were originally in English in 2020, over 90 per cent of staff in the Commission considered it their main drafting language in 2009, 95 per cent of staff regarded it as the most used language in performing their duties in 2016, and 95 per cent of legal texts are estimated to have been written in it in 2018 (see European Commission 2009; 2020; Robinson 2014, 194; Barbier 2018, 337). In the early 1980s, only 30 per cent of texts were drafted in English; by the late 1990s, that proportion had risen to 42 per cent (Van Parijs 2015, 248). EU translators Emma Wagner, Svend Bech and Jesús Martínez explain that "it is unreasonable to allow everyone to write their contribution in their mother tongue" as it would "take too long (because of translation) and would impose an additional burden on translation services that are already fully occupied" $(2014,71)$.

A lot of texts issued by the EU are therefore written in English and not translated - often not even into French and German - whereas virtually everything drafted in other languages gets translated into English. This has been the source of bitter internal quarrels; anecdotes hereof have become de rigueur in analyses of the EU's language regime: a Finnish minister once declined to deliver a talk in an English translation, a German chancellor refused to sign a text in English without a German translation, a German delegation boycotted meetings to which no interpreting had been provided, among many others (see e.g. Phillipson 2003, 21-22; Craith 2006, 47; Barbier $2018,337)$. These incidents highlight both the symbolic value of language instrumentally these people could have coped fine in English, but the benefit of using their own language transcends the realms of pragmatism - and its 
concrete value - allowing only some to use their mother tongue constitutes an injustice.

The reader will remember that Articles 21 and 22 of the (legally binding) Charter of Fundamental Rights prohibit discrimination on grounds of language and oblige the EU to respect linguistic diversity. Does this lack of language services not violate these articles? Not to mention Regulation 1, whereby all 24 languages enjoy the status of official and working languages (see e.g. Phillipson 2003, 120). When the calls for tenders, grants and expressions of interest, for example, are available in English only, English speakers have an unfair advantage and other applicants are discriminated against on grounds of language. 4

It would, however, be unfair to claim that the EU's language services do not contribute to multilingualism. After all, legislation is available in 24 languages and so are key democratic platforms, such as public consultations - whereby EU citizens can express their views on new initiatives and existing policies and the European Citizens' Initiative (ECI) - through which citizens can ask the Commission to bring forward legislative proposals. ${ }^{5}$ Thanks to interpreting services, members of the European Parliament (MEPs) can routinely use 24 languages in official meetings - though in smaller meetings, those MEPs who do not speak English and French will struggle (Wright 2004, 222). Those of us who get in touch with the EU do receive a reply in the chosen language - as long as it is one of the official 24.

Still, considering that the EU's motto is "united in diversity", and that linguistic diversity is at the heart of "diversity", the contribution of the EU's language services is modest - and, accordingly, so is their budget. Public opinion and some hasty academic and journalistic appraisals of the costs of EU multilingualism may suggest otherwise (see e.g. Cogo \& Jenkins 2010, 272; Van Parijs 2011, 88); however, as noted in Section 2.2, language services only take up around 1 per cent of the EU's total budget. ${ }^{6}$ The latest enlargements (2007 and 2013) did not affect this figure significantly. Adding languages to the EU's official repertoire does not entail an exponential growth in the number of possible language combinations - i.e. $X(X-1)$, where $X$ is the number of official languages. Now, for example, technically there are $24 \times 23$ language combinations, i.e. 552. This is the language regime that François Grin (2008) calls "panarchic", whereby all 24 official languages are working languages, too. In reality, however, there are not 552 possible language combinations in the EU because translation and interpreting take place increasingly via pivot languages (usually English, French and German). This system, called "triple symmetrical relay" by Grin (2008), effectively reduces the current language combinations to 132 , i.e. $3(2 \times 24-3-1)$ - assuming that the output for each of these pivot languages is equal. ${ }^{7}$

Both the "panarchic" and the "triple symmetrical relay" regimes entail, in principle, no foreign language learning needs, since language services ensure multilingual written and oral communication flows. Officially, the EU's language regime is "panarchic" but moved into the "triple symmetrical relay 
system" due to pragmatic factors, such as costs, infrastructure (especially for interpreting booths) and the availability of translators and interpreters in more "exotic" combinations, say, Maltese-Irish. Obviously, the "triple symmetrical relay" regime is more financially sustainable than the "panarchic" system, without the obvious inequality issues that would arise from a downright monolingual arrangement - in Grin's terminology, a "monarchic" system. Nevertheless, the delays entailed in the relay system and the ensuing hierarchy between "pivot" and "ordinary" languages should not be overlooked (see e.g. Wright 2004, 222; 2007, 157-158; Gazzola 2006, 404-405).

Particularly regarding translation, what we de facto have in the EU today most of the time is neither the "panarchic" nor the "triple symmetrical relay" regime, but rather the "oligarchic" system, i.e. two or three languages (English, French and increasingly less German) are treated as sole working languages. This does not quite reduce the number of language combinations to six (i.e. $3 \times 2$ ) at all times because some documents are still translated into all 24 languages, often via pivot languages. So in these situations, the "triple symmetrical relay" regime remains in place. We should also bear in mind that the less the EU uses French (and German), the closer it comes to a quasi "monarchic" system with English as the sole working language - again with the caveat that some information is still translated into all 24 official languages, so the "triple symmetrical relay" is employed.

Both the "oligarchic" and the "monarchic" regimes may seem more financially sustainable, with only four to six language combinations most of the time, in the case of the former, and hardly any need for translations in the latter. Nevertheless, both entail colossal foreign language learning efforts and investments - quite apart from the inequalities these systems generate and their political consequences. Annually, citizens contribute approximately $€ 2.20$ $(€ 2.70$ if we only consider those aged $15+$ ) to all language service units across the EU (Gazzola 2014, 232). The costs of learning a foreign language greatly exceed $€ 2.70$ a year. To put these numbers into perspective, each Canadian citizen contributes around $€ 36$ a year to keep their federal services bilingual more than 15 times as much as EU citizens (ibid., 232, based on Vaillancourt \& Coche).

Moreover, any cuts to the current budget for language services and/or any reductions in the number of official languages at the supranational level would lead to a transfer - not an elimination - of the current expenditure (Gazzola \& Grin 2013, 103-104). It is estimated, for instance, that 60-80 per cent of national laws are direct enactments of legislation agreed upon at the supranational level (Phillipson 2003, 18). If these policy texts were not made available in the member states' official languages, translations would have to be arranged locally anyway.

Table 3.1 displays the EU's translation regimes mentioned in this section. Differences between external communications - i.e. documents that are eventually published and accessible to the general public - and internal communications i.e. texts that circulate within the institutions and are not meant for open 
Table 3.1 The EU's translation regimes

\begin{tabular}{|c|c|c|}
\hline Translation regime & Status & Use \\
\hline $\begin{array}{l}\text { Panarchic ( } 24 \text { offi- } \\
\text { cial and working } \\
\text { languages) }\end{array}$ & $\begin{array}{l}\text { Official (sanctioned in the } \\
\text { treaties) }\end{array}$ & $\begin{array}{l}\text { Most legally binding documents } \\
\text { are drafted in English and trans- } \\
\text { lated into the other } 23 \text { languages }\end{array}$ \\
\hline $\begin{array}{l}\text { Triple symmetrical } \\
\text { relay ( } 24 \text { official } \\
\text { and working lan- } \\
\text { guages with three } \\
\text { pivot languages) }\end{array}$ & $\begin{array}{l}\text { Semi-official (informally } \\
\text { mentioned in official sources, } \\
\text { e.g. European Parliament } \\
\text { n.d.) }\end{array}$ & $\begin{array}{l}\text { The small proportion of legally } \\
\text { binding documents drafted in } \\
\text { languages other than English are } \\
\text { translated into the other } 23 \\
\text { (often via a pivot language) }\end{array}$ \\
\hline $\begin{array}{l}\text { Monarchic* (one } \\
\text { working language) }\end{array}$ & $\begin{array}{l}\text { Unofficial (not mentioned in } \\
\text { official sources, possibly in } \\
\text { breach of EU legislation, e.g. } \\
\S 21 \text { and } \$ 22 \text { of the Charter of } \\
\text { Fundamental Rights) }\end{array}$ & $\begin{array}{l}\text { Most non-legally binding texts } \\
\text { are drafted in English and not } \\
\text { translated at all }\end{array}$ \\
\hline $\begin{array}{l}\text { Oligarchic* (three } \\
\text { working languages) }\end{array}$ & $\begin{array}{l}\text { Semi-official (informally } \\
\text { mentioned in official sources, } \\
\text { e.g. European Commission } \\
\text { 2009) }\end{array}$ & $\begin{array}{l}\text { The small proportion of non- } \\
\text { legally binding texts drafted in } \\
\text { languages other than English are } \\
\text { translated into English and } \\
\text { sometimes French, rarely } \\
\text { German }\end{array}$ \\
\hline
\end{tabular}

Source: The first column was taken from Grin (2008).

* In Grin's terminology, the languages pertaining to these regimes are both official and working languages. Yet the EU's de jure "panarchic" system seems permanent. I therefore suggest adapting the "monarchic" and "oligarchic" regimes to entail working languages only - or rather "procedural” languages, as noted in Section 2.2.

publication - seem negligible. In comparison to outgoing documents, a marginally larger proportion of ingoing files seems to be drafted in languages other than English and French (see Wagner et al. 2014, 53, 59). ${ }^{8}$ Let us bear in mind here, nevertheless, that the statistics on the distribution of drafting languages in the DG Translation, quoted earlier, pertain both to internal and external documents.

The reader might wonder why these regimes - particularly regarding the EU's internal communications - and the ensuing language hierarchies are relevant beyond Brussels. Two points are crucial here: first, the EU's internal linguistic regime sends clear messages beyond its institutions as to which languages accrue value and prestige; second, both the EU's internal and external linguistic regimes are an out-and-out political issue, for they reflect "the political identity of the Union" (Kraus 2008, 134; more in Chapter 4). In Section 3.3, we will focus on the legal statements that regulate the status of translations in the EU.

\subsection{Translations That Are Originals That Are Translations}

In addition to the reach of the EU's language services and their translation regimes, the official status of translations within the EU plays a pivotal role in 
our discussions here. Article 248 of the final provisions of the Treaty establishing the European Community (today Article 55 of the final provisions of the Treaty on European Union) states that the treaty was "drawn up in a single original in the Dutch, French, German, and Italian languages, all four texts being equally authentic" (emphasis added). This article has been updated with each new accession, so that subsequent versions of the treaty produced in (i.e. translated into) the new languages are also "authentic". This is known as the authentication of translations, an invisible step in the translation process which places originals and translations on an equal footing. ${ }^{9}$

Any document translated by the EU is hence not "presented as a translation, but as an original, an authentic piece of Community legislation, with a legal force identical to that of all the other language versions" (Wagner et al. 2014, 47; see also 8; European Commission 2010, 55; Bengoetxea 2011; Bobek 2011, 130-132; Leal 2016, 7). This applies to legally binding and non-legally binding information alike; in the EU, documents are "produced" in whatever languages in which they are available and then called "language versions", with no version being labelled "original”.

This model of authentication, albeit widespread in international law, is not the only one. The 1971 Berne Convention for the Protection of Literary and Artistic Works and the 1955 Protocol Amending the Warsaw Convention of 1929, for example, both available in several languages, state that the French version shall prevail in the case of disputes, thus clearly indicating that the French document is the original (Hermans 2014, 14). This system is sometimes in place in the Organization for Security and Co-operation in Europe as well, whereby the English version prevails in the case of disputes. Why has the EU not opted for this model instead?

As Theo Hermans explains, "authentication has a double effect. It makes two or more parallel texts equally authentic; and in so doing it creates the presumption of sameness of meaning between these texts" or, in other words, it creates the presumption of equivalence, which in this context "is not a feature that can be extrapolated on the basis of textual comparison"; instead, equivalence "is imposed on [texts] through an external intervention" (ibid., 9, 12). Furthermore,

if one or more versions of a treaty have come into being as a result of a process of translation from one initial version, authentication erases the memory of this process. Upon authentication, translated texts become authentic texts and must forget that they used to exist as translations. In fact, authentication strikes not only translations with amnesia, but also originals ... Where there are no translations there are no originals - unless all are agreed to be originals. Nor ... are there translators.

(ibid., 9)

Not presenting certain (mostly English-language) documents as originals and others as translations serves two key purposes. First, to circumvent legal 
questions arising from different versions of the same document. In a nutshell, because EU law is multilingual - i.e. because no single language version prevails in the case of disputes - the Court of Justice of the EU, along with all EU courts, must employ multilingual judicial reasoning. In other words, legislation cannot be taken in any one language version in isolation; no single language version or group of languages shall prevail; an unambiguous interpretation must always be arrived at (see Bengoetxea 2011; Bobek 2011, 133-138).

Michal Bobek notes that "the prohibition of majoritization is absolute; [even] in cases of evident ... mistakes in translation" (ibid., 134). Case UAB Profisa of April 2007 (C-63/06) illustrates this point: a 1992 directive on duties on alcoholic beverages had been mistranslated into Lithuanian and then implemented into national law, leading to an importer of chocolate products being wrongly denied exemption from certain duties. In this case, the meaning of the other (then) 19 language versions of the directive was clear - only the Lithuanian version diverged from the rest. Still, the Court of Justice ruled that one language version cannot be singled out. As Bobek observes, this ruling implies that national legislators are expected to read all language versions when implementing EU law. Extrapolating from that, citizens cannot rely on the individual versions of EU law published in their own language(s) either (see Kjaer \& Adamo 2011, 7).

The presumption of equivalence mentioned by Hermans, as an a posteriori construct, brings the different versions together, pulling their potentially different meanings into one (ambitious) univocal whole. Fully multilingual judicial reasoning is of course an ideal rather than a description of actual practices, which remain constrained to monolingual reasoning, as Joxerramon Bengoetxea (2011) argues convincingly and the UAB Profisa case illustrates. Others note that English is the consultation language de rigueur for all national courts - new members translate the acquis communautaire ${ }^{10}$ from English and routinely resort to the English version of legislation in the conviction that it is the original (see e.g. Derlén 2011). Monolingual or bilingual judicial reasoning apart, the fact remains that authentication precludes the possibility of a single version being deemed more "correct" than others in the event of a dispute.

The second purpose fulfilled by the authentication of translations is erasing linguistic hierarchy. Status equality among official languages is enshrined in EU law; privileging one language version, thereby officially instating a hierarchy among the official languages, would be tricky. When all language versions are originals, the boundaries between originals and translations are effaced and linguistic hierarchies are obscured. In the two examples mentioned earlier, the Berne Convention and the Protocol Amending the Warsaw Convention, the French document is quite clearly the original - hence it (along with its speakers) is privileged.

At first glance, authenticating a single language might seem unjust because it lays bare the status chasm between originals and translations - and between their respective languages and speakers. Ironically, however, perhaps this is 
just what the EU needs. That English is the EU's procedural language is beyond dispute - despite EU legislation, despite the EU's repeated symbolic nods to multilingualism and frequent declarations of good will. The EU's current translation culture - understood here as a combination of its translation regimes, the pecking order of its target and source languages and the system of authentication - makes it difficult to keep track of linguistic hierarchy and to hold the EU accountable. If the EU labelled translations and originals, the distribution of source and target languages would be made transparent, translation statistics could be kept, and measures could be taken to foster a more even distribution of source and target languages. Labelling translations and originals as such would not preclude authentication; originals and translations could still be placed on a par with each other via authentication while being clearly labelled. In fact, it would be a breath of fresh air if translations were placed on an equal footing with originals while being openly acknowledged as translations - more in Section 3.7 and Section 5.3.

Which brings us to another issue, namely the prompt association, on the part of the EU, between translations and lack of authenticity. Why do translations require authentication to be taken seriously? "A translation”, Hermans asserts sarcastically, "simply cannot have the same force of law as an authentic version"; after all,

any reminder that the text in question is in fact a translation threatens the assumption of equivalence and tells the reader: oh yes, this is only a translation, not quite the same thing as the original, ... not fully as authoritative.

$(2014,11,24)$

It follows that translators are not to be taken seriously either - in the context of international law discussed by Hermans, there are indeed no translators. What does this say about the EU's underlying notion of translation? What does it say about the hierarchy between originals and translations and the role of translators in society (see Leal 2016, 8-9)? These questions will permeate Sections 3.4 and 3.5 .

\subsection{Translations and Originals: From Belabouring the (Seemingly) Obvious to Breaking Free from the Dichotomy}

The relationship between originals and translations has been the source of heated debate since time immemorial. As George Steiner and Rosemary Arrojo remark, much of what has ever been written on translation in more than two millennia has revolved either around the question of translatability or around the basic dilemma of the relationship between translations and originals under the guise of equivalence and fidelity (Steiner 1998, 251; Arrojo 2010, 247-248; 2019, 36). These three issues are intertwined: as soon as one asks whether translations are possible, this begs the questions "to what extent can 
original and translation be deemed equivalent?", and "how close (or how faithful) do translations stay to their source texts?" These all-time translation dilemmas afflict the EU as well - the need for authentication casts doubt both on translatability and on equivalence.

Cicero was among the first to write about the controversial relationship between originals and translations and to warn against "word-for-word" translations - a method he despised - probably in the year 46 BC (Cicero 2011, 13-15). Horace shared the same view: in a much-quoted passage from his Ars Poetica (19 BC), he cautions poet-translators against word-for-word renderings. As Susan Bassnett reminds us, both followed the dictum "non verbum de verbo, sed sensum exprimere de sensu", or not word for word but rather sense for sense (Bassnett 2002, 52; see also Venuti 2008, 37).

Fast forward over 1,500 years and Martin Luther was saying something similar in his "Sendbrief vom Dolmetschen" from 1530 (Luther 2006, 104). While Cicero and Horace were concerned with the aesthetic features of poetic translation, Luther wanted to make the Bible accessible to ordinary people in their German vernacular. Yet what they have in common is the conviction that translators should engage more in producing acceptable target texts, according to target audience standards and expectations, than in word-for-word translations.

Numerous variations on the same theme have emerged since Cicero, the most renowned of which probably are Johann W. von Goethe's and Friedrich Schleiermacher's. Within a few months of each other in 1813, they postulated this basic dilemma in terms of a source-culture orientation, which they both favoured, versus a target-culture orientation (Goethe 2001, 18-19; Schleiermacher 2001, 42-43; see also Venuti 2008, 87). It will be remembered that Goethe's and Schleiermacher's ultimate intellectual goal was to establish a national culture and literary canon and, in this sense, translations that transpired source-culture elements served to refine and enrich the German linguaculture.

The list of thinkers who went on to elaborate this basic dilemma between word-for-word and sense-for-sense translations is long, and this is not the place to recount it. At times, the former method was deemed superior; at others, the latter, depending on whether the will to enrich the target linguaculture or the need to improve readability, respectively, had the upper hand. More recently, Eugene Nida $(1964,159)$ proposed the categories "formal equivalence", when target readers are made to slip into the shoes of source readers, and "dynamic equivalence", when target texts are adapted according to target culture expectations - which largely correspond to Goethe's and Schleiermacher's maxims (see Koller 1979, 125; Leal 2012, 41). Nida's work was predominantly devoted to Bible translation; in this context, he considered dynamic equivalence a more fitting method to bring the Bible closer to the realities of target readers, particularly when those realities were culturally distant from that of the source text - thus resonating with Luther. Following Nida, we could adapt expressions such as "our daily bread" to "our daily fish" 
or "our daily rice" in cultures where bread is not a staple (see Snell-Hornby 2006, 25).

A lot of the mainstream approaches to translation devised in the West had the notion of equivalence at their centre (see Leal 2012, 39-42; 2014b, 107). Whether predominantly descriptive or prescriptive, approaches such as those of Jean-Paul Vinay and Jean Darbelnet, in the 1950s, John Catford and Otto Kade in the 1960s, Wolfram Wilss, Werner Koller in the 1970s, and later, Peter Newmark, in the 1990s, attached great value to equivalence and equivalence typologies. Starting in the 1970s, however, equivalence became embedded in a purpose-oriented framework; in other words, it was no longer perceived as a fixed textual imperative. Together with other bodies of research, the German functional school, led by Katharina Reiß and Hans J. Vermeer, played a pivotal role in bringing about this change of focus, which culminated in a paradigm shift in translation studies in the 1980s (see Snell-Hornby 2006, 4767; Leal 2012, 42-43). Equivalence remained an important concept in future theories, though no longer in terms of an absolute obedience to an original text but rather with a view to fulfilling target-culture expectations. The merits of both a more "word-for-word" and a more "sense-for-sense" translation method were contingent on the purpose fulfilled by the translation in the target culture (see Nord 2005).

In 1995, Lawrence Venuti reformulated and expanded Goethe's and Schleiermacher's maxims as "foreignization" - i.e. when the target text remains close to the source text - and "domestication" - i.e. when the target text is adjusted to the target culture - favouring the former, as the two German thinkers had done, albeit for different reasons. Venuti's context is the literary translation market in the USA - in which little is translated, and translations are domesticated to the extent that most foreign aspects are adapted to the target readers' taste. His project was rather to "restrain the ethnocentric violence of translation" and thereby "resist the hegemony of transparent [i.e. domesticating] discourse in English-language cultures" (Venuti 2008, 16, 263).

The translation theories mentioned thus far have multiple intricacies into which I cannot go. Of course, the expressions "word-for-word" and "sensefor-sense" are oversimplifications; anyone who has engaged with translation knows that matters are significantly more complex. The point is not to reduce these theories to what they have in common, namely the focus on the possible relationships between originals and translations, often along with the commendation of one of these clusters of relationships. Each of these theories has added greatly to translation studies in their own unique way, but they do revolve around the same issues of equivalence and faithfulness.

For Steiner, our near obsession with the question of equivalence stems from the greater issue of translatability, which in turn "is rooted in ancient religious and psychological doubts on whether there ought to be any passage from one tongue to another" $(1998,251)$. Underpinning the question of (un)translatability is the issue of meaning: how meaning is produced and conveyed and 
whether it can be transferred from one language to another (see Leal 2014b, 108). As argued in Chapter 1, there is no "third realm" in which meaning is contained - it has never been found or artificially created. Translation theories that rely on the decoding of the source text and on the recoding of this "meaning" in the target language (be it through a word-for-word or a sensefor-sense strategy) are "logocentric", at least on Derrida's account, because they "assig[n] the origin of truth in general to the logos" $(1997,3)$. If there is no stable reservoir of meaning out there, no third space or Ursprache [original language], equivalence becomes an illusion.

Translatability is at the heart of contemporary thought because translation lays bare the functioning of natural languages - the eternal question of meaning - and ultimately determines the possibility of philosophy:

What does the philosopher say when he is being a philosopher? He says: What matters is truth or meaning, and since meaning is before or beyond language, it follows that it is translatable ... The origin of philosophy is translation or the thesis of translatability, so that wherever translation in this sense has failed, it is nothing less than philosophy that finds itself defeated.

(Derrida 1985, 120; see also $152-153)^{11}$

As noted in Section 1.6, because Derrida sees translation as "regulated transformation" and not as "some 'transport' of pure signifieds from one language to another", equivalence is impossible [here is that word again] and so is total translatability $(1981,20)$. Translatability ensures the survival of the text - total translatability (or total equivalence) would cause the text to disappear, whereas total untranslatability (the impossibility of equivalence) would lead to the immediate death of the text (Derrida 1979, 102-103). For Derrida, the only choice is to live in an eternal double bind of translatability-untranslatability: "I don't believe that anything can ever be untranslatable - or, moreover, translatable" (Derrida 2001b, 178 - translated by Venuti - see Leal 2019, 237).

Paul Ricoeur's notion of "linguistic hospitality" complements this picture of translatability-untranslatability. Our "universal ability [to use language] is contradicted by its fragmented, scattered and disorganised execution", which leaves us with two "paralysing alternatives", namely "the diversity of languages" is such that untranslatability ensues, or languages share a "common fund", putting us either on the "original" or the "universal language" tracks, which he sees as dead ends (Ricoeur 2006, 12; see also Leal 2019, 226). "Linguistic hospitality" emerges as a viable alternative: in it, we give up the hope of filling "the gap between equivalence and total adequacy" and enjoy both "the pleasure of dwelling in the other's language" and "receiving the foreign word at home, in one's own welcoming house" (Ricoeur 2006, 10). ${ }^{12}$

Ricoeur posits that to criticise a translation effectively, we would have to compare source and target texts to a third text, "the bearer of the identical meaning, supposed to move from the first to the second" (ibid., 34). Nevertheless, 
as noted earlier, no theory of language has ever managed to locate or (re)create this "third place". Therein lies the "paradox" of translation, asserts Ricoeur, for equivalence is always and only "supposed equivalence" because there is no "demonstrable identity of meaning" - it is "[a]n equivalence without identity" (ibid., 22). It follows that translation "can only aim at supposed equivalence", because equivalence is never a priori as it is produced by translation (ibid., 34-5; see Leal 2019, 237).

Still, discourse on translation outside (and to a lesser extent, inside) translation studies remains in part stubbornly punctuated by translatability and equivalence within an out-and-out logocentric framework. As noted in Chapter 1, many strands of universalism which came to form our mainstream notion of language imply that there is a "substance" of content before and outside language, and that each language articulates it differently. This legacy, started by the classical paradigm and crystallised in Saussure's structuralism, had a lasting impact on translation studies and neighbouring disciplines, thus explaining the belief in - or the yearning for - stable meanings that can be transferred across languages (see Rodrigues 1999, 187; Leal 2019, 228).

Today equivalence remains a useful concept in translation studies, often employed as a blanket term to describe the relationship between originals and translations or assess translation quality. Equivalence has, nonetheless, lost much of its scientistic ambition and rigidity typical of the decades preceding the paradigm shift in translation studies. When it features in contemporary works, it is often taken for granted or loosely defined (see Leal 2012, 39, 4344; 2014b, 108).

Does the survival of equivalence in translation studies represent a contradiction? If we follow Derrida, to eschew logocentrism is to give up the logos, or to abandon the quest for a source of meaning - an "identity of meaning" in Ricoeur's words. One such abandonment entails the rejection of equivalence as well. Yet, as we have seen, neither Ricoeur nor Derrida do away with equivalence completely - they too refer to it in passing as a useful, blanket concept to describe the relationship between originals and translations (see e.g. Derrida 1997, 134). As Christopher Norris puts it in relation to deconstruction, poststructuralism resides in driving the Saussurean project to its limit and challenging (but not abandoning) its premises (2002, 30, 145; see also Leal 2019, 238). This point is relevant throughout this book: we can be critical of the illusory character of such useful constructs as language, native speaker and equivalence, without necessarily eliminating them from our discourse.

As for translatability, generalising somewhat, contemporary translation studies is no longer punctuated by the sanctification of an original which cannot be conveyed in other languages. This sensu stricto understanding of translation - as a straightforward operation through which a perfect equivalent is found - is definitely passé. Translatability has been relativised, so that it has become a truism to say that anything can be translated into any language which does not mean that all possible nuances of meaning potentially attributed to a given word, sentence or text will find "perfect correspondents" in 
another language, not least because these nuances can only be "established" a posteriori, transiently and partially, never a priori, permanently and fully. Accordingly, even the more conservative translation thinker today is unlikely to claim that translations are the equivocal, unauthentic versions of univocal, authentic originals.

The journey of breaking free from the dichotomy translation-original has been long and winding, with key hurdles being removed by researchers from inside and outside translation studies. From inside the discipline, Vermeer, and the German functional approach as a whole, "dethroned" the original text back in 1980s, demoting it from the position of key parameter to assess translation quality to a mere "offer of information" [Informationsangebot in German] - which in turn is interpreted differently by individual translators according to numerous factors, most notably the target audience and the translation skopos [from Greek, purpose or goal] (Vermeer 1986, 33; see also Snell-Hornby 2006, 53-54; Leal 2014a, 89-94).

To name but two thinkers for want of space, another pivotal contribution was made by Rosemary Arrojo who, starting in the 1980s, relentlessly denounced the moments of aporia of translation studies, a discipline which was then still trapped within a structuralist framework despite the developments in poststructuralist theory. Influenced by thinkers such as Sigmund Freud, Friedrich Nietzsche, Roland Barthes, Michel Foucault, Jacques Derrida and Stanley Fish, she deconstructed the main dichotomies that dominated translation studies then - chiefly original-translation, author-translator, formcontent, translatability-untranslatability and faithfulness-betrayal - revealing their illusory character and highlighting their deleterious effect on the status of translators in society (see Leal 2014a, 99-200). ${ }^{13}$

From outside translation studies, Julia Kristeva's work on intertextuality contributed significantly to the deconstruction of the notion of originality, showing that so-called "original" texts were derivative, invisible patchworks of other texts and discourses (see e.g. Kristeva 1980). Barthes's work on textuality and authorship also played a key role in this respect, particularly through his rejection of the integrity of the Text with a capital $\mathrm{T}$, as a complete piece of merchandise resulting from its author's conscious intentions (see e.g. Barthes 1979). Similarly, Foucault's re-inscription of authors as a mere functional principle in the reading process - themselves a mutating cultural construct and no longer the ontological holders of the text's truth - mitigated the authority of original authorship in translation studies, placing it in a long list of factors that flow into the interpretation of a given text (see e.g. Foucault 1979). Also, Derrida's ground-breaking reflections on language, outlined in Section 1.6, helped reveal the pitfalls of the notion of an original text as a stable reservoir of meaning - carefully encapsulated in the text's signifiers - which dominated translation studies. All these contributions must be read against the backdrop of Nietzsche's philosophy and Freud's psychoanalysis. From Nietzsche, we especially take his work on the concept of truth and its inextricable ties to language and power (see e.g. Arrojo 2019), whereas, from Freud, the force of 
the unconscious is of particular interest (see e.g. Derrida 1967). Combining both, we understand that truth and meaning cannot be ontological entities, before and above human mediation and power relations.

In short, translation studies have largely broken free from the dichotomy original-translation and the dilemmas of equivalence and translatability although to "break free" does not mean to dismiss these categories altogether, but rather to perceive them from outside an essentialist, Platonic lens which inevitably links translation to failure. Having said that, two areas remain taboo, namely religious and legal translation (for religious translation, see Long 2005). We will come back to legal translation in Section 3.7, the issue at the heart of the EU's translation culture. Let us first address, in Section 3.5, a fresh debate on these old dichotomies, which has swept through the humanities in recent years.

\subsection{Intraduisible, Intradução, Untranslatable: Back with a Bang}

The debate surrounding translatability was recently reignited by the publication of the Vocabulaire européen des philosophies: Dictionnaire des intraduisibles, the fruit of a 10-year project involving some 150 researchers from multiple countries spearheaded by philosopher Barbara Cassin. First published in French in 2004, it appeared in English in 2014 as the Dictionary of untranslatables: A philosophical lexicon under the auspices of Emily Apter, Jacques Lezra and Michael Wood (with translations by Steven Rendall, Christian Hubert, Jeffrey Mehlman, Nathanael Stein and Michael Syrotinski). The more than 1,500-page long lexicon hosts a list of key philosophical terms and their translations into various languages across times, accompanied by comments in the metalanguages French, in the original, and English, in the American translation. At the time of writing, translations into Arabic, Brazilian Portuguese, Farsi, Hebrew, Italian, Romanian, Russian and Ukrainian are underway (see Apter 2014, vii).

In her Preface, Cassin stresses that "untranslatables" are not words which cannot be translated, but rather those we "kee[p] on (not) translating"14 (Cassin 2014a, xvii, in Michael Wood's translation). Their untranslatability lies in the fact that there is no one definitive translation available, but rather multiple conceptual networks that are juxtaposed (without being superimposed) afresh with each new translation - or, indeed, with each new reading (ibid., xvii). ${ }^{15}$ This resonates with Derrida's thoughts on (un)translatability outlined in Section 3.4. If the words featuring in Cassin's lexicon cannot be translated sensu stricto, i.e. if they cannot be mechanically transposed from source into target language under the guise of perfect equivalents, it follows that we "keep on (not) translating" them.

In the Preface to the English-language translation, Apter (2014, xiv) lends a nostalgic air to the notion of untranslatability, linking it to "the private anguish that we as translators experience when confronted with material that we don't want to translate or see translated". This anguish may be due to 
[a] certain density or richness or color or tone in the source language [which] seems so completely to defy rendering into another language that we would just as soon not try: the poverty of the result is too distressing, makes us miss the first language as we miss a friend or a child.

She nonetheless warns that equivalence "rests on a mystification, on a dream of perfection we cannot even want, let alone have", adding that "the constant recourse to the metaphor of loss in translation is finally too easy". For her, the Dictionnaire and its English-language translation are about "mak[ing] a virtue out of seeing differences".

Curiously, the first of such differences lies in the word "untranslatable" itself, which in the French "intraduisible" sets different conceptual frameworks into motion. There is a felicitous coincidence of the prefixes "in-" and "intra-" in "intraduisible", which softens and even reverses the negativity of "untranslatable”. The link between Cassin's “intraduisible” and Augusto de Campos' "intradução" is particularly fruitful in this respect (see Santoro 2014). Campos, the renowned translator, poet and literary critic, coined the term "intradução" in 1974 to refer to a strategy of poetry translation based on Ezra Pound's writings (see Pound 1954). By calling a translation "intradução", Campos underlined the mediating nature of translation - intra in the sense of inside and in between languages - as well as the ineluctable "intervention" of the translator - intradução resembles introdução [in the sense of introduction, introduce, insert]. Intradução is one of the many neologisms proposed by Augusto de Campos and his brother Haroldo de Campos "to question originality and authorship; [to] underpin a concept of translation as an active reinterpretation, reinvention and re-formation, and hence as an act of creation, a playful bricolage of our own and the other's cultural and literary tradition" (Leal \& Strasser 2020, 211).

Cassin's point of departure in the Dictionnaire is the existence of multiple languages in Europe, which she sees as one of its "most urgent problems". Rejecting the "solution" offered by the adoption of "a globalized AngloAmerican" as a lingua franca of sorts, she proposes instead "the retention of many languages, making clear on every occasion the meaning and the interest of the differences - the only way of really facilitating communication between languages and cultures" (Cassin 2014a, xvii). This is indeed the principle that guides the organisation of the Dictionnaire. Cassin also cautions readers against "ontological nationalism" (the term borrowed from Jean-Pierre Lefebvre), distancing herself from Martin Heidegger's sacralisation of Greek and German and, thus, from an "absolute incommensurability of languages". Accordingly, she distances herself from "a teleological history organized according to a register of gain and loss" and stresses that no language has a "special status" in her book (ibid., xviii; see Crane 2015, for some important objections).

Cassin's team's resulting work can be read as a kind of concrete poem: it becomes or creates that which it seeks to portray. With a few exceptions, the 
entries do not idealise an original concept in its alleged fullness or perfection, sneering translations as imperfect, incomplete imitations. In her Introduction, Cassin asserts that she likes to think of Europe and of individual languages as Energeia, not Ergon - i.e. as works in progress rather than finished works (see Section 1.4). Well, the Dictionnaire is also Energeia, not Ergon: it beseeches more translation, more interventions from more researchers and translators with different backgrounds. "Many languages first of all”, proclaims Cassin: the commitment to multilingualism, inspired by Humboldt, is fulfilled in the entries (Cassin 2014a, xix).

Despite its best intentions, the Dictionnaire touched a nerve in translation studies by bringing back to life a bete noire which everyone hoped was halfdead, namely "untranslatability". Venuti's much-discussed, fiery critique of the book encapsulates the resentment it caused in the area (Venuti 2016). In his view, the Dictionnaire relies on a notion of "mistranslation" which, nevertheless, is not grounded in a fair and thorough translation analysis. To assess the merits of a translation, there must first be a clear source text, which is not always the case in the Dictionnaire, as some of the concepts are only available in translations (as an example, Venuti mentions the entry "subject"). Second, Venuti highlights the importance of textual units in translation: by taking individual words, often out of context, one cannot accurately assess the quality of a translation. Third, a code or theme must be established to guide the appraisal of the translation - one that is not anachronistic in relation to the translator in question. Yet Venuti finds that, in the Dictionnaire, this code is invariably the personal interpretation of the author of the entry, which in turn cannot be expected to match, say, a medieval translator's interpretation.

In a nutshell, Venuti finds the whole enterprise treats translation at best in a sloppy fashion, clinging to such negative epithets as "untranslatable", "mistranslation" and "distortion". In the English-language translation, he feels that these drawbacks were exacerbated through the openly domesticating translation strategy adopted. According to him, both the French and the English versions of the Dictionnaire are underpinned by a "centuries-old idea of translation: it preserves the source text under a romantic concept of original integrity" and thus "disparages translations as the destruction or contamination of that integrity, treating them as perpetual yet insufficient compromises" (ibid., 198). Even if we disagree with this, the American editors do seem to cling to a nostalgic notion of originality as something complete; the differences between the languages, which could be portrayed simply as differences, become absences of something that was allegedly present in the original (see Apter 2014, xiv).

Understandably, Venuti's main concern is that a project that set out to celebrate multilingualism and translation might turn out to worsen the already negative discourse on translation and translators. His critique is embedded in a larger critical estimate of the meagre space allocated to translation in comparative literature in the US - a discipline which owes its existence to translation. He has been hammering away at this argument since the 1990s (see Venuti 2008) and little has changed, in his opinion. 
The somewhat willy-nilly treatment of translation in certain entries - especially in the English version of the Dictionnaire - denounced by Venuti, is evident; yet to "savage" (Hermans 2020, 605) the entire project and subsume it under the "centuries-old idea of translation" that sanctifies originals and demonises translations seems exaggerated. ${ }^{16}$ A volume of this magnitude, involving this many languages, would have been downright unfeasible if the authors had strictly followed the three principles suggested by Venuti and outlined earlier. More importantly, Cassin's entire ceuvre and intellectual project unambiguously dispel any charges of logocentrism (see e.g. Petry 2017). She systematically defends the abandonment of ontological nationalism and of logocentric notions of translation, conceptualising it rather as a key mechanism in contemporary citizenship to embrace and celebrate the Other in their alterity (see e.g. Cassin et al. 1999; Cassin 2014b; 2016).

It must be added that Cassin's intellectual project is permeated by a new sophistics of translation. Relying, for example, on Protagoras, she distances herself from the dichotomy true versus false, opting for the notion of "better" instead. In relation to translation, this means that a particular translation cannot be considered right or wrong in absolute terms, but rather "better" and this comparative is always qualified, for "better" is always for someone in a given context. Seen through this prism, the "mistranslations" of the Dictionnaire sound less categorical (see Végsö 2019).

What do we take from the acrimonious Venuti-Cassin debate for our reflections on EU translation here? First, the issue of an adequate epistemology and terminology - not at odds with our postmodern condition - arises again, this time in relation to translation. Is "L1 speaker" a more wholesome term than "native speaker"? Similarly, would "weak and entropic interpretations" - the phrase chosen by Venuti to describe certain English-language translations of Rilke (2016, $195)$ - appease more readers than "mistranslation" and "distortion"? ${ }^{17}$ Venuti most certainly does not mean that all translations are always equally good and can never be criticised; his concern is rather that some entries in the Dictionnaire make categorical charges of "mistranslation" - thus implying there is a correct, perfect translation. To signal the inadequacy of these tricky expressions, perhaps we should cross them out or strike them through - place them sous rature, ${ }^{18}$ as it were - as John O'Regan (2016), for instance, does with English as a lingua franca, Heidegger with and Derrida in the famous "the sign that ill-named (Derrida 1997, 19). But where do you stop?

Most importantly for us here, this debate on (un)translatability highlights that there is no perfect equivalence between languages and, if there were, "the result would not be translation; it would be a replica. And if such replicas were possible on a regular basis, there would not be any languages, just one vast, blurred international jargon" (Apter 2014, xiv). Translation and multilingualism would be proven superfluous and/or machine translation would fully replace translators; the dream of a transparent language, as envisioned, for example, by the early Wittgenstein and so many others before and after him, would come true (see Section 1.5). 
Yet Venuti and Cassin concur that linguistic diversity is a fact to be celebrated, and translation is "a means of establishing a common ground, even if riddled with linguistic, cultural, and social differences” (Venuti 2016, 204) and "the only way of really facilitating communication between languages and cultures" (Cassin 2014a, xvii). The debate (or the wound) that Cassin's Dictionnaire opened in translation studies has had more ramifications than I can go into (see e.g. Crane 2015; Petry 2017; Hermans 2020). It highlights the uncomfortable boundaries between originals and translations and reminds us that, even if we erase these boundaries, as the EU does, the hierarchies between their respective creators and languages will not disappear.

To come back to the questions raised at the end of Section 3.3, the clichéd idea that original texts are authentic, univocal and complete, whereas translations are unauthentic, devious and faulty underpins the EU's translation culture. By authenticating translations, the EU creates an illusion of equality of meaning and status across multiple language versions. Since there can be no equality of meaning, no perfect equivalence, no total translation and no identity of meaning, equivalence (and thereby translatability) have to be imposed on EU documents a posteriori through authentication. This gesture effectively erases the differences between the language versions, at least from a legal point of view, and forces these different documents into a - welcome and necessary common interpretive framework. Still, disputes about the meaning of certain words and expressions arise, as noted earlier. After all, exogenous equivalence may make up for the lack of endogenous equivalence among the language versions, but it does not produce univocity in the interpretation of these documents. Monolingual judicial systems are not without their disputes over conflicting interpretations of legislation either, ${ }^{19}$ but this state of affairs is exacerbated when multiple languages and cultures come into contact.

Authentication is the easy way out precisely because it is undeniable that different language versions are different texts with different meanings, and that originals and translations are two different instances of text production. However clearly poststructuralist theories have revealed the elusive character of the dichotomy original-translation, the point was never to presume them to be equal. The derivativeness of translations is more patent because they bear an often overt, always special, relation to one particular text - its original. In this sense, translations will tend to be sub-ordinate to their originals, even if we pretend that all translations are originals, as the EU does. The key to breaking free from this dichotomy does not lie in considering translations and originals to be equally authentic or equivalent; rather in acknowledging their differences and the consequences of their differences - as Cassin's Dictionnaire does. In this sense, authenticating translations does more harm than good and it does not prevent interpretive disputes from emerging, nor does it stop language hierarchies from taking hold.

In summary, what underpins the EU's translation culture is not only a predominantly logocentric notion of translation, but also the tension between unity and multiplicity. Recognising two dozen languages, having all legally 
binding documents "drafted" in these languages and granting both these language versions and the languages per se the same status are steps towards multiplicity. This multiplicity, nevertheless, can also be perceived as a cover-up for mechanisms that help maintain a particular notion of unity in the EU one which always has the upper hand for pragmatic reasons. In other words, the EU recognises and grants 24 languages the same status (multiplicity), while relying predominantly on English to conduct its affairs (unity); it makes sure that binding legislation is available in all 24 languages and that these 24 versions have the same status (multiplicity), while drafting the vast majority of these documents in English and then erasing the tracks between originals and translations (unity). Is there an alternative to this impasse between unity and multiplicity? Also, is another translation culture possible - one that is less logocentric and more compatible with recent developments in translation studies and neighbouring disciplines? Let us look into these questions in Section 3.6.

\subsection{Unity Versus Multiplicity and the EU's Double Responsibility: A Necessary Aporia}

The EU's paradoxical stance on multilingualism manifests itself in its translation culture, too. A single de facto working language and translations that are originals foster a sense of unity, "consensus" and "transparency", whereas multilingualism and translation remind us of the ineluctable multiplicity and "dispersion" inherent to the EU (Derrida 1992, 41, 54, here in Pascale-Ann Brault and Michael B. Naas's translation). Indeed, the tension between unity and multiplicity has been at the heart of the EU from the outset. How much multiplicity is allowed for the EU effectively to constitute a union? How much unity is required before this union starts homogenising the diversity of its members? Must the EU opt for pure unity or pure multiplicity? And does this tension between unity and multiplicity require a solution?

Though made in 1991, Jacques Derrida's recommendations for “today's Europe" sound surprisingly current and illuminate these questions from - as ever - unexpected angles. He calls for a double duty, a double injunction which he also names "contradiction", "antinomy", "paradox", "aporia” and even "paradox of the paradox"; indeed, a paradox which "[is taking] unprecedented forms ... today in Europe” (ibid., 80). This double injunction seeks to integrate unity and multiplicity in unparalleled ways, ${ }^{20}$ thus requiring an unprecedented type of responsibility:

Responsibility seems to consist today in renouncing neither of these contradictory imperatives [to maintain unity and multiplicity]. One must therefore try and invent gestures, discourses, politico-institutional practices that inscribe the alliance of these two imperatives ... That is not easy. It is even impossible to conceive of a responsibility that consists in being responsible for two laws, or that consists in responding to two 
contradictory injunctions ... But there is no responsibility that is not the experience and experiment of the impossible.

(ibid., 44-45; emphasis added to the last sentence as it encapsulates the notion of impossibility that permeates this book)

He goes on to defend that "ethics, politics, and responsibility ... will only ever have begun with the experience and experiment of the aporia". In other words, " $[\mathrm{w}]$ hen the path is clear and given, when a certain knowledge opens up the way in advance [and] the decision is already made, it might as well be said that there is none to make" (ibid., 41). This aporia or double responsibility can take numerous forms. In one of his last texts, for instance, Derrida describes his "dream" for Europe through several of these double injunctions: "A Europe where we could criticize Israeli policy ... without being accused of antiSemitism or Judeophobia”, or "[a] Europe where we could simultaneously be concerned about the rise of anti-Semitism and Islamophobia”, among others (2006, 410-411).

Regarding language and translation, we can understand this double responsibility as follows (Derrida 1992, 38-39): “[f]irst tension, first contradiction, double injunction: on the one hand European cultural identity cannot be dispersed ... into a myriad of provinces, into a multiplicity of self-enclosed idioms or petty little nationalisms, each one jealous and untranslatable". However, to complete the double injunction, "[Europe] cannot and must not accept the capital of a centralized authority that, by means of trans-European cultural mechanisms ... would control and standardize, subjecting ... discourses and practices to ... channels of immediate and efficient communication" (see Leal 2016, 16-17). Further, we must beware of " $[t]$ he best intentioned of European projects", which

may try ... to impose the homogeneity of a medium, of discursive norms and models ... Claiming to speak in the name of intelligibility, good sense, common sense or the democratic ethic, this discourse tends ... to discredit anything that complicates this model.

(Derrida 1992, 54-55)

He exhorts Europe to "avoid both the nationalistic tensions of linguistic difference and the violent homogenization of languages through the neutrality of a translating medium that would claim to be transparent, metalinguistic and universal" (ibid., 58; see Leal 2016, 11).

To come back to the questions asked above as to whether the tension between unity versus multiplicity requires a resolution and whether the EU must opt for pure unity or pure multiplicity, in a later work Derrida asserts that "pure unity or pure multiplicity - when there is only totality or unity and when there is only multiplicity or dissociation - is a synonym of death" (Caputo \& Derrida 1997, 106). In other words, we have to be capable of "nonbinary judgements" (Derrida 2006, 410) and go beyond the principle of 
reversibility [in the Latin sense of revertere, to turn or move in the opposite direction] implied in binary oppositions. Reversibility is crucial here, because any "solution" to today's Europe cannot simply remain trapped between two extremes. As Rodolphe Gasché (2007, 16-17) notes, “in reversibility, the sphere or realm of the same remains fully intact, no opening to otherness in all its unpredictability occurs there". In other words, reversibility is "a way of securing sameness: a celebration of sameness". When we remain trapped between two extremes, "the other, or the foreign to and into which the self reverts, is only the opposite of oneself (thus the self can always reassert itself in the other, or reappropriate it)".

What does this mean for our unity-multiplicity dilemma discussed here? Pure unity or pure multiplicity would be unfeasible and undesirable. Derrida's double junction or double responsibility hence entails a double duty: "[this] duty dictates respecting differences, idioms, minorities, singularities, but also the universality of formal law, the desire for translation, agreement and univocity ...” (Derrida 1992, 78). The EU's current language and translation regimes clearly strengthen unity at the expense of multiplicity. To turn this around and enact the necessary double injunction - without falling prey to reversibility - what can the EU do regarding translation?

I argued earlier that labelling originals and translations - quite apart from authentication - would be a key step towards more transparency, a more multilingual EU and a more equitable treatment of its official languages (at least potentially). Moreover, if the EU adopted this model and were to truly abide by its own treaties, it would have to ensure an ideally equitable distribution of source and target languages. This would force the EU to keep its policy and lawmakers diverse and truly multilingual (and not simply Englishspeaking); it would prevent the EU from privileging English speakers when choosing staff or making information available.

Of course, it is unrealistic to expect, say, a new EU regulation concerning the use of pesticides to be originally drafted in Bulgarian, because although there may be Bulgarian speakers among the authors of the regulation, it is unlikely to function as the link language among all authors. But let us remember Derrida's warning that "there is no responsibility that is not the experience and experiment of the impossible" (ibid., 44-45) - the impossible, highlighted repeatedly throughout this book, can never be overstated. The impossible refers not only to that which cannot be done, but also - and more importantly - to that for which we strive despite knowing that it cannot be easily or fully achieved. If it could, then it would not require striving for. ${ }^{21}$

Therein lies the advantage of maintaining the distinction between translations and originals: the EU would be forced to seek alternatives if all or nearly all original texts remained persistently in English after some time. This is already the case now, but because of the effacement of the boundaries between translations and originals, this fact goes unnoticed and the fiction of equality among languages prevails. The Commission itself clings to this illusion to justify the special status of English (see the Appendix). By forcing itself to 
address its own language hierarchy, the EU might find ways to mitigate it - at the very least, its language bias would be laid bare. This could be an interesting way both to enact Derrida's double responsibility and to answer his call to "invent gestures, discourses, politico-institutional practices that inscribe the alliance of these two imperatives" (1992, 44), without simply falling back on reversibility. This translation model might even lead to a new dynamic between translations and originals, potentially affecting the EU's and the mainstream (logocentric) notion of translation. Imagine what it would be like if the original version of an important piece of legislation were, say, in Portuguese, and the corresponding English version were a translation?

If originals and translations were clearly labelled and continued to be authenticated, the ideal of multilingual judicial reasoning (see Section 3.3) would remain in place: the original would not prevail over the translations. For once, the labels "original" and "translation" would not be marks of prestige but rather tracks of the process of text production of vital importance to multilingualism in the EU. Further implications pertaining to this proposed reform, along with additional suggestions regarding the EU's translation culture, will follow in Section 3.7.

\section{7 "Invent Gestures, Discourses, Politico-Institutional Practices": A Language Turn and a Translation Turn for a More Multilingual EU}

The EU will most likely remain in a perennial double bind between unity and multiplicity in all relevant realms - linguistic and cultural but also political and economic. As long as fresh proposals regarding the functioning of the EU remain caught between these extreme poles - in other words, as long as they fall prey to reversibility - little genuinely new can be achieved. This point will be developed specifically in relation to multilingualism in Chapter 5.

As for translation, the EU's de jure policy gives weight to multiplicity while its de facto policy favours unity, at times arguably in breach of its own legislation. Appeals either for the adoption of English as the EU's sole working language (or lingua franca) or for the permanence of the EU's symbolic equal treatment of all official languages are unlikely to break the deadlock (examples in Chapter 4). In this context, I propose a language turn and a translation turn for the EU - which will be the focus of Chapter 5. In the present chapter, let us look at two clusters of suggestions pertaining to both turns: one more symbolic but crystallised in concrete gestures and practices, and one pertaining to the budget and staff allocated to the EU's language services.

To heed Derrida's call to invent "gestures, discourses, politico-institutional practices that inscribe the alliance of these two imperatives", which features in the title of this section, I propose making translations visible in the EU by labelling all texts, be they legally binding or not, as translations or originals as noted earlier. A simple sentence along the lines of "This text was originally drafted in [language]" would suffice. 
If this measure were adopted and if the EU kept its "panarchic" regime in place (i.e. with 24 official and working languages; see Table 3.1), the next step would be to put whole-hearted efforts into maintaining a certain balance in the distribution of source and target languages, particularly ensuring that the pool of source languages is not restricted to the same one or two. I say a "certain balance" because downright equality in the distribution of target and source languages would be impossible, which means that we can strive for it through steps that strengthen multilingualism without, nevertheless, expecting to achieve it in full. Language delegations could take turns, for example, drafting the final version of documents; EU staff could receive training in transcultural competence and intercomprehension (see Section 4.8); recruitment processes could give more weight to less widely spoken languages, ensuring that staff are not multilingual in the same one or two common languages (see note 4), but in multiple languages; each subunit in bodies, agencies and institutions could have language goals - such as an equitable distribution of drafting languages, a high number of languages represented in the department, as well as a large number of staff being trained in transcultural competence, intercomprehension and/or EU languages.

Measures such as these would not (and must not) lead to perfect equality among all official languages or bring instant results. They would nonetheless help establish a new ethos grounded in renewed language practices and ideologies, shifting the focus away from the pragmatic imperative of one or two common languages to the normative and symbolic imperative of multilingualism. In this new ethos, languages and translations always remain visible. Making translations invisible is analogous to making "named" languages invisible: as noted in Section 1.6, in some circles of language policy research, it has become taboo to speak of languages as bounded entities because multilinguals do not speak individual languages separately but rather "language" or "translanguage". Regardless of whether we agree with this view, the concomitant effacement of "named" languages does a disservice to linguistic minorities, because "denying the existence of languages blocks the access of minoritised groups to it" (Grin 2018, 259). Moreover, and critically for our purposes here, effacing "named" languages may seem to erase hierarchies by placing all languages on an equal footing in a continuum; yet, in fact, this effacement precludes the possibility of monitoring and counter-balancing language hierarchies. "We should not naturalise named languages"; they are, after all, constructs; "but even less should we naturalise linguistic hegemony" (ibid., 264).

The same applies to translation: while the boundaries between originals and translations may be illusory, making them visible is vital for transparency. Here, at least two dimensions of the invisibility of translations are relevant in the EU's context. The first has permeated this chapter thus far - when a translation is published as though it were an original text, it is made invisible. The same happens when translations are read as though they were originals (without any thought on their differences). The second dimension of the 
invisibility of translations lies in their often domesticated character, particularly when the target audiences enjoy more prestige on the world stage (see Venuti 2008; Bennett 2013). When translations are domesticated to the extent that the source canon, values and local colour are sacrificed in the name of readability, they are made invisible.

These two facets of invisibility are key in relation to the dominance of English in (and beyond) the EU and to the role that translation plays in facilitating this hegemony. When English is the main (often only) source language, for native and non-native speakers alike, and when there is a dominant nativespeaker-based writing standard, we have a flow of input that benefits English and English speakers at every turn. ${ }^{22}$ Research in translation studies has consistently revealed that "epistemicide" is in full swing, for example, in academia. The term, borrowed by Karen Bennett from the Portuguese sociologist Boaventura de Sousa Santos, conveys "the obliteration of an alternative way of construing knowledge" due to the hegemony, today, of English (Bennett 2013, 171). Her research shows that translations of scholarly works into English fall prey to epistemicide in that the epistemological framework of the original often has to be destroyed to accommodate Anglo-Saxon standards. Refuse to do that and these translations into English are dismissed for being "unnatural" and "vague" (ibid., 182; see also Mossop 1988, 65, for the curious example of translations of Freud's works into English).

Texts translated from English (or any other major language) cannot escape epistemicide either: the tendency is for translators to foreignise their translations often through calquing, and these calques are gradually incorporated into the target language - a phenomenon abetted by the trend to write directly in English, for instance, in academia. Bennett sums up the phenomenon of epistemicide in translation as follows: "texts translated into English have to be heavily domesticated in order to ensure publication, while translations out of English tend to stick very closely to the original" (2013, 171).

Therefore, labelling translated texts as translations is but one step to increase the visibility of translations in the EU. Following Bennett, consciously avoiding an overly domesticating strategy when translating into English (and to a lesser extent, French), as well as an overly foreignising strategy when translating from these languages, would allow multiple linguacultures to remain visible, thus avoiding epistemicide. This, of course, is of no help as long as English remains the only source language; a wider repertoire of source languages is vital.

When non-native speakers of English write in English, we can also make our linguistic repertoires visible in our English through our syntax, word choice and use of idiomatic expressions, as well as by openly taking up language issues that arise from the differences among our working languages. The reader will remember Barbara Cassin's words in the Dictionnaire here: we need "the retention of many languages, making clear on every occasion the meaning and the interest of the differences" (2014a, xvii).

Language contact and language change need not be feared and cannot be halted; I am in no way defending language conservatism, purism or much less 
nationalism for the EU - although, as Joshua A. Fishman reminds us, seemingly nationalistic approaches to language are not so much about nationalism as about maintaining a certain social reality that constitutes its speakers' life-world (Fishman 1972, 77-85). In any case, the point is rather the celebration and maintenance of linguistic diversity through concrete measures that reach beyond the symbolic level.

This first cluster of suggestions subsumed under a language and a translation turn for the EU poses the question of equality among official languages and language versions. Equality is neither about expecting languages to be used with the same frequency in all areas of the EU (equality in use) nor about presuming them to convey the exact same meanings (equality of meaning). Equality in use can be replaced by the notion of aimed equity - because total equity would be impossible. Ideological and physical space must be carved out in the EU so that aimed equity can be striven for. Status equality should not prevent the EU from acknowledging the differences (in meaning and in use) among these languages. There will always be differences in the frequency, distribution and use of the EU's official languages.

As for equality of meaning, of course equivalence is always either supposed or a posteriori equivalence. Nonetheless, as noted earlier, legal translation and religious translation remain taboo as regards the need for total equivalence. In the context of the EU, total equivalence can be bestowed upon translations through authentication; for ethical reasons, however, we can still label these texts translations. Their differences will most likely continue to surface in court cases, which represent one of the arenas where the differences among our languages (ultimately, our differences) can be debated. Between 1960 and 2010, the Court of Justice of the EU acknowledged that there were discrepancies between language versions of EU legislation in 170 cases (3.4 cases per year; see Robinson 2014, 209). These legal disputes are the least we can expect from such a multilingual organisation; indeed, to be successfully united in diversity, in any kind of union, big or small, we need to allow room for differences to emerge.

The second cluster of suggestions pertaining to the language and translation turns refers to the budget and staff allocated to the EU's language services. The first cluster of suggestions proposed above would require additional funds and, moreover, for the current, de jure "panarchic" translation regime (coupled with "triple symmetrical relay") to be used more often, more staff and more resources would be needed (Grin 2008; see Table 3.1). One of my chief arguments throughout this book is that language is not an accessory, a "vanity project" the EU insists on promoting for no plausible reason. To argue that other areas - such as the customs union, monetary policy, commercial policy, internal market, common economic policies, agriculture, fisheries, industry, and so on - are more important than language policy is to ignore the fact that every transaction effected, every meeting conducted, every document drafted in these areas takes place in and through language. From this point of view, 10 per cent does not sound like a big enough proportion of the EU's workforce to handle the demand for language services. 
To assume that the choice of language and the number (and quality) of translations available are trivial matters in the EU could have serious consequences for the dialectics between unity and multiplicity in the bloc. Though the withdrawal of the United Kingdom from the EU cannot be pinned on communication problems, they certainly played a relevant part in it, as the "leave" campaign capitalised on language and translation "peculiarities" to persuade the electorate that the EU was detached from the UK's reality. Witness, for example, the fuss they made about the EU's "five presidents" (and the "Five presidents' report" of 2015), a term rarely used in British companies or committees and often associated with their prime minister's counterparts in other countries. $^{23}$

As noted in the previous chapters, an instrumental approach to the EU's language and translation regimes, whereby even fewer languages would be used - possibly only English - would imply that languages can be stripped of their expressive value and employed in a neutral fashion, without any consequences for standing power relations, language hierarchies, education language policies or language practices and ideologies beyond EU institutions. An instrumental approach to language and translation would imply, in short, that language is not a component of our identity. Let us bear in mind here that the sheer fact that mammoth language services are in place is hugely symbolic of the EU's willingness to respect diversity (see e.g. Kraus 2008, 124).

For these reasons, the only way forward for the EU seems to reside in expanding its language services, begging the question of the costs. The budget for multilingualism may be low, as noted in Section 3.2, but any boost would require additional resources. The often-acrimonious long-term budget negotiations were compounded in 2020 not only by the pandemic, but also by the hole left by Brexit. As a result, the 2021-2027 budget represents a compromise reached largely at the expense of the EU's science and research programmes, which suffered substantial cuts. New priorities and an increased budget for, for example, climate action, migration and digitalisation are on the table but, as ever, language is not mentioned at all. Since the 1990s, national governments have made yearly contributions of, on average, just over 1 per cent of their gross national income to the EU and to the European Development Fund. Currently, between 0.15 and 0.3 per cent of national VAT-based revenues goes to the EU (European Commission n.d.b). It is estimated that the sum of the yearly national budgets of all EU members states is 50 times the EU's annual budget (Wirtschaftskammer Österreich 2020, 6).

Would national governments and citizens be willing to foot the bill of increased language services for the EU? Unfortunately, questions about language and translation rarely feature in EU surveys. For instance, no languagerelated questions were covered in any of the surveys on the future of Europe (Special Eurobarometer 251, 379, 394, 413, 451 and 467, along with Standard Eurobarometer 71$).{ }^{24}$ To my knowledge, the only relatively recent survey carried out in the area of language and translation is Special Eurobarometer 386, "Europeans and their languages", of 2012. The results reveal that most EU 
citizens find that translation plays an important or very important role in seven of eight areas, namely (1) getting news about world events (67 per cent); (2) leisure activities (57 per cent); (3) health and safety (71 per cent); (4) accessing public services (59 per cent); (5) education and learning (76 per cent); (6) job seeking (68 per cent); and, finally, (7) participating in or obtaining information about the EU (60 per cent). Only in the area of everyday life do a minority of respondents (43 per cent) feel that translation has an important role to play. Younger, educated and multilingual respondents rank the importance of translation even more highly (ibid., 124, 139-140).

More detailed surveys would be required to assess whether this positive outlook on translation correlates with a readiness to invest more in EU language services. Questions about how EU citizens view the annual cost of language services of $€ 2.20$ per citizen, considering that the total annual contribution of each citizen to the EU budget amounts to around $€ 240$, would be imperative, as well as questions about whether the important role respondents ascribe to translation warrants a larger expenditure on language services in general. ${ }^{25}$

\subsection{Final Remarks}

The EU is torn between unity and multiplicity: regarding languages and cultures, its discourse favours multiplicity whereas its practices enforce unity. Pure unity or pure multiplicity are neither viable nor desirable options. This chapter has been dedicated to the interplay of unity and multiplicity as regards translation. Total translatability, or total equivalence, would imply that we do not perform our languages differently after all, that every use of language can be an exact replica of another use of language; it would entail, ultimately, that we do not need multiple languages or multiplicity. Total untranslatability, in turn, would render unfeasible and pointless any relation, any meaningful interaction or contact with the Other. Similarly, pure unity in the EU would entail the homogenisation of cultures, languages and peoples to the extent that they would be deprived of their differences; in language, pure unity would entail nothing less than the realisation of the most logocentric, universalist dream. Pure multiplicity, in turn, would exacerbate our differences enormously, precluding any positive contact in some hardcore strand of linguistic determinism.

Fully escaping the double bind between unity and multiplicity seems unrealistic; after all, this double bind is always in place whenever and wherever there is any kind of union or contact between individuals. How united must, say, a couple, family, community or a country be to be worthy of the noun "union"?; how diverse can they be before they jeopardise their union or the individuality of their members? In this chapter, I proposed measures that seek to go beyond the tension between unity and multiplicity by "invent[ing] gestures, discourses, politico-institutional practices that inscribe the alliance of these two imperatives" (Derrida 1992, 44). These measures include the 
expansion of the EU's language services and their staff, on the one hand, along with a system whereby translations/originals are labelled and source/target languages are distributed more evenly - thus requiring staff to be multilingual in more varied language combinations, to master transcultural competences and intercomprehension, and to actively use more than the same one or two languages. These suggestions should result in aimed equity and in the visibility of translations and languages in the EU. Together, these measures make up a language turn and a translation turn in the EU (more in Chapter 5).

These suggestions should also lead to a shift in the EU's translation culture or "philosophy of translation" (Derrida 1992, 58) to fit contemporary views on the status of translations, while at the same time complying with our double responsibility towards unity and multiplicity. Rather than pushing for pure unity by advocating the official adoption of fewer, or even a single working language, and rather than pushing for pure multiplicity simply by arguing for the permanence of (symbolic) official status equality for the EU's 24 languages, the measures proposed here should open physical and ideological space for de facto multilingualism. This space can then be filled with practices that foster multilingualism - but, inevitably, they will also be filled with monolingual, mostly English-language practices that foster unity. This (im)balance can then be monitored; its consequences acknowledged, documented and openly debated.

In Section 2.8, we wondered whether multilingualism amounts to many little "monolingualisms" in the EU. In other words, is the EU a simple collection of juxtaposed nationalities and their respective languages, which is expected to work by having everyone acquire the same one (at times two, rarely three) language(s)? It certainly seems so from the perspective of the EU's language services, which are limited and revolve around English - and will remain so, at least according to the DG Translation (see the Appendix). The suggestions made in this chapter take it for granted that the EU will continue to have 24 official languages whose status is symbolically the same. Should this regime change? Will Brexit have an impact on the de jure and/or on the de facto status of English in the EU's institutions, bodies and agencies? What are the political contours of the unity-multiplicity paradox? I will take up these questions in Chapter 4.

\section{Acknowledgements}

An earlier version of Section 3.6 featured in Leal (2021).

\section{Notes}

1 See Grin (2018) for a comparable paradox, in the context of EU multilingualism, between inclusion and mobility.

2 In this book, the focus will be on translation, with only a few general statistics pertaining to interpreting as well. 
3 All EU legislation mentioned throughout this book, including court cases, was taken from the EUR-Lex portal: (C) European Union, available at: https://eur-lex. europa.eu/. All electronic sources quoted here were last accessed in December 2020.

4 Italy has continuously brought actions against the European Commission because of language restrictions in notices of open competition, see e.g. cases T-71/18 and T695/17. In 2004, it challenged a Decision adopted by the European Commission to publish job vacancies for senior management posts in the Official Journal of the EU in English, French and German only - case T185/05, Italy v Commission. In 2008, the Court of Justice of the EU annulled the Decision due to discrimination on grounds of language, setting an interesting precedent. The Court did, however, fall back on its ruling in the Kik $v$ OHMI case (C-361/01) and reiterated that Regulation no. 1 does not constitute "a general principle of community law that confers a right on every citizen to have a version of anything that might affect his interests drawn up in his language in all circumstances" (see Section 2.2). Since then, there have been similar rulings by the Court, see e.g. T-117/08, joint cases T-124/13 and T-191/13 and C-566/10. This last case routinely features in EU recruitment notices because its ruling stipulated that any restrictions in EU job applicants' choice of second language must be justified. Generalising somewhat, candidates are expected to speak at least two of the 24 official languages, one of which having to be English or French, sometimes German. Since this ruling, recruitment notices include an explanation that English and French "are the most common languages (and specifically English) used in the area of expertise", that it "has long been the practice to use mainly English and French for internal communication", and that these are languages "most often needed when communicating with the outside world and in performing day-to-day work" (see e.g. recruitment notices PE/219/S and PE/200/S).

5 An example of an ECI that is directly relevant to us here is entitled "Minority SafePack", the main objective of which is to "improve the protection of persons belonging to national and linguistic minorities and strengthen cultural and linguistic diversity in the Union" through the adoption of 11 legal Acts. Proposed in 2013, this ECI was initially rejected by the Commission because it "manifestly fell outside the [EU's] powers" - as noted in Section 2.2, language policy is not within EU jurisdiction. The authors of the ECI appealed this decision and, on 3 February 2017, the Court of Justice agreed to publish it with the caveat that two out of the 11 legal Acts proposed "manifestly fall outside the framework of the Commission's power to propose legislation". The ECI went on to gather 1,128,385 signatures across all the then 28 member states; it was officially submitted in January 2020 and had its first public hearing in the European Parliament in October 2020 - see Case T-646/ 13.

6 Peter A. Kraus $(2008,124)$ reports that the cost of multilingualism is in fact so low that the European Parliament "has consistently voted against revoking the directive that all official languages should be treated equally", since this would have an insignificant impact on the EU's budget.

7 This may change depending on the circumstances, and English is probably the most used pivot language anyway. 132 is by no means an exact figure.

8 See Wright (2007), Bengoetxea (2011), Robinson (2014) and Barbier (2018) for different appraisals of drafting processes across different EU institutions and their bias towards English.

9 This system of authentication of translations has a long history in countless multilingual settings in the West (see Hermans 2014, 7-17). It is in place in the United Nations, for instance. Article 111 of the Charter of the United Nations reads as follows: "The present charter, of which the Chinese, French, Russian, English, and Spanish texts are equally authentic ..." (United Nations 1945). But in the UN, too, this has not prevented language hierarchies from emerging. See e.g. Baigorri-Jalón 
(2004, 30-31, 34) for more on the "the progressive ascent of English" in the UN, here in Anne Barr's translation (see also Leal 2016, 8-9).

10 That is, the entire body of EU law, including legislation, legal acts and court decisions.

11 See Section 5.2 for the "translation turn" in the humanities.

12 See also Antoine Berman's notion of "auberge du lointain", or "inn of the remote" (Berman 1999; Massardier-Kenney 2010).

13 Arrojo never wrote about Vermeer; Vermeer, for his part, wrote in 1997 that he perceived Arrojo's work as a welcome radicalisation of the German functional approach (Vermeer 1997, 9; see Leal 2014a, 90).

14 This definition had featured in a previous work by Cassin as follows: "L'intraduisible n'est pas ce qui n'est pas ou ne peut pas être traduit, c'est plutôt ce qu'on ne cesse pas de (ne pas) traduire" [The untranslatable is not what isn't or cannot be translated, rather that which we never stop (not) translating.] (Cassin 1995). I thank Fernando Santoro for the reference (see Santoro 2014).

15 In a later work, Cassin speaks of the "untranslatables" as

des symptômes sémantiques et/ou syntaxiques de la différence des langues, non pas ce qu'on ne traduit pas, mais ce qu'on ne cesse pas de (ne pas) traduire. Le Vocabulaire s'est donné pour ambition de capitaliser le savoir des traducteurs en faisant passer l'ensemble des notes de bas de page et des parenthèses dans le plein texteou le plein-texte ... Le Dictionnaire des Intraduisibles ne fournit pas la bonne traduction de quelques intraduisible que ce soit, il explicite les discordances, il met en présence et en réflexion, il est pluraliste et comparatif en un geste sans clôture, beaucoup plus borgésien ou oulipien que destinal et heideggérien.

$(2016,54)$

[the semantic and/or syntactical symptoms of the differences between languages not what we don't translate but rather what we keep on (not) translating. The ambition of the Vocabulaire was to capitalise on the translators' knowledge by placing all footnotes and parenthetical remarks into the main body of the text - as the body text. The Dictionary of Untranslatables does not provide the correct translation of any old untranslatables, rather it makes the dissonances between languages explicit, it approaches them, reflects upon them in a never-ending pluralistic and comparative gesture. It is hence much more Borgesian and Oulipian than destinal or Heideggerian.]

16 Even when passages such as the following, quoted from the Preface to the American edition, do make translation researchers cringe and wonder whether we are bringing back Eugene Nida's cargo train metaphor from the 1960s (whereby the cargo can be distributed differently among the wagons as long as the entire shipment arrives intact at the destination) to describe translation:

Wood [one of the editors and contributors to the English-language translation] pictures the situation as something like a traffic system. Three or four vehicles carry whatever is needed in any language, but the vehicles circulate differently in different places, and divide their loads differently ... it's easy to follow the wrong vehicle.

(Apter 2014, x; see Nida 1975, 190; Arrojo 2007, 12; Leal 2014a, 77)

17 In the original, the expression "traduction erronée" appears, for example, in the entry mentioned by Venuti ("Sujet"; Balibar et al. 2019, 1238) but seems to be a rare occurrence - though I have not read the Dictionnaire from cover to cover. In the English-language translation, the electronic version of which I have accessed via the University of Vienna, a quick search found four occurrences of "mistranslate" and its inflections across the dictionary. "Distortion", for example, is used more often - but still only nine times. 
18 For more on this, see Sarup (1993, 35, 42).

19 Ronald Dworkin draws a parallel between reading legislative acts and a poem by W. B. Yeats: we may agree on the meaning of the individual words but still disagree on the overall meaning of the text (quoted in Robinson 2014, 187).

20 Paul Ricoeur proposes a similar reflection along the lines of "identity" versus "alterity", adding that "[w]hat we most desperately lack [in Europe] are models of integration between these two poles", here in Eileen Brennan's translation $(1996,10)$.

21 This is reminiscent of Derrida's appraisal of the notion of forgiveness: paradoxically, we can only forgive the unforgivable, because that which is easily forgivable does not require forgiveness in the first place (see Derrida 2001a; Leal 2014c).

22 Works by proponents of the "English as a lingua franca" paradigm have contributed to challenging the dominance of English native-speaker norms in academia, for example. I may disagree with their premises (see Section 1.9), but their efforts to dethrone "native-speakerism" in the English-teaching canon, in academia and in publishing have been notable (see e.g. Seidlhofer 2011; Jenkins 2014).

23 I thank Jeremy Gardner, former senior translator at the Court of Auditors of the EU, for this example.

24 All Eurobarometer survey results can be accessed via the GESIS Eurobarometer Data Service, available at: www.gesis.org/en/eurobarometer-data-service/home.

25 The questions of whether and how citizens should be consulted lie beyond the scope of this book but will appear fleetingly in Section 4.2.

\section{Further Reading}

Derrida, Jacques. 1992. The other heading: Reflections on today's Europe. Translated by Pascale-Ann Brault and Michael B. Naas. Bloomington, IN: Indiana University Press.

European Commission. 2010. Translation at the European Commission: A history. Luxembourg: Office for Official Publications of the European Communities.

Hermans, Theo. 2014. The conference of the tongues. New York: Routledge.

Snell-Hornby, Mary. 2006. The turns of translation studies: New paradigms or shifting viewpoints?Philadelphia, PA: John Benjamins.

\section{References}

Apter, Emily. 2014. "Preface". In Dictionary of untranslatables: A philosophical lexicon, edited by Barbara Cassin, Emily Apter, Jacques Lezra and Michael Wood, viixvi. Princeton, NJ: Princeton University Press.

Arrojo, Rosemary. 2007. Oficina de tradução: A teoria na prática. São Paulo, Brazil: Ática. Arrojo, Rosemary. 2010. "Philosophy and translation". In Handbook of translation studies vol. 1, edited by Luc van Doorslaer and Yves Gambier, 247-251. Philadelphia, PA: John Benjamins.

Arrojo, Rosemary. 2019. "Nietzsche". In The Routledge handbook of translation and philosophy, edited by Piers Rawling and Philip Wilson, 34-48. New York: Routledge.

Baigorri-Jalón, Jesús. 2004. Interpreters at the United Nations. A history. Translated by Anne Barr. Salamanca: Ediciones Universidad de Salamanca.

Balibar, Étienne, Barbara Cassin and Alain de Libera. 2019. "Sujet". In Vocabulaire européen des philosophies: Le dictionaire des intraduisibles, edited by Barbara Cassin, 1233-1253. Paris: Éditions du Seuil \& Dictionnaires Le Robert.

Barbier, Jean-Claude. 2018. "European integration and the variety of languages: An awkward co-existence". In The politics of multilingualism: Europeanisation, 
globalisation and linguistic governance, edited by François Grin and Peter A. Kraus, 333-357. Philadelphia, PA: John Benjamins.

Barthes, Roland. 1979. "From work to text". In Textual strategies: Perspectives in poststructuralist criticism, edited and translated by Josué V. Harari, 73-81. Ithaca, NY: Cornell University Press.

Bassnett, Susan. 2002. Translation studies. London: Routledge.

Bengoetxea, Joxerramon. 2011. "Multilingual and multicultural legal reasoning: The European Court of Justice". In Linguistic diversity and European democracy, edited by Anne Lise Kjaer and Silvia Adamo, 97-122. Farnham: Ashgate.

Bennett, Karen. 2013. "English as a lingua franca in academia". The Interpreter and Translator Trainer 7 (2): 169-193.

Berman, Antoine. 1999. La traduction et la lettre ou l'Auberge du lointain. Edited by Barbara Cassin, Isabelle Berman and Alain Badiou. Paris: Seuil.

Bobek, Michal. 2011. "The multilingualism of the European Union law in the national courts: Beyond the textbooks". In Linguistic diversity and European democracy, edited by Anne Lise Kjaer and Silvia Adamo, 121-142. Farnham: Ashgate.

Buck, Tobias. 2006. "Romania's less than glittering prize". Financial Times, 1 November. Available at: https://web.archive.org/web/20110711045737/http://us.ft.com/ftga teway/superpage.ft?news_id=fto110120060255093038.

Caputo, John and Jacques Derrida. 1997. Deconstruction in a nutshell: A conversation with Jacques Derrida. New York: Fordham University Press.

Cassin, Barbara. 1995. "De l'intraduisible en philosophie". Rue Descartes 14.

Cassin, Barbara. 2014a. "Introduction”. In Dictionary of untranslatables: A philosophical lexicon, edited by Barbara Cassin, Emily Apter, Jacques Lezra and Michael Wood, translated by Michael Wood, xvii-xx. Princeton, NJ: Princeton University Press.

Cassin, Barbara (ed.). 2014b. Philosopher en langues: Les intraduisibles en traduction. Paris: Éditions Rue d'Ulm.

Cassin, Barbara. 2016. Éloge de la traduction: Compliquer l'universel. Paris: Fayard.

Cassin, Barbara, Isabelle Berman and Alain Badiou. 1999. "Notes des éditeurs". In La traduction et la lettre ou l'Auberge du lointain, by Antoine Berman, edited by Barbara Cassin, Isabelle Berman and Alain Badiou, 7-9. Paris: Seuil.

Cicero, Marcus Tullius. 2011. "De optimo genere oratorium”. Scientia Traductionis 10: 4-15.

Cogo, Alessia and Jenkins, Jennifer. 2010. "English as a lingua franca in Europe: A mismatch between policy and practice”. European Journal of Language Policy 2 (2): 271-294.

Craith, Máiréad Nic. 2006. Europe and the politics of language: Citizens, migrants and outsiders. New York: Palgrave Macmillan.

Crane, Tim. 2015. "The philosophy of translation”. Times Literary Supplement, 28 January. Available at: www.the-tls.co.uk/articles/the-philosophy-of-translation/.

Derlén, Mattias. 2011. "In defence of (limited) multilingualism: Problems and possibilities of the multilingual interpretation of European Union law in national courts". In Linguistic diversity and European democracy, edited by Anne Lise Kjær and Silvia Adamo, 143-166. Farnham: Ashgate.

Derrida, Jacques. 1967. "Freud et la scène de l'écriture". In L'écriture et la différence, 293-340. Paris: Éditions du Seuil.

Derrida, Jacques. 1979. "Living on / Border lines". In Deconstruction and criticism, edited by Harold Bloom, translated by James Hulbert, 75-176. New York: The Seabury Press. 
Derrida, Jacques. 1981. Positions. Translated by Alan Bass. Chicago:University of Chicago Press.

Derrida, Jacques. 1985. The ear of the Other: Otobiography, transference, translation. Translated by Peggy Kamuf. Lincoln, NE: University of Nebraska Press.

Derrida, Jacques. 1992. The other heading: Reflections on today's Europe. Translated by Pascale-Ann Brault and Michael B. Naas. Bloomington, IN: Indiana University Press.

Derrida, Jacques. 1997. Of grammatology. Translated by Gayatri Chakravorty Spivak. Baltimore, MD : Johns Hopkins University Press.

Derrida, Jacques. 2001a. On cosmopolitanism and forgiveness. Translated by Michael Hughes. London: Routledge.

Derrida, Jacques. 2001b. "What is a 'relevant' translation?" Translated by Lawrence Venuti. Critical Inquiry 27 (2): 174-200.

Derrida, Jacques. 2006. "A Europe of hope". Translated by Pleshette DeArmitt, Justine Malle and Kas Saghafi. Epoché 10 (2): 407-412.

European Commission. 2009. Translating for a multilingual community. Luxembourg: Office for Official Publications of the European Communities.

European Commission. 2010. Translation at the European Commission: A history. Luxembourg: Office for Official Publications of the European Communities.

European Commission. 2012. "Special Eurobarometer 386: Europeans and their languages”. Available at: https://ec.europa.eu/commfrontoffice/publicopinion/archives/ ebs/ebs_386_en.pdf.

European Commission. 2019. "EU budget for the future”. European Union. Available at: https://ec.europa.eu/info/sites/info/files/factsheet-modern-eu-budget-future-challenges.pdf.

European Commission. 2020. "Translation in figures 2020”. Luxembourg: Publications Office of the European Union. Available at: https:/op.europa.eu/en/publication-deta il/-/publication/c29be934-9588-11ea-aac4-01aa75ed71a1/language-en/format-PDF/ source-128980315.

European Commission. n.d.a. "Calls for tenders, grants and calls for expression of interest”. Available at: https://ec.europa.eu/taxation_customs/calls-tenders-grants-ca lls-expression-interest_en.

European Commission. n.d.b. "EU budget own resources". Available at: https://ec. europa.eu/info/strategy/eu-budget/revenue/own-resources_en.

European Parliament. n.d. "Which languages are in use in the Parliament?" Available at: www.europarl.europa.eu/news/en/faq/21/which-languages-are-in-use-in-the-parliament.

European Union. 2018. Interpreting and translating for Europe. Luxembourg: Publications Office of the European Union. doi:10.2862/8728.

European Union. 2019. "Language policy". Available at: https://europa.eu/europea n-union/abouteuropa/language-policy_en.

Fishman, Joshua A. 1972. Language and nationalism: Two integrative essays. Rowley, MA: Newbury House.

Foucault, Michel. 1979. "What is an author?" In Textual strategies: Perspectives in post-structuralist criticism, edited and translated by Josué V. Harari, 141-160. Ithaca, NY: Cornell University Press.

Gasché, Rodolphe. 2007. "This little thing that is Europe”. CR: The New Centennial Review 7 (2): 1-19.

Gazzola, Michele. 2006. "Managing multilingualism in the European Union: Language policy evaluation for the European Parliament”. Language Policy 5: 393-417. 
Gazzola, Michele. 2014. "Partecipazione, esclusione linguistica e traduzione: Una valutazione del regime linguistico dell'Unione Europea”. Studi Italiani di Linguistica Teorica e Applicata XLIII (2): 227-264.

Gazzola, Michele and François Grin. 2013. "Is ELF more effective and fair than translation? An evaluation of the EU's multilingual regime". International Journal of Applied Linguistics 23 (1): 93-107.

Goethe, Johann Wolfgang von. 2001. "Drei Stücke vom Übersetzen”. In Clássicos da teoria da tradução, vol. 1, edited by Werner Heidermann, 16-23. Florianópolis: UFSC.

Grin, François. 2008. "Principles of policy evaluation and their application to multilingualism in the European Union". In Respecting linguistic diversity in the European Union, edited by Xabier Arzoz. Philadelphia, PA: John Benjamins.

Grin, François. 2018. "On some fashionable terms on multilingualism research: Critical assessment and implications for language policy". In The politics of multilingualism: Europeanisation, globalisation and linguistic governance, edited by François Grin and Peter A. Kraus, 247-274. Philadelphia, PA: John Benjamins.

Grin, François et al. (eds). 2018. The MIME Vademecum: Mobility and inclusion in multilingual Europe. Grandson, Switzerland: Artgraphic Cavins.

Hermans, Theo. 2014. The conference of the tongues. London: Routledge.

Hermans, Theo. 2020. "Translatability". In The Routledge encyclopedia of translation studies, edited by Mona Baker and Gabriela Saldanha, 602-606. London: Routledge.

Jenkins, Jennifer. 2014. English as a lingua franca in the international university: The politics of academic English language policy. London: Routledge.

Kjaer, Anne Lise and Silvia Adamo. 2011. "Linguistic diversity and European democracy: An overview". In Linguistic diversity and European democracy, edited by Anne Lise Kjaerand Silvia Adamo, 1-15. Farnham: Ashgate.

Koller, Werner. 1979. Einführung in die Übersetzungswissenschaft. Heidelberg: Quelle und Meyer.

Kraus, Peter A. 2008. A union of diversity: Language, identity and polity-building in Europe. Cambridge: Cambridge University Press.

Kristeva, Julia. 1980. Desire in language: A semiotic approach to literature and art. Edited by Leon S. Roudiez. Translated by Thomas Gora, Alice Jardine and Leon S. Roudiez. New York: Columbia University Press.

Küchler, Teresa. 2008. "Language director defends EU's costly translations". Eurobserver, 25 February. Available at: https://euobserver.com/news/25712.

Leal, Alice. 2012. "Equivalence". In The handbook of translation studies, vol. 3, edited by Yves Gambier and Luc Van Doorslaer, 39-46. Philadelphia, PA: John Benjamins.

Leal, Alice. 2014a. Is the glass half empty or half full? Reflections on translation theory and practice in Brazil. Berlin: Frank \& Timme.

Leal, Alice. 2014b. "Linguistic scepticism and the Jung-Wien: Towards a new perspective in translation studies". trans-kom 7 (1): 99-114.

Leal, Alice. 2014c. "Truth in translation: Interpreters' subjectivity in the truth and reconciliation hearings in South Africa". In Research into the realities of translation fiction, edited by Klaus Kaindl and Karlheinz Spitzl, 233-245. Philadelphia, PA: John Benjamins.

Leal, Alice. 2016. "Translation at the European Union and English as a lingua franca: Can erasing language hierarchy foster multilingualism?” New Voices in Translation Studies 14: 1-22.

Leal, Alice. 2019. "Equivalence". In The Routledge handbook of translation and philosophy, edited by Piers Rawling and Philip Wilson, 224-242. New York: Routledge. 
Leal, Alice. 2021. "Multilingualism and translation in the European Union". In The Routledge handbook of translation and globalisation, edited by Esperança Bielsa and Dionysios Kapsaskis, 483-497. New York: Routledge.

Leal, Alice and Melanie Strasser. 2020. “Anthropophagy”. In The Routledge encyclopedia of translation studies, edited by Mona Baker and Gabriela Saldanha, 19-22. New York: Routledge.

Long, Lynne (ed.). 2005. Translation and religion: Holy untranslatable? Clevedon, Multilingual Matters.

Luther, Martin. 2006. "Sendbrief vom Dolmetschen (1530)". In Clássicos da teoria da tradução, vol. 3, edited by Mauri Furlan, 94-115. Florianópolis: UFSC.

Massardier-Kenney, Françoise. 2010. “Antoine Berman's way-making to translation as a creative and critical act”. Translation Studies 3 (3): 259-271.

Mossop, Brian. 1988. "Translating institutions: A missing factor in translation theory". TTR: traduction, terminologie, rédaction 1 (2): 65-71.

Nida, Eugene. 1964. Toward a science of translating. Leiden: E. J. Brill.

Nida, Eugene. 1975. Language structure and translation: Essays. Stanford, CA: Stanford University Press.

Nord, Christiane. 2005. Text analysis in translation: Theory, methodology, and didactic application of a model for translation-oriented text analysis. Translated by Christiane Nord and Penelope Sparrow. Amsterdam: Rodopi.

Norris, Christopher. 2002. Deconstruction: Theory and practice. London: Routledge.

O'Regan, John. 2016. "Intercultural communication and the possibility of English as lingua franca". In The cultural and intercultural dimensions of English as a lingua franca, edited by Prue Holmes and Fred Dervin, 203-217. Bristol: Multilingual Matters.

Petry, Simone Christina. 2017. "Resenha: CASSIN, Barbara. Éloge de la traduction: compliquer l'universel. Paris: Fayard, 2016. 247p”. Remate de males 37 (2): 10071016.

Phillipson, Robert. 2003. English-only Europe? Challenging language policy. London: Routledge.

Pound, Ezra. 1954. "How to read". In Literary essays of Ezra Pound, edited by T. S. Eliot, 13-40. London: Faber.

Ricoeur, Paul. 1996. "Reflections on a new ethos for Europe". In Paul Ricoeur: The hermeneutics of action, edited by Richard Kearney, translated by Eileen Brennan, 1015. London: SAGE.

Ricoeur, Paul. 2006. On translation. Translated by Eileen Brennan. London: Routledge.

Robinson, William. 2014. "Translating legislation: The European Union". The Theory and Practice of Legislation 2 (2): 185-210.

Rodrigues, Cristina Carneiro. 1999. Tradução e diferença. São Paulo, Brazil: Editora UNESP.

Santoro, Fernando. 2014. "Intraduction: La traduction de la philosophie rencontre les défis de la traduction poétique". In Philosopher en langues: Les intraduisibles en traduction, edited by Barbara Cassin, 167-182. Paris: Éditions Rue d'Ulm.

Sarup, Madan. 1993. An introductory guide to post-structuralism and postmodernism. Harlow: Pearson Education Ltd.

Schleiermacher, Friedrich. 2001. "Ueber die verschiedenen Methoden des Uebersetzens". In Clássicos da teoria da tradução, vol. 1, edited by Werner Heidermann, 26-85. Florianópolis: UFSC. 
Seidlhofer, Barbara. 2011. Understanding English as a lingua franca. Oxford: Oxford University Press.

Snell-Hornby, Mary. 2006. The turns of translation studies: New paradigms or shifting viewpoints? Philadelphia, PA: John Benjamins.

Steiner, George. 1998. After Babel: Aspects of language and translation. Oxford: Oxford University Press.

United Nations. 1945. "Charter of the United Nations". Available at: www.un.org/en/ charter-united-nations/index.html.

Van Parijs, Philippe. 2011. "Interview by the European Commission". In Lingua franca: Chimera or reality?, edited by European Commission DGT, 81-91. Luxembourg: Publications Office of the European Union.

Van Parijs, Philippe. 2015. "The ground floor of the world: On the socioeconomic consequences of linguistic globalization". In Language policy and political economy: English in a global context, edited by Thomas Ricento, 231-251. Oxford: Oxford University Press.

Végsö, Roland. 2019. “Current trends in philosophy and translation”. In The Routledge handbook of translation and philosophy, edited by Piers Rawling and Philip Wilson, 157-170. New York: Routledge.

Venuti, Lawrence. 2008. The translator's invisibility: A history of translation. London: Routledge.

Venuti, Lawrence. 2016. "Hijacking translation: How comp lit continues to suppress translated texts". boundary 243 (2): 179-204.

Vermeer, Hans J. 1986. “Übersetzen als kultureller Transfer”. In Übersetzungswissenschaft: Eine Neuorientierung, edited by Mary Snell-Hornby, 30-53. Tübingen: Francke.

Vermeer, Hans J. 1997. "Vorwort”. In Übersetzungswissenschaft in Brasilien: Beiträge zum Status von „Original“ und Übersetzung, edited by Michaela Wolf, 9-11. Tübingen: Stauffenburg.

Wagner, Emma, Svend Bech and Jesús M. Martínez. 2014. Translating for the European Union institutions. London: Routledge.

Wirtschaftskammer Österreich. 2020. "Finanzierung der EU”. Vienna. Available at: http s://news.wko.at/news/oesterreich/eutt_Finanzierung-der-EU.pdf.

Wright, Sue. 2004. "Language rights, democracy and the European Union”. In Language rights and language survival, edited by Jane Freeland and Donna Patrick, 219-242. Manchester: St. Jerome.

Wright, Sue. 2007. "English in the European Parliament: MEPs and their language repertoires”. Sociolinguistica Jahrbuch 21: 151-165. 


\title{
4 The EU as a Community in Formation in the Wake of Brexit
}

\author{
For a New Linguistic Regime
}

\subsection{Introduction}

So far in this book, the paradox of unity versus multiplicity has revolved around language-related issues - notably around the EU's de jure multilingualism versus de facto monolingualism and the implications of this conundrum for translation. Yet we should never lose sight of the political contours of this paradox. The EU is unlike any other intergovernmental organisation in the world, as its breadth and level of harmonisation among its members - i.e. its level of unity - remain unparalleled. This notwithstanding, member states are not willing to give up their individuality - i.e. the union's inherent multiplicity - in the name of this union.

The paradox of unity versus multiplicity manifests itself in the tension between an ever-growing, EU-wide sense of transnationalism and the member states' sovereignty. The 2020 coronavirus pandemic epitomised this tension in an unprecedented fashion: member states were torn between defending their own interests and appeasing their electorate (nationalism, multiplicity), on the one hand, and taking advantage of the benefits of being together in mutual ties of solidarity (transnationalism, unity), on the other. Just what kind of union is the EU and which element of the paradox has the upper hand: unity or multiplicity? Can we speak of the dawn of transnationalism in the bloc and, if so, how does it impact such notions as (national) identity and democracy? Sections 4.2 and 4.3 will be dedicated to these questions.

With a clearer picture of the political contours of the unity versus multiplicity paradox in mind, in Section 4.4 we will revisit some of the questions about language contact and language dynamic in the EU left unanswered in the previous chapters. Linguistic justice will emerge in Section 4.5, as it encapsulates the normative difficulties of an English-only EU and further illuminates the language-related questions discussed in Section 4.4.

Will English maintain its tight grip on the EU and the world? All languages that played the role of lingua franca in the past eventually met their doom. Different forecasts, discussed in Section 4.6, point to a more multilingual future with a diminished role for Jane Austen's language. In Section 4.7, the focus will lie on the future of English in the EU in the wake of Brexit: will it 
spell the fate of the "lingua franca" in EU institutions, bodies and agencies and - in the long run - in the member states as well? Or will it rather strengthen the de jure and/or the de facto status of the language in the bloc? The present chapter will end in Section 4.8 with a plea for a new language regime for the EU grounded in multilingualism through intercomprehension and transcultural awareness - in other words, through a transcultural turn. In an EU more capable of intercomprehension, we may keep our individuality while taking a step towards others, who, in turn, get to keep their otherness.

\section{2 "Together in Disunity": The EU as a Common Market and a Community of Shared Fate n Formation}

The opening page of the Treaty establishing the European Coal and Steel Community $(1951)^{1}$ features three clusters of reasons to justify the creation of the community. The first and most pronounced revolves around peace: to "safeguard" "world peace", to "organis[e]" "Europe" to "maintain peaceful relations", to "further the works of peace" and "to substitute ... age-old rivalries". The second is centred on unity and "shared destiny": to "create real solidarity", to "merg[e] ... essential interests", to "create ... the basis for a broader and deeper community among peoples" and to establish "institutions which will give direction to a destiny henceforth shared". Finally, the third has to do with the economy: to "establis $[\mathrm{h}]$... common bases for economic development" and to "expan[d] basic production, to raise the standard of living". Yet the remaining 300 pages of the treaty focus almost exclusively on this third cluster, with the common market showcased in every section. The words "language" and "translation" are entirely absent from the document. How can we achieve peace and engender a sense of "shared destiny" and unity among different peoples without giving any thought to their languages?

Fast forward 42 years, the EEC (European Economic Community) and the EAEC (European Atomic Energy Community or Euratom) had been established and the EU was about to be born with the Maastricht Treaty. Still, language remained persistently absent, as Abram De Swaan reports from 1993:

There was much talk of milk pools and butter mountains, of a unitary currency, of liberalizing movements of EC citizens and restricting access for outsiders, but the language in which these issues were dealt with remained itself a non-issue.

$(1993,244)$

It was as though the common market should suffice to bring about both peace and a notion of solidarity and shared destiny in the bloc - a common market which itself was beyond and above language. Yet there can be no de facto nopolicy language policy; states may eschew, for example, issues of religion, but they cannot eschew language, they cannot replace a given language in its 
courts and institutions with no language (Kymlicka, quoted in De Schutter \& Robichaud 2015b, 89; see also Kraus 2008, 84).

Today we can say that the EU has unequivocally achieved at least two of the three clusters of goals laid out in 1951. As far as peace is concerned, Umberto Eco opportunely reminds us that a war between Germany and France would be unthinkable today, even though their bitter rivalry had been the rule for two thousand years $(2005,16)$, and economically the single market remains unparalleled. But what about the second cluster of unity, solidarity and shared destiny?

The EU's founding fathers, Jean Monnet in particular, believed that the formation of the EU would be piecemeal, with individual policy areas taken on board gradually, ultimately and naturally culminating in a European federation, a United States of Europe. From Staatenbund [association of states] to Bundesstaat [federal state], as it were. "If we were to do it all over again, we should begin with culture", goes the apocryphal quote by Jean Monnet, which some attribute to Hélène Ahrweiler (see Collins 1996, 13; Kraus 2008, 43; Lamour \& Lorentz 2019, 357). If this is the case, to what extent is there a sense of unity, solidarity and shared destiny in the EU despite the fact that its jurisdiction in the social and cultural (and linguistic) realms is limited?

This book is being written during the coronavirus pandemic of 2020. Enrico Letta, Italy's prime minister in 2013-2014, has recently warned that the "Trump virus" can have even more devastating effects in the EU than Covid19. By "Trump virus", he is alluding to Donald Trump's presidential campaign slogan of 2016, "America first". If every EU country puts its interests first, "we will all sink together" (Letta, quoted in Rankin 2020). Indeed, the news that stole the spotlight in the early months of the pandemic was of Russia's and China's prompt shipments of medical supplies to Italy - against the backdrop of the EU's inertness and disunity. The crisis had scarcely broken out when the borders between EU members, both physical and symbolic, were up again. It is, however, the member states', not the EU's, inertness that is crucial here, as Luxemburg's foreign minister, Jean Asselborn, reminds us. In his view, the EU is at a crossroads and the outcome of this "solidarity crisis" [Solidaritätskrise] will determine the future of the bloc (Asselborn 2020).

It is telling that the vast majority of Spanish and Italian nationals felt that neither other member states nor the EU institutions were helping them during the first wave of the pandemic (European Parliament n.d.). It is precisely this lack of solidarity, lack of unity and lack of a sense of shared destiny (or fate more below) among member states that underpin the EU's inertness when momentous decisions must be taken. Through this prism, the issue of unity versus multiplicity gains yet another layer: when multiplicity amounts to the juxtaposition of individual nations and their nationalisms, and when unity requires that these nationalisms - or the "Trump virus", in Letta's words - be overcome in the name of a "one for all, all for one" mentality, it becomes clear that "multiplicity" has the upper hand. In this context, multiplicity is a synonym for "fragmentation" and "individualism". It is as Gerald Kernerman puts 
it in relation to Canada: in the EU, we seem to be "together in disunity", and not "united in diversity", as the EU motto professes (2004, 164).

The history of nation-building in the West teaches us that critical times often bring people together, fostering a deep sense of solidarity and shared destiny among those of us who, for whatever reason, feel that we are "in it" together. There was hope in the early 2000s that the US invasion of Iraq and the subsequent altercations between the US and the EU would bring about one of these decisive moments - a Hamiltonian moment - for the EU. Jürgen Habermas and Jacques Derrida, for instance, put a lot of faith in the 15 February, the day in 2003 when record-breaking numbers of people took to the streets of Europe (and the entire world) to protest against the imminent Iraq War (Habermas \& Derrida 2005). Yet meanwhile this date has long been forgotten - and the constitutional movement came to a standstill after the Treaty establishing a Constitution for Europe was blocked in 2005 by national referenda in France and the Netherlands.

Initially, the 2020 pandemic highlighted the lines that divide the member states, causing the solidarity crisis to flare up. Yet health is not an EU area of competence (see Articles 3, 4 and 6 of the TFEU), begging the question whether there should be more unity in the EU, whether its competences should be expanded, whether, indeed, it should become a federation of sorts. Though too multifaceted to be undertaken at length here, this debate is decisive regarding the EU's language and translation regimes. There is certainly no talk about decreasing the EU's areas of competence or "loosening" the ties that bind its members together - in fact, the opposite applies. The key questions for us here are hence the following: What kind of union is the EU today and what can it become in the future? What part do language and translation play in this immensely complex question? And will Brexit have an impact on the EU's language and translation regimes?

For Adolf Muschg, "Europe is a reality that comes into being simply by virtue of the fact that it is created", adding the important caveat - "not unfamiliar to the Swiss" - that "what is created is also what is desired" $(2005,23-$ 24). Indeed, a theory of "postnational government" or "governance" is yet to be written (Kraus 2008, 15). Hence, "sui generis" is probably one of the most used phrases to describe the EU's political system (see e.g. Kraus 2008, 59; Knaut 2014, 106; Behr \& Stivachtis 2016, 1). It remains unparalleled in the world as a political order that goes beyond other intergovernmental organisations, such as the United Nations, the Association of Southeast Asian Nations or the African Union, but stops somewhere between a federation, a confederation and a consociation.

In Peter Kraus's view (2008, 60-61), the EU's decision-making system in supranational institutions, the directly elected European Parliament, the prominent position of the Court of Justice of the EU, along with the advent of EU citizenship are clear federative traits. However, the absence of a "teleology leading from the European alliance of states to the European federal state" places it closer to a confederation. Yet unlike both a federation and a 
confederation, in the EU, the division of power follows national lines; in other words, only in common areas of concern can the EU take supranational action, and even in these shared areas of competence veto rights may be accorded to its members, as is the case in consociations.

Crucially, Kraus also emphasises that in officially multilingual states the objective is never to override ("pure unity"; see Section 3.6), but rather to coordinate the member states' interests. It follows that there will never be a perfect balance between these interests; the best we can expect is "the precarious expression of a politically contested status quo" (ibid., 43). It is thus a union predicated on the multiplicity of its members' interests; but a union presupposes the existence of common concerns and targets, too.

From this perspective, the fact that member states often struggle to reach an agreement in critical moments is a natural, even desirable, outcome of the EU's very set-up. Any mechanism allowing for a "teleology ... from the European alliance of states to the European federal state" would defeat the objective of the EU (ibid., 63). Back to Muschg, this unstable and shifting existence is enough for the EU and means that "all European organs, head and limbs, 'Brussels' and the old nation-states, become bearers of a process of intelligent self-creation" which never ends and does not require a common identity (Muschg 2005, 27).

What it requires is a sense of "shared destiny" (ibid., 27), a concept that goes hand in glove with Melissa Williams's (2004) notion of "citizenship as shared fate", proposed in the Canadian context, or with the notion of "communities of fate", by Herman van Gunsteren (2018). ${ }^{2}$ In "communities of shared fate", we are "bound to each other not by shared values or moral commitments" or a common national, ethnical, cultural or linguistic identity, but rather "by relations of interdependence that may or may not be positively valued" (Williams 2004, 104). She stresses that this is a descriptive, as opposed to a normative category, and that shared identities are neither the sole source nor an obligatory component of shared fate. In fact, "[i]nstitutional linkages ... are another important source of shared fate", which is key in relation to the EU (ibid., 105; emphasis added).

As it currently stands, the EU can thus be seen as a political order sui generis, in which aspects of a federation, a confederation and a consociation merge into a community of shared fate in a perennial state of self-creation and formation. Has this set-up been enough to engender a sense of deep solidarity and unity among member states, regardless of nationality and language? If we understand ties of solidarity as embedded in a larger framework of self-representation, then a buzzword weighs on the EU, namely "democratic deficit".

The national dynamic of directly electing representatives, who in turn make decisions which are widely publicised in the media and for which the electorate can hold them accountable, is largely absent from the EU. Unlike national parliaments, the European Parliament has limited legislative powers; even though its jurisdiction has been gradually expanded through the Treaties of Maastricht, Amsterdam and Nice, the Council of the European Union (the 
main decision-making body) and the European Commission (the executive branch) remain the key players in the legislative process. None are directly elected, and their actions and exact set-up are not communicated to the general public to the same extent that the actions and set-up of national governing groups are. National media privilege national news; EU-wide channels for disseminating information have been on the rise since the millennium but are still dwarfed by national channels - not least because of the question of language (see Wright 2011). Therefore, there are issues with accountability and democratic representation as far as key EU decision-makers are concerned, as well as with the communication channels available to inform the public about who these decision-makers are and which decisions they are making.

This conundrum has prompted calls, backed by public opinion, that the European Parliament be granted the traditional legislative powers committed to national parliaments and that the president of the Commission, as well as the commissioners, be directly elected (see European Commission 2014; European Parliament 2019b); others find that EU-wide plebiscites would counter the democratic deficit (see Kraus 2008, 18-20; Wright 2011, 51). ${ }^{3}$

But the issues of language and the channels of communication remain. A culture of European politics with EU-wide political parties is only timidly beginning to emerge now. And although the European Parliament has been steadily gaining ground in the EU, its elections remain "second-order national contests" (Hix, quoted in Kraus 2008, 56). Turnout sank to a record low in 2014 (42.61 per cent) and then rose again in 2019 (50.66 per cent), with huge national variations (Belgium with 88.47 per cent and Slovakia with 22.47 per cent; European Parliament 2019a).

The Members of the European Parliament's (MEPs) platform for discussion and deliberation is riddled with language challenges - which is unsurprising given the staggering number of languages they bring to the Parliament. The MEPs' contributions have to be kept short and simple. Debates can only take place in smaller, often unofficial meetings, but both in smaller meetings and in the full assembly, language hierarchies determine one's chances of being heard and taken seriously. Interpreting services play a crucial role but entail delays, particularly when pivot languages are needed. Sue Wright's research among MEPs reveals that some choose to use English (to a lesser extent, French) to avoid translation and interpreting, and that language choice is an out-and-out political matter for them (Wright 2007, 159; see also Wright 2004; 2011). And even though MEPs cannot be required to speak certain languages - as anyone can run for office - those who do not speak English (and to a lesser extent, French) are gravely disadvantaged.

Language seems to be both the culprit and the potential solution to some of the EU's most pressing problems. The EU may very well be a "[novel, young and unprecedented] supra-national polity in formation" (Wright 2011, 36), and its shifting character may be one of its distinctive features. Even once the geographical limits of Europe have been reached and the EU's set-up seems definitive, it will remain "a polity in formation". It may seem banal, but we 
should remember that any polity, nation or grouping of any sort is always in formation, since its members are not static and neither is the dynamic among them. The case of the EU is paradigmatic because of its size and complexity. It is clear that certain areas of competence should remain the prerogative of individual member states, despite the push for unity. Any union, big or small, should make room for individuality. The question is whether language policy should be one of these exclusive areas. The fact that the EU is a polity in formation does not mean that the question of language should be left to resolve itself, not least because, when it comes to language, so much is at stake. As argued in the previous chapters, language is not a frill in the European project; rather, it is the Raum [place, space] where the EU, in all its different realms and areas of competence, is articulated, constructed, developed, contested, lived.

The EU is thus a polity in formation which encompasses not only a single market but also a community of shared fate. The bloc cannot but seek a single common good, well aware of the impossibility of this task. It has stood at many crossroads before, torn between "pure unity" and "pure multiplicity", and has always found an alternative route (see Section 3.6). In the 2020 coronavirus pandemic, news in the EU has not all been bad. After the initial shock waves subsided, news of solidarity began to pop up, with Italian and Spanish patients being treated in Germany, French patients being welcomed in Austrian hospitals, among others. News about an unprecedented EU recovery fund, though riddled with doubts and quarrels, brought hope to the entire bloc, ${ }^{4}$ as did collective initiatives to coordinate the member states' response to the pandemic (see e.g. Adler 2020; EU Reporter Correspondent 2020). The Union's coordinated response to the second wave in autumn 2020 was a far cry from the first response. Are these signs of transnationalism - "Trump's virus" trumped - and a nascent community of shared fate with its own complex public spheres and repertoires of (niched) identities?

\subsection{EU Democracy, Public Sphere(S), Nationalism and Transnationalism: Juxtaposing and Mixing Identities}

In Section 4.2, we wondered whether a greater sense of unity and solidarity is gradually emerging in the EU, and whether this would help it fulfil its democratic potential. Crucially, we wondered about the part played by language in this process. Different answers have been sketched in different disciplines. In political theory, an influential line of thought links John Stuart Mill, Karl Deutsch, Jürgen Habermas and Dieter Grimm in the belief that a common political culture, a "community of communication", a public sphere - in the Habermasian sense of Öffentlichkeit (Habermas 1962) - are prerequisites for democracy. In other words, without a shared communication forum which is open to all and through which the people can challenge and influence political decision-making, there can be no EU democratic community. In this scenario, language plays a decisive role, for one such community needs a common 
language to fulfil its democratic potential (see van de Steeg \& Risse 2010; Kraus 2011, 21-22; Wright 2011).

Against the backdrop of this line in political theory and Robert Dahl's wellknown democracy criteria (Table 4.1), we realise the extent of the challenge facing the EU (see also Warren 2004, 213).

Due to space constraints, I cannot go into the (dissonant) citizenship requirements across the member states. However, let it be noted that awareness of the inconsistencies inside the bloc and of the often exclusionary measures in place in many member states dovetails with the minority issues raised in Chapter 2. For more on this, refer to Étienne Balibar, who speaks of a "virtual European apartheid" in this respect, as "the other face of the development of the European Union and its quest of identity" (2004, x, 65). His analysis is particularly interesting because it links the EU's democratic deficit to its treatment of citizenship. One of his arguments is that the EU will have to

Table 4.1 Dahl's democracy criteria in the EU

\begin{tabular}{|c|c|c|}
\hline $\begin{array}{l}\text { Democracy } \\
\text { criteria }\end{array}$ & Description & In the EU \\
\hline $\begin{array}{l}\text { Effective } \\
\text { participation }\end{array}$ & $\begin{array}{l}\text { "equal and effective oppor- } \\
\text { tunities for making ... } \\
\text { views known” }\end{array}$ & $\begin{array}{l}\text { Theoretically, all EU citizens can } \\
\text { make their views known through } \\
\text { public consultations and European } \\
\text { Citizens' Initiatives - provided that } \\
\text { they use one of the } 24 \text { official } \\
\text { languages }\end{array}$ \\
\hline Voting equality & $\begin{array}{l}\text { "equal and effective oppor- } \\
\text { tunity to vote" }\end{array}$ & $\begin{array}{l}\text { All EU citizens can vote in the Eur- } \\
\text { opean Parliament elections - but the } \\
\text { parliament does not have traditional } \\
\text { parliamentary powers }\end{array}$ \\
\hline $\begin{array}{l}\text { Enlightened } \\
\text { understanding }\end{array}$ & $\begin{array}{l}\text { "equal and effective oppor- } \\
\text { tunities for learning about } \\
\text { the relevant alternative } \\
\text { policies and their likely } \\
\text { consequences" }\end{array}$ & $\begin{array}{l}\text { The lack of information made } \\
\text { available by the EU in languages } \\
\text { other than English, coupled with the } \\
\text { fact that only about } 9 \text { per cent of } \\
\text { EU citizens are proficient in English, } \\
\text { excludes many }\end{array}$ \\
\hline $\begin{array}{l}\text { Control of the } \\
\text { agenda }\end{array}$ & $\begin{array}{l}\text { "exclusive opportunity to } \\
\text { decide how and, if they } \\
\text { choose, what matters are to } \\
\text { be placed on the agenda" }\end{array}$ & $\begin{array}{l}\text { Without full access to information, } \\
\text { there cannot be equal chances to } \\
\text { control the agenda }\end{array}$ \\
\hline $\begin{array}{l}\text { Inclusion of } \\
\text { adults }\end{array}$ & $\begin{array}{l}\text { "all, or at any rate most, } \\
\text { adult permanent residents } \\
\text { should have the full rights } \\
\text { of citizens that are implied } \\
\text { by the first four criteria" }\end{array}$ & $\begin{array}{l}\text { Permanent residents are excluded; } \\
\text { only adult citizens are included, but } \\
\text { they will struggle without profi- } \\
\text { ciency in English - both as ordinary } \\
\text { citizens trying to obtain information } \\
\text { and as MEPs trying to get their } \\
\text { voices heard }\end{array}$ \\
\hline
\end{tabular}

Source: First and second columns: Dahl (1988, 37-38). 
become more democratic than the member states to succeed, and that this democratic surplus must be accessible to all who “'happen' to live and therefore work, bear children, support relatives, find partners for every sort of 'intercourse'" in the member states (ibid., 132). In his view, the EU's problematic and conflicted stance on citizenship will block "European unification as a democratic construction" (ibid., 170).

As for enlightened understanding, a recent Eurobarometer survey reveals that more than three-quarters of EU citizens would like "to receive more information on the activities of the European institutions", particularly on " $[\mathrm{t}]$ he concrete consequences of EU legislation at local, regional and national level" and on "the activities of the European Parliament and its Members". Additionally, three in 10 respondents claim they would engage more with the activities of their MEPs if they received "more information on their roles and activities, or [saw] them more often in the media" (European Parliament 2019b, 61-73).

The EU's democracy challenge materialises in - and is compounded by - the five aspects of the EU's “demos problem”, sketched by Kraus (Table 4.2).

For Grimm, language is indeed the main source of the demos problem - the missing link in the EU's public sphere (see Kraus 2008, 22-23). Because he sees language as nation-bound and expressive, there can be no transnational, instrumental alternative to break the deadlock. Unlike Grimm, Habermas believes that language can transcend nation-related expressive bonds, famously commending transnational networking in English as Europe's "second first language" (Habermas 2006, 104; see Section 1.5). The tension between this nation-bound, expressive field, represented by Grimm and the transnational, instrumental field, championed by Habermas, is the tension between unity and multiplicity. Whereas Habermas's call for English to become the EU's second

Table 4.2 Kraus's demos problem

\begin{tabular}{lll}
\hline Problem & Description & In the EU \\
\hline Boundaries & $\begin{array}{l}\text { Clearly demarcated territorial } \\
\text { boundaries }\end{array}$ & $\begin{array}{l}\text { The EU is an unfinished, open } \\
\text { process of integration }\end{array}$ \\
Historical & $\begin{array}{l}\text { Shared historical experience, a } \\
\text { shared consciousness and collective } \\
\text { memories }\end{array}$ & $\begin{array}{l}\text { Though present in the EU to } \\
\text { some extent, these are seen as } \\
\text { prerogatives of the state }\end{array}$ \\
Solidarity & $\begin{array}{l}\text { Faith in the state and solidarity } \\
\text { towards fellow citizens based on } \\
\text { shared political identities }\end{array}$ & $\begin{array}{l}\text { This remains stronger within } \\
\text { than beyond national borders }\end{array}$ \\
& $\begin{array}{l}\text { Community cohesion for mino- } \\
\text { rities to accept majority decisions }\end{array}$ & $\begin{array}{l}\text { This, too, remains stronger } \\
\text { within than beyond national } \\
\text { borders }\end{array}$ \\
& $\begin{array}{l}\text { Communities of communication in } \\
\text { Language }\end{array}$ & $\begin{array}{l}\text { The member states remain the } \\
\text { sites of public deliberation }\end{array}$ \\
\hline
\end{tabular}

Source: Kraus (2008, 24-25). 
first language pushes for unity, Grimm's defence of linguistic diversity urges multiplicity. Both views are understandable and indispensable: Grimm's "defensive posture" may be "inspired by the model of the homogeneous nation-state" but gives due weight to language as a constitutive element of our identity; Habermas's "offensive strategy" may neither "bridg[e] [nor] respect $[\mathrm{t}]$ the diversity of linguistic identities" but puts faith in Europe's transnational bonds beyond language-specific affiliations (Kraus 2008, 144). In a way, this is also the tension between relativistic and universalist theories of language, discussed in Chapter 1 - universalism seeks common traits to unite us, whereas relativism reaffirms and celebrates our differences. Can we "inscribe the alliance of these two imperatives" (Derrida 1992, 44)?

It is not that Habermas sees the nation-state model as outdated; rather, he believes transnational ties of "solidarity among strangers" can be forged much like in the process of state-formation in Europe in the nineteenth century (quoted in Ives 2004, 23). In his view and that of others too, there are key features shared across the EU despite linguistic and cultural differences, such as secularisation, the welfare state, the desire for an international order, along with faith in the state, the rule of law and human rights (Habermas \& Derrida 2005, 9). Eco highlights "the Greek and Judeo-Christian heritage", such notions as "freedom and equality", "modern science", "the capitalistic form of production" and "justice achieved through class struggle" $(2005,15)$. Gianni Vattimo adds "the gene of 'socialism'" to the list $(2005,32)$, while for Jean-Pierre Faye, Europe simply is the place "where there is no death penalty" (quoted in Savater 2005, 43).

Obviously, an emphasis on our similarities always risks homogenising our differences and downplaying the influence of other factors - Islam, for one - in the formation of Europe (Kraus 2008, 39). Still, it is telling that what brings EU citizens together is perceived as more important than what separates us - at least according to different EU surveys (see e.g. the 2019 Flash Eurobarometer "Emotions and political engagement towards the EU", Standard Eurobarometer 89 and Special Eurobarometers 451, 467, 476; all Eurobarometer survey results can be accessed via the GESIS Eurobarometer Data Service, available at: www. gesis.org/en/eurobarometer-data-service/home.). Also, in these surveys, democracy, the rule of law and human rights are systematically ranked highly as the EU's main assets. Therefore, it seems clear that the basis for the formation of transnational ties is given. Do we need a common language to achieve that, as Habermas suggests, or are we trapped in "ontological nationalism" and the "absolute incommensurability of languages", as Grimm's view, when taken to its limit, implies (Cassin 2014, xviii; see Section 3.5)?

Politically speaking, this dilemma is encapsulated in what Kraus calls "thin nationalism" - i.e. "a 'banal' phenomenon" and "a general organizing principle of modern societies" - versus "transnationalism" - i.e. "a new political configuration of identity options", whereby "cultural identities below and beyond the nation-state level" are articulated $(2008,64)$. Through this prism, the EU's political ethos is grounded in the search for a transnational and a national volonté de tous, which do not coincide at all times (see ibid., 75). 
Normatively, the goal of coordinating these two common goods is colossal, as the 2020 coronavirus pandemic illustrates very well. However, therein lies the potential for any community or union, big or small.

The tension between nationalism and transnationalism begs the question of (especially national) identity. As argued in the previous chapters and repeated in contemporary linguistics, anthropology and political theory, "identity" - like "language" - are constructs, convenient labels concealing immense complexity. Jan Blommaert reminds us that identity is always a dynamic "repertoire of different possible identities" undergirded by "multiple, often unpredictable and volatile identity work" which we perform all the time (2006, 245). From this perspective, national identity is inevitably "niched", "encapsulated in and interacting with many othe[r]" activities and factors (ibid., 249).

If we agree with Blommaert, the ideal of a common (national and/or political) identity as a prerequisite for the formation of a public sphere in the EU is severely compromised. Indeed, recent studies on the Europeanisation of national platforms (chiefly the media) suggest that national and transnational public spheres exist simultaneously. There is evidence of a European public sphere "being constructed through social and discursive practices [in national media], creating a common horizon of reference", "a transnational community of communication" and "similar meaning structures across countries and ... different media sources" - and, crucially for us here, across different languages (van de Steeg \& Risse 2010, 2, 6). Multiple studies demonstrate that the treatment of EU-related issues in EU newspapers, for example, does not follow national lines. Instead, a range of views is encountered throughout the EU, distributed not by member states but by other "background characteristics" such as a right or left-wing orientation (ibid., 11).

Additionally, and this point is key, EU and non-EU media coverage of EU events are clearly different: "when it comes to questions that concern 'us' as ... EU citizens, these themes are indeed being discussed at the same time, at similar levels of attention and using similar frames of references and meaning structures" (ibid., 13-14). Therefore, despite the language issue, there already seems to be a public sphere in the EU, one which fulfils Habermas's criteria of Öffentlichkeit and whose formation is being accelerated by social media (see e.g. Dutceac Segesten \& Bossetta 2019; Hänska \& Bauchowitz 2019). Perhaps Williams is right: living together in a community of shared fate suffices to make us see "our own lived experiences of social practices and institutions" and "our narratives about those experiences ... as entwined with the experiences and narratives of others”, regardless of the languages we speak $(2004,106)$.

The Europeanisation of national (and social) media reveals just how niched identity can be. When certain EU-related issues emerge, a common horizon and a shared meaning framework arise throughout the EU; these exist alongside - in interaction with but not encroaching upon - other possible national, regional, local common horizons and frameworks of shared meaning. These "repertoires of different identities", to borrow from Blommaert (2006, 245), are in constant interaction and formation, much like the EU and its member 
states. Most importantly, these different identities are not strictly languagebound; they are language-bound inasmuch as language plays a key part in our identity repertoires, but not to the extent of precluding different identity layers from being shared across multiple language communities. It follows that the EU does not need a common language because a public sphere - underpinned by and underpinning complex, niched identity repertoires - already exists across the EU, however incipiently.

There can be no "European identity" as such, as a static set of features often rooted in the past - which intrinsically unites people. The "demos problem", sketched in Table 4.2, is based on the traditional nation-state model, founded on the "cuius regio, eius lingua" principle and centred on several key constructs, notably a shared national identity and language. But there need not be a "European identity" or a shared language, as argued earlier. Ideally, we have in the EU a feeling of "attachment to a transnational context that [enables] a Belgian of Moroccan descent as well as ... an Italian to regard themselves as political equals in a community that has no wish to level [their] differences" (Kraus 2008, 191). This bond "must not be confused with an illusory multicultural paradise" or "a magical tool for generating consent"; at best, it can "foster an intercultural willingness to learn" (ibid., 191). Here, the question of language dovetails with our willingness to accept others as others, and to conceive of all the groupings to which we belong (be they our families, workplaces, circles of friends, cities, states, nations or the EU) as unions in which we get to keep our otherness while striving for unity - well aware that pure unity is not desirable. In Section 4.8, we will see what this union that accommodates otherness might look like in relation to language.

Yet, to be "political equals in a community that has no wish to level [our] differences" (ibid., 191), we need an approach to diversity which neither homogenises and obliterates our differences (diversity as mixing) nor merely places them side by side (diversity as juxtaposition). In other words, as Astrid von Busekist puts it, "[w]e want to avoid diversity that is detrimental to vulnerable communities which are dominated by hegemonic groups [diversity as mixing], but we also want to achieve meaningful diversity without simply juxtaposing entities [diversity as juxtaposition]" (2018, 313). We need "meaningful diversity", with parity of participation and parity of esteem, but "[p] arity of participation is only possible by downplaying differences" whereas "parity of esteem can only be achieved by recognizing the equal moral weight of all participants regardless of their language skills” (ibid., 313). In her view, diversity in the EU is tantamount to mere juxtaposition, a collection of disconnected uniformities, as argued in Section 2.8 and Section 3.8, and this "enhances the centrality of English" (ibid., 314; see Laponce 2001). Is there an alternative?

Perhaps the first step should be to acknowledge that a no-policy language policy is an illusion, first, because decisions about language cannot be avoided language cannot be replaced with no language - and, second, because of our "institutional linkages" and the political consequences of the EU's internal 
language policies and practices (Williams 2004, 105). "Which specific communication rules hold within European civil society may ultimately be less important than how these rules are formulated and implemented" (Kraus 2008, 179). If the EU's internal language regime continues to be reduced to English in a seemingly ad hoc fashion, despite Brexit and without public debate or overt language policies, then the democratic deficit is likely to increase, becoming the "Achilles' heel of democracy" (Ives 2004, 27). In this scenario, a re-nationalisation of Europe is not unthinkable: if "English become[s] a genuine competitor for the national languages in key areas of administration and education", leading to a "thoroughgoing Europeanization of diglossia", the very least we can expect is for nationalistic agendas across the political spectrum to capitalise on it - the consequences of which can be but anticipated (Kraus 2008, 175). In Section 4.8, the transcultural turn will be presented as a set of alternatives to the question of linguistic diversity in the EU. In Section 4.4, let us focus on language contact and dynamic in the EU.

\subsection{Language Contact and Language Dynamic: Ligatures Without Options}

If we agree that the EU does not require a common language to fulfil its democratic potential and establish ties of solidarity among the citizenry, what linguistic diversity is possible in the bloc today? At the moment, the EU institutions' language policies, de facto practices and presumed ideologies reveal an increasingly diglossic ${ }^{5}$ scenario centred on English as a lingua franca - a status quo which both reverberates in and is perpetuated by member states' emphasis on the model of the national language(s) plus English.

Every term since 2008, I ask my BA and MA students at the Centre for Translation Studies of the University of Vienna which languages they are taking - usually German plus one or two others. In 2020, for the first time, 100 per cent answered "English". In 2012, for example, the proportion was 64 per cent (out of around 100 students who attended my classes). This choice is often linked to the students' school history, as B2/C1 exams in the languages chosen are prerequisites to enter university. When most schools at most levels teach most pupils English, it is hardly surprising that most translation students go on to study English.

More significantly, a recent Facebook survey on home languages among Cumbuca members - a group of over 1,000 Brazilian women residing in Austria - revealed that English is the sole home language of 27 per cent of respondents and one of the home languages of another nearly 9 per cent. Some 25 per cent have German and 15 per cent Portuguese as their sole home language; 20 per cent answered: "German and Portuguese 50-50", 3 per cent said: "German and sometimes English", 3 per cent said: "Portuguese and sometimes English", 3 per cent said: "English and sometimes German", 2 per cent said: "German and sometimes Portuguese", almost 2 per cent replied: "other languages" and nearly 1 per cent said: "Portuguese and sometimes German". 
According to Natalie Machado Rios, one of the group's founders, most of these women are mothers and have Austrian partners. Let us bear in mind here that English - albeit Brazil's most widely taught foreign language - is not spoken by a significant portion of the population: 5.1 per cent claim to have some knowledge, of whom only 16 per cent consider themselves proficient users (British Council 2014, 7-8). Cumulatively then, less than 1 per cent of Brazilians speak English well; still, English has been chosen as the home language by more than a third of these Brazilian women living in Austria. It is difficult to imagine that a completely different language dynamic exists in other comparable circles in the EU.

To try and tease out the motivations behind this trend towards English, I conducted a poll among my own friends and acquaintances in Austria and Germany whose home language is English but who are not inner- or outer-circle speakers - 23 families altogether. These families are all couples aged 30-45, either childless (two) or with children under 10 (21), most of whom are from the EU. The most common set-up was one German speaker and one speaker of another language (such as Bulgarian, Italian, Romanian and Russian). In a few cases, neither were German speakers. ${ }^{6}$

When asked why English is their home language, all replied that their knowledge of their partner's preferred language was limited, and that English was their common denominator. When asked whether they had enough passive skills in their partners' language to rely on passive bilingualism (or intercomprehension), most (17) admitted that they did but found it odd to speak in two different languages. Many (15) also mentioned the reluctance to change the language the couple used originally (invariably English) - a phenomenon described by Bernard Spolsky as "inertia condition" (1991, 146).

From the parents polled (21), all believe that their children can speak English just as well as their other language(s), while many (16) admitted that they expose their kids to as much, or more, English-speaking material (books, videos, songs, games) as to material in the other family language(s). Almost all parents (20) feel that English is a more useful language for the child than their mother tongue(s), even though some (11) also stress that they want their children to form an emotional bond to their mother tongue(s). From these, all pointed out that they found it difficult to speak their preferred language with their children instead of English, both because they more or less conduct their lives in English anyway, and because older children tend to prefer English. From these 21 families with children, five have all but replaced their other languages with English; 10 have added English to the family repertoire and admit it is the most spoken language by everyone; and six have added English to their home language(s) and feel it is used just as often as the other language(s).

These preliminary, informal findings unveil a picture that matches the one provided by large-scale studies, such as the Eurobarometer survey mentioned earlier, according to which 79 per cent of parents consider English one of the two most useful languages for their children's future (European Commission 2012a, 141). More data is urgently needed here, but if this trend is confirmed, 
English can no longer be portrayed as a mere instrumental tool in the EU. Indeed, in Section 1.9, we wondered about the phenomenon of ELF (English as a lingua franca) as a mother tongue. These children being brought up in English in the expanding circle by expanding-circle parents are growing up surrounded by English both at school and beyond the school's gates. When they move out and choose their home language(s), it seems unlikely that any other language - perhaps except for German here in Austria - will stand a chance, unless language practices and ideologies change dramatically in the coming years.

There is consensus in language policy research that migrant languages are usually dropped at the latest by the third generation (see e.g. Spolsky 2004, 44). Moreover, the overwhelming evidence in different disciplines is that diglossia in situations like these tends to be unstable and detrimental to less "robust" languages unless language policies are introduced to balance the scales (see e.g. De Swaan 1993; Phillipson \& Skutnabb-Kangas 1994; May 2006; Kraus 2008, 175; Van Parijs 2008; Trabant 2010; Edwards 2013; Kraus 2018; see also Ricento 2006). More research is needed to ascertain language shift in the complex settings surveyed here, i.e. national language plus English, national language plus migrant language plus English, migrant language plus English. Though underreported, the issue of diglossia with English in the EU is not a new phenomenon and has been unfolding for several decades. Robert Phillipson and Tove Skutnabb-Kangas $(1994,82)$, for example, report from the mid-1990s that it is indeed "imminent" and already visible in Scandinavia. For them, a "diglossic division of labour", whereby English is seen as a more adequate, efficient and prestigious language in increasingly more areas," "marginalizes the state language" and can displace it.

As Spolsky notes in relation to the revitalisation of Hebrew in Israel, "the decision on home language use, at the family level, is ... one of the most critical in determining the status of a language" (1991, 139). Hebrew, an official language in Israel, is hardly comparable with English in the EU; still, the combination of factors that led to the successful revitalisation of Hebrew are very much present in the EU - notably presence in the education system, along with opportunities and incentives to speak the language outside the classroom and, increasingly more, in the home, too. In the EU, however, the territoriality principle may slow the process of displacement of local languages by English. Yet the fact that across the EU everyone is learning the same second language obviously "hinders the effective implementation of the linguistic territoriality principle" (Van Parijs 2008, 37; more in Section 4.5).

Why do people willingly choose to replace their home languages with English - and why should we care? Kraus's (2018) theory of languages as "ties" and "gates", based on Ralf Dahrendorf's theory of options and ligatures, offers an interesting answer. According to Dahrendorf, our "life chances" - in the Weberian sense of opportunities to improve our lives - are contingent on a certain balance between our allegiances, emotional ties or bonds ("ligatures") and the real choices available to us ("options"). Ligatures provide meaning to 
our actions and positions in society, whereas options determine the framework of possible actions. Dahrendorf warns that "ligatures without options are oppressive, whereas options without bonds are meaningless" (Dahrendorf 1979, 31; see also Kraus 2018, 95).

Kraus applies Dahrendorf's “options and ligatures” to linguistic diversity: the role of a certain language in our life chances is a result of the relational function between the options and ligatures entailed by that language. For Kraus (ibid., 94), a language can function as a "tie" and as a "gate", i.e. it can create "a basic tie between an individual and the life-world to which he or she feels emotionally attached", but it can also "operate as a gate to a universal koiné, to a virtually unbound community of speakers that provides them with an endless range of learning opportunities" - "especially if this language is a lingua franca". If our allegiances or bonds limit the number of options available to us, or if the options available to us are deprived of emotional attachment, a new balance between ligatures and options must be found - knowing that there can be no "zero-sum relationship" between the two (ibid., 95).

For Dahrendorf and others, modernisation entailed the erosion of ligatures coupled with the multiplication of options. Appling this to linguistic diversity, it seems that ligatures are in place whenever a language creates meaningful links to the speakers' life-world, however limited. The crux of the matter, if this analysis is correct, does not lie solely in the balance between one's ligatures and the options that they bring, but also in the conditions surrounding the establishment of these ligatures. Dahrendorf's (social) liberalism renders his theory somewhat one-dimensional as he does not enquire further into how and why certain ligatures are established or whether forging them was an option among viable options in the first place. Put differently, there seem to be options that precede ligatures and options that succeed ligatures. English may well open the most gates today, provide the most options that succeed ligatures; yet it also entails the fewest options that precede ligatures, because whether or not to adopt it is often a non-choice as there is no viable alternative. ${ }^{8}$

Through the question of diglossia, the dynamic between options and ligatures becomes evident. A "higher" language usually entails more options than a "lower" language, in relation to which there are probably more ligatures to begin with. The more options are associated with the "higher" language, the more the allegiances to the "lower" language shift towards the "higher" language. Real, viable opportunities and incentives to use the "lower" language are needed to tip the scales in its favour - even though we know that a zerosum relationship between "higher" and "lower" languages is impossible. ${ }^{9}$ The theory of options and ligatures also poses some uncomfortable questions about EU multilingualism: what of this multilingualism (ligatures) without real, legitimate, equally valid and beneficial opportunities to use these languages (options)? When the only viable options remain the member states' official language(s) and, in many realms, only English, ${ }^{10}$ then the EU's approach to multilingualism is oppressive, to come back to Dahrendorf. 
Here, the Laponce mechanism, summarised by Philippe Van Parijs as " $[t]$ he nicer people are with one another, the nastier languages are with each other", sheds light on the phenomenon of English displacing home languages in the EU (Van Parijs 2015b, 233; see Laponce 2001 and Fishman 1972, 84). In short, when languages come into peaceful contact, the odds in favour of the more powerful language displacing the less powerful are overwhelming. Unlike the situation at more local and regional levels, in which contact among languages is often riddled with conflict as minorities struggle for rights and recognition, at the supranational level 24 languages are guaranteed equal de jure respect (see Kraus \& Kazlauskaitè-Gürbüz 2014, 520). The compartmentalisation repeatedly mentioned here is key: well aware of the secure place that our languages (provided they are among the official 24) occupy in the EU, we believe that we can enjoy the gate-opening magic of English in various societal realms while reserving our mother tongue(s) for more intimate settings. Following Laponce, if speakers felt their place in the sun were under threat, they might demand more viable options to their existing ligatures. ${ }^{11}$ In the end, equal $d e$ jure respect exacerbates the detrimental effect of ligatures without options in the EU.

But does it matter that English is displacing languages in classrooms, workplaces and homes? One could argue, as, for instance, Van Parijs does, that " $[\mathrm{n}] \mathrm{o}$ one's honour or dignity is being threatened if a language with whom no one identifies is ... left to agonize and die" (2008, 37). As we will see in Section 4.5, he welcomes the fact that Europe may "be approaching a situation analogous to the terminal stage of many 'dialects', whose native speakers were persuaded to identify with a more or less cognate grander language”. A similar view is held by the ELF paradigm:

[If communities] prefer to embrace what they perceive as progress as represented by the materialism of global capitalism, then as their values change, so will their language, and to the extent that English is the language of this materialism, so it is bound to intrude and gradually dominate.

(Schendel et al. 2003, 181)

For ELF proponents, the English spreading across the EU is not an inner-circle variety, with its particular repertoires of cultural and ideological markers, but rather a lingua nullius - the expression coined by Phillipson (2018) and based on the notion of terra nullius [from Latin, "nobody's land"]. Through the theory of options and ligatures, ELF becomes a meaningless option without any ligatures or emotional bonds. After all, if ELF speakers' ligatures lie exclusively with their mother tongue(s), as ELF proponents have it, then ELF opens many gates without creating any significant links between its speakers and their life-world. However, as English spreads through multiple realms, and as expanding-circle speakers start choosing it as their home language, it seems untenable that English is merely an empty option, a vessel deprived of ligatures. 
As argued repeatedly here, we all speak multiple "languages" - perhaps "national languages", perhaps different dialects, sociolects, registers, etc. of the "same" language. Interacting in these languages, experiencing and creating culture and ideology, being exposed to input, forming our identities in and through these languages do not form a static, neat process through which some languages are consciously deprived of ligatures whereas others are not (see e.g. the contributions by Will Baker, Eric S. Henry, John O'Regan and Karen Risager in Holmes \& Dervin 2016). One could of course reasonably argue that very superficial, limited uses of language may be deprived of ligatures. My Russian, for example, is enough to exchange a few sentences; I cannot consume cultural goods in Russian or express myself in it; there are no ties between it and my life-world. But ELF proponents defend that all English uses in the expanding circle, simple or complex, basic or advanced, are neutral, ligature-deprived ELF. Yet, the more a language creates a tie to one's lifeworld and the more it pervades one's life, the more ligatures it entails.

Peter A. Kraus and Rūta Kazlauskaitè-Gürbüz stress that this dynamic between language ligatures and ties should not be left to market forces, urging the EU to "create options, while maintaining ligatures" and to "provide us with linguistic gates, while allowing us to cultivate our linguistic ties" (2014, 524). Which brings us to the issue of "meaningful linguistic diversity" addressed earlier (von Busekist 2018). Currently, it is not only diversity as juxtaposition that is in place in the EU. On the one hand, increasingly more people are learning the same second language ("mixing"); on the other, member states cling to their national languages ("juxtaposition”), thus also entrenching English as their lingua franca. Similarly, at the EU level, we have de jure multilingualism ("juxtaposition") and de facto monolingualism ("mixing”). There will most likely always be a mixture of both: the fact that one holds de jure legitimacy, whereas the other enjoys de facto power, goes to say that they are both important. My suggestion is that we heed Derrida's call and circumvent this morass by creating new gestures which go beyond simple reversibility between these two poles and protect ligatures while creating more options (more in Section 4.8) - not least because of the linguistic injustices caused by the dominance of English in the bloc.

\subsection{Linguistic Justice: English as Friend and Foe}

Let us open this section with a scenario, sketched by Van Parijs, in which the developments outlined in Section 4.4 are exacerbated by lifting the territoriality principle and giving English free rein (2015b, 242):

In a high-mobility, high-contact world, lifting the territoriality principle would no doubt eventually result in flattening the linguistic surface of the earth. But this would amount to nothing more terrible than turning the whole planet into a large number of Republics of Ireland, with only vestiges of the local languages - in the names of most places, many people, 
and a few institutions - and with a somewhat idiosyncratic way of pronouncing the lingua franca, now promoted to mother tongue status. Why would it be such a loss, especially if matched against the tremendous economic and cultural advantages of sharing the same language worldwide?

The "economic and cultural advantages of sharing the same language worldwide", hailed by Van Parijs, are debatable, as he himself admits. There is evidence, for example, that the "Straight for English" approach adopted in many African nations has been detrimental on multiple levels, and there is no reason to believe that the situation would be much different in other parts of the world, such as in South America (see Romaine 2015). Moreover, the cultural advantages of English monolingualism are questionable on several accounts. For one, universal intelligibility seems highly unlikely, as already today different inner-circle varieties are not mutually intelligible. However, even if Van Parijs's "universal English" were kept unified by unprecedented, supra-human efforts of codification and standardisation, how desirable is this notion of culture largely deprived of diversity? Monolingualism in English would entail "the loss of the conceptual repertoires and cultural references associated with all the languages", to mention only one obvious and significant drawback (Grin 2015, 136; see also Trabant 2010, 896).

Different studies show that a multilingual world is more efficient and fairer than a monolingual world, and that the benefits of multilingualism outweigh its costs (see e.g. Grin 2010; 2018). Multiple ligatures (to multiple languages) may enhance our life chances - provided these ligatures are coupled with options. When languages are displaced, it is not languages that suffer, but their speakers; it is the speakers' ligatures that are lost. Let us not forget that our ligatures give meaning to our actions and place in the world - they are intimately connected with our sense of dignity and self-esteem (see Kraus 2008, 81). In this context, linguistic justice is key.

In the "first monograph" devoted to this issue (De Schutter 2018, 168), Van Parijs (2011) proposes a tripartite division of linguistic (in)justice: (1) cooperative (in)justice (i.e. the effortless, costless benefits enjoyed by native-speakers thanks to the learning efforts of non-natives); (2) distributive (in)justice (i.e. increased opportunities and financial gains to native speakers given the increased value of their mother tongue); and (3) (dis)parity of esteem (i.e. the more privileged position of native-speakers to the detriment of non-natives and the concomitant effect on one's self-esteem and dignity). He notes that all three injustices are present in relation to English in the EU, for example, but remains a stark defender of English as the world's lingua franca because so many people around the globe already speak it to some degree.

Van Parijs argues that the more people speak a given language, and the more widespread the use of this language, the more likely it is that others will choose to learn it and have the "motivation" and the "opportunity" to make progress learning it - a principle he calls "probability-driven language learning" (ibid., 11-13). The reader might have noticed a similarity with De 
Swaan's well-known notion of Q-value here, or the communication potential of a language. The higher the "plurality" and the "centrality" of a certain language, the higher its communication potential or Q-value; put differently, "the higher the number of speakers [of a language], the more attractive the language” (De Swaan 1993, 246-247; 2001, 33).

Van Parijs complements this picture with the concept of "maxi-min language use": in multilingual settings, we tend to speak the "language ... best known by the member of [our] audience who knows it least well", or the language of "maximal minimal competence" $(2011,14)$. For Van Parijs, probability-driven language learning and the maxi-min criterion ensure that English is learned and used across the globe (instead of any other language), placing it in a steadily accelerating motion which, unless interrupted by external forces (such as language policy), will continue indefinitely, exacerbating those three injustices. $^{12}$

So how can we compensate for linguistic injustice while at the same time tapping into English as a global resource? Van Parijs proposes a language tax to be imposed on "countries ... in proportion to the number of English native speakers they house" and whose proceeds should be distributed "among other linguistic communities" (ibid., 76). ${ }^{13}$ Admitting that English-speaking countries would never concede to adopting such a tax, Van Parijs advises "compensatory poaching" of English-speaking materials instead, especially on the web. This means "accessing useful information [in English] without compensatory payment” (ibid., 79, 81).

Van Parijs emphasises, nevertheless, that whichever compensatory measures are taken, they will gradually become superfluous, as the number of competent English speakers increases around the globe. Rather than focusing on mitigating the dominance of English or compensating for the injustices caused, he stresses the importance of embracing English and democratising and accelerating learning for all non-Anglophones - chiefly through immersion schooling and banning dubbing - while at the same time enforcing strict territoriality to ensure the longevity of national languages alongside English.

Yet he admits that territoriality becomes tricky in places like the EU, in which an ever-growing portion of the population share a second language (Van Parijs 2008, 37). As "local linguistic diversity" increases with the addition of English to a people's repertoire, "inter-local diversity" decreases as various peoples speak the same lingua franca and as this lingua franca gradually brings people's languages closer through language contact (Van Parijs 2011, 185-188). In this scenario, all languages other than the lingua franca become minority languages, which in turn pushes today's minority languages (i.e. regional, nonterritorial and migrant languages, or any languages that do not enjoy territorial majority) over the edge of the cliff as collateral damage. ${ }^{14}$ Van Parijs's model admittedly damages local diversity in the long run as well, as implementing the territoriality principle may secure some inter-local diversity at the expense of local diversity (see e.g. De Schutter \& Robichaud 2015b, 103-104). Also, considering that schools are one of the key implementers of the 
territoriality principle, replacing them with English immersion schools would be at odds with the goal of preserving national languages.

Van Parijs is openly not a defender of linguistic diversity in and of itself. As the quotation that opens this section suggests, he believes languages should only be maintained if their communities demand recognition on grounds of dignity and self-esteem. He largely disregards the forces that persuade, coerce or compel communities to form ligatures to a new language, often to the detriment of their old ligatures. When home languages are replaced by English or by any other majority language out of a sense of inevitability, or as a result of an absence of options, the lack of support by their own speakers is not simply a matter of personal choice, but rather a loss motivated by complex cultural, political and socioeconomic factors. To mention a drastic example: when local languages gradually lost support from their own speakers in the Spanish colonies of America in the wake of the Real Cédula of 16 April 1770 (a royal decree whose explicit purpose was to suppress these languages), can we say that the language deaths and loss of ligatures that ensued do not matter because, in the end, people were "persuaded" to switch to Castilian anyway?

The pitfalls of linguistic justice with English as the world's lingua franca have been debated at length by numerous scholars (see e.g. Gosseries \& Vanderborght 2011; De Schutter \& Robichaud 2015a). It must be added that Van Parijs's notion of "English" seems far too idealised. He may admit that "English" is in fact more plural than he makes out (see Van Parijs 2015a); still, my experience of English being used as a lingua franca of sorts has often made me wish people used languages in which they feel more comfortable instead, for everyone's sake. Anyone in academia is probably familiar with English-only academic events which often leave us wondering about the quality of some of the presenters' research until we hear them speaking about it in another language. Granted, Van Parijs's maxi-min criterion ensures the highest levels of (superficial) intelligibility. But is it always better to communicate very little to the widest possible audience, who in turn might understand only a fraction of this "very little"? And if efficient and effective communication is so important, why is interpreting undervalued and underused, particularly in academia? ${ }^{15}$

Can Van Parijs's "English" really bridge gaps in communication and act as the world's common denominator, facilitating exchange, trade deals, transnational solidarity and even contributing to global democracy and global justice? Is it realistic to expect significant portions of the world's population to become proficient in a "lingua franca" while at the same time preserving other languages, in some utopian stable diglossia? In a world in which languages are dying at an unprecedented pace, 750 million people are illiterate and more than two billion are functionally illiterate ${ }^{16}$ This is a tall order - even for Europe. As Kraus very aptly puts it, there is quite a bit of normative wishful thinking in Van Parijs's theories (private communications).

Here, François Grin offers an interesting counterpoint to Van Parijs's views. Focussing on linguistic justice in the context of the spread of English particularly in Europe, Grin identified five key types of transfers enjoyed by native speakers, displayed in Table 4.3. Together, these "uncompensated transfers in 
Table 4.3 Transfers enjoyed by native speakers of English

1 Privileged markets

Quasi-monopoly over translation/interpreting and English teaching branches, including exchange programmes, materials, etc.

2 Communication sav- No translation/interpreting expenditure for native speakings effort ers as non-natives make the effort and financial investment to learn English

3 Language learning Because English is so widely spoken, native speakers do savings effort not need to invest the time and money in learning additional languages

4 Knock-on effects Time and resources allocated to translation/interpreting services, language learning and foreign language teaching (e.g. in school curricula) can be devoted to something else

5 Legitimisation effects Native speakers are almost always in a better position to control the agenda, negotiate, influence others, etc. as their language "carries intrinsic legitimization"

Source: Grin (2015, 132-134).

favour of the United Kingdom" amounted to 17 billion euros in the EU alone back in 2005 - and this is a "conservative" estimate (Grin 2008, 80).

As regards school curricula, Grin (2015, 133-134), explains that continental European countries

typically teach two foreign languages to $95 \%$ of their school-going population. The corresponding expenditure averages $10 \%$ of total educational spending ... By having largely abandoned the requirement for schools to teach foreign languages at all, the English education system ... saves roughly $6 \%$ of total spending, This, of course, is at the expense of learners of English, in Europe and beyond, who learn it as a foreign or second language, at significant public, and often private, expense.

As for legitimisation, Paul Kaye, former language officer at the now defunct European Commission Representation in the UK, reminds us of the other side of the coin. Growing up as an English native speaker has a "more subtle and insidious disadvantage":

You are not forced into having to think in another language, into having to communicate in another language, and so you don't develop all the skills that come with having to do that, you don't develop the insights into other cultures, into other ways of expressing yourself, you don't develop that mental flexibility of slipping into and out of different languages.

He worries about generations growing up without this "mental, intellectual stimulation” in the UK (private communications). 
Grin, for his part, stresses that legitimisation effects are the hardest to quantify but probably the most significant. Indeed, Nicholas Ostler, for example, attributes the privileged position of English today "above all to the global prestige of its speakers" (2010, 25). Native-born Anglophones are often overrepresented in key positions across large enterprises and international organisations. In 2010, 42 per cent of the EU commissioners' spokespersons were native speakers of English (Grin 2015, 134-135). ${ }^{17}$ Grin's studies and others confirm, however, that acquiring English does not necessarily entail financial advantages and social mobility to all individuals in all contexts; in fact, very few jobs worldwide require knowledge of English. Therefore, the claim that English is becoming a basic skill, just like literacy, is questionable, since the number of jobs that require reading and writing skills is far greater (Graddol 2006; Grin 2015, 129).

From an allocative point of view, English proficiency can be advantageous for workers holding certain qualifications and working in specific areas, but so can proficiency in any other widely spoken language. In fact, in particular contexts, proficiency in other languages is linked to higher salary increments, such as in some Swiss and Belgian companies in which there is more demand for the other national languages (Grin 2015, 128). The crux of the matter lies in the distributive effects of the dominant position of English, which brings us back to the issue of linguistic justice: the benefits enjoyed by the inner circle exceed the weight of its population and generate linguistic injustices which, in turn, translate into financial, social and political injustices.

As a steadfast defender of multilingualism, Grin proposes different strategies to counteract the hegemony of English and promote linguistic justice in the EU, namely maintaining the EU's panarchic regime and the concomitant translation/interpreting services (see Section 3.2); adopting Esperanto (e.g. Grin 2008; 2011); and fostering receptive competences and intercomprehension skills within the bloc (e.g. Grin 2011; more in Section 4.8). Above all, he highlights the need for a complex set of well-coordinated measures in which English also plays a part.

Grin's defence of the panarchic regime, though coherent with the greater goal of maintaining and fostering multilingualism, sometimes seems to overlook two facts. First, only legally binding documents are translated into all official languages and, second, the distribution between source and target languages is in no way balanced. The regime is hence semi-panarchic, for it does not apply to all texts and has a clear bias towards English. Further, Grin's defence of Esperanto, based on the fact that it is "7-8 times cheaper and faster to learn than any other language" $(2008,62)$, could come across as too unrealistic - even though theoretically it would be an excellent alternative (see Bormann 1970; Phillipson 2003; Fiedler \& Brosch 2018). Yet just as people are reluctant to learn ELF - as a hybrid language detached from the inner circle - so too are they hesitant to invest time and resources into learning Esperanto, which they see as a de-territorialised language. Esperanto may tick different linguistic justice boxes: it "belongs" to no nation and so cannot accrue any financial gains to anybody; it is almost nobody's 
mother tongue, so everyone has to learn it more or less from scratch. ${ }^{18}$ Paradoxically, however, its detachment from communities of speakers anchored, however loosely, in a certain spatial-cultural framework, is not enticing for new learners. $^{19}$

It seems that neither the maintenance of the semi-panarchic regime nor the adoption of Esperanto represent attractive, viable and, at the same time, effective strategies to maintain multilingualism in the EU. Van Parijs's call to accelerate the spread of English does not give due weight to linguistic diversity, and his compensatory measures do little for linguistic justice. What is needed are rather measures to foster de facto multilingualism in the bloc, with more than one language used actively; a kind of multilingualism that taps into the EU's existing wealth, without necessarily adding planned languages to the mix. Grin's last cluster of suggestions - intercomprehension and receptive competences - seem the most promising for the purposes of this book and will be addressed in Section 4.8. One point is beyond dispute, though: English is here to stay, at least for now. Or is it not?

\subsection{The Future of English in the World: ELF, EFL, ELT}

Experts from different areas forecast that the end of the reign of English is imminent. Ostler's predictions are probably among the best known:

The forces making for the spread of English will soon peak, and the sequel will be a long retrenchment, as auxiliary English comes to be less widely used, but no single language takes its place. There is no convincing reason to think that the future of English will diverge from the pattern of all the great world languages that have preceded it.

(2010, xix)

On Ostler's account, the key driving force behind this impending peak is the will of "communities that historically have little or no link with an Englishspeaking community", i.e. the expanding circle, "to be taken seriously by the world, and especially by global economic players" (ibid., 29). In these contexts, English remains a lingua franca because "[t]here is no accepted, self-consciously asserted special style of English" (ibid., 43). In his view, when local varieties start emerging and entering people's homes, governments either "disregard" them or "suppress" them as unwelcome "pidgins" (ibid., 47, 52). In order to remain a "lingua-franca" with a hyphen - i.e. "a general means of contact between those whose mother tongues may be quite different" - "English needs to be kept at a healthy distance" so as not to become "too heavily influenced by the other [local] languages" (ibid., 29). Both because governments are not keen to establish new Englishes and because learners are drawn not so much to the English language as to a certain inner-circle way of life, Ostler does not believe that English could ever branch out into vernaculars like Latin did. And even if that were the case, it would probably become like 
Arabic, with lots of local varieties perceived as "more or less corrupt ways of speaking a single perfect language” (ibid., 39).

Others see potential in the emergence of local Englishes in the expanding circle. Because local expanding-circle Englishes present unique surface features, derived from the speakers' respective national and/or main languages, Helder De Schutter (2018), for example, suggests codifying and standardising them as local varieties of English within the World Englishes paradigm. He argues that this would contribute to linguistic justice in that speakers' dignity would be heightened: "What counts for dignity, for example, is that there should be a way to speak English whereby non-native speakers themselves determine what the norm is" (ibid., 191).

He concedes, nevertheless, that this solution would not improve other aspects of linguistic injustice. More importantly, he admits that the successful implementation of local Englishes would presuppose that one day an ideal state would be reached, in which all Europeans would speak their local variety of English just as well as their other local language(s); that these languages would co-exist in harmony (stable diglossia); that each nation would provide its own English-language teaching materials, along with translation/interpreting services, and cater to its own market; that learners would feel content with the local variety and no longer aspire to inner-circle norms; that these local Englishes would gain worldwide legitimacy and accrue just as much prestige as inner-circle varieties - an altogether unrealistic picture. Moreover, as Ostler reports, national governments are unwilling to invest in such a development, as their scramble for English is undergirded by such ideals as prestige and upward mobility, which in turn are based on inner-circle English $(2010,44)$.

Unlike De Schutter, Ostler is not so much interested in promoting linguistic justice as in predicting the future of English. If it remains a lingua franca, when will it meet its fate - and what fate? Next to those ancient languages whose lingua franca status span a millennium or longer - notably Chinese, Egyptian, Greek, Latin, Persian and Sanskrit - English is a young lingua franca, with its modest two and half centuries (Ostler, 2010, 231), or even less if we consider the Treaty of Versailles to be the dawn of English dominance. Scrutinising the fate of these giants, Ostler concludes that a lingua franca either dies out or becomes a mother tongue, with the latter being "the root of most examples of language shift, where one language comes to replace one or many others" (ibid., 174).

Having ruled out the possibility of English branching out into vernaculars, Ostler also rejects the mother tongue route, because "languages are strongly maintained at the national and regional level" (ibid., 269). Overestimating the power of territoriality and underestimating the impact of a common additional language on territoriality (particularly in a bloc like the EU), Ostler concludes that "[e]verywhere outside its mother tongue countries, English will be like a friend of the family, but never a family member" (ibid, 278). He would be surprised at the number of children growing up with what he calls "linguafranca English" very much as a family member. 
The only fate left for English in Ostler's book is death. So far, this has happened through one or more of the three Rs of lingua franca death: Ruin, Relegation and Resignation. Ruin is "the downfall of an economic network", such as the one that befell the Portuguese Empire and displaced Portuguese as trade lingua franca. Relegation is "a political act, summarily ending an official status", as was the case of Persian in Central Asia in the twentieth century. Finally, resignation is "a social trend that undermines and demeans the position of a previously respected elite" (ibid, 183), such as the one behind the decline of Latin. The demand for vernaculars, spoken by everyone - and not just a thin elite spread through the continent - squeezed out the demand for Latin, which had "no substantial domestic market" (ibid., 217). Effective competition also plays a decisive role in these Rs, as these languages were not displaced but replaced.

This last point is key: Ostler is adamant that English faces no effective competition, not even from Chinese, which remains a regional lingua franca operating on a continental scale - like other major languages, such as Swahili and Malay. Also, "the era of global empire-building" - the chief mechanism through which a dominant language established itself as a lingua franca - is over (ibid., 232). Unless Chinese turns out to have a strong impact in Africa, or computer software developments stemming from outside the inner circle puts another language in the spotlight, for Ostler, there is no effective competition in sight (ibid., 249, 254). In his prognosis, English will hence not be replaced - but rather simply displaced.

In the near term, Ostler forecasts that English will remain a lingua franca but with its own, alternative norms detached from the inner circle ("Austrian English", "Brazilian English", etc.), presumably along the lines proposed by De Schutter. Ostler nicknames this temporary stage the "Wimbledonization" of English, i.e. "becoming an institution that is dominated by foreigners, while continuing to bring some prestige and profit to its source country" (ibid., 269, 272). At the same time, he foresees the emergence of machine translation tools so potent as to ensure universal, instant and high-quality communicability, and this as early as "by the middle of the twenty-first century" (ibid., 261). So far, however, there are few signs of these developments, at least in the way Ostler predicts.

In the long term, his not entirely convincing forecast is that Wimbledonisation plus machine translation will heighten awareness and acceptance of multilingualism, making people realise that their local languages are enough, calling positive attention to pockets of local languages spoken by immigrants and indigenous groups and, finally, pushing new nations to officially recognise multilingualism, as South Africa did (ibid., 284-285). And thus "the last lingua-franca to be of service to a multilingual world, will be laid down"; "everyone will speak and write in whatever language they choose, and the world will understand" (ibid., 286). "Lingua-franca English" will thus have met its doom through relegation and resignation.

Ostler concedes that the fate of each lingua franca so far was decided by a number of unique factors, and that the position of English is unprecedented. 
Unlike Persian, English seems unlikely to meet relegation at the hands of former British colonies, and any losses sustained in this realm would be more than compensated for in the expanding circle. Unlike Portuguese, English is unlikely to face ruin through the simultaneous economic downfall of all innercircle powers and the emergence of "effective competition". Unlike Latin, English has substantial inner- and outer-circle markets which would guarantee the demand for English-speaking goods even if there were a decrease in the expanding circle.

Ostler adheres to a notion of "lingua-franca English" predicated on the instrumental need to bridge linguistic gaps here and there - despite admitting that inner-circle prestige plays a part in this, too. This instrumental need, he claims, will be met by near-perfect machine translation in the next few decades. Yet I watch Austrian kids on the train every day as their flow of (apparently native) German is punctuated by English words - not only by semantically charged buzzwords such as "internet" or "podcast", but by trivial expressions like "pretty much" and "you bet". For younger generations growing up in the EU, speaking English is increasingly becoming a life-style choice very much linked with their identities and linguistic ligatures. Using English is an ideological marker - if the instrumental value of language were uppermost in their minds, i.e. if people only wanted to get their message across as efficiently as possible, they would simply use German (see e.g. Dąbrowska 2004 and Kozak 2004, for studies on this phenomenon in Poland).

From the perspective of English teaching and learning trends, Ostler's predictions should gradually cause demand to decrease - and this is indeed David Graddol's conclusion in his studies on the future of English funded by the British Council (1997; 2006) (Table 4.4). Graddol's work is seen critically by those who oppose his "rather unquestioning acceptance of a neo-liberal economic model” (Phillipson 2009, 46). Phillipson even places Graddol's arguments on a par with those by "his colonial predecessors" $(2018,284)$. It is true that neither Ostler nor Graddol engage with such issues as linguistic or social justice; they see the current status of English as a natural development and do not focus on the implications for other languages. Crucially for us here, however, both envisage a more multilingual future and a new role for the English language, albeit in different ways.

Graddol emphasises two key points: first, that what has spread around the world is not English but rather bilingualism with English and, second, that English is becoming a basic skill, much like literacy and numeracy. Consequently, it is not so much that people will lose interest in English, as Ostler predicts, as that English will soon reach its "saturation point", which Graddol forecasts to be around 40 per cent of the world's population by 2040 (2006, 107). When so many become "functional users" of English, so his prediction goes, it gradually achieves such market penetration that it becomes a given, which in turn means it is knowledge in other languages that provides an edge. He forecasts the coming decades will witness the downfall of English teaching 
Table 4.4 The future of English, according to Graddol

\begin{tabular}{|c|c|c|}
\hline 1 & "The rise and fall of learners" & $\begin{array}{l}\text { The number of learners will peak (at about } \\
\text { two billion by 2021) and then fall }\end{array}$ \\
\hline 2 & $\begin{array}{l}\text { "Widening of student age and } \\
\text { need" }\end{array}$ & $\begin{array}{l}\text { A more complex mix of learners' needs and } \\
\text { ages will emerge }\end{array}$ \\
\hline 3 & "Rising competition" & $\begin{array}{l}\text { Teaching services from the expanding circle by } \\
\text { non-native speakers will create competition }\end{array}$ \\
\hline 4 & "Loss of traditional markets" & $\begin{array}{l}\text { The market for traditional teenage and young } \\
\text { adult learners will decline significantly by } 2016\end{array}$ \\
\hline 5 & $\begin{array}{l}\text { "Irrelevance of native } \\
\text { speakers" }\end{array}$ & $\begin{array}{l}\text { As English becomes a basic skill, inner-circle } \\
\text { norms will lose relevance }\end{array}$ \\
\hline 6 & $\begin{array}{l}\text { "The doom of } \\
\text { monolingualism" }\end{array}$ & $\begin{array}{l}\text { Monolingual English speakers will be penalised } \\
\text { financially for their monolingualism }\end{array}$ \\
\hline 7 & $\begin{array}{l}\text { "The economic advantage is } \\
\text { ebbing away" }\end{array}$ & $\begin{array}{l}\text { As English becomes a basic skill, more diverse } \\
\text { language repertoires will become more } \\
\text { advantageous }\end{array}$ \\
\hline 8 & $\begin{array}{l}\text { "Retraining needed for English } \\
\text { specialists" }\end{array}$ & $\begin{array}{l}\text { English teachers will have to acquire specialist } \\
\text { skills as English stops being a subject taught on } \\
\text { its own }\end{array}$ \\
\hline 9 & $\begin{array}{l}\text { "The end of 'English as a for- } \\
\text { eign language"” (EFL) }\end{array}$ & $\begin{array}{l}\text { Conventional EFL models will be left behind as } \\
\text { new learners' needs and market conditions } \\
\text { arise }\end{array}$ \\
\hline
\end{tabular}

Source: Graddol (2006, 14-15).

as a foreign language, though not because no one wants to learn it any longer; rather because they will have already learned it.

It is difficult to fit Ostler's and Graddol's forecasts into a single timeline. Unlike Ostler, Graddol does not envisage the emergence of expanding-circle Englishes, nor does he believe that multilingualism will eventually topple English - it will rather complement it. Nonetheless, both argue that the demand for English learning should have started decreasing by now, whereas the value of other languages should have started increasing. Yet, as remarked earlier, there is little evidence of these trends as the tendency is for English teaching to take up increasingly more time and resources instead of other languages, at least in EU schools.

Ema Ushioda (2017), for example, reports that proficiency in English impacts negatively on motivation to learn additional languages, and there is no sign of change. In her view, there is little motivation to go beyond English because foreign languages (in the EU, mostly English) are typically framed as instrumental skills needed in the job market for better financial prospects, ${ }^{20}$ and not as something to broaden our horizons, diversify our repertoires of identity, heighten awareness of our differences and become "informed and educated speakers and mediators" (ibid., 474). Of course learning English leads to these outcomes anyway, even if teaching is often not marketed in these terms. As argued repeatedly here, those who come to include English in their 
language repertoires inevitably also include it in their identity repertoires. But the key point is that the shift predicted by Graddol, whereby English speakers seek more multilingual repertoires, has not taken place (yet?). Even if local companies value proficiency in other languages more than in English, as reported by Grin $(2015,128)$, we cannot speak of a general demand for more diverse language repertoires.

Graddol's other key predictions regarding teaching and learning trends outlined in Table 4.4 have not yet shown any signs of coming true either, at least according to the English teaching professionals I interviewed for this book, namely my former colleagues and supervisors in three language schools in Brazil and Austria, along with experienced (10-30 years) freelance teachers in both countries. Though small, this sample is representative of the spectrum, with a global player, Berlitz, a large but local player, Talken English School (Brazil), a small school in Austria, Multi Lingua, along with freelance teachers, native and non-native, in the most varied settings - as English assistants in schools, private tutors working with people of all ages, as well as English trainers in governmental institutions and in small and large corporations (such as HSBC, Bank Austria, Siemens, Cirque du Soleil, A1 Austria and many others).

Berlitz is one of the largest language schools worldwide, with more than 500 language centres in 70 countries, offering classes in numerous languages though English lessons account for 75 per cent of its revenue. According to market research provider Technavio, the English language teaching (ELT) market is poised to grow by nearly $\$ 70$ billion in the 2020-2024 period in China alone, and Berlitz is one of the top players in this market. Talken is one of the most prestigious English schools in southern Brazil, with five branches and 75 teachers catering to about 2,400 students. It has grown significantly in the 35 years since its inauguration, as has the entire language teaching sector in the country, in which English is by far the largest language, trailed by Spanish. Multi Lingua is a small, one-branch, 30-year-old, family-run language school in Vienna's nineteenth district.

In our interviews, we talked about four clusters of issues, as follows: (1) trends in the number of English learners, their ages and backgrounds and trends in the number of learners of other languages; (2) shifts in the traditional EFL teaching model and signs that English learning is becoming more specialised; (3) the relevance of native speakers in ELT; (4) the predominance of inner-circle norms and the emergence of "international English" or local varieties as alternative norms.

1 None of the interviewees have noticed a decline in their numbers of English learners - if anything, an increase, as demand for English courses has emerged in unexpected sectors. One of the freelancers, James Mowlam, provided the most curious example here: sewage workers in Vienna are now learning English with him. Birgit Seisenbacher, a local Berlitz coordinator specialising in programmes for companies, confirms this trend. 
Nor have those interviewees who offer courses in a range of languages registered an increased interest in other foreign languages. One branch coordinator at Talken, Regina Ramalho, believes that the profile particularly of young learners is changing slowly as they are being exposed to English-speaking videos, songs, games, etc., from early on and hence come to the school with a little knowledge to begin with. However, there has been no sign yet of the "loss of traditional markets" of teenage and young adult learners predicted by Graddol.

2 A few freelancers admit that more specialised courses, say, in sports or arts, taught through the medium of English, are starting to appear, though they do not think that these classes cater to the needs of "typical" English learners, who in turn still flock to language schools and private tutors. It seems telling that an international giant like Berlitz is not investing in these specialised courses, but rather in mobile learning and streaming technologies - a shift that gained momentum due to the 2020 pandemic.

3 All interviewees confirm that native speakers have largely retained their privileged position in the sector. Seisenbacher confirms that the Berlitz model of native-speaker teaching is as successful as ever and that, when exceptions apply, it is not because native speakers are losing prestige, but because beginners would rather start learning English with someone who shares their mother tongue. Nevertheless, as soon as they reach a certain level, they prefer to switch to native speakers. However, both the owner of Multi Lingua, Susanne Vosahlo, and a branch coordinator at Talken, Ricardo Todeschini, have had students who prefer non-native teachers because they can usually teach native norms better than natives - not because students no longer aspire to inner-circle norms and adhere to an alternative standard instead. The non-natives interviewed admitted that students want to find out more about inner-circle cultures just as much as they want to learn the language, so having lived abroad and sounding "near native" helps.

4 Interest in an alternative - be it international or localised - variety of English is virtually non-existent, even when students admit they only need English to interact with other non-native speakers. Inner-circle norms remain de rigueur, with some students going as far as to book private lessons before meetings and presentations to have their notes and pronunciation corrected because they do not want to sound like they speak "Austrian English" or "international English" - which is perceived as degrading. Ana Alberti, English teacher in Brazil, speaks of an "insatiable hunger for culture" alongside the interest in more "instrumental" aspects of language learning. At Talken, exchange programmes in the USA are run alongside the English courses and remain an attractive, prestigious option for those who want to learn "proper English".

Though mostly anecdotal, these data paint a different picture to those suggested by Graddol and Ostler, at least in Brazil and Austria. To be fair, some 
of their predictions were more medium-term, but unless they come out of the blue, we should have started noticing signs of change by now. The demand for inner-circle Englishes is ever-growing, and English is neither branching out into vernaculars nor being officially appropriated by states in the expandingcircle. In this scenario, what does the future have in store for English in a postBrexit EU?

\subsection{The Future of English in the EU in the Wake of Brexit}

A long-awaited referendum on whether the UK should remain in the EU was held on 23 June 2016. With an overall turnout of 72.2 per cent, 52 per cent of voters chose to leave - a majority in England and Wales, but a minority in Scotland and Northern Ireland. After Article 50 of the Lisbon Treaty - which sets out the legal mechanism for a member state to withdraw from the EU had been triggered in March 2017, a series of national and supranational negotiations ensued, punctuated by popular protests, ministers' resignations and fudged extensions to the withdrawal date. On 31 January 2020, the UK officially left the EU to enter an 11-month transition period, starting a race against time to establish the particulars of the post-Brexit UK-EU relationship.

Just out of curiosity: 66 per cent of respondents to the 2018 Parlemeter across the EU would vote "remain" in a hypothetical remain/leave referendum, 17 per cent "leave" and 17 per cent "not sure" (European Parliament 2018, 27). In Ireland and Luxembourg, some 85 per cent chose "remain". Only in the Czech Republic and in Italy did "remain" obtain a minority of votes -47 and 44 per cent, respectively, but still more than "leave" (with 24 per cent each). The survey was conducted in the UK, too: 53 per cent would vote "remain", 35 per cent "leave" and 12 per cent "not sure" (ibid., 28). In the subsequent Parlemeter, six in 10 respondents said they "are in favour of their country's EU membership" - these figures have remained stable between 57 and 66 per cent since the Brexit vote (European Parliament 2019b, 11). Also, 59 per cent of respondents see EU membership as a "good thing", 29 per cent as "neither good nor bad" and 11 per cent as "a bad thing". More younger respondents (15- to 24-year-olds) regard EU membership positively (64 per cent) than the $55+$ cohort (54 per cent). In the UK, 42 per cent considered EU membership good in 2019, 31 per cent neither good nor bad and 24 per cent bad (European Parliament 2019b, 11-13).

Focussing on language now, the key question is whether Brexit will have an impact on the de jure and/or de facto status of English in the EU's institutions, bodies and agencies. Whether Brexit will eventually impact the status of English in the member states' education language policies, practices and ideologies is equally important. Another crucial question - into each we cannot go here is how the UK's linguistic diversity is going to be impacted by Brexit. Though language policy may not be the EU's forte, membership brought some protection to vulnerable languages - Welsh and Scottish Gaelic, for instance, enjoyed the status of semi-official (or co-official) EU languages alongside Basque, 
Catalan and Galician, a status now lost. Unsurprisingly, language policy does not feature in the Withdrawal Bill at all, hence the apprehension of some linguistic minorities across the UK (see e.g. Mac Giolla Chríost \& Bonotti 2018, 41). ${ }^{21}$ Another interesting question which I cannot address is whether the UK will perpetuate its chronic monolingualism post-Brexit (see e.g. Kelly 2018).

Regarding the status of English as an official EU language, the EU has been sending mixed messages from the start. Polish MEP Danuta Hübner was among the first to make controversial statements about the alleged downgrading of English in June 2016: "English is our official language because it has been notified by the UK", she said. "If we don't have the UK, we don't have English", a claim that prompted immediate rejection by the European Commission Representation in Ireland, which underlined the need for unanimity to change the list of official EU languages. (The reader probably recalls the labyrinthine path to amend the treaties described in Section 2.2.) Malta and, more significantly, Ireland would most likely never agree to this downgrading as Irish is only spoken by a minority in the country. A long list of statements announcing the doom of English followed, by no lesser figures than the then President of the Commission, Jean-Claude Juncker, himself. For example, in May 2016, he declared that "slowly but surely English is losing importance in Europe", and in September 2018, "we are not under the rule of the only lingua franca, which is English" (Stolton 2018). Nevertheless, different sources in the EU assure me that these rumblings were typical of Juncker's sense of humour and not earnest declarations of intent.

Still, there was a noticeable increase in the use of French and German in speeches and statements to the press in the aftermath of the Brexit referendum, a shift confirmed by some of my interviewees as well (see e.g. Steinhauser 2016; Derlén 2018, 347). The epitome of this new stance towards English is encapsulated in the request by Michael Barnier, the EU's lead Brexit negotiator, that negotiations be conducted in French (Mac Giolla Chríost \& Bonotti 2018, vi), or in Emmanuel Macron's pledge to "loosen [the] grip of English on Brussels" (Chrisafis 2018). Outside the EU, public figures such as French politician Jean-Luc Mélenchon and Italian politician Eugenio Giani also commended the downgrading of English and the upgrading of French and Italian, respectively. By the same token, calls for English to retain its status, or even for it to be upgraded to official EU lingua franca, emerged - for instance, from former commissioners Günther Oettinger and Mario Monti, as noted in Section 2.4.

Some plead for the status of English (sometimes alongside French) to be raised in the EU for the simple reason that, de facto, English already enjoys a superior status in the EU. In the context of EU law, Matthias Derlén (2011), for instance, proposes the adoption of these two mandatory consultation languages for national courts, for these are virtually the only drafting languages anyway. To his knowledge, most national courts already consult the English, sometimes also the French versions, in the conviction that they are the originals, so this step would merely acknowledge a basic fact. Others, like Kraus, 
reject this predominantly monolingual regime and endorse the promotion of English, French and German as EU official working languages - the regime which Grin calls "oligarchic" (see Section 3.2). However, with two caveats: these three languages must be used in the same proportion and no one should be allowed to use their mother tongue (Kraus 2008, 135-137). Kraus avers that these three languages function as "transeuropean hinges": English and French are spoken across the globe, German has the largest demographics in the EU and all three are spoken in more than one member state (ibid., 136). This is indisputable, but do these proposals still hold after Brexit?

Regulation 1 of 15 April 1958 does not specify whether a member state can request the EU to grant official status to more than one of its national languages. However, even if it did, all it would mean is that no member state may have more than one of its official languages recognised as official EU language upon accession - or indeed at a later point, as noted in Section 2.1. The withdrawal of a member, nonetheless, is absent from the regulation. If, say, Slovenia decided to leave the EU, it seems quite clear that Slovenian would be dropped from the list of official EU languages by consensus. The case of English is much more complex not only because it happens to be an official language in more than one member state, but especially because it is the EU's unofficial lingua franca. Amending the treaties requires unanimity - which is easy to imagine in the case of Slovenian, but unthinkable for English. By allowing Ireland and Malta to keep a second official EU language, however, the EU will be inviting other member states to seek officialdom for their other languages. On the other hand, forcing Ireland and Malta to replace their official EU languages with English would cause outrage among speakers of Irish and Maltese. All in all - and given the Commission's somewhat willy-nilly attitude towards this linguistic predicament (see the Appendix) - it seems nothing will change in its de jure linguistic regime.

The more relevant question is hence the de facto status of English in the EU. After all, the dominance of English has little to do with its statuary rank - 23 other languages enjoy the same status. Juncker, for example, addressed the unofficial status of English as the EU's lingua franca of sorts in the above quotations, and so did the measures taken by the Commission to give French and German a more prominent role in its external communications. Victor Ginsburgh, Juan Moreno-Ternero and Shlomo Weber (2018) are confident that English will retain its role of lingua franca, not least because it is the main pivot language in the EU's language services - replacing it would wreak havoc across all institutions. However, they float the idea that "EU citizens may decide to forego speaking or learning English" if they feel it is losing symbolic space, which could come about not only as a result of Brexit, but also if "trade with China, India, Brazil, Africa or the Arab world becomes more important" (ibid., 148).

Assuming English retains both its official EU language and its unofficial EU "lingua franca" status, the question is whether the latter will remain unchanged or be formally acknowledged. One prediction that stole the limelight in the 
aftermath of the Brexit vote was that the EU would claim its own variety of English. Somewhat like De Schutter, Marko Modiano foresees the emergence of what he calls "Euro-English", defined as a language "not decidedly based on any one Inner Circle variety but ... characterized by influences from standardized English as well as their [speakers'] native tongues" and by "culture-specific features common to the manner in which English is used as an L2 in continental Europe" (Modiano 2017, 322).

Although Euro-English has not yet been codified, Modiano has compiled a list of its most common grammatical, lexical and phonological features (ibid., 322-323; see also Modiano 2006). In his view, the EU should sever all ties left with the UK by establishing this new variety of English within the World Englishes paradigm as a "quasi-Outer Circle English" (Modiano 2017, 313). He predicts that Brexit will not affect the current role of English as the EU's lingua franca of sorts, and that the establishment of Euro-English will be aided and abetted both by the physical absence of inner-circle speakers ${ }^{22}$ and by the symbolic absence of the only nation that appointed English as its official language upon accession. Even though he does not mention linguistic justice, he does subscribe to the view associated with the ELF paradigm that, once EuroEnglish has been established, its use "will benefit no particular culture or speech community within the EU, with the exception of the Irish and the Maltese" (ibid., 321). However, he predicts that Euro-English will follow American English - presumably, then, any benefits will accrue to the United States.

The view that an alternative variety of English should become the EU's sole lingua franca post-Brexit is also defended by Diarmait Mac Giolla Chríost and Matteo Bonotti (2018). They call it EGLF, i.e. "English as a global lingua franca", the creation of which should be the responsibility of citizens and officials alike during the negotiations of a post-Brexit trade deal. Following Van Parijs's rationale regarding linguistic justice (see Section 4.5), Mac Giolla Chríost and Bonotti endorse the introduction of a language tax which, unlike Van Parijs, they see as a realistic measure, given the EU's new stance on the English language. In their view, it is in the UK's best interest to contribute to the establishment of EGLF just as much as it is in the EU's best interest to make sure all citizens become proficient in it - not least to mitigate the linguistic injustices outlined by Van Parijs. The proceeds of this language tax should thus be directed to English learning across the bloc. Mac Giolla Chríost and Bonotti believe that one such tax should be introduced within all "cooperative schemes" between the EU and any other anglophone countries to placate linguistic injustice (ibid., 66).

As for injustices pertaining to "parity of esteem" (Van Parijs) or "legitimisation" (Grin), Mac Giolla Chríost and Bonotti concur with Modiano and with the general appraisal of linguistic justice within the ELF paradigm in that they see Brexit as an opportunity to detach the English language from Britain, thus making it "neutral" and "Esperantized": "Since English, after Brexit, would no longer be associated with the collective identity of any linguistic 
community within the EU ..., there would no longer be the need to ensure parity of esteem between English and other languages" (ibid., 68). Another outcome of Brexit would be the decentralisation of English in the member states and the establishment of local Englishes, along the lines proposed by De Schutter. This would further help address any symbolic injustices left (ibid., 72). A further step proposed by them is to "reduc[e] the opportunities of native Anglophones by making it more difficult (though not impossible) for them to settle and find jobs in non-Anglophone countries in a post-Brexit EU" (ibid., 75).

A more controversial aspect of Mac Giolla Chríost and Bonotti's book lies in their argument that Brexit will bring some much-needed certainty in relation to the status of the English language in the UK. They see the EU as partly responsible for the emergence of subnational groups centred on its linguistic minorities, and Brexit as the uprooting of these minority movements: "Brexit detaches sub-State linguistic actors in the UK from this European social imaginary" (ibid., 40). Furthermore, they show genuine concern that the devolution of powers to the Scottish Parliament, the Welsh Assembly and the Northern Ireland Assembly may threaten English: “one simply cannot assume that the historic freedoms enjoyed by English speakers will remain as they always have been" (ibid., 36). They see Brexit as the perfect opportunity to convert EU law into UK law, preferably within a codified constitution, and secure the position of English as the UK's sole official language, with some space devoted to "autochthonous minority language rights and freedoms" (ibid., 28; see also 36). Further, they are confident that " $[\mathrm{t}]$ he place of English in a post-Brexit EU is likely to become one of the most controversial issues in the ongoing negotiations between the EU and the UK" (ibid., 75). Yet given the absence of language-related questions both from the Withdrawal Bill and from the Conservative Party Manifesto, it seems doubtful that any attention will be devoted to language within the Brexit negotiations at all.

Nor does the EU's systematic disregard for language questions, outlined in this book, give any hope that much will change at all post-Brexit. To be fair, a large portion of this disregard is due to member states' unwillingness to share language policy competences with the EU. Still, it is telling that the European Commission's DG Translation, as the EU's current multilingualism watchdog, denies the existence of language hierarchies and linguistic injustices in the EU (see the Appendix). From our interview, it appears that the predominant view in the Commission is that there is no need to change anything in the de jure or in the de facto roles of English in the EU, Brexit or no Brexit. This makes the language turn and the translation turn proposed here all the more urgent. The transcultural turn, the third and last proposed in this book, will feature in Section 4.8.

\subsection{Intercomprehension and Transcultural Skills: When Others Remain Others}

The main alternatives to the EU's de jure and de facto language policies revolve around elevating the status of "English" (e.g. Van Parijs, Habermas), 
appropriating an EU English variety (e.g. Mac Giolla Chríost, Bonotti, Modiano), establishing the hybrid, fluid notion of "European ELF" (e.g. Jenkins, Cogo), stripping English of EU officialdom (e.g. Mélenchon, Giani), choosing a smaller number of official working languages (e.g. Derlén, Kraus) and introducing Esperanto (e.g. Phillipson, Grin). Raising the status of English, in whichever shape or form, incurs the linguistic injustices outlined earlier. Raising the status of a small pool of languages runs into the same difficulty - particularly if only Romance and Germanic languages are promoted, thus reinforcing an already unwelcome sense of a privileged "core Europe" (more in Section 5.2). Subjecting English to summary relegation is not on the table either, not least because language policies must either reflect existing language practices and ideologies or seek to transform them. English is the most taught foreign language across EU school curricula and the all-but-ubiquitous language in different areas of our lives. Finally, adding Esperanto to the picture would entail not only additional language training to EU staff, but also the creation of Esperanto higher education departments across 27 member states a difficult enterprise even for natural languages.

Intercomprehension and transcultural ${ }^{23}$ competences emerge in this complex scenario as an interesting, albeit undervalued, alternative. Grin describes this cluster of solutions as "banking on people's receptive competence in languages structurally related to their mother tongue", and suggests that it "considerably widens the range of possible language regimes" of the EU $(2008,76)$. Christina Reissner defines it as the ability to communicate within a group of languages without having formally learned each language individually (2010, 821). Over

Table 4.5 Official EU languages by language family and percentage of EU population

\begin{tabular}{lll}
\hline Language family & Language & Percentage $^{1}$ \\
\hline Afro-asiatic & Maltese & 0.11 \\
Baltic & Latvian, Lithuanian & 1.05 \\
Celtic & Irish & 0.03 \\
Germanic & Danish, Dutch, English, & 30.76 \\
& German, Swedish & \\
Hellenic & Greek & 2.59 \\
Romance & French, Italian, Portu- & 46.7 \\
& guese, Romanian, Spanish & \\
Slavic & Bulgarian, Croatian, & 15.03 \\
& Czech, Polish, Slovak, \\
Uralic & Slovenian & \\
& Estonian, Finnish, & 3.72 \\
\hline
\end{tabular}

Sources: Eurostat from 1 January 2020 and Special Eurobarometer 386 (European Commission 2012a). All Eurostat survey results can be accessed via the Eurostat database at: https://ec.europa. eu/eurostat/data/database.

1 These numbers reflect the member states' populations rather than language speakers. 
100 definitions of intercomprehension have emerged recently, giving rise to different teaching models (see e.g. Strasser \& Ollivier 2013), so I will have to paint with a broad brush here.

Receptive skills in two or three language families increase communicability within the EU significantly (see Reissner 2010, 839; Gravier \& Lundquist 2011, 88). Currently, the Germanic, Romance and Slavic language families cover roughly 92.5 per cent of the EU. ${ }^{24}$ In a nutshell, teaching and learning languages through intercomprehension means focussing on the similarities within and across language families to build receptive skills. English, for example, works as an excellent "bridge" to the Romance family thanks to its Norman roots. The choice of bridge language is linked with learners' linguistic biographies - the starting point from which language families are added (see Reissner 2010, 823-824).

One way of grouping these cross-language similarities for pedagogical purposes is through the sieben Siebe [from German, "seven sieves"]. This method was originally devised by Tilbert D. Stegmann and Horst G. Klein in the late 1990s to grant German speakers (with some knowledge of French) access to the Romance family - so French was the bridge language. Meanwhile, the approach has been adapted to cater to various language combinations. Authentic texts (written and oral) are usually at the heart of these intercomprehension models. Stegmann and Klein (1999) recommend carrying out a preliminary extratextual analysis, to set the scene, and then to sift these texts through "seven sieves", as follows:

1 Internationaler Wortschatz [international vocabulary]: words whose roots are easily recognisable across multiple language families. A classic example here that spans all official EU language families - but the Celtic family - is information in German (with a capital "i”), French and English; informació in Catalan; informacija in Croatian; informatie in Dutch; információ in Hungarian; informazione in Italian; informāciju in Latvian; informazzjoni in Maltese; informação in Portuguese; informácie in Slovak; información in Spanish, etc.

2 Panromanischer, panslavischer, pangermanischer usw. Wortschatz [panromance, panslavic, pangermanic etc. vocabulary]: words typically present across the family in question. For example, the verb "to love" in the Romance family: aimer in French, amar in Galician, Portuguese and Spanish, amare in Italian, etc.

3 Lautentsprechungen [sound correspondences]: typical constructions and their correspondences across the spectrum, such as bras in French, braccio in Italian, braço in Portuguese, brazo in Spanish, etc.

4 Graphien und Aussprachen [letters and pronunciation]: pronunciation systems of each language and their respective orthography. For instance, in the previous example, once we know how the letters "cc", "ç" and "z" are pronounced in Italian, Portuguese and Spanish, respectively, it is easier to establish this and other correspondences. 
5 Kernsatztypen [core sentence types]: common syntactical features, to better anticipate the position of pronouns, verbs, conjunctions, etc.

6 Morphosyntax: typical inflections to mark distinctions of number, gender, tense, person, etc. In Portuguese and Spanish, for example, first person plural verbs contain the inflectional suffix "-mos".

7 Präfixe und Suffixe: Greek and Latin - in the case of the Romance family derivational suffixes and prefixes. For instance, the English noun suffix "-ation" is usually the same in French, "-azione" in Italian, "-ação" in Portuguese, "-ación” in Spanish, etc.

Stegmann and Klein maintain that only a few words and expressions will have fallen through the sieves at the end of the analysis, and that their meaning can be easily inferred from the rest of the text (1999, 12). "False friends" are usually approached during vocabulary work, i.e. sieves one and two (see e.g. Tafel et al. 2009).

Intercomprehension exercises can easily be incorporated into teaching in general, be it in content lessons in school, for example, or in language courses always following the learners' language repertoires (see Reif-Breitwieser 2011). At the Centre for Translation Studies of the University of Vienna, for instance, it is common practice for teachers to - often spontaneously - compare items across languages without explicitly talking about intercomprehension. It would be fruitful to have a more systematic approach to it across the board - especially in schools.

Intercomprehension fosters transcultural skills, understood here as the ability to recognise different cultural traits and to mediate among them. Intercomprehension and transcultural skills go hand in hand with the language turn and the translation turn proposed here and make up a transcultural turn for the EU, whose viability seems clear for different reasons (more in Section 5.4). First, linguistic diversity is enshrined in EU law and reflects people's current ideologies - at least to some degree. ${ }^{25}$ More than four in five Europeans agree that "all EU citizens should be able to speak a foreign language", more than seven in 10 believe that it should be "two foreign languages", more than eight in 10 agree that "all languages spoken within the EU should be treated equally” (European Commission 2012a, 109, 117).

Second, fostering intercomprehension and transcultural skills would entail neither the addition of a language with which people do not identify (e.g. Esperanto) nor the suppression of a language on which many have come to rely (English).

Third, whole-hearted intercomprehension efforts on the part of the EU would be an invaluable gesture to signal that multilingualism matters, and that the dominance of English is at odds with the EU's principles.

Fourth, the EU already subsidises language courses for its staff, so no substantial additional funds would be required as some of the current budget could be allocated to intercomprehension courses. Also, the EU has already funded intercomprehension projects and could tap into their wealth of teaching resources (see note 24 ). 
Fifth, intercomprehension could make translation services more efficient, as revealed in a 2012 report by the DG Translation, in that it would allow for the establishment of a "multilingual concordance" group to compare translations across all 24 languages, an "external translation" group to assess the quality of translations done by freelancers, as well as a "training" group to grant other translators, particularly in the departments of French and English, access to other languages in their language families (European Commission 2012b, 45).

In addition to viability, much speaks in favour of a more transculturally competent EU. ${ }^{26}$ Intercomprehension allows all communication partners to express themselves in the language(s) in which they feel the most comfortable. Though still relevant in larger gatherings in which intercomprehension may not suffice and interpreting cannot be provided, Van Parijs's maxi-min principle would lose its supremacy. But perhaps the greatest benefit of an EU capable of intercomprehension lies in its power to force us to accept others as others. When I speak Portuguese and my colleague responds in Polish - provided we both had training in Romance and Slavic languages - we can fulfil our communicative potential without compromising on a language in which neither of us are particularly fluent or articulate. Accepting others as others also goes a long way towards raising awareness of our differences: we speak different languages, we frame our messages differently, we have different understandings of the world, of ourselves and of each other. As Kraus puts it, we need "the kind of intercultural ethos ... Humboldt had in mind when he made a connection between learning a new language and 'gaining a new standpoint in how we view the world"” (2008, 177). Indeed, if we want an "ever-closer union”, then "intercultural empathy" and "a high level of intercultural competence ... in European civil society" are a must (ibid., 192).

Another benefit of the proposed transcultural turn is the automatic inclusion of lesser-used languages. Researchers from the Goethe-Universität Frankfurt am Main, for example, confirm that after a single semester of training in the Romance family, students are able to read authentic texts not only in the languages targeted in the course (namely Catalan, Italian, Portuguese, Romanian and Spanish), but also in languages with which they had never had any contact before, namely Ladin, Occitan and Sardinian. They also found intercomprehension strategies can be applied to a wide range of learning situations, and that the mental processes involved in it have a positive impact on the students' ability to learn autonomously (Reissner 2010, 823-824).

As argued in Section 4.3, a multilingual public sphere appears to be emerging in the EU, with a common meaning framework and horizon of reference despite the lack of a shared language. Intercomprehension and transcultural skills would cement this public sphere - not in the singularity of a major language (today English) but in the plurality of multilingual understanding. Put differently, it would help "break down barriers to understanding by creating overlapping communicative repertoires” (Kraus 2008, 177). Through this prism, "united in diversity" no longer means "together in disunity" (Kernerman 2004, 164), i.e. neither the haphazard juxtaposition nor the mixing and 
watering down of peoples and languages which is so threatening to minorities. Rather, the EU motto can mean that we are united through our multilingual and transcultural understanding of our diversity. ${ }^{27}$

An EU capable of intercomprehension is not an EU without English or an EU in which everyone speaks only their mother tongue. English is the EU's lingua franca of sorts, whether we like it or not, and it will remain so for the foreseeable future. It is a useful tool which should be employed in certain settings, especially when speakers are proficient and comfortable with it. The EU only recruits functionally multilingual staff anyway, so adding intercomprehension to the mix would give rise to a more flexible, richer palette of language arrangements - one that is not restricted to English but certainly includes English.

A more transculturally competent EU has the potential to tip the scales in favour of multilingualism across the entire bloc. If member states were persuaded to include intercomprehension in their school curricula - in the same way that they were partially convinced to offer two instead of one foreign language - it might reach beyond the confines of Brussels and Luxembourg and engender a true shift in language practices and ideologies. As suggested earlier, same-family and neighbouring languages would be the starting points, so instead of finishing school with relatively advanced skills in English, Austrian pupils, for instance, would probably still know a lot of English - one can hardly avoid it outside school - and have at least passive skills in Germanic and/or Slavic/Romance languages, possibly along with Uralic languages as well. Here, some coordination among the member states would be crucial: "a reciprocal effort across the border turns communication into a shared enterprise rooted in a shared multilingual ethos" (Grin 2011, 63).

In the medium term, English would still have the upper hand - and this would probably appease parents against their children learning, say, Slavic languages instead of English only. But as pupils gained insight into their peers' mother tongues and into languages in their own language family, they would probably show an interest in cultural goods in these languages, they might want to learn one or two of these languages more thoroughly, they would engage with these languages and cultures differently when on holiday in these neighbouring countries, etc.

Intercomprehension and transcultural competence also dovetail with the notion of "critical language awareness" (Shohamy 2006, 156). If children and policymakers alike received training in intercomprehension and transcultural skills, discrimination on grounds of language would become a rare occurrence. For a generation trained in intercomprehension, defending minority rights would probably be second nature and not necessarily the stuff of activism. A parallel with the environment illustrates this point: younger generations were infused with environmental awareness, leading to an ideological shift whereby simple steps, like recycling and being mindful about wasting resources - which would have been uncommon only a few decades ago - became commonplace. Eurobarometer surveys on public attitudes to the environment reveal how the level of concern rose gradually, starting from the 1980s. Such an ideological shift required a set of measures, including public policy, and the same applies to language awareness. 
Table 4.6 The impact of intercomprehension on linguistic justice

\begin{tabular}{lll}
\hline & Grin's injustice & Impact of intercomprehension \\
\hline 1 & Privileged markets & $\begin{array}{l}\text { Markets would gradually shift once interest in other } \\
\text { languages and their goods rose } \\
\text { With a more equitable distribution of source and target } \\
\text { languages, no community would be benefited } \\
\text { ings effort }\end{array}$ \\
disproportionately
\end{tabular}

Source: See Table 4.3.

In terms of linguistic justice (see Table 4.6), if a significant shift in ideology gradually occurred, intercomprehension could impact all six of Grin's categories positively. Injustices 2, 3 and 4 stem largely from non-English-speaking nations' and individuals' will to invest heavily in English-learning and to conduct their affairs in English when dealing with native speakers and/or foreigners. If the EU became more functionally multilingual, it would also become less compliant with Van Parijs's maxi-min principle. The onus to provide translation and interpreting would thus fall on English native speakers more often - assuming that the $\mathrm{UK}^{28}$ retained its model of monolingualism.

The transcultural turn should not collide with the translation turn, on the contrary: more intercomprehension should not lead to a decrease in the need for translation/interpreting in official settings, and it should help translation services work more efficiently, as noted above. It would be wildly unrealistic to expect full intercomprehension to be achieved - with any luck, a part of the population would acquire passive skills in a few language families, which would still leave language families out.

The transcultural turn, together with the language and translation turns proposed here, are an attempt to heed Derrida's call to "invent gestures, discourses, politico-institutional practices that inscribe the alliance of [the] two imperatives" of unity and multiplicity $(1992,44)$ and will be the focus of Chapter 5.

\subsection{Final Remarks}

The EU is a sui generis polity in formation in which the tension between unity and multiplicity is the epitome of any meaningful relation with the Other. Notions such as territory, borders, citizenship, national identity, national 
language and national culture are being challenged across the globe. This is shaking the foundations upon which the European project rests, calling for genuinely new approaches. Language policy, practices and ideologies (along with their implications for translation) may be but one aspect in this extraordinarily complex and unparalleled scenario; nevertheless, it is the one that pervades all other aspects. Hence the need for a renewed understanding of language and a strengthened translation regime geared towards real multilingualism, coupled with intercomprehension and transcultural awareness both in EU institutions, bodies and agencies and in member states.

While it is true that the reforms proposed here have been urgent for quite some time, Brexit has forced the entire bloc to rethink its treatment of language - of the English language in particular. Both the EU's internal language (and translation) regime and the member states' education language policies revolve around English, a language which can no longer be pinned to the accession of a member state. Politically and normatively, this poses a challenge to the EU, whose aftereffects will be felt in the coming years, as English occupies more of the spaces in which other languages once thrived (including our homes).

As ever, the EU's attitude towards this normative and political crisis afflicting its already flimsy language policy is ambiguous. On the one hand, the only part of the EU's framework dedicated to language policy, DG Translation, denies the existence of language hierarchies and injustices in the EU and believes Brexit will change nothing in its language and translation regimes. On the other hand, Brexit has prompted some key EU figures to speak out against the dominance of English and to boost the use of French and German, at least externally. The attitude of the DG Translation, understood here as representative of the Commission as a whole, suggests that the EU intends to circumvent these normative and political challenges by pretending that they do not exist. As a body of institutions which, even before Brexit, was being accused of "practising linguistic apartheid" (Phillipson 2016, 146), the EU runs the risk of allowing the Brexit mess to undermine the little that is left of its dignity regarding language policy. As Kraus warned before Brexit, "the systematic promotion of English as a lingua franca by the European institutions would be like giving Microsoft a public subvention to develop software"; after Brexit, this uncritical, stealthy "promotion" is all the more perplexing (Kraus 2008, 177).

The EU's motto, "united in diversity", epitomises its somewhat lackadaisical attitude towards this paradox at its heart. Establishing a deep unity based on common features is at odds with respecting member states' sovereignty. Yet, these two goals are often casually placed side by side, as though they could be reconciled effortlessly, much like in a United Colors of Benetton ad in which everyone comes together in peace and harmony despite their differences (Kraus $2008,196)$. As argued here chiefly in relation to language, there often seems to be a dangerous trade-off between the two terms of the paradox: yes, the EU respects member states' sovereignty, but it insists on an efficient institutional 
framework based on English - and the fact that it remains the EU's unofficial, default lingua franca of sorts is inevitably "in tension with the vision of a multilingual, multicultural, democratic political entity" the EU claims to be (Ives 2004, 43).

Graddol's and Ostler's forecasts for the future of English notwithstanding, English is becoming more entrenched in the EU, be it as the unofficial working language of its staff or as the main foreign language in the education systems of its current and prospective member states. Recent trends in linguistics and political theory depicting English as a harmless, empty vessel for communication that exists harmoniously alongside other languages, further entrench and legitimise the privileged position of English and its native speakers - albeit inadvertently. The DG Translation and some of the EU translators consulted for this book defensively and somewhat flippantly justify the dominance of English by claiming that it has long been detached from English-speaking countries and now belongs to whomever speaks it - a justification which fails to acknowledge both the ensuing linguistic injustices and the normative framework in which the EU's language and translation regimes are embedded. Democratising English is undoubtedly a positive development, and liberation linguistics must be commended for its part in legitimising all those Englishes spoken beyond the inner circle. Yet this does not make English "Esperantised" - for one thing, because even Esperanto entails ideological and cultural ties despite the lack of a fixed territorial link and, more importantly, because "de-territorialising" English in one place, while it remains very much territorialised in others, hardly makes it a neutral language.

\section{Notes}

1 All EU legislation mentioned throughout this book, including court cases, was taken from the EUR-Lex portal: (C) European Union, https://eur-lex.europa.eu/. All electronic sources quoted here were last accessed in December 2020.

2 The differences between "shared fate" and "shared destiny", though important, cannot be addressed here. The notion of a "community of destiny" enjoys a long and controversial tradition in Western philosophy, for example, in Martin Heidegger's work (see Balibar 2014, 144). Herman van Gunsteren $(2018,61)$ prefers the term "community of fate" to stress that members of these communities "cannot avoid each other without depriving themselves of what is essential for their way of life (for instance, water supply, a viable economy, institutions of learning, military protection, a judicial system, and territory)".

3 To increase participation, i.e. to allow ordinary citizens to make informed judgements about EU politics and policy, Kraus recommends the creation of issue-specific, transnational public spheres with experts and interest groups (based on Eder's work), as well as more Europeanisation of national public spheres, particularly of national media (Kraus 2008, 150-151; more in Section 4.3). Here, James Fishkin's deliberative opinion polls, though controversial, could be an interesting add-on (see e.g. Fishkin \& Laslett 2003; Fishkin 2009). In a nutshell, these polls consist of a large cross-section of the population, sampled like citizen juries to ensure fair representation, who comes together to discuss specific issues with the help of moderators and experts in the area in question. It would be interesting to put language 
and translation policy through these deliberative polls - for example, via the Commission's representations in the member states.

4 After extended and heated negotiations - in which Emmanuel Macron is said to have thumped the table and Giuseppe Conte to have warned Mark Rutte that his frugality would go down in history as lack of solidarity - the 27 member states reached a historic deal in July 2020 both in terms of scope and presupposed monetary unity. The future will tell whether the recovery fund is a "leap towards genuine integration" (Vallée 2020) or "another step towards disintegration" (Varoufakis 2020). For the purposes of our reflections here, the level of fiscal and monetary unity entailed in the deal, along with the member states' willingness to borrow money jointly and give out grants to those member states hit hardest by the crisis, is a sign of increased solidarity.

5 Roland Willemyns reports that the concept of diglossia was already widely used in French Hellenistic studies (see Phillipson 2003, 83) when it became well known in English in the mid-twentieth century, in the writings of Charles A. Ferguson. In Ferguson's terms, "diglossia" referred to two varieties of the same language, such as Modern Standard Arabic and local varieties of Arabic. Joshua A. Fishman then proposed the notion of "extended diglossia", i.e. when two genetically unrelated languages play a "higher" and a "lower" role within the same community, such as French and Basque, respectively, in France (see Fishman 1967; Spolsky 2004, 134; Kraus 2008, 101).

6 In households where there is one English inner-circle speaker (I counted 11 among my friends and acquaintances), the main (often the only) home language is always English. Here we see the "love and destroy" mechanism described by Jean Laponce at work (Laponce 2001, 183). In my survey, I did not include monolingual families who speak English occasionally at home with their children. This latter category is more common than one might think and is present, at least in my circle of friends and acquaintances, in the EU and in Brazil alike. Some of these families set a day of the week when everybody speaks English; some parents randomly utter a few sentences here and there in English every day to expose the kids to the language; some read books and play their children songs and videos in English; many have Englishspeaking babysitters or send their children to English-speaking nursery schools. Surprisingly, some parents barely speak English themselves; in Austria, some are of recent Eastern European descent and can still speak their heritage language - but see English as more important for their children.

7 See e.g. Ammon (2001) and de Cillia (2003) for an overview of the spread of English in the sciences across the globe, along with a wealth of studies that demonstrate this spread and its impact on local languages.

8 This idea is at the heart of the debate among liberal nationalists and liberal multiculturalists, in which languages are seen as "contexts of choice necessary for the value of autonomy to be satisfied" (De Schutter 2018, 174). This is one of the key arguments, for example, in Kymlicka's defence of group-differentiated language rights. A lack of choice is also a paramount factor in linguistic domination, defined by De Schutter et al. $(2018,60)$ as follows:

(1) the fact that one of the groups needs to adapt linguistically to the other, but not the other way round ...; (2) a frequent repetition of this pattern on a daily basis; and (3) the fact that the members of the dominated group have no real alternative, apart from eschewing interactions with majority speakers altogether.

9 This is relevant to the debate surrounding the prominent role of English in former British colonies, such as India and Pakistan. Is it an instance of successful appropriation and "de-anglicising" of the oppressor's language, or rather a regretful act of capitulation (see e.g. Fishman 1996; Rushdie 1997; Ch'ien 2004; Dissanayake 
2006; Gargesh 2006; Kachru 2006, 454; Phillipson 2009; 2017; wa Thiong'o 2009; Van Parijs 2011)? Through the prism of options and ligatures, English can only be liberating if it remains an option that precedes ligatures. If not belonging to an English-speaking community in the outer circle entails significant penalties (such as financial loss, exclusion from certain circles, less access to information, less prestige, etc.), then it is hardly an option - or rather, it is the only option, which makes it a non-option. Another relevant question here is whether ties to English corrode or prevent ties to other languages from being nurtured, as other languages do not open as many gates as English.

10 Avoiding English today is often impossible. A case in point: this book could have been written in Portuguese or German, but this would have entailed a number of difficulties which would have rendered its publication unfeasible. A smaller publisher would have charged a publication fee, the book would obtain only a fraction of the circulation of an English-language book, and I would have taken much longer to write it in any other language - not least because of my own ligatures to the English language. Not writing it in English would have entailed multiple penalties. Laponce $(2001,186)$ illustrates the issue of viable options thus

In 1998, more than half a million articles were published in the field of chemistry surveyed by the Chemical Abstracts, the most comprehensive of abstracting services ... Out of this ... list covering 70-odd languages, 60 percent were written in English in the mid-1970s. [I]n the mid-1990s, the percentage is over 80 percent. The three closest competitors - Russian, Japanese and Chinese are in the 5 percent range; German stands at 1.5 percent, French at 0.5 percent, Polish at 0.3 percent and all other languages account for a total of only 1.7 percent. If one hopes to get a Nobel prize, the implications are obvious.

11 Icelandic is a case in point: as reported by Ásta Svavarsdóttir (2004), even though most Icelanders claim to speak English well, it has had little influence on Icelandic a corpus study of over 200,000 written and spoken words reveals a negligible proportion of borrowings from English. Svavarsdóttir attributes this to the general feeling in Iceland that their territory, culture and language are under threat and need protecting.

12 Both De Swaan and Van Parijs, in their attempts to account for the spread of English, downplay or disregard somewhat the role of states in consolidating and perpetuating the status of English in the world (see e.g. Phillipson 2009, 251-265).

13 I have discussed this proposal with economists from the International Monetary Fund and the European Central Bank. They found it comical (private communications).

14 As Templin et al. $(2018,64)$ argue, migration already exacerbates the vulnerability of regional minority languages in the EU as states push for monolingualism in the national language(s).

15 It is telling that mainstream translation studies conferences are often monolingual (in English) and rarely offer interpreting services. The European Society for Translation Studies is a case in point. Its parallels with the EU have been scrutinised elsewhere (Leal 2013); its almost all-pervading English-only policy has been criticised by one of its founders (e.g. Snell-Hornby 2014; see also Leal 2010). Organising multilingual conferences and publications is obviously not easy, as I know from experience. But if translation studies cannot be bothered with multilingualism, what does this say about translation studies?

16 These data stem from the World Literacy Foundation (https://worldliteracyfounda tion.org).

17 In international organisations, I am told that a good command of English is a requirement, even if not always an overt one in job announcements. All things 
being equal, a job candidate with English proficiency and little knowledge of other languages will be favoured over a candidate with proficiency in three, four, five other major languages but little or no English skills. Different players in intergovernmental institutions in the EU and the OSCE reported having witnessed that (private communications).

18 Some 75 per cent of Esperanto's vocabulary comes from Romance languages, so speakers of these languages learn it more easily. According to the Universal Esperanto Association, 1,000 people speak it as a first language (https://uea.org/).

19 It must be noted that many are unaware of the fact that Esperanto has its own complex cultural repertoires, including literature, music, etc. As Seán Ó Riain, senior Irish diplomat, reminds us, Esperanto is clearly ahead of its time - "a 22nd Century idea which appeared in the 19th Century". While it is an optimal, culturally rich solution in multilingual settings, we are not prepared to expand our vision beyond the ties between language and state just yet (private communications).

20 See Kraus and Kazlauskaitè-Gürbüz (2014) for an analysis of the EU's role in propagating this.

21 The Conservative and Unionist Party Manifesto 2019 does not give any clues as to the future status of these languages either.

22 British nationals currently employed in EU institutions, bodies and agencies are allowed to keep their posts until they retire. No more British nationals will be recruited after Brexit unless they hold dual citizenship. Some of Modiano's remarks in relation to this are hasty, as he assumes that all Brits working in EU translation and interpreting services will "lose their jobs" (Modiano 2017, 315). Also, as Jeremy Gardner, former senior translator at the Court of Auditors of the EU, notes, the EU might compensate for the lack of inner-circle speakers employed in their language services through freelancers and outsourcing, which it reportedly already does.

23 The prefix "trans-" suggests continuities across and despite borders, implying that cultures are not bounded entities that can be acquired and juxtaposed to one another. When cultures come into contact, new hybrid spaces are created in highly dynamic and localised processes.

24 In the early 2000s, the EU started devising online teaching tools in these families within the European Intercomprehension project (see e.g. de Cillia 2003, 36; Reissner 2010; Gravier \& Lundquist 2011, 88-89). However, the websites of these projects, though still active, have never been completed. Messages promising completion by 2008 are still in place. Other intercomprehension projects were later funded by the EU (see e.g. https://evalic.eu/).

25 It is true that this ideology often does not translate into practice, as an "English is enough" mentality also pervades the EU. Yet, as noted in Section 2.6, language ideologies, when backed by language policies, can gradually lead to renewed language practices.

26 See Grin et al. (2018) for numerous appraisals of the benefits of intercomprehension from a social, educational, political, economic, organisational and cultural perspective.

27 Nordic nations are renowned worldwide for their intercomprehension skills; yet other same-family languages spoken in neighbouring countries are not much further apart. The difference lies in their formal pact, for example, through the Declaration on Nordic Language Policy, to actively foster intercomprehension mainly in schools (see Gravier \& Lundquist 2011, 87).

28 Grin's model pertains chiefly to linguistic injustices in the EU in relation to the UK, but of course the general principle applies to any nations whose languages are in a privileged position. 


\section{Further Reading}

Arzoz, Xabier (ed.). 2008. Respecting linguistic diversity in the European Union. Philadelphia, PA: John Benjamins.

Kraus, Peter A. 2008. A union of diversity: Language, identity and polity-building in Europe. Cambridge: Cambridge University Press.

Levy, Daniel, Max Pensky and John Torpey (eds). 2005. Old Europe, new Europe, core Europe: Transatlantic relations after the Iraq War. London: Verso.

Strasser, Margareta and Christian Ollivier. 2013. Interkomprehension in Theorie und Praxis. Vienna: Praesens.

\section{References}

Adler, Katya. 2020. "Coronavirus: Why fractious EU still believes together is better". BBC News, 23 April. Available at: www.bbc.com/news/world-europe-52383141.

Ammon, Ulrich. 2001. The dominance of English as a language of science: Effects on other languages and language communities. Berlin: Mouton de Gruyter.

Asselborn, Jean. 2020. “Grenzschutz-Fetischismus': Interview by Ingrid Steiner-Gashi”. Kurier, 22 April.

Balibar, Étienne. 2004. We, the people of Europe: Reflections on transnational citizenship. Translated by James Swenson. Princeton, NJ: Princeton University Press.

Balibar, Étienne. 2014. Equaliberty: Political essays. Translated by J amesIngram. Durham, NC: Duke University Press.

Behr, Hartmut and Yannis A. Stivachtis. 2016. "European Union: An empire in new clothes?" In Revisiting the European Union as empire, edited by Hartmut Behr and Yannis A. Stivachtis, 1-16. New York: Routledge.

Blommaert, Jan. 2006. "Language policy and national identity". In An introduction to language policy: Theory and method, edited by Thomas Ricento, 238-254. Oxford: Blackwell Publishing.

Bormann, Werner. 1970. "Sprachenproblem in den europäischen Institutionen". La monda linguo-problemo 2: 114-126.

British Council. 2014. "Demandas de aprendizagem de inglês no Brasil”. São Paulo, Brazil: British Council Brazil. Available at: www.britishcouncil.org.br/sites/default/ files/demandas_de_aprendizagempesquisacompleta.pdf.

Cassin, Barbara. 2014. "Introduction”. In Dictionary of untranslatables: A philosophical lexicon, edited by Barbara Cassin, Emily Apter, Jacques Lezra and Michael Wood, translated by Michael Wood, xvii-xx. Princeton, NJ: Princeton University Press.

Ch'ien, Evelyn Nien-Ming. 2004. Weird English. Cambridge, MA: Harvard University Press.

Chrisafis, Angelique. 2018. "Macron launches drive to boost French language around world". The Guardian, 20 March. Available at: www.theguardian.com/world/ 2018/mar/20/macron-launches-drive-to-boost-french-language-around-world.

Collins, Richard. 1996. "The North Atlantic cultural triangle: The Bermuda syndrome?" In Difference and community: Canadian and European cultural perspectives, edited by Peter Easingwood, Konrad Gross and L ynetteHunter, 13-26. Amsterdam: Rodopi.

Dąbrowska, Marta. 2004. "English impact on the electronic media communication". In Speaking from the margin: Global English from a European perspective, edited by Anna Duszak and Urszula Okulska, 261-274. Frankfurt a.M.: Peter Lang. 
Dahl, Robert A. 1988. On democracy. New Haven, CT: Yale University Press.

Dahrendorf, Ralf. 1979. Life chances: Approaches to social and political theory. Chicago: University of Chicago Press.

de Cillia, Rudolf. 2003. "Tendenzen und Prinzipien europäischer Sprachenpolitik”. In Sprachenvielfalt: Babylonische Sprachverwirrung oder Mehrsprachigkeit als Chance?, edited by Hans-Jürgen Krumm, 27-40. Innsbruck: StudienVerlag.

Derlén, Mattias. 2011. "In defence of (limited) multilingualism: Problems and possibilities of the multilingual interpretation of European Union law in national courts". In Linguistic diversity and European democracy, edited by Anne Lise Kjær and Silvia Adamo, 143-166. London: Ashgate.

Derlén, Mattias. 2018. "Multilingualism and the European Court of Justice: Challenges, reforms and the position of English after Brexit". In The new EU judiciary. An analysis of current judicial reforms, 341-356. Alphen aan den Rijn: Kluwer Law International.

Derrida, Jacques. 1992. The other heading: Reflections on today's Europe. Translated by Pascale-Ann Brault and Michael B. Naas. Bloomington, IN: Indiana University Press.

De Schutter, Helder. 2018. "Linguistic justice and English as a Lingua Franca". In The politics of multilingualism: Europeanisation, globalisation and linguistic governance, edited by François Grin and Peter A. Kraus, 167-199. Philadelphia, PA: John Benjamins.

De Schutter, Helder and David Robichaud (eds). 2015a. "Linguistic justice: Van Parijs and his critics". Critical Review of International Social and Political Philosophy 18 (2).

De Schutter, Helder and David Robichaud (eds). 2015b. "Van Parijsian linguistic justice: Context, analysis and critiques". Critical Review of International Social and Political Philosophy 18 (2): 87-112.

De Schutter, Helder, Nenad Stojanović and Sergi Morales-Gálvez. 2018. "Should minority languages be taught to majority language speakers?" In The MIME Vademecum: Mobility and inclusion in multilingual Europe, edited by François Grin et al., 60-61. Grandson, Switzerland: Artgraphic Cavins.

De Swaan, Abram. 1993. "The evolving European language system: A theory of communication potential”. International Political Science Review 14 (3): 241-255.

De Swaan, Abram. 2001. Words of the world: The global language system. Cambridge: Polity Press.

Dissanayake, Wimal. 2006. "Cultural studies and discursive constructions of World Englishes". In The handbook of World Englishes, edited by Braj B. Kachru, Yamuna Kachru and Cecil L. Nelson. Oxford: Blackwell Publishing.

Dutceac Segesten, Anamaria and Michael Bossetta. 2019. "The Eurosceptic Europeanization of public spheres: Print and social media reactions to the 2014 European Parliament elections”. Comparative European Politics 17: 361-379.

Eco, Umberto. 2005. "An uncertain Europe between rebirth and decline". In Old Europe, new Europe, core Europe: Transatlantic relations after the Iraq War, edited by Daniel Levy, Max Pensky and John Torpey, 14-20. London: Verso.

Edwards, John. 2013. "Bilingualism and multilingualism: Some central concepts". In The handbook of bilingualism and multilingualism, edited by Tej K. Bhatia and William C. Ritchie, 6-25. Malden, MA: Blackwell Publishing.

EU Reporter Correspondent. 2020. “\#Coronavirus - \#RescEU masks delivered to Spain, Italy and Croatia”. eureporter, 5 May. Available at: www.eureporter.co/frontpage/ 2020/05/05/coronavirus-resceu-masks-delivered-to-spain-italy-and-croatia-2/. 
European Commission. 2012a. "Special Eurobarometer 386: Europeans and their languages”. Available at: https:/ec.europa.eu/commfrontoffice/publicopinion/archives/ebs/ ebs_386_en.pdf.

European Commission. 2012b. Studies on translation and multilingualism: Intercomprehension. Luxembourg: Publications Office of the European Union.

European Commission. 2014. "Special Eurobarometer 413: Future of Europe". Brussels: Directorate-General for Communication. Available at: https://ec.europa.eu/comm frontoffice/publicopinion/archives/ebs/ebs_413_en.pdf.

European Parliament. 2018. "Parlemeter 2018. Taking up the challenge: From (silent) support to actual vote”. Brussels: Directorate-General for Communication, Public Opinion Monitoring Unit. Available at: www.europarl.europa.eu/at-your-service/ files/be-heard/eurobarometer/2018/parlemeter-2018/report/en-parlemeter-2018.pdf.

European Parliament. 2019a. "2019 European election results”. 22 October. Available at: www.europarl.europa.eu/election-results-2019/en/turnout/.

European Parliament. 2019b. "Parlemeter 2019. Heeding the call beyond the vote: A stronger parliament to listen to citizens' voices". Brussels: Directorate-General for Communication, Public Opinion Monitoring Unit. Available at: www.europarl. europa.eu/pdf/eurobarometre/2019/parlemeter-2019-heeding-the-call-beyond-the-vote/ report/en-report.pdf.

European Parliament. n.d. "Public opinion monitoring in the time of COVID-19". Available at: www.europarl.europa.eu/at-your-service/en/be-heard/eurobarometer/p ublic-opinion-in-the-time-of-covid-19.

Fiedler, Sabine and Cyril Brosch. 2018. "Should a planned language such as Esperanto be promoted as an international lingua franca?" In The MIME Vademecum: Mobility and inclusion in multilingual Europe, edited by François Grin et al., 150-151. Grandson, Switzerland: Artgraphic Cavin.

Fishkin, James S. 2009. When the people speak: Deliberative democracy and public consultation. Oxford: Oxford University Press.

Fishkin, James S. and Peter Laslett (eds). 2003. Debating deliberative democracy. Malden, MA: Blackwell Publishing.

Fishman, Joshua A. 1967. "Bilingualism with and without diglossia; diglossia with and without bilingualism”. Journal of Social Issues XXIII (2): 29-38.

Fishman, Joshua A. 1972. Language and nationalism: Two integrative essays. Rowley, MA: Newbury House.

Fishman, Joshua A. 1996. "Introduction: Some empirical and theoretical issues". In Post-imperial English: Status change in former British and American colonies, 19401990, edited by Joshua A. Fishman, Andrew W. Conrad and Alma Rubal-Lopez, 3-12. Berlin:Mouton de Gruyter.

Gargesh, Ravinder. 2006. "South Asian Englishes”. In The handbook of World Englishes, edited by Braj B. Kachru, Yamuna Kachru and Cecil L. Nelson, 80-113. Malden, MA: Blackwell Publishing.

Ginsburgh, Victor, Juan Moreno-Ternero and Shlomo Weber. 2018. "The fate of English in the EU after Brexit: Expected and unexpected twists". VOX CEPR Policy Portal. Available at: https://voxeu.org/article/english-language-eu-after-brexit.

Gosseries, Axel and Philippe Vanderborght (eds). 2011. Arguing about justice: Essays for Philippe Van Parijs. Louvain: Presses Universitaires de Louvain.

Graddol, David. 1997. The future of English? A guide to forecasting the popularity of the English language in the 21st century. London: The British Council. 
Graddol, David. 2006. English next: Why global English may mean the end of 'English as a Foreign Language'. London: The British Council.

Gravier, Magali and Lita Lundquist. 2011. "Getting ready for a new tower of Babel”. In Linguistic diversity and European democracy, edited by Anne Lise Kjær and Silvia Adamo, 75-96. Farnham: Ashgate.

Grin, François. 2008. "Principles of policy evaluation and their application to multilingualism in the European Union”. In Respecting linguistic diversity in the European Union, edited by Xabier Arzoz, 73-83. Philadelphia, PA: John Benjamins.

Grin, François. 2010. "Why multilingualism is affordable". Seminario sobre lingua, sociedade i política en Galicia. Santiago de Compostela. 1-15. Available at: www. unige.ch/fti/elf/files/5314/5865/9208/elfwp6.pdf.

Grin, François. 2011. "Interview by the European Commission”. Lingua franca: Chimera or reality? 59-70.

Grin, François. 2015. "The economics of English in Europe”. In Language policy and political economy: English in a global context, edited by Thomas Ricento, 119-144. Oxford: Oxford University Press.

Grin, François. 2018. "On some fashionable terms in multilingualism research: Critical assessment and implications for language policy". In The politics of multilingualism: Europeanisation, globalisation and linguistic governance, edited by François Grin and Peter A. Kraus, 247-274. Philadelphia, PA: John Benjamins.

Grin, François et al. (eds). 2018. The MIME Vademecum: Mobility and inclusion in multilingual Europe. Grandson, Switzerland: Artgraphic Cavin.

Habermas, Jürgen. 1962. Strukturwandel der Öffentlichkeit. Untersuchungen zu einer Kategorie der bürgerlichen Gesellschaft. Darmstadt: Luchterhand Verlag.

Habermas, Jürgen. 2006. Time of transitions. Translated by Ciaran Cronin and Max Pensky. Cambridge: Polity.

Habermas, Jürgen and Jacques Derrida. 2005. "February 15, or, what binds us together: Plea for a common foreign policy, beginning in core Europe". In Old Europe, new Europe, core Europe: Transatlantic relations after the Iraq War, edited by Daniel Levy, Max Pensky and John Torpey, translated by Max Pensky, 3-13. London: Verso.

Hänska, Max and Stefan Bauchowitz. 2019. "Can social media facilitate a European public sphere? Transnational communication and the Europeanization of Twitter during the Eurozone crisis”. Social Media + Society 5 (3).

Holmes, Prue and Fred Dervin (eds). 2016. The cultural and intercultural dimensions of English as a lingua franca. Bristol: Multilingual Matters.

Ives, Peter. 2004. "Language, representation and suprastate democracy: Questions facing the European Union". In Representation and democratic theory, edited by David Laycock, 23-47. Vancouver: UBC Press.

Kachru, Braj B. 2006. "World Englishes and culture wars". In The handbook of World Englishes, edited by Braj B. Kachru, Yamuna Kachru and Cecil L. Nelson, 446-471. Malden, MA: Blackwell.

Kelly, Michael (ed.). 2018. Languages after Brexit: How the UK speaks to the world. Basingstoke: Palgrave.

Kernerman, Gerald. 2004. "The new constitutionalism and the polarizing performance of the Canadian conversation". In Representation and democratic theory, edited by David Laycock, 161-178. Vancouver: UBC Press.

Knaut, Annette. 2014. "Politische Imaginative. Vom Narrativ der Öffentlichkeit zu transnationalen Diskursräumen”. In Politische Narrative: Konzepte - Analysen - 
Forschungspraxis, edited by Frank Gadinger, Sebastian Jarzebski and Taylan Yildiz, 93-117. Wiesbaden: Springer.

Kozak, Jolanta. 2004. "Between catachresis and tautology. Multilingual discourses in translation". In Speaking from the Margin: Global English from a European perspective, edited by Anna Duszak and Urszula Okulska, 145-156. Frankfurt a.M.: Peter Lang.

Kraus, Peter A. 2008. A union of diversity: Language, identity and polity-building in Europe. Cambridge: Cambridge University Press.

Kraus, Peter A. 2011. "Neither united nor diverse? The language issue and political legitimation in the European Union". In Linguistic diversity and European democracy, edited by Anne Lise Kjaer and Silvia Adamo, 17-34. Farnham: Ashgate.

Kraus, Peter A. 2018. "From glossophagic hegemony to multilingual pluralism? Re-assessing the politics of linguistic identity in Europe". In The politics of multilingualism: Europeanisation, globalisation and linguistic governance, edited by François Grin and Peter A. Kraus, 89-109. Philadelphia, PA: John Benjamins.

Kraus, Peter A. and Rūta Kazlauskaitè-Gürbüz. 2014. "Addressing linguistic diversity in the European Union: Strategies and dilemmas". Ethnicities 14 (4): 517-538.

Lamour, Christian and Nathalie Lorentz. 2019. "If I were to do it all over again, should I begin with culture?' The European integration from a cultural perspective in a multinational Grand Duchy". Journal of Contemporary European Studies 27 (3): 357-374.

Laponce, Jean. 2001. "Politics and the law of Babel". Social Science Information 40 (2): 179-194.

Leal, Alice. 2010. "Being a CETRA student”. Scientia Traductionis 7: 190-206.

Leal, Alice. 2013. "The European Union and translation studies: Unity, multiplicity and English as a lingua franca”. Translation Spaces 2: 63-80.

Mac Giolla Chríost, Diarmait and Matteo Bonotti. 2018. Brexit, language policy and linguistic diversity. London: Palgrave Macmillan.

May, Stephen. 2006. "Language policy and minority rights". In An introduction to language policy: Theory and method, edited by Thomas Ricento, 255-272. Malden, MA: Blackwell Publishing.

Modiano, Marko. 2006. "Euro-Englishes". In The handbook of World Englishes, edited by Braj B. Kachru, Yamuna Kachru and Cecil L. Nelson, 223-239. Oxford: Blackwell Publishing.

Modiano, Marko. 2017. "English in a post-Brexit European Union". World Englishes 36 (3): 313-327.

Muschg, Adolf. 2005. “'Core Europe': Thoughts about the European identity”. In Old Europe, new Europe, core Europe: Transatlantic relations after the Iraq War, edited by Daniel Levy, John Torpey and Max Pensky, 21-27. London: Verso.

Ostler, Nicholas. 2010. The last lingua franca: The rise and fall of world languages. London: Penguin.

Phillipson, Robert. 2003. English-only Europe? Challenging language policy. London: Routledge.

Phillipson, Robert. 2009. Linguistic imperialism continued. London: Routledge.

Phillipson, Robert. 2016. "Linguistic imperialism of and in the European Union". In Revisiting the European Union as empire, edited by Hartmut Behr and Yannis A. Stivachtis, 134-163. New York: Routledge.

Phillipson, Robert. 2017. "Myths and realities of 'global' English". Language Policy 16 (3): 313-331.

Phillipson, Robert. 2018. "English, the Lingua Nullius of global hegemony". In The Politics of multilingualism: Europeanisation, globalisation and linguistic governance, 
edited by François Grin and Peter A. Kraus, 275-303. Philadelphia, PA: John Benjamins.

Phillipson, Robert and Tove Skutnabb-Kangas. 1994. "English, panacea or pandemic". Sociolinguistica 8: 73-87.

Rankin, Jennifer. 2020. "Coronavirus could be final straw for EU, European experts warn”. The Guardian, 1 April. Available at: www.theguardian.com/world/2020/apr/ 01/coronavirus-could-be-final-straw-for-eu-european-experts-warn.

Reif-Breitwieser, Susanne. 2011. Wir sprechen zehn Sprachen!Vienna: Bundesministerium für Unterricht, Kunst und Kultur.

Reissner, Christina. 2010. "Europäische Intercomprehension in und zwischen Sprachfamilien”. In Handbuch der Eurolinguistik, edited by Uwe Hinrichs, 821-842. Leipzig: Harrassowitz.

Ricento, Thomas. 2006. "Language policy: Theory and practice - An introduction”. In An introduction to language policy: Theory and method, edited by Thomas Ricento, 10-23. Malden, MA: Blackwell Publishing.

Romaine, Suzanne. 2015. "Linguistic diversity and global English: The pushmi-pullyu of language policy and political economy". In Language policy and political economy: English in a global context, edited by Thomas Ricento, 252-275. Oxford: Oxford University Press.

Rushdie, Salman. 1997. "Damme, this is the Oriental scene for you!" The New Yorker, 23 June, 50.

Savater, Fernando. 2005. "Europe, both needed and in need". In Old Europe, new Europe, core Europe: Transatlantic relations after the Iraq War, edited by Daniel Levy, Max Pensky and John Torpey, 41-43. London: Verso.

Schendel, Herbert, Barbara Seidlhofer and Henry Widdowson. 2003. "Weltsprache Englisch - Bedrohung oder Chance?" In Sprachenvielfalt: Babylonische Sprachverwirrung oder Mehrsprachigkeit als Chance?, edited by Hans-Jürgen Krumm, 181-198. Innsbruck: StudienVerlag.

Shohamy, Elana. 2006. Language policy: Hidden agendas and new approaches. London: Routledge.

Snell-Hornby, Mary. 2014. "EST 2012: A vision fulfilled?” Target: International Journal of Translation Studies 26 (2): 239-246.

Spolsky, Bernard. 1991. "Hebrew language revitalization within a general theory of second language learning". In The influence of language on culture and thought: Essays in honor of Joshua A. Fishman's sixty-fifth birthday, edited by Robert L. Cooper and Bernard Spolsky, 137-156. Berlin: Mouton de Gruyter.

Spolsky, Bernard. 2004. Language policy. Cambridge: Cambridge University Press.

Stegmann, Tilbert D. and Horst G. Klein. 1999. EuroComRom: Die sieben Siebe. Aachen: Shaker Verlag.

Steinhauser, Gabriele. 2016. "English loses currency as Europe's lingua franca after Brexit vote". The Wall Street Journal, 27 June. Available at: www.wsj.com/articles/ eu-to-say-au-revoir-tschuss-to-english-language-1467036600.

Stolton, Samuel. 2018. "Juncker: We are not 'under the rule' of English". EURACTIV, 18 September. Available at: www.euractiv.com/section/english-language/news/junck er-we-are-not-under-the-rule-of-english/.

Strasser, Margareta and Christian Ollivier. 2013. Interkomprehension in Theorie und Praxis. Vienna: Praesens.

Svavarsdóttir, Ásta. 2004. "English borrowings in spoken and written Icelandic". In Speaking from the margin: Global English from a European perspective, edited by Anna Duszak and Urszula Okulska, 167-176. Frankfurt a.M.: Peter Lang. 
Tafel, Karin, Rašid Duric, Radka Lemmen, Anna Olshevska and Agata PrzyborowskaStolz. 2009. Slavische Interkomprehension: Eine Einführung. Tübingen: Narr Francke Attempto.

Templin, Torsten, Bengt-Arne Wickström and Michele Gazzola. 2018. "How important is demolinguistic concentration for the survival of minority languages in a world of increasing mobility?" In The MIME Vademecum: Mobility and inclusion in multilingual Europe, edited by François Grin et al., 64-65. Grandson, Switzerland: Artgraphic Cavin.

Trabant, Jürgen. 2010. “Europäisches Sprachdenken”. In Handbuch der Eurolinguistik, edited by Uwe Hinrichs, 881-898. Wiesbaden: Harrassowitz.

Ushioda, Ema. 2017. "The impact of global English on motivation to learn other languages: Toward an ideal multilingual self". The Modern Language Journal 101 (3): 469-482.

Vallée, Shahin. 2020. "With its recovery deal, is the EU finally starting to act like a unifying force?" The Guardian, 22 July. Available at: www.theguardian.com/comm entisfree/2020/jul/22/recovery-deal-eu-unifying-economic-boost-integration.

van de Steeg, Marianne and Thomas Risse. 2010. "The emergence of a European Community of communication: Insights from empirical research on the Europeanization of public spheres". KFG Working Paper Series 15: 1-30.

van Gunsteren, Herman R. 2018. A theory of citizenship: Organizing plurality in contemporary democracies. New York: Routledge.

Van Parijs, Philippe. 2008. "Linguistic diversity as curse and as by-product". In Respecting linguistic diversity in the European Union, edited by Xabier Arzoz, 17-46. Philadelphia, PA: John Benjamins.

Van Parijs, Philippe. 2011. Linguistic justice for Europe and for the world. Oxford: Oxford University Press.

Van Parijs, Philippe. 2015a. "Lingua franca and linguistic territoriality. Why they both matter to justice and why justice matters for both". Critical Review of International Social and Political Philosophy 18 (2): 224-240.

Van Parijs, Philippe. 2015b. "The ground floor of the world: On the socioeconomic consequences of linguistic globalization". In Language policy and political economy: English in a global context, edited by Thomas Ricento, 231-251. Oxford: Oxford University Press.

Varoufakis, Yanis. 2020. "The EU coronavirus fund will take Europe another step towards disintegration". The Guardian, 24 July. Available at: www.theguardian. $\mathrm{com} /$ world/commentisfree/2020/jul/24/eu-coronavirus-fund-europe-recovery-package.

Vattimo, Gianni. 2005. "The European Union faces the major points of its development”. In Old Europe, new Europe, core Europe: Transatlantic relations after the Iraq War, edited by Daniel Levy, Max Pensky and John Torpey, 28-33. London: Verso.

von Busekist, Astrid. 2018. "Idealism or pragmatism? Ad hoc multilingualism and Open English". In The politics of multilingualism: Europeanisation, globalisation and linguistic governance, edited by François Grin and Peter A. Kraus, 305-332. Philadelphia, PA: John Benjamins.

Warren, Mark E. 2004. "What can democratic participation mean today?" In Representation and democratic theory, edited by David Laycock, 197-219. Vancouver: UBC Press.

wa Thiong'o, Ngũgi. 2009. "Translated by the author: My life in between languages". Translation Studies 2 (1): 17-20. 
Williams, Melissa S. 2004. "Sharing the river: Aboriginal representation in Canadian political institutions". In Representation and democratic theory, edited by David Laycock, 93-118. Vancouver: UBC Press.

Wright, Sue. 2004. "Language rights, democracy and the European Union”. In Language rights and language survival, edited by Jane Freeland and Donna Patrick, 219-242. Manchester: St. Jerome.

Wright, Sue. 2007. "English in the European Parliament: MEPs and their language repertoires”. Sociolinguistica Jahrbuch 21: 151-165.

Wright, Sue. 2011. "Democracy, communities of communication and the European Union". In Linguistic diversity and European democracy, edited by Anne Lise Kjaer and Silvia Adamo, 35-56. Farnham: Ashgate. 


\title{
5 The Future of Language and Translation in the EU
}

\author{
The Language Turn, the Translation Turn \\ and the Transcultural Turn
}

\subsection{Introduction}

One of my chief arguments in Chapter 4 is that the imperative of a common language for the EU should be replaced with the imperative of intercomprehension - a more just and normatively defensible alternative which also fosters the bloc's nascent transnationalism. The previous chapters featured three sets of recommendations to achieve this goal, structured around the language turn, the translation turn and the transcultural turn. In this final, shorter chapter, we will take a closer look at these turns and their accompanying steps and measures, displayed in Table 5.1. Though presented separately, the three turns should be understood as the inseparable components of a whole. For one thing, the rationale behind all three is the same: we need a multilingual modus operandi for the EU grounded in intercomprehension, transcultural awareness and translation. Also, the steps and measures associated with each turn are intimately interconnected and often pertain to all three simultaneously - leaving one or more out would hamper the implementation of the others. Unlike other recommendations made in the area of language policy, such as in the European Charter for Regional or Minority Languages (see Section 2.3) or in Robert Phillipson's English-only Europe? (2003), Table 5.1 is organon-like, i.e. an organic body of suggestions rather than an opt-in/opt-out menu.

These turns have a strong symbolic component, as they require first and foremost gestures of acknowledgement of the language question, as well as a willingness to openly discuss, challenge and rethink language practices and ideologies. In the previous chapters, we saw how different voices share the same fundamental wish regarding EU language policy, namely that one is at long last formulated. The suggestions made here concur with this basic recommendation and are meant as a general orientation for anyone interested in EU language policy. These turns also represent an attempt to heed Jacques Derrida's call to "invent gestures, discourses [and] politico-institutional practices" for a new language ethos in the EU $(1992,44)$.

The language turn will feature in Section 5.2, followed by the translation (Section 5.3) and transcultural turns (Section 5.4). Section 5.5 suggests four areas in dire need of research. 


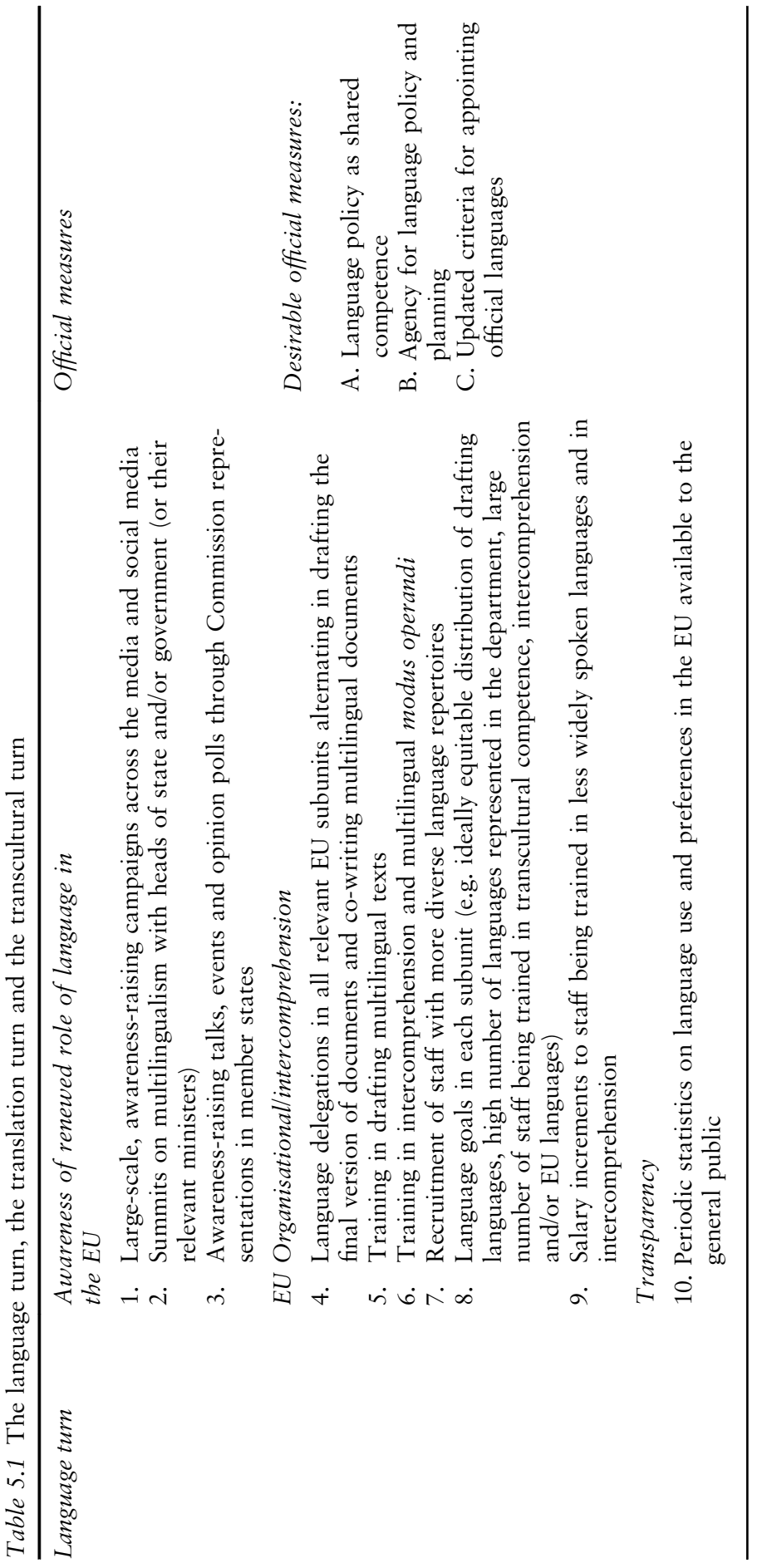



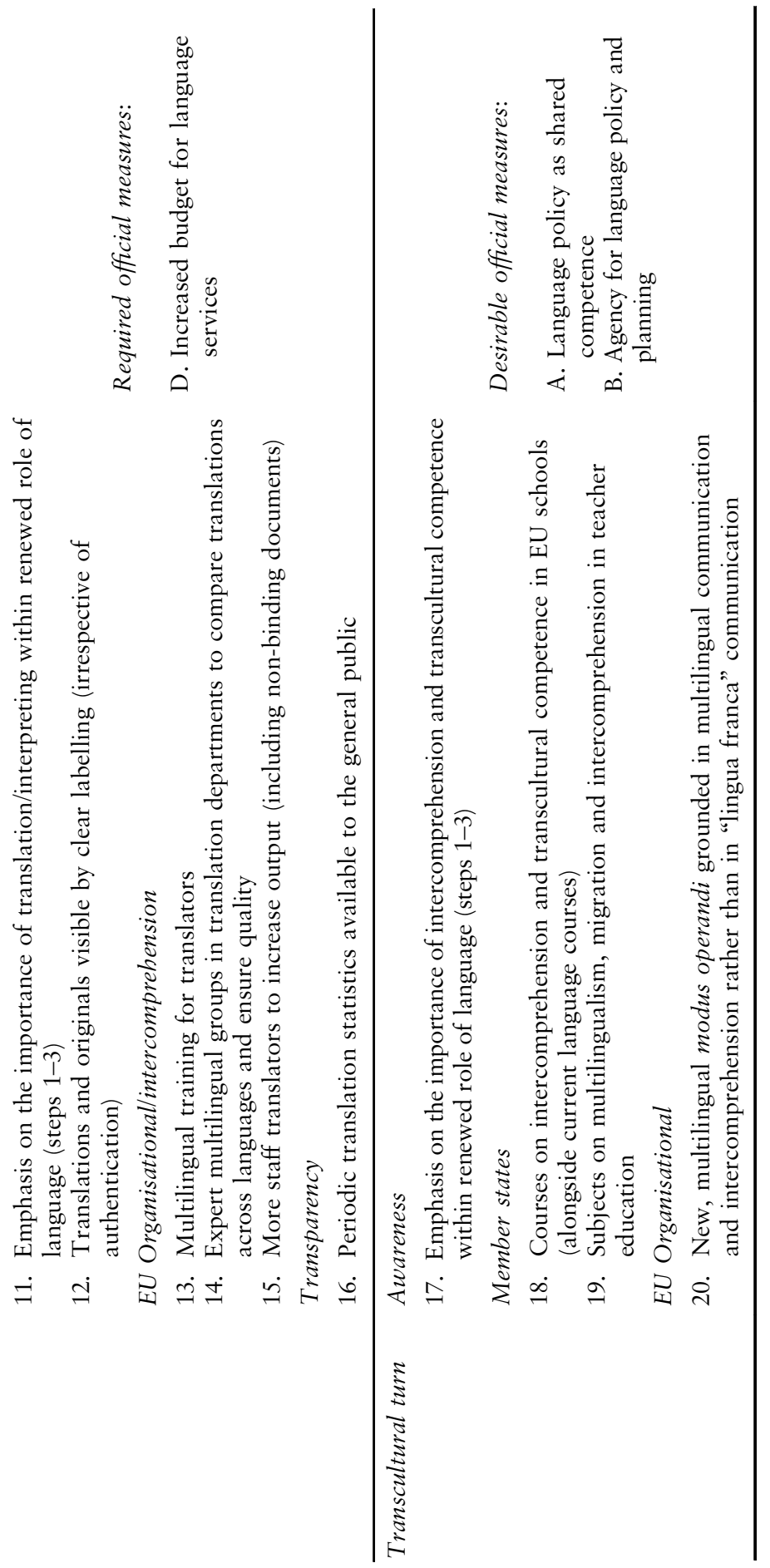


\subsection{The Language Turn}

As noted in Section 1.5, the linguistic turn placed language in the spotlight in philosophy. While earlier language was seen as a possible object of philosophical inquiry, after the linguistic turn, it took centre stage, as an unavoidable subject in any philosophical investigation. A language turn should lead to a similar outcome in the EU.

The current tendency is for the EU to remain caught up in the double bind of unity versus multiplicity. In some areas, multiplicity will have the upper hand, whereas in others unity will prevail. The tension between the two will (and should) never disappear, because this would mean nothing less than the assimilation of all difference. The language turn should take the EU both beyond the paradox of unity versus multiplicity and the reversibility principle discussed throughout this book.

The first step is thus symbolic and entails recognising, much like in the linguistic turn in philosophy, that the question of language cannot be detached from the EU's areas of competence and practices because they exist only in and through language. In this light, EU multilingualism should amount to more than the de jure recognition of 24 languages: only when EU institutions become multilingual will the celebration of linguistic diversity, found in EU discourse, materialise and flow into the member states' language policies, practices and ideologies.

This awareness of the ubiquity of language is the core value in the renewed role of language mentioned in Table 5.1 - a tripartite awareness in fact, as it includes translation and intercomprehension as well (more below). In the language turn, we move from a "language-as-problem" and a "language-as-right" to a "language-as-resource" orientation (see Section 2.6). The three awareness-raising measures proposed should gradually engender new language practices, ideologies and policies (taken broadly here, as overt, covert, bottom-up and top-down) both within EU institutions and in member states. The suggested steps are by no means a panacea that will quickly and effectively instil an appreciation for this renewed role of language. When repeated over the years, however, they could lead to new language policies, practices and ideologies - not unlike an appreciation for environmental issues, for example, was gradually instilled in the past decades and became de rigueur among younger generations, as already noted.

The second set of efforts (steps 4-9) comprise organisational steps to make the EU more multilingual internally. They overlap with steps 13 and 20, in that they call for EU staff to be trained in intercomprehension and transcultural competence and to gradually change their modus operandi from the need for a common language (usually English) to multilingualism through intercomprehension. Step 9 resonates with Sue Wright's suggestion for the European Parliament whereby MEPs' language skills should be reflected in their pay, given that "multilinguals facilitate the European political process" and ultimately help save money (2007, 163). This could be extrapolated to all staff, as a means to nudge them to become more multilingual. Though partially in place already, this salary increment scheme should be expanded, and the language teaching programmes reformed. 
Some of the EU staff interviewed for this book report that the language programmes have been "dismantled" gradually as a result of the diffusion of English (private communications).

There should be no fixed standards for establishing what a "more diverse" language repertoire is. In steps 7-9, this criterion should reflect the linguistic reality of each subunit at a given moment in time, considering both the languages new staff bring to their workplace and the language and intercomprehension skills acquired later.

The last measure pertaining to the language turn (step 10) has been mentioned repeatedly in this book and is probably among the most urgent. Surveys on EU citizens' and permanent residents' languages should be detailed, aiming at providing an accurate portrait of language policies, practices and ideologies. These surveys should include questions about people's language repertoires (the language(s) in which they were socialised, their current home language(s), their work/education language(s), other language(s) used in other realms, along with the motivations behind their particular language choices); their beliefs about language choice, language learning and the value (both symbolic and concrete) of their respective languages; their language practices in all relevant realms.

The EU's discourse on language (and arguably its language ideologies) is already partly compatible with the "renewed role" of language proposed here. The push for EU education systems to offer at least two foreign languages, including neighbouring languages, and for everyone to take on a "personal adoptive language" (i.e. a language "different from [their] language of identity, and also different from [their] language of international communication") are clear signs that the EU does not see bilingualism with English as sufficient or desirable, at least in theory (European Commission 2008, 7). In practice, however, monolingualism in English (and sometimes in French) are enough in EU institutions, bodies and agencies. A change in language practices, better aligned with the EU's discourse on language, is thus urgently needed.

The language turn would be greatly facilitated by the official measures listed in Table 5.1. Nonetheless, it is clear that they seem unlikely as they would require unanimity among member states. Still, if we perceive the language turn as a process whose fruits will be reaped by future generations, it is not unimaginable that initial, small steps could slowly gain momentum and prepare the ground for more thorough reforms.

The first of such desirable - albeit unlikely - measures is making language policy a shared EU competence, like the internal market or the environment. A shared competence means that both the EU and the member states can legislate and adopt legally binding acts (see Article 4 of the Treaty on the Functioning of the European Union, TFEU). Although the steps pertaining to the language turn and listed in Table 5.1 do not require any legally binding acts, making language policy a shared competence would be a welcome development in view of the gross injustices and discrepancies among EU countries regarding the protection, rights and recognition of linguistic minorities (addressed in Section 2.3). This kind of linguistic injustice and inconsistency would be anathema to 
a post-language-turn EU, hence the need for a formal means for the EU to intervene in these matters. When there is more unity is policy, there can be more multiplicity in practice.

The second desirable official measure is a truism, as so many others have pleaded for it before: creating an agency for language policy and planning. Niamh Nic Shuibhne, for example, makes a strong point in this regard:

There is ... no linguistic coherence in EU language planning ... there seems to be no planning at all. How can a situation in which Irish acquires enhanced status, Catalan acquires none, while trademark, patent and even Euro job applications must be submitted in fewer and fewer languages be seen as progress? ... We do not just need ... an Agency for Linguistic Diversity and Language Learning. We need an EU Agency for Language Planning, which can take an overview of all linguistic needs and linguistic developments, and the complex interactions among them, and which can attempt to devise a more rational yet ideologically sound EU language scheme. Otherwise, the linguistic dimension of EU citizenship will have no meaningful substance. And virtually all EU language questions will become the stuff of "minority".

(2008, 138-139; see also Phillipson 2018, 294-295)

Ideally, this agency should not be centralised but include local representations in the member states - along the same lines or even in coordination with the Commission's local representations. This would ensure that their actions reflect local needs and plural realities and include all players, from policy-makers and government representatives to educators and parents.

If a dedicated agency is off the table, the EU should at the very least reconsider the institutional framing of multilingualism, which is currently under the auspices of the DG Translation. As noted earlier, between 2007 and 2010, multilingualism was granted its own portfolio under Commissioner Leonard Orban. Back then, the DG Translation was under Orban's aegis. Multilingualism was later merged with the portfolio for education (whose name changes with every new Commission presidency) and finally abolished altogether. The DG Translation is now under the Commissioner for budget and administration, Johannes Hahn, and remains in charge of multilingualism in the EU, even though it has no subunit dedicated to it. With its staff working around the clock to meet translation deadlines, having a specific department to represent multilingualism would be a basic step in the right direction (more in Section 5.3). Whether as its own body or as a subunit in the DG Translation, this language policy and planning agency should oversee and coordinate efforts with the member states as regards all steps listed in Table 5.1. It should, in other words, act as a multilingualism watchdog across the EU.

The third desirable measure refers to the number of and criteria to appoint or remove official EU languages. As remarked in Section 4.7, existing legislation is either insufficient or ambiguous in terms of how many languages can be appointed by each member state and, crucially, what happens should a member state leave the Union. If, say, Hungary voted to withdraw from the 
EU, should Hungarian be excluded as an official EU language? How about the large Hungarian-speaking minorities in Austria, Croatia, Romania and Slovakia? If the Council of Ministers unanimously decided to remove Hungarian, these populations (over a million in Romania alone) would be left in the lurch. If, however, a consensus were blocked, we would have the extraordinary situation - at least considering current EU regulations - whereby a minority language in a few member states would retain official status despite not being a national language in any current EU country. Not introducing concrete, detailed criteria for adopting and excluding official languages post-Brexit risks becoming another instance of the EU's lackadaisical treatment of language.

If English retains its official EU status, this should be explained by the EU either as a special and unique circumstance because English is the EU's lingua franca, or as an exception allowed because of Ireland, in which English is a national language and the de facto tongue of the vast majority of the population - and, to a lesser extent, because of Malta, too. The former option would not be without its controversies, while the latter would mean that other member states would be likely to seek official EU status for their additional national languages. First in line would be Cyprus with Turkish and Luxembourg with Luxembourgish, and others might consider elevating their larger minority languages to catapult them to EU officialdom.

Officially and publicly addressing the post-Brexit role of English in the EU should be the stepping stone towards a robust set of regulations for adopting and excluding official languages. One obvious option would be to introduce a numeric criterion in addition to the national language criterion, so that larger minority languages deprived of national status could seek EU officialdom. All linguistic minorities at least as large as the smallest national linguistic majorities - currently Irish and Maltese - should be gradually included in the club of official EU languages, provided that they meet certain criteria (number of translator and interpreter training institutions and number of translators and interpreters available in the relevant language combinations). Arabic, Catalan, Russian, Romani languages, Tamil, Turkish and others would be strong contenders. In the fictitious Hungarian example mentioned earlier, the numeric criterion would make it easier to decide whether a given language should lose its official status upon the withdrawal of its respective EU country. In that concrete example, Hungarian would retain its official status even if Hungary were to leave the Union, since its number of speakers in other member states is larger than the EU's smallest national linguistic majorities.

The question whether allochthonous and non-territorial languages should also be included in the numeric principle is controversial, as argued in Section 2.3. Moreover, the criteria to determine how many speakers a certain language has are by no means straightforward. Here Irish is an extreme example, with estimates ranging from 44,000 to 170,290 native speakers, 73,803 daily speakers outside school, and 1,761,420 speakers. These issues make the creation of an EU agency for language policy and planning with a diverse team of experts all the more urgent, as only a group of specialists could lay down the foundations of EU language policy. In any case, as argued earlier, excluding migrant and 
non-territorial languages seems hardly justifiable considering the number of EU citizens ${ }^{1}$ (not to mention permanent residents) whose mother tongues are not autochthonous.

Adopting additional official languages begs the question of costs. Though we know that the EU's language services only take up roughly 1 per cent of its total budget, we also know that member states are unwilling to increase their contributions. A solution - at least temporarily - lies in the compromise already in place: Basque, Catalan and Galician are co-official languages subsidised by Spain. A similar arrangement could ease the adoption of new coofficial and official languages of linguistic minorities that met the numeric criterion, with contributions flowing both from the respective member states and from third countries, in the case of allochthonous languages. ${ }^{2}$

These three desirable measures could be seen as steps towards a closer, more federation-like Union. Their implementation is almost unthinkable now, as the widespread no-policy language policy endorses the notion that monolingualism with English and bilingualism with one official EU language and English are enough, as well as the view that languages are a dispensable, negligible factor in European integration. The language turn should gradually transform these practices and ideologies and pave the way for these reforms in the long term.

Regarding the first and second measures, a two-speed $\mathrm{EU}^{3}$ could be a viable alternative - much like in the introduction of the euro. In other words, initially only a handful of member states - which met certain language policy criteria would have language policy as a shared EU competence and rely on a dedicated agency. The objective would be to include all EU countries eventually and, again like environmental policy, the hope is that the language-related injustices and negligence witnessed today would gradually become anathema.

One final remark: the way the language turn is described here, it is an awarenessraising, transformative process enacted in a top-down fashion. This does not preclude the possibility of these steps, if taken by the EU, leading to bottom-up initiatives as well, which in turn could help create ideological and physical space for renewed language practices and ideologies. One example: a primary school teacher who received training in multilingualism, migration and intercomprehension, and/or who attended events organised by her local Commission representation on the renewed role of language in the EU, and/or who took part in opinion polls about language diversity, and/or who followed the news on the EU's awareness-raising campaign about multilingualism - this teacher would most likely introduce language practices in her classes and convey certain language ideologies in her discourse about multilingualism, which could gradually lead to the establishment of new language policies in her school and in her other realms of influence (such as her family, circle of friends, religious or leisure groups, etc.). This admittedly archetypal example embodies top-down and bottom-up measures in a virtuous circle. We should not underestimate the role of "agency" in implementing the language turn - nongovernmental initiatives, grassroots initiatives and the agency of individuals should ultimately contribute just as much as top-down measures to the goals of the language turn (see e.g. Hornberger 2006, Shohamy 2006, Bale 2015). 


\subsection{The Translation Turn}

Much like the linguistic turn in philosophy in the early twentieth century, a translation turn (also called the "translational" and "translative" turn) is now gaining momentum in the humanities (see e.g. Bachmann-Medick 2009; Arrojo 2010). This is due to the awareness that translation (sensu lato) permeates all our exchanges, be they economic, political, social, cultural, linguistic, and so on. The intense migration flows of the past few years have heightened this realisation, as contact and conflict take centre stage in different disciplines. The translation turn in the humanities has been foreshadowed by different thinkers, notably by Derrida in the 1980s, as he attributed the "origin of philosophy" to "translation or the thesis of translatability", arguing that without translation and translatability or, in other words, without the possibility of establishing truth and meaning across languages, there can be no philosophy (Derrida 1985, 120). Seen through this prism, translation becomes a precondition of sorts, an inescapable issue in the humanities and beyond ("there is no outside-text"; Derrida 1997, 158).

The translation turn proposed here is rooted in this very realisation, too: while everything takes place in language (the language turn), our exchanges, interactions, differences and conflicts are underpinned by a translation dynamic. Therefore, like the language turn, the translation turn should begin by raising awareness through those same steps suggested for the language turn - step 11 in Table 5.1. The second awareness-raising step (step 12) entails making translations visible by labelling texts as translations or originals and maintaining authentication in place, as argued in Chapter 3. This would be key to step 16 as well, pertaining to statistics and transparency towards the general public regarding the EU's language hierarchy.

Steps 11 and 12 are about normalising and making translation visible, thus breaking the deadlock recognised, for example, by Magali Gravier and Lita Lundquist, whereby the EU cannot capitalise on translation as a "successful redistributive policy" because translations are condemned to invisibility (2011, 93). Put differently, most public policies tend to bring about visible results, which can then be used to gather political support. When the fruits of a policy are invisible - albeit widespread, as is the case with translation - it becomes more difficult to justify its existence. Let it be noted that these steps also dovetail with the multiple and longstanding efforts to raise the status of translators in society - both from within translation studies and by practising translators (see e.g. Arrojo 1998).

Incidentally, the European Commission launched the campaign \#DiscoverTranslation in September 2020 to achieve precisely this. With the slogan "translation all around us", they hoped to raise awareness of the importance and ubiquity of translation, "highlight[ing] its vital role in our daily life" (European Commission n.d.). The campaign's website includes seven info sheets on topics such as translation myths and machine translation. The first of these info sheets, entitled "Imagine a world without translation", opens as follows: "Without translation, the world would be a duller, poorer and more unequal place, both economically and culturally, where only the 'happy few' 
with a knowledge of other languages would have access to goods, information and culture from other countries." The irony is that all seven info sheets are available in English only.

Campaigns such as this go hand in glove with the awareness-raising measures proposed in Table 5.1, but their potential is reduced without the accompanying steps to make translations visible and to expand language services to make languages other than English visible, too.

Furthermore, the question of communication is key as regards not only the language of the campaign, but also its transmission channels. Claudia Kropf, from the European Commission's Representation in Austria and translator at the DG Translation, called my attention to the initiative, which I otherwise would not have come across. Online campaigns can be hugely influential, but risk remaining trapped within their initiating bubbles - the campaign's hashtag had only been tweeted 315 times in the first weeks of September, when it started dwindling. Adding further activities to boost the campaign, such as podcasts, webinars, talks and workshops, and coordinating their efforts with local players, such as universities, associations of translators and interpreters, translation agencies, schools, libraries, language-related NGOs, the media, among many others, would be crucial to its success.

Coming back to the need to make translations visible, it goes without saying that clearly labelling documents as translations or originals implies the need to strive for some balance in the distribution of source and target languages. As noted in Section 3.7, perfect equality is impossible, but a few (admittedly fundamental) changes to the EU's modus operandi should help revert the current one-language-only trend. These changes pertain to all three turns proposed here; specifically regarding translation, they amount to offering training in multilingual work strategies and to officially entrenching multilingualism in every department and subunit (steps 13 and 14 in Table 5.1). Based on the conversations I have had with EU employees - especially EU translators - for this book, it seems clear that a move towards more multilingualism would be welcomed by many. Kropf, for example, admits she would love to work with multilingual texts, but points out that this would require longer deadlines and additional training (private communications).

Step 15, already mentioned in Section 3.7, refers to the expansion of the EU's language services, requiring a more generous budget (measure $\mathrm{D}$ in Table 5.1). Recent surveys reveal EU citizens already see translation positively, despite its invisibility; the language turn could gradually engender new language ideologies, practices and policies, leading to an even more positive perception. This would hopefully result in a willingness to invest more and expand these services, allowing them to hire more translators and increase the output in languages other than English. ${ }^{4}$

However, the DG Translation warns that the current "trend" is not to hire more in-house translators but rather to "to exploit as much as possible progress in language technologies (including machine translation) and further use of external freelance translators" (see the Appendix). The importance of 
machine translation in optimising the DG Translation's colossal amounts of work is undeniable. Freelance translators are also key across EU institutions, as their sheer numbers make evident (see Section 3.2). Yet it seems regrettable that the "trend" should not be to hire in-house staff, as both external translators and translation software should merely complement the work carried out chiefly by internal translators. The DG Translation's statement could be misconstrued, particularly by laypersons, to mean that their budget can be cut back anyway and that in-house translators can be replaced with (cheaper) external translators and machine translation after all.

Also, the DG Translation adds that "managing demand" is more important than upping supply - a controversial viewpoint, particularly in the context of an ever-expanding EU. They doubt that non-binding information should be translated at all, an attitude which epitomises the "English-is-enough" mentality and poses difficult questions regarding the democratic access to information in the EU (see Table 4.1). When speakers of certain languages have privileged access to information, and when this privileged access is brushed aside by the main EU body devoted to multilingualism as an unavoidable by-product of the spread of English around the world, it is time to rethink the role of language and multilingualism in the EU.

The translation turn proposed here should result in more translation and more translations in the EU. More "translation", in the singular, as in the willingness to communicate with and take a step towards others despite our differences. "Translation", in the sensu lato encapsulated in the translation turn in the humanities, represents an automatic openness and an unrelenting willingness to understand others. "Translation" does not mean absence of conflict or a guarantee of perfect understanding or total equivalence; rather, the focus lies in the fundamental disposition to reach out to others and acknowledge our differences. It is as Paul Ricoeur puts it in relation to a new ethos for Europe grounded in "linguistic hospitality" and in the "ethical requirements of translation": "It is really a matter of living with the other in order to take that other to one's home as a guest" (1996, 11, 12). And we need "translations" (and interpreting), in the plural, as one of the gestures through which this openness towards others materialises, access to information is democratised and a level playing field is created. Though this may seem obvious, let it be noted that the gesture of linguistic hospitality implied in translation and interpreting has little to do with settling on a common language which is often no one's home.

Having more translation and translations, normalising translation and making it more visible also mean understanding translation and interpreting in their complexity, as well as embracing them as sophisticated, legitimate and desirable tools to achieve communicative goals. The three turns proposed here should help dissociate translation and interpreting from the age-old preconceptions that they are easy, more-or-less automatic tasks which, alas, always fall short of their goals.

At present, the Commission's translation rationale seems utilitarian and mechanistic - a state of affairs identified before the millennium by, for instance, 
Kaisa Koskinen (2000; see also 2008). The DG Translation's claim that they need better translation technologies, more freelance translators and a reduced translation demand suggests that their focus lies on producing as many translations as quickly and cost-effectively as possible - which is of course understandable. Yet this rationale is not only at odds with current developments in translation studies, but also casts a shadow over the role of translations and translators in the EU. Koskinen warns that EU translation is less about communicating effectively than about producing "monuments" as "proof of linguistic equality" (2000, 51). How, why, for what purposes and for whom translations are done are less important, as long as a translation exists. She reveals alarming details of the translation culture at the DG Translation, including the fact that "surface-level similarity" (i.e. similar text length, structure, punctuation, distribution of sentences, list items and paragraphs) is often all that counts, not least because there is no multilingual unit to compare all 24 language versions (ibid., 54; more in Section 5.4). There is little time for stylistic questions, resulting in "Finnish EU translations" sounding like "propaganda material of the former Soviet Union" (ibid., 61). She also stresses that the invisibility of translations and translators is not only external but internal, too:

[T] he army of Commission translators works mainly "undercover" and unbeknown to the other participants in the process. Writers are physically and emotionally detached from translators, and often demonstrably unaware of the nature of translation. For the writers, the translation service seems to be like a machine: you just pull the lever and the required number of new language versions miraculously appear. Background material or extratextual information about the intended use of the translation is seldom offered ... From the point of view of the translator it sometimes genuinely feels like being locked inside a machine with two black holes: from one of them, out of nowhere, enters the source text, from the other one, the finished translation disappears into the great unknown.

(ibid., 60-61)

Surely a lot has changed since Koskinen's experience at the DG Translation in the 1990s. There are now language departments, more focus on quality control and editing of original texts, translation guidelines, among others. Yet Koskinen's call for the Commission to "rethink the role of translators" has not been heeded.

Removing translation from this utilitarian and mechanistic framework also entails lifting the stigma associated with it. Wright's research in the European Parliament reveals that MEPs often feel forced to use English (and less often French) to avoid translation and interpreting and thus to remain "in control of their text as far as possible" (2007, 159). Perhaps if MEPs had their own interpreters and translators and were accustomed to working directly with them, they would feel more comfortable with having their words conveyed in different tongues. When decision-makers start having their own translators 
and interpreters (and not an assistant whose English is rather OK), and when these translators and interpreters start being seen and given credit for their pivotal work - instead of remaining an "undercover army" - translation will be normalised and its status elevated.

Finally, anglophone epistemicide is mentioned in Section 3.7 but does not feature in Table 5.1. Ideally, the renewed role of language encapsulated in these turns should help raise awareness among translators, interpreters, language experts, along with scholars and students in the relevant fields, about the effects of epistemicide and how to thwart it. Despite their stubborn invisibility, translators and interpreters do hold some power to subvert these patterns not only by adopting translation strategies that counteract epistemicide, as argued earlier, but also by trying to influence decision-makers, such as translation commissioners, editors and publishers. As for translator/interpreter training, multilingualism and English as a lingua franca have long been a part of university curricula, at least in Europe. Addressing the phenomenon of epistemicide in our classes and conducting research on it would be crucial to raising awareness of it among future generations of translators, interpreters and researchers.

However, combating epistemicide does not mean condoning an "anything goes" attitude towards the English language. Epistemicide is just as common as the assumption that everyone speaks - and can write in - English without the help of translators, interpreters and proof-readers; that we, outside the inner and outer circles, have appropriated English and hence can use it as we please. The much-needed relativisation of such notions as "native speaker" and "grammatical error" should and must not lead to an "anything goes" mentality - against which even the staunchest defender of the English as a lingua franca paradigm will warn (see e.g. Jenkins 2009). We can embrace the hybridity of language, very much in line with contemporary reflections in philosophy of language and linguistics discussed in Chapter 1, while at the same time opposing epistemicide and complying with anglophone grammatical rules. The number of English-language publications containing grammatical deviations is astounding and, paradoxically, they do a disservice to the fight against epistemicide by compromising their own credibility. Allowing thought patterns and rhetorical strategies of our other languages to emerge in our English is not the same as writing poor English. ${ }^{5}$

\subsection{The Transcultural Turn}

The third and final turn put forward here, the transcultural turn, is crucial for two main reasons: first, because it cuts across the other two turns and, second, because it renders them more feasible. Without the transcultural turn, we might find ourselves in an EU in which more lip service is paid to the symbolic value of multilingualism, in which more is translated into more languages, but which remains de facto monolingual in English, with English maintaining its position of most common drafting language and automatic common denominator in most exchanges. It is as Virginie Mamadouh puts it: "the pertinent question for the EU is not so much 'How many languages?' or 'Which languages?' ... as 'How should 
the mediation between speakers of different languages be organized?'” (2002, 341). While the language turn and the translation turn stress the role that multilingualism and translation play in this latter question, the transcultural turn adds the vital aspect of de facto multilingualism.

As noted in Section 4.8, the transcultural turn encompasses intercomprehension and transcultural awareness and competence. As in the language and translation turns, the transcultural turn should begin with those same awareness-raising measures that highlight the renewed role of language in the EU (step 17 in Table 5.1).

The next steps (steps 18 and 19) should implement the transcultural turn in the member states' education systems, ideally through transcultural awareness and language-family-based intercomprehension lessons. To enable teachers to conduct these courses, subjects on multilingualism, migration and intercomprehension should (at long last) be introduced into teacher education (see e.g. Dannerer et al. 2013). Translation also plays a pivotal role in these steps: raising awareness of its importance and complexity as a key strategy for a more multilingual EU should be one of the targets of these new courses aimed at school pupils and educators alike. Realistically, these steps could only be achieved if official measures A and B were taken as well, i.e. if language policy became a shared EU competence and if an agency for language policy and planning were created to help coordinate these efforts. After all, at present, the EU already advises teaching two foreign languages, one of which being a less widely spoken and preferably a neighbouring language - a far cry from the actual language policies and practices (see Section 2.7).

As noted earlier, the EU is unlikely to take measures A and B, at least at first, and although this would hamper the implementation of steps 18 and 19, a transcultural turn in EU schools and universities could still be engendered from grassroots levels. The project Wir sprechen zehn Sprachen! [We speak ten languages!] illustrates that educators can capitalise on their pupils' language repertoires to introduce both transcultural awareness-raising activities and language teaching strategies that foster intercomprehension (Reif-Breitwieser 2011). This can be achieved without additional resources or curricular reform; without, in other words, top-down measures coming from the EU, national government, local authorities and/or school direction. Indeed, educator agency as regards language policy and planning has a special place in language policy research (see Sections 2.6 and 2.7). As already mentioned, the hope is that both bottom-up and topdown initiatives would feed into a virtuous circle of multilingualism.

Austria is a case in point. As an early signatory to the European Charter for Regional or Minority Languages (see Section 2.3), Austria went on to grant Burgenlandcroatian, Czech, Hungarian, Romani, Slovak and Slovenian special regional rights. It is also one of two EU member states in which teacher training includes subjects on multilingualism, particularly with a view to the integration of migrant pupils (see Section 2.7). ${ }^{6}$ Therefore, it does not come across as an exceedingly backward country in terms of language policy. Yet, 90 per cent to virtually all primary school and lower secondary school pupils 
learn English as a foreign language. And even though Austria is also among the few EU member states that offer mother-tongue tuition, these classes are limited and take place mostly outside school hours.

In Vienna, for example, where German is not the home language of about 50 per cent of all pupils starting school, there are only seven bilingual primary schools, all of them in English and German (see Österreichischer Integrationsfonds 2018, 4; Burger 2020, 3-4). ${ }^{7}$ But Austria does not have large communities of immigrants from English-speaking countries - the number of all inner-circle nationals residing in Austria did not reach 23,000 in 2017. In the same year, there were 120,988 Serbian, 116,877 Turkish, 99,634 Romanian, 94,535 Bosnian, 75,616 Hungarian and 75,559 Croatian nationals in the country - to mention only the largest groups. The fact that the city is willing to invest in bilingual tuition, which costs significantly more as additional staff and resources are needed, is a welcome sign. Learning and experiencing English with the help of native teachers from early on will certainly open many "gates" in these children's futures. But should the education system not also cater to the needs of those pupils entering primary school whose family language is not German (nor English)? Some speak of a lost generation of multilingual children in Austria - chiefly because the system is not designed for them, but rather for "ideal", monolingual pupils (see e.g. Erkurt 2020).

As argued in earlier, languages are not dispensable; they cannot simply be substituted by the national language (and/or English) without serious consequences for these children's "ligatures", self-esteem and future prospects. ${ }^{8}$ Also, multilingual children still do systematically worse at school compared to monolingual children, despite the fact that multilingualism has been proven to bring cognitive advantages. In this sense, the transcultural turn proposed here is about mobilising multilingualism as an asset.

Next, step 20 refers to the EU's internal language regime and is the logical consequence of the organisational and intercomprehension measures pertaining to the language and translation turns. The objective of this step is to gradually replace the EU's often monolingual internal modus operandi, grounded in lingua franca communication, with a multilingual work culture.

The transcultural turn would be crucial to transforming the EU into a "laboratory for learning an intercultural competence which can be politically effective" and to implementing strategies that "allow for a reflective "processing' of diversity" (Kraus 2008a, 99). Currently, EU multilingualism often means institutional monolingualism in English or individual bilingualism in a national language plus English (and sometimes French). Those who do not fit into this model are pushed into it in the education system; those who still do not fit into it are penalised by the lack of options their language ligatures offer, or the lack of gates they open (see Section 4.4). A multilingual EU should, instead, cultivate institutional multilingualism, grounded in language services and intercomprehension, and individual multilingualism, chiefly through a reform of education systems (see e.g. de Cillia 2003). These two pillars should be erected simultaneously, culminating in a gradually more multilingual EU. 


\subsection{Areas in Urgent Need of Research}

There are at least four key areas mentioned in this book that require urgent research. Any developments in these fields would be of utmost relevance to the issues discussed here. The first refers to the role of the English language in EU member states. How many people use it as their home language? How many have replaced other home languages with English and why? How many use it, how often and where/when? In Austria, for example, language-related statistics are collected based on a monolingual ideal. Participants are asked about their Muttersprache [mother tongue] and can only give one answer. Yet there are so many children like mine, particularly in Vienna, who grow up speaking two or more languages (see Ogris 2020). ${ }^{9}$ Dynamic processes of language "addition" and "subtraction" are not at all picked up by these traditional censuses. Think of all those friends and acquaintances whose language regimes I surveyed for this book (see Section 4.4): say, an English-speaking couple with one German and one Portuguese native speaker will simply answer "German" and "Portuguese". The facts that their home (and possibly also work) language is English and that their children are being socialised in English go unnoticed. These surveys are at odds with the linguistic reality of vast sections of the population and need urgent updating in line not only with the demographics, but also with the "latest" (starting in the 1960s) developments in linguistics.

This data crisis is a symptom of the EU-wide no-policy language policy and highlights the need for an agency for language policy and planning. It also lays bare the EU's and the member states' lackadaisical attitude towards language policy: when they opened up the borders, introduced EU citizenship and encouraged everyone to work and live in different EU countries, no one seems to have thought about the impact that these migration flows would have on language. Ideally, they should have come up with language policies to accommodate the dramatic increase in linguistic diversity that ensued, particularly in schools. ${ }^{10}$ Collecting thorough, up-to-date data according to current scientific standards is not simply about providing a snapshot of a region's language regime; more importantly, it is about generating tools to deal with multilingualism in a fair way to all involved (see Mamadouh \& el Ayadi 2018).

The second area that needs urgent research refers to the so-called de-territorialisation of EU law. In a nutshell, because EU law is supranational, key EU legal terms should as far as possible not coincide with basic national legal terms to avoid confusion. ${ }^{11}$ In other words, EU law should not be directly associated with any particular national legal system. This is stated, for instance, in the main EU-wide guide for drafting legislation (European Union 2015, section 5). Yet there is a puzzling discrepancy between legal drafting and legal translation in the EU, across which I came almost by accident. When interviewing Jeremy Gardner, former senior translator at the European Court of Auditors and author of the controversial ${ }^{12}$ guide "Misused English words and expressions in EU publications", I pointed out to him that some of the terms listed in his guide as "misused English words" might have been chosen 
on purpose, due to the principle of de-territorialisation of EU law. Indeed, a less familiar English word or expression might have been selected to avoid associations with EU English-speaking legal systems. But Gardner had never heard about this principle of de-territorialisation, and neither had any of his colleagues across different EU institutions or any of the EU translators whom I interviewed. A few translators who wish to remain anonymous said the principle is "nonsense" and "a post hoc excuse" for the fact that EU law is "heavily influenced by French jargon".

However, two different legal experts in the Legal Service of the European Commission confirmed, in the name of the head of the unit, Daniel Calleja Crespo, the validity of this principle, but admitted they have nothing to do with the translation unit and hence cannot account for the fact that the translators whom Gardner and I contacted seem to be unaware of it. I then consulted the DG Translation, which confirmed that this principle is largely in place but added that the situation is complex. From some of the translators, I get the feeling that what matters is that translations exist, and not what they are like (to refer back to Koskinen 2000). Gardner, for example, argues that it is "very difficult" to change the translation of a legal term which already features in multiple documents (private communications). Machine translation plays a pivotal role here as well, as it guides translators' terminological decisions by matching words with their previously used translations (and mistranslations). Given the relevance of translations in the EU, it is somewhat disconcerting that this crucial issue of drafting and translation strategies does not seem to be handled consistently throughout the institutions. As translators, we decide on our strategies before we embark on a translation project. This decision is paramount and permeates all subsequent decisions; whether the translation is going to be read as a familiar or as an unfamiliar text is a direct outcome of this fundamental choice. Due to time and space constraints, I decided against taking up this additional question in this book, but it would be important to verify which drafting/translation strategies are employed, as well as how much awareness of it and how much coordination among legal drafters and translators there is across EU institutions, bodies and agencies.

Which brings us to the third pressing question that requires further research, namely the role of language and translation in the Brexit vote. If we agree with Gardner that the EU's unofficial lingua franca, English, contains numerous deviations from inner-circle norms, have these deviations helped alienate British voters? As noted earlier, the leave campaign capitalised on language issues and mistranslations to tarnish the EU's reputation in relation to the UK. If this is the case, why has this issue not had an impact on the EU's approval rate in Ireland and, to a lesser extent, Malta? Perhaps because in these countries English is the coloniser's language and not the citizens' sole or main object of the identification? In any case, how the EU communicates with citizens - how (and whether) it translates - help determine whether and how citizens identify with it. As many have warned in the past several decades, a laissez-faire attitude to language and a no-policy policy could mushroom into the re-nationalisation of the EU, anti-EU 
sentiment and downright conflict (see e.g. Kraus 2008b, 172-176). The question here is to what extent Brexit can be considered an instance of these developments.

The last issue that requires further research is interpreting in the EU. Though mentioned here repeatedly in passing and considered in some general statistics in Chapter 3, interpreting entails its own particular dynamics and requires specific solutions. There is of course a lot of research in EU interpreting, though not specifically in the context of the EU's de jure multilingualism and de facto monolingualism - at least not to my knowledge (see e.g. Duflou 2016). It would be interesting to assess the extent to which the EU's de facto monolingualism manifests itself in interpreting, too, as well as whether and how the three turns proposed here could be applicable to interpreting.

\subsection{Final Remarks}

At present, the EU sees the dominance of English in its institutions as a natural and inescapable development, as conveyed in the following statement by the DG Translation (see the Appendix):

There is no formal decision to favour the use of one language or another for internal communication and interaction. English has replaced French as the most widely spoken common language within the institutions not by design but because it is the language that the great majority of these generations' EU officials have learned at school as first or second foreign language and master best to communicate in the multilingual environment.

This suggests that English owes its current position in the EU to forces beyond the EU's purview, forces to which the EU merely submits. We can understand this stance as an offshoot of the fact that language policy lies outside the EU's areas of competence and is indeed officially beyond the EU's remit. Yet they seem to completely disregard the fact that they are neither an isolated, physical person making a personal language choice nor a juridical person making a corporate language choice. They are a bugely influential and unparalleled supranational organisation whose actions are predicated on language choices, which in turn are clearly communicated to everyone across the globe. It may be the case that English is so dominant in the EU because many people "happen" to have learnt it; however, it seems either naïve or cynical to presuppose that the EU's internal language practices do not favour and actively promote English.

Even idealists will concur that it is impossible [this notion has been crucial throughout this book] to have equality among all languages present in the EU's territory; it is impossible to have everything translated into every single EU language; it is impossible to increase the number of official EU languages to cater to all EU citizens and permanent residents. We have here another aporia, whereby equality, though a desirable goal, would entail the effacement of all differences, the squaring of all language communities according to universal, fixed criteria. Nevertheless, equality can and should remain a goal, 
something the EU should defend and strive for if it is to abide by its own founding principles. It may be "historically and culturally valid to claim that Europe lives from its contradictions", but "European politics cannot abide any thoughtless contradictions" (Muschg 2005, 25).

The DG Translation dismisses the issues of the dominance of English, linguistic injustice and hierarchies as non-existent, even though they are in plain sight. While clear language policies may not automatically materialise as language practices and ideologies, they would be a good start at the very least to identify difficulties and lay the foundation for gradual change. The language turn, the translation turn and the transcultural turn put forward in this chapter should be understood as stepping stones in this direction. While they may seem bold, if they can be implemented anywhere in the world, then it must be in the EU. As Richard Rorty reminds us, "[t]he European Union ... is already the realization of what the Realpolitiker thought was an idle fantasy" $(2005,38)$.

Alternative solutions are not without their doses of utopia either, particularly if we look at Esperanto and the English as a lingua franca paradigm (ELF). Though in completely - arguably opposite - ways, both require too large a leap from current language ideologies based on territoriality. Which state is going to back Esperanto or ELF when they are both de-territorialised? How can we get significant portions of the population to want to learn either when the chief motivational learning factors are anchored in territoriality having native speakers, native territories, native norms, cultural goods, etc.?

The three turns sketched here are thus an attempt to strike a balance between normative and pragmatic imperatives. Normatively, both Esperanto as a lingua franca and an all-inclusive language approach - whereby all languages spoken by EU citizens and permanent residents are granted officialdom - would be perfect, but unfeasible and/or impractical. Theoretically, ELF would also class as a normatively viable option if it were indeed neutral, if there were not hundreds of millions of English native speakers worldwide. Pragmatically, adopting a single (or a few) lingua franca may seem easier, but it is normatively taboo and anathema to the EU's principles of equality and non-discrimination.

I would be lying if I said that any of the paths discussed in the previous paragraphs - be it Esperanto, ELF or indeed the three turns - are likely to be taken by the EU. As the interview with the DG Translation suggests, the most likely scenario is that nothing whatsoever will change because there is little to no political will even to acknowledge that something needs to be changed (see Appendix). However, as noted in the previous sections, there is hope that these three turns can be orchestrated at grassroots levels, by local agents in education, academia, translation and policy-making, gradually infusing the EU with these renewed language practices, policies and ideologies.

\section{Notes}

1 As remarked in Section 4.3, I cannot go into the contentious question of EU citizenship and the privileges attached to it (see Balibar 2004). But it is clear that a 
reassessment of the EU's language policies, practices and ideologies begs the question of citizenship. Harmonising citizenship laws among member states and democratising access to EU citizenship are urgent matters.

2 Of course, this would be controversial in the case of a language such as Russian: its sizeable minorities in Estonia, Latvia and Lithuania would greatly profit from its inclusion in the pool of official EU languages, but their governments might be unwilling to put their hands into their pockets to subsidise the Russian language not least due to the not too distant annexation of these countries by the former Soviet Union. In this case, it would make sense for Russia to foot the bill if it wished to seek EU officialdom for its national language. Be that as it may, a dedicated agency should help settle these issues case by case.

3 There has been much criticism of this system, particularly regarding the introduction of the euro and the suggestion by philosophers such as Jürgen Habermas that the EU should take over other policy areas (most notably defence) via a two-speed strategy. However, in the particular case of language policy, a two-speed EU would not exacerbate the familiar tensions between North and South or West and East, nor would it further entrench the notion of a "core Europe" based on seniority. There is at least one country in this "core Europe" (namely France) which would certainly tick fewer boxes than more recent members regarding the protection of linguistic minorities. If a two-speed EU were to materialise in relation to language, it would thus not be along the traditional lines of a "core EU" and "the rest". For more on this tension, see e.g. Esterházy (2005), Krzemiński (2005) and Spinelli (2005).

4 As Xabier Arzoz notes, "[w]ithout the existence of a dominant culture in favour of linguistic diversity, it is unlikely that the Union will be prepared to put more money into it ..., or to accept the political implications of preserving it" $(2008,165)$. At the same time, without more investment to transform language practices, policies and ideologies, it is unlikely that "a dominant culture in favour of linguistic diversity" will ever emerge.

5 Examples from works recently sent to me to be reviewed: "despite of", "had began", "it does not loose track of", "in stead of", "specially" rather than "especially", among dozens of others.

6 "Integration" is a controversial word, as noted in Chapter 2, and often means the assimilation of immigrants into the receiving culture. As Nadja Thoma, expert in Education at the University of Vienna, explains, the term lacks a conceptual basis and would have to be complemented, for example, by the notion of "institutional discrimination". She also adds that even though Austria is one of the only EU countries to offer this kind of training for prospective teachers, it is usually limited to those teachers specialising in German. Yet issues of migration and multilingualism are urgently relevant to teachers of all subjects (private communication; see also Dannerer et al. 2013).

7 The Marie Jahoda primary school, in Vienna's sixteenth district, is the only that offers a multilingual literacy programme, whereby Turkish and Bosnian-CroatianSerbian-speaking pupils learn their mother tongue alongside German.

8 In Austria, 5-year-olds and 6-year-olds are tested for their German skills before starting school - quite apart from their proficiency in any other language(s). Those whose knowledge is deemed insufficient cannot enter regular school and must instead attend the so-called "Deutschförderklassen" [lessons to promote German] for 15 hours a week. Some remain segregated in these classes for up to four semesters, when they can then finally join the German-speaking pupils - but often these migrant children must start from year one, even though they are two years older than year-one pupils. "Ideal" children are thus monolingual in German; other languages brought into the school are irrelevant. This out-and-out monolinguistic model is then expanded to become bilingualism with English, flying in the face of the EU's ideal of multilingualism. As Rudolf de Cillia puts it, "[d]ie in den 
Klassenzimmern, v.a. der urbanen Ballungsgebiete, obnehin vorhandene Mehrsprachigkeit schließlich muss von der Schule aufgegriffen und gefördert werden, anstatt dass sie von einem monolingual orientierten Schulsystem verschüttet wird" [the multilingualism already present in classrooms, particularly in urban areas, must at last be taken up and promoted by schools rather than being buried under a monolingually minded school system] $(2003,36)$.

9 The 2001 statistics mentioned in the Introduction refer to the so-called Umgangssprache [vernacular language] and appear to have been discontinued. In 2001, almost 60,000 respondents selected English, even though clearly the vast majority were not inner- or outer-circle speakers.

10 See Directive 77/486/EEC (1977). All EU legislation mentioned throughout this book was taken from the EUR-Lex portal: (C) European Union, https://eur-lex.europa.eu/. All electronic sources quoted here were last accessed in December 2020.

11 Jean-Claude Barbier tells an interesting anecdote here: the expression "public services" is avoided in EU law because of its well-established meaning in Englishspeaking legal systems. Instead, where in French we find "services publics", the English version reads "services of general interest". However,

in order to nudge Irish citizens towards voting for the Lisbon Treaty that they had rejected in 2008, the European Council issued [in 2009] a 'solemn' declaration stating that it attached an extreme importance to 'public services', a notion that does not feature in EU primary law.

$(2018,343)$

So much for the symbolic value of language.

12 "Controversial" from the perspective of contemporary linguistics, as the guide classes any deviations from inner-circle norms as errors. However, Gardner highlights "the practical need to have a consistent and coherent model to enable mutual intelligibility" (private communications).

\section{Further Reading}

Grin, François et al. (eds). 2018. The MIME Vademecum: Mobility and inclusion in multilingual Europe. Grandson, Switzerland: Artgraphic Cavin.

\section{References}

Arrojo, Rosemary. 1998. "The revision of the traditional gap between theory and practice and the empowerment of translation in postmodern times". The Translator 4 (1): 25-48.

Arrojo, Rosemary. 2010. "Philosophy and translation". In Handbook of translation studies, vol. 1, edited by Luc van Doorslaer and Yves Gambier, 247-251. Philadelphia, PA: John Benjamins.

Arzoz, Xabier. 2008. "The protection of linguistic diversity through Article 22 of the Charter of Fundamental Rights". In Respecting linguistic diversity in the European Union, edited by Xabier Arzoz, 145-173. Philadelphia, PA: John Benjamins.

Bachmann-Medick, Doris (ed.). 2009. Special issue, Translation Studies 2:1.

Bale, Jeff. 2015. "Language policy and global political economy". In Language policy and political economy: English in a global context, edited by Thomas Ricento, 7296. Oxford: Oxford University Press.

Balibar, Étienne. 2004. We, the people of Europe: Reflections on transnational citizenship. Translated by James Ingram. Princeton, NJ: Princeton University Press. 
Barbier, Jean-Claude. 2018. "European integration and the variety of languages: An awkward co-existence". In The politics of multilingualism: Europeanisation, globalisation and linguistic governance, edited by François Grin and Peter A. Kraus, 333-357. Philadelphia, PA: John Benjamins.

Burger, Deborah. 2020. Bildungsdirektion für Wien: Fremdsprachenprojekte. Vienna: Bildungsdirektion für Wien.

Dannerer, Monika, Magdalena Knappik and Birgit Springsits. 2013. "Pädagoginnenbildung in einer mehrsprachigen Gesellschaft: Deutsch als Zweitsprache und Mehrsprachigkeitsdidaktik in der Aus- und Weiterbildung von Lehrerinnen und Kindergarten-Pädagoginnen in Österreich”. In Sprachenpolitik in Österreich, edited by Rudolf de Cillia and Eva Vetter, 29-47. Frankfurt a.M.: Peter Lang.

de Cillia, Rudolf. 2003. "Tendenzen und Prinzipien europäischer Sprachenpolitik”. In Sprachenvielfalt: Babylonische Sprachverwirrung oder Mehrsprachigkeit als Chance?, edited by Hans-Jürgen Krumm, 27-40. Innsbruck: StudienVerlag.

Derrida, Jacques. 1985. The ear of the other: Otobiography, transference, translation. Translated by Peggy Kamuf. Lincoln, NE: University of Nebraska Press.

Derrida, Jacques. 1992. The other heading: Reflections on today's Europe. Translated by Pascale-Ann Brault and Michael B. Naas. Bloomington, IN: Indiana University Press.

Derrida, Jacques. 1997. Of grammatology. Translated by Gayatri Chakravorty Spivak. Baltimore, MD: Johns Hopkins University Press.

Duflou, Veerle. 2016. Be(com)ing a conference interpreter: An ethnography of EU interpreters as a professional community. Philadelphia, PA: John Benjamins.

Erkurt, Melisa. 2020. Generation Haram: Warum Schule lernen muss, allen eine Stimme zu geben. Vienna: Zsolnay.

Esterházy, Péter. 2005. "How big is the European dwarf?" In Old Europe, new Europe, core Europe: Transatlantic relations after the Iraq War, edited by Daniel Levy, Max Pensky and John Torpey, 74-79. London: Verso.

European Commission. 2008. A rewarding challenge: How language diversity could strengthen Europe. Luxembourg: Office for Official Publications of the European Communities.

European Commission. n.d. “ \#DiscoverTranslation”. Available at; https://ec.europa. eu/info/departments/translation/discovertranslation_en.

European Union. 2015. Joint practical guide of the European Parliament, the Council and the Commission for persons involved in the drafting of European Union legislation. Luxembourg: Publications Office of the European Union.

Gravier, Magali and Lita Lundquist. 2011. "Getting ready for a new tower of Babel”. In Linguistic diversity and European democracy, edited by Anne Lise Kjær and Silvia Adamo, 75-96. Farnham: Ashgate.

Hornberger, Nancy H. 2006. "Frameworks and models in language policy and planning”. In An introduction to language policy: Theory and method, edited by Thomas Ricento, 24-41. Malden, MA: Blackwell Publishing.

Jenkins, Jennifer. 2009. "English as a Lingua Franca: Interpretations and attitudes". World Englishes 28 (2): 200-207.

Koskinen, Kaisa. 2000. "Institutional illusions: Translating in the EU Commission". The Translator 6 (1): 49-65.

Koskinen, Kaisa. 2008. Translating institutions: An ethnographic study of EU translation. Manchester: St. Jerome.

Kraus, Peter. 2008a. "A one-dimensional diversity? European integration and the challenge of language policy". In Respecting linguistic diversity in the European Union, edited by Xabier Arzoz, 85-103. Philadelphia, PA: John Benjamins. 
Kraus, Peter. 2008b. A union of diversity: Language, identity and polity-building in Europe. Cambridge: Cambridge University Press.

Krzemiński, Adam. 2005. "First Kant, now Habermas: A Polish perspective on 'core Europe"”. In Old Europe, new Europe, core Europe: Transatlatic relations after the Iraq War, edited by Daniel Levy, Max Pensky and John Torpey, 146-152. London: Verso.

Mamadouh, Virginie. 2002. "Dealing with multilingualism in the European Union: Cultural theory rationalities and language policy". Journal of Comparative Policy Analysis: Research and Practice 4 (3): 327-345.

Mamadouh, Virginie and Nesrin el Ayadi. 2018. "How should municipalities collect and share data about the linguistic profiles of their resident communities?" In The MIME Vademecum: Mobility and inclusion in multilingual Europe, edited by François Grin et al., 104-105. Grandson, Switzerland: Artgraphic Cavin.

Muschg, Adolf. 2005. “Core Europe': Thoughts about European identity”. In Old Europe, new Europe, core Europe: Transatlantic relations after the Iraq War, edited by Daniel Levy, Max Pensky and John Torpey , 21-27. London: Verso.

Ogris, Günther. 2020. "Der unsaubere Umgang mit der Umgangssprache”. Der Standard, 14 September. Available at: www.derstandard.at/story/2000119970995/der-unsa ubere-umgang-mit-der-umgangssprache.

Österreichischer Integrationsfonds. 2018. "Fact-sheet 30: Migration und Schule". Available at: www.integrationsfonds.at/fileadmin/content/AT/Fotos/Publikationen/Fa ctSheet/Fact_Sheet_30_Migration_und_Schule.pdf.

Phillipson, Robert. 2003. English-only Europe? Challenging language policy. London: Routledge.

Phillipson, Robert. 2018. "English, the Lingua Nullius of global hegemony". In The politics of multilingualism: Europeanisation, globalisation and linguistic governance, edited by François Grin and Peter A. Kraus, 275-303. Philadelphia, PA: John Benjamins.

Reif-Breitwieser, Susanne. 2011. Wir sprechen zehn Sprachen!Vienna: Bundesministerium für Unterricht, Kunst und Kultur.

Ricoeur, Paul. 1996. "Reflections on a new ethos for Europe". In Paul Ricoeur: The hermeneutics of action, edited by Richard Kearney, translated by Eileen Brennan, 1015. London: SAGE.

Rorty, Richard. 2005. "Humiliation or solidarity?" In Old Europe, new Europe, core Europe: Transatlantic relations after the Iraq War, edited by Daniel Levy, Max Pensky, and John Torpey, 34-40. London: Verso.

Shohamy, Elana. 2006. Language policy: Hidden agendas and new approaches. London: Routledge.

Shuibhne, Niamh Nic. 2008. "EC law and minority language policy: Some recent developments". In Respecting linguistic diversity in the European Union, edited by Xabier Arzoz, 123-143. Philadelphia. PA: John Benjamins.

Spinelli, Barbara. 2005. "The end of Europe". In Old Europe, new Europe, core Europe: Transatlantic relations after the Iraq War, edited by Daniel Levy, Max Pensky and John Torpey, 47-52. London: Verso.

Wright, Sue. 2007. "English in the European Parliament: MEPs and their language repertoires”. Sociolinguistica Jabrbuch 21: 151-165. 


\section{Final Remarks}

I think we do not have to choose between unity and multiplicity. Of course deconstruction ... insisted not on multiplicity for itself, but on the heterogeneity, the difference, the dissociation, which is absolutely necessary for the relation to the other. What disrupts the totality is the condition for the relation to the other ... Now this does not mean that we have to destroy all forms of unity wherever it occurs ... Of course, we need unity, some gathering, some configuration ... What interests me is the limit to every attempt to totalize, to gather, versammeln.

Jacques Derrida

In March 2014, a narrow majority of the residents of Vienna's sixth and seventh districts voted in favour of turning the city's longest shopping street, Mariahilfer Straße, into a Begegnungszone [a "contact zone" or "shared space"] in a polemic referendum. Its nearly 2 kilometres are now shared by pedestrians, cyclists, motorcyclists, as well as car and bus drivers. Although intricate traffic rules are in place there, they can be summarised very simply as "bigger vehicles watch out for smaller vehicles and pedestrians". No one is allowed to block anyone else's way or endanger anyone - awareness of one another is a prerequisite for using that space. The transformation of Mariahilfer Straße was riddled with controversy, protests and bus strikes. Why should cars have to slow down because of pedestrians and cyclists? Why should pedestrians have to share the road with cars and bikes? How would bus drivers be able to do their job without putting everyone else at risk? Fast forward six years and the number of accidents on Mariahilfer Straße has fallen 65 per cent, and more shared spaces are being planned across the country.

Vienna's shared spaces are a simple example of a practice that circumscribes the alliance of two imperatives (traditional mobility and smart mobility) without falling back on the reversibility principle, whereby roads either belong to motorised vehicles or become pedestrianised. Pedestrianisation fuels the anger of the car lobby, which sees in a "pedestrianised way of life" the opposite of what they stand for. The reverse happens when urban spaces remain the prerogative of motorised vehicles, in a self-perpetuating cycle of reversibility. When everyone is put together and must negotiate the terms of their own

DOI: $10.4324 / 9780429282812-7$ 
encounters, case by case, they are allowed to exercise their preferred mobility styles while having to come to terms with other people's mobility styles.

The issue of EU linguistic diversity is more complex than the traffic rules of a shopping street in Vienna. Still, the language turn, the translation turn and the transcultural turn proposed here aim to achieve more or less the same goal, i.e. that we take responsibility for making communication work for everybody without having to settle on a common denominator. Traffic on Mariahilfer Straße had to be slowed down to make the shared space viable - the speed limit is $20 \mathrm{~km} / \mathrm{h}$. Similarly, the turns suggested in this book would slow down the EU's communicative thoroughfares, giving rise to a new notion of communicative efficiency centred on quality and parity of esteem.

In the Introduction, I summarised as follows the two key questions this book attempted to unravel: What does the EU's ad hoc use of English and effacement of translations say about its underpinning notion of language and translation? And how will Brexit impact the EU's use of language and translation?

From the classical paradigm to contemporary thought in philosophy of language and linguistics, there are crucial differences in the dialectics between language and thought, meaning and identity. The EU's discourse on language (and arguably facets of its language ideologies) seem firmly anchored in a relativistic premise à la Herder and Humboldt, whereby a language represents a nation's genius. This discourse and ideology underpin its (scarce) overt, de jure language policies, which call for the protection of linguistic diversity univocally. The EU's language practices or de facto policies, on the other hand, reveal a predominantly universalistic, pragmatic, Platonic and instrumental notion of language. This mix culminates in the compartmentalisation of languages - albeit informally - into languages for identification and languages for communication.

The EU admits that it relies on English (to a lesser extent, French) as its lingua franca of sorts; it does not consider its promotion of English to be at odds with the equal status of its 24 official languages. English is the EU's language for communication - a state of affairs which will not be affected by Brexit, at least not on the Commission's account. The other 23, along with dozens more not included in this exclusive club, are seen as languages for identification. The member states' education systems reproduce these hierarchies more and more, as English is allocated ever more time and space in ever more schools. Combined, these factors could lead to diglossia with national languages plus English in the EU - a state of affairs that is already visible in certain realms and is gradually expanding.

This compartmentalisation is noticeable in the EU's translation regime as well, whereby only legally binding documents are deemed worthy of translation, leading to the majority of information being available in English only sometimes French, rarely German and almost never other languages. But even if the EU did translate everything into all its official languages, English (and anglophone epistemicide) would still dominate as by far the most used drafting 
language. And the fact that all translations are authenticated and read as though they were originals masks the pecking order among the official languages and exacerbates the already precarious status of translations and translators in society. The effacement of the boundaries between originals and translations epitomises the EU's logocentric notion of translation, according to which originals are authentic and complete, whereas translation requires an external gesture of authentication - thereby erasing its translation status.

At the heart of the EU's language challenge lies the tension between unity and multiplicity. Thin nationalism remains the chief organising principle in member states and the golden thread that binds people together. It is in the name of nationalism that multiplicity sometimes translates into fragmentation, meaningless juxtaposition and individualism. At the same time, a sense of transnationalism is on the rise across the bloc, taking such notions as national identity to its limit and forcing us to accept that fluid, niched identity repertoires exist across national borders and languages. In this sense, transnationalism is tantamount to unity: despite our differences, supranational ties unite us in a community of shared fate. However, unity also has an uglier face: when it calls for differences to be homogenised and total translatability - or total equivalence - to be obtained at all costs. Both multiplicity and unity heighten the centrality of English - the former as the bridge between multiple islands and the latter as the homogenising common denominator.

When we remain caught in the paradox of pure unity versus pure multiplicity, trapped, as it were, between two extreme poles, reversibility is the only option. To work with dichotomies is to work with sameness, for one extreme simply reverts to - and thus reaffirms itself in - the other extreme. There is no space for anything genuinely new. In the case of EU multilingualism, these "paralysing alternatives", to borrow from Ricoeur, amount to either pure monolingualism in English or pure multilingualism - i.e. when everything is said and written in every language spoken by a significant portion of the population, and/or every permanent resident knows all of these languages. There is no need to say on which side the EU is erring - and, in any case, we should not have to pick sides, to come back to this chapter's epigraph. When we take a step towards others and others towards us - without settling on a common denominator, without attempting to level our differences - this sheer gesture circumscribes the alliance of unity and multiplicity. 


\section{Appendix}

\section{Interview with DG Translation (July 2020)}

This interview was conducted in July 2020 with the Director-General, Rytis Martikonis, and the Deputy Director-General, Christos Ellinides, of the European Commission's Directorate-General for Translation (DGT). Originally planned to take place in person, it was conducted by email due to the coronavirus pandemic.

AL: Question 1: In my book, I argue that the language services of the EU institutions play a pivotal role in the maintenance and fostering of multilingualism in the EU. Yet, despite the colossal work, for instance, of the DG Translation, a lot of non-legally binding information is published in English only, sometimes in English and French - but rarely in other languages. Based on different EU translators' accounts (e.g. Koskinen 2000; Wagner, Bech of Martinez 2014), this seems to be largely due to budgetary reasons. If the DG Translation were allocated a larger budget, would you be able hire more staff and offer translations into a larger range of languages?

DGT: Rather than increasing the budget for in-house translation staff, the trend is to exploit as much as possible progress in language technologies (including machine translation) and further use of external freelance translators, employing an agile and flexible resource model comprised of internal resources, complemented by professional freelancers from member states and use of state-of-art technology.

In addition, one way of reconciling demand for translation with available resources on the supply side has been to manage demand. This meant establishing clear rules on which documents exactly must be translated under all circumstances, and which documents can be translated with the available resources (human, financial and technical). This was recognized as an important mitigating measure in the run-up to the 2004, 2007 and 2013 EU enlargements as the addition of a total of 12 new official languages (nine in 2004 alone) would have led to a disproportionate increase of the Commission's translation services. The length of Commission Communications addressed to other EU institutions or member states, for example, is limited to 15 pages. DG Translation offers an editing service 
which helps not only to improve the linguistic quality and readability of Commission texts but also to make them more concise, thus reducing the translation workload. DG Translation also runs a Clear Writing initiative to help Commission staff draft plain and accessible documents.

Another question is whether there is really a demand to have all "nonlegally binding information" translated. Where does its definition start, where does it end? Proportionality with regard to real use must also be considered. The Commission gives priority to translating material that is relevant for general public and to documents that will be used for a longer time. For more information on the languages used on the Commission's website, see https://ec.europa.eu/info/language-policy_en.

Having said that, the Commission's proprietary machine translation system eTranslation is added to more and more online platforms and websites to facilitate the translation of content that has not yet been translated or cannot be translated due to the lack of translation capacity.

AL: Question 2: In 2007 and 2009, the DG Translation issued a special report entitled "Translating for a multilingual community", in which translation statistics (distribution of source and target languages) were disclosed. Why have these publications been discontinued? In 2008, English was the most common drafting language, with 72.5 per cent of the total source pages, followed by French (11.8 per cent), German (2.7 per cent) and other languages (13 per cent). What are the current numbers?

DGT: The drafting languages of documents in 2019 were: 85 per cent English, 4 per cent French, 2 per cent German and 9 per cent other languages. For more information, see the new DGT brochure "Translation in figures" (European Commission DGT 2019).

AL: Question 3: The system of authentication of translations, whereby translations and originals are placed on an equal footing, is crucial regarding legislation and plays a key role in maintaining uniformity in EU law. It does, nevertheless, have the side-effect of erasing the tracks between originals and translations and obfuscating, at least officially, the hierarchy among the official EU languages. When it comes to legislation, it is widely documented that the original is most likely English (on rare occasions, French), so national courts routinely consult this version in addition to their language version (e.g. Barbier 2018). This information on the exact distribution of source and target languages is, however, not officially or systematically made available by the EU. The fact that de jure all official EU languages enjoy the same status, coupled with the authentication of translations, gives the impression that all languages are used equally often. Would it be imaginable for the EU to label all texts - legally binding or not - "original" or "translation" while maintaining the authentication system in place, so that the public can have access to the EU's language hierarchy and translation statistics can be kept?

DGT: There is no "language hierarchy" in the European Commission. For purely practical reasons, one language is used more than others between 
Commission staff to make communication in a multilingual work environment possible (this was French until about the turn of the century, since then, English has become the main common language). Likewise, there is no step in the Commission's text production process to "authenticate" translations. As multi-drafting is unrealistic (drafting texts simultaneously in 24 languages, thereby avoiding translation as the text production step after drafting), a text is drafted in one language and then translated into the other 23 languages. EU legal acts become authentic in 24 language versions through adoption (and publication in the EU's Official Journal), not because of an additional production step called "authentication". Also the Court of Justice of the European Union relies on all language versions when it interprets EU law. For details regarding distribution of source and target languages, please, see the brochure "Translation in figures" referred to in Question 2.

All languages are used equally often if you consider the EU's legal acts (with the exception of certain decisions directed at only one member state or a company in one member state); this is definitely the case for regulations because they become national law following adoption by the European Parliament and the Council and publication in the Official Journal in 24 languages. As for communication material, we have no information whether, at national level, our translations are read and used or whether users turn to what they may consider to be the original drafting language or any other language of their choice.

AL: Question 4: In the wake of the Brexit vote, the European Commission made it clear that the status of the English language would not be affected. Considering that English is an official language in Malta and Ireland, and that Maltese and Irish are official EU languages, too, having English retain its official status is likely to prompt other member states to push for their additional official languages to be granted EU officialdom as well. How does the European Commission see this conundrum?

DGT: No additional formal request for adoption of a new EU official language has been submitted, to our knowledge, to the Council of the European Union, which is the decision-making body regarding the language regime. Any change in the language regime - such as the addition of a new official language or the removal of an existing one - must be agreed unanimously by the Member States in the Council. The Commission is not involved in this process and, notably, it has no right of initiative.

AL: Question 5: Still regarding Brexit, despite the European Commission's reassurance that English would remain an official EU language, several key EU figures did allude to the fact that English was gradually losing importance in the EU - most notably Jean-Clause Juncker in May 2017. English is by far the most common drafting language in the EU institutions, agencies and bodies. Staff reports from 2016 confirm that English is the most used language by staff members in performing their duties (95 per cent) as well. Even if English does retain its official EU status, do you 
believe that it is losing symbolic value among EU staff; in other words, has there already been a shift in mentality in relation to the role of the English language as the EU's most used language? If so, how? If not, do you believe that Brexit might have triggered a gradual process of displacement of English as the most used language within EU institutions, bodies and agencies?

DGT: First of all, we must distinguish between English as an official language for the purposes of law-making and official communication, on the one hand, and English being used as a common language for internal communication and for drafting and discussing texts in the EU's multilingual setting, on the other. Whereas the former derives from the Treaties that establish both the concept and the use of the EU's official languages, the latter depends on the language that the majority of EU officials have learned and speak as their foreign language. This, in turn, is the consequence of a societal reality and educational choice: English has become the predominant language in so many fields of our lives (from economy to science and technology). There is no formal decision to favour the use of one language or another for internal communication and interaction. English has replaced French as the most widely spoken common language within the institutions not by design but because it is the language that the great majority of these generations' EU officials have learned at school as first or second foreign language and master best to communicate in the multilingual environment.

AL: Question 6: Before Brexit, there had already been calls from different academic disciplines for the English language used in EU institutions, bodies and agencies to be "detached" from its British sources (e.g. Modiano 2009; 2017; Cogo \& Jenkins 2010). Since the Brexit vote, these calls have been intensified. The reasoning behind them is that the English language used in EU settings does not correspond to standard British English (itself a problematic construct). There are particular words, expressions and even grammatical trends in "EU English" which would be considered deviations from "standard British English". For these scholars, Brexit offers the perfect opportunity to retain the English language in the EU but with a renewed status, no longer associated with the United Kingdom. In their view, this detachment would help to solve, at least on a symbolic level, the linguistic justice problem created by the use of English in the EU (e.g. Van Parijs 2011a; 2011b; Mac Giolla Chriost \& Bonotti 2018). What is your opinion on this proposal?

DGT: We do not see a "linguistic justice problem created by the use of English in the EU". The use of English has two sources and rationales. Languages are living expressions of cultural diversity; they evolve over time due to the exposure to foreign cultural, economic, technical or legal influences. Just like languages around the world are influenced by the predominance of English concepts and terms in areas like economics, finance, science, (information) technology, aerospace, trade, internet, etc., the English used 
by a majority of non-native speakers of English in the EU institutions undergoes changes and develops its own way of using the language and forming expressions. Standard British English is not immune to imported concepts and terms, be it from other variants of English (US-American, Australian, Canadian, etc.), be it from other languages of the world.

AL: Question 7: The EU's stance on multilingualism is clear and reflects its pledge to protect linguistic and cultural diversity, enshrined in its legislation: all official EU languages enjoy the same status, all are equally valued. The EU has pushed, as far as its limited jurisdiction in language policy allows, for the member states to introduce more foreign language teaching into their school curricula in a wider range of languages; it has also repeatedly stressed that it does not wish to adopt a de jure lingua franca (e.g. "Promoting language learning and linguistic diversity: action plan 2004-06" European Union 2006 ; "Lingua franca: chimera or reality?", European Commision DGT 2011). However, for pragmatic reasons, English - along with French and German to a lesser extent - is the de facto lingua franca of the EU. The gradual ascent of English in EU institutions, bodies and agencies has prompted scholars from different fields to call for a reassessment of the EU's internal language regime. Some believe that the predominance of English must urgently be reverted; others call for a more equitable use of ideally all official EU languages; others commend the official adoption of a larger pool (four or five) of working languages (e.g. Kraus 2008; Phillipson 2016). Despite their differences, what unites these proposals is the wish for an official, transparent language regime that is the result of public debate. These scholars feel that the predominance of English within the EU seems ad hoc, unavoidable and somewhat surreptitious - inasmuch as it enjoys no special status but is the most used language. Do you think that there is a paradox between the EU's de jure multilingualism policy and its de facto internal language regime? Do you believe that fostering a more egalitarian distribution of drafting languages among all official EU languages, and/or the adoption of a larger pool of working languages would be desirable and feasible?

DGT: We see no paradox, as the de facto use of English as the most common drafting language in the Commission is not the result of a political or administrative decision but the consequence of pragmatic considerations and internal needs for communication in a language that all actors can speak in a multinational, multicultural, multilingual environment.

AL: Question 8: As the EU's largest language service provider, the DG Translation is faced with the monumental task of balancing the expressive value of language - which in turn is directly linked with the member states' sense of sovereignty and self-esteem - and the pragmatic demands of a large, unparalleled, intricate set of institutions. In a blog post from February 2017, you, Rytis Martikonis, along with Roberto Viola, quote Wilhelm von Humboldt and highlight the expressive value of language and the EU's role in respecting it. Thanks to the DG Translation and other 


\section{Appendix}

language service units, the EU does achieve a significant amount of multilingualism. Binding documents and key services for citizens are generally available in all official EU languages. Beyond these realms, however, it is difficult to find information in languages other than English. There have been numerous cases brought to the Court of Justice of the EU (most of which by Italy) regarding postings of job vacancies, for example, in a limited number of languages. Some scholars argue that more multilingualism - i.e. a wider range of languages actively being used in EU settings - would help to counter what many see as the EU's democratic deficit, in the sense of a lack of support for democratic deliberation and participation in decision-making. Do you agree that more multilingualism in EU institutions, bodies and agencies would be desirable to allow all EU citizens to remain informed and feel included, thus mitigating the alleged democratic deficit?

DGT: The issue of multilingual job vacancies has been solved by the Court. We do not see that more multilingualism within EU institutions, bodies and agencies would change the way in which they communicate with the EU's citizens. What counts is that information that concerns citizens at large is available in as many languages as possible, and that they can contact the EU institutions in the language of their choice, thanks to our translation services.

AL: Question 9: Language policy lies outside the EU's areas of competence, which makes it difficult for the EU to tackle pressing issues, such as the linguacultural aspects of the democratic deficit, the status of regional and minority languages, the socioeconomic hurdles faced by speakers of migrant and nonterritorial languages, among many others. The EU's symbolic actions in these areas have certainly been fruitful; EU language policy researchers do nonetheless argue that legally binding steps are urgently needed in these areas (e.g. Skutnabb-Kangas 2006; Shuibhne 2008), which could only be achieved by turning language policy at least into an EU shared or supporting competence. Though it seems extremely unlikely that all member states would agree to such a change, would you welcome this development?

DGT: It is not in our remit to request changes to the distribution of competences between the member states and the EU. In some cases, not even the MS central government has such competences (in this case, in the field of education) as they lie with the regions.

AL: Question 10: In addition to enlarging and strengthening language services, one suggestion that I make in my book is that intercomprehension and transcultural skills be fostered among EU staff (e.g. Grin 2008; Kraus 2008; Gravier \& Lundquist 2011; Schjerve 2011). Even if more translations into a wider range of official EU languages were produced, having English as the greatly predominant drafting language would still constitute an injustice - whose impact has been widely documented (e.g. Gazzola o Grin 2013). In your view, if proper training were offered, would it be 
realistic to expect a gradual, slow shift in EU staff's mentality towards a more multilingual modus operandi, whereby one would be trained to passively deal with input in a range of languages instead of relying on a single (or two) common language(s)? The EU seems to be moving towards this model when it recommends, for example, that member states offer a wider range of foreign languages in their school curricula, that pupils are taught passive skills in neighbouring languages, etc. Can you imagine a scenario in which, say, a Polish and an Italian-speaking EU staff members exchange emails or have a meeting each in their own language, relying on their passive knowledge of Slavic and Romance languages, rather than automatically switching to English?

DGT: We do not see the predominant use of English as common language for internal communication and, hence, for drafting as an "injustice". No language has the "right" to be in a particular position; if, in the past, French and, nowadays, English happened to acquire such a position, it was for historical or pragmatic reasons mainly due to educational choices in the member states, not thanks to a legal act. The EU institutions always recruit staff with the knowledge of, at least, two official EU languages without prescribing which ones; in the case of translators, they require the knowledge of at least three official languages. For the first career promotion, an official needs to demonstrate the acquisition of skills in a third language; in terms of learning and development, language courses are a constant feature on the institutions' training menu. French is still used in many conversations. Multilingual conversations (e.g. Polish/Italian) are not an exception, but drafting happens in a language that allows all those concerned to contribute.

\section{References}

Barbier, Jean-Claude. 2018. "European integration and the variety of languages: An awkward co-existence". In The politics of multilingualism: Europeanisation, globalisation and linguistic governance, edited by François Grin and Peter A. Kraus, 333-357. Philadelphia, PA: John Benjamins.

Cogo, Alessia and Jenkins, Jennifer. 2010. "English as a lingua franca in Europe: A mismatch between policy and practice". European Journal of Language Policy 2 (2): 271-294.

European Commission DGT. 2011. Lingua franca: chimera or reality?Luxembourg: Publications Office of the European Union.

European Commission DGT. 2019. “Translation in figures”. Available at: https://op. europa.eu/en/publication-detail/-/publication/62f8069c-67d4-11e9-9f05-01aa75ed71a1/ language-en

European Union. 2006. "Promoting language learning and linguistic diversity: action plan 2004-06". Available at: https:/op.europa.eu/en/publication-detail/-/publication/ b3225824-b016-42fa-83f6-43d9fd2ac96d. 


\section{Appendix}

Gazzola, Michele and François Grin. 2013. "Is ELF more effective and fair than translation? An evaluation of the EU's multilingual regime". International Journal of Applied Linguistics 23 (1): 93-107.

Gravier, Magali, and Lita Lundquist. 2011. "Multilingual and multicultural legal reasoning: The European Court of Justice". In Linguistic diversity and European democracy, edited by Anne Lise Kjær and Silvia Adamo, 75-96. Farnham: Ashgate.

Grin, François. 2008. "Principles of policy evaluation and their application to multilingualism in the European Union". In Respecting linguistic diversity in the European Union, edited by Xabier Arzoz, 73-83. Philadelphia, PA: John Benjamins.

Koskinen, Kaisa. 2000. "Institutional illusions: Translating in the EU Commission". The Translator 6 (1): 49-65.

Kraus, Peter A. 2008. A union of diversity: Language, identity and polity-building in Europe. Cambridge: Cambridge University Press.

Mac Giolla Chríost, Diarmait and Matteo Bonotti. 2018. Brexit, language policy and linguistic diversity. London: Palgrave Macmillan.

Modiano, Marko. 2009. "Inclusive/exclusive? English as a lingua franca in the European Union”. World Englishes 28 (2): 208-223.

Modiano, Marko. 2017. "English in a post-Brexit European Union”. World Englishes 36 (3): 313-327.

Phillipson, Robert. 2016. "Linguistic imperialism of and in the European Union”. In Revisiting the European Union as empire, edited by Hartmut Behr and Yannis A. Stivachtis, 134-163. New York: Routledge.

Schjerve, Rosita Rindler. 2011. “Aktuelle Tendenzen in der europäischen Sprachenpolitik". In Europasprachen, edited by Peter Cichon and Michael Mitterauer, 145-158. Vienna: Böhlau Verlag.

Shuibhne, Niamh Nic. 2008. "EC law and minority language policy: some recent developments". In Respecting linguistic diversity in the European Union, edited by Xabier Arzoz, 123-143. Philadelphia. PA: John Benjamins.

Skutnabb-Kangas, Tove. 2006. "Language policy and linguistic human rights". In An introduction to language policy: Theory and method, edited by Thomas Ricento, 273-291. Malden, MA: Blackwell Publishing.

Van Parijs, Philippe. 2011a. Linguistic justice for Europe and for the world. Oxford: Oxford University Press.

Van Parijs, Philippe. 2011b. "Interview by the European Commission". In Lingua franca: Chimera or reality? edited by European Commission DGT, 81-91. Luxembourg: Publications Office of the European Union.

Wagner, Emma, Svend Bech and Jesús M. Martínez. 2014. Translating for the European Union institutions. London: Routledge. 


\section{Index}

Ahrweiler, Hélène 129

analytic philosophy $16,36 \mathrm{n} 6$

Apter, Emily 104-105, 120n16

Aristotle 9, 18, 36n1

Arrojo, Rosemary 98, 103, 120n13, 189

Asselborn, Jean 129

authentication of translations 96-99, 108, 112, 115, 119n9, 183, 189, 206, 208-209

Babel, myth of 13

Bachmann-Medick, Doris 4, 189

Bale, Jeff 70

Balibar, Étienne 120n17, 134-135, 169n2, 199n1

Barnier, Michel 158

Barthes, Roland 4, 103

Bassnett, Susan 99

Bennett, Karen 114

Blommaert, Jan 11-12, 62, 137

Bonotti, Matteo 160-162

Brexit 30-31, 34-35, 53, 60-61, 63, 80n11, 116, 118, 127, 130, 139, 157-161, 168, 172n22, 187, 197-198, 205, 209-211

Campos, Augusto and Haroldo de 105

Cassin, Barbara 104-108, 114, 120n14, 120n15, 136

Cicero 99

classical paradigm in philosophy of language 8-13, 36n1, 102, 205

Cogo, Alessia 30-31, 34-35, 162

content and language integrated learning (CLIL) 76-77

Cooper, Robert L. 65

coronavirus pandemic of 2020 79n9, 116, 127, 129-130, 133, 137, 156, 207

Craith, Máiréad Nic 55

Crystal, David 23, 58, 69
Dahl, Robert 134

Dahrendorf, Ralf 141-142

De Schutter, Helder 32, 64, 151-152, 160-161, 170n8

De Swaan, Abram 47, 128, 145-146, $171 \mathrm{n} 12$

deconstruction see Derrida, Jacques

democracy 5, 49-51, 127, 132, 133-136, 139 see also European Union, democratic deficit

Derlén, Matthias 158, 162

Derrida, Jacques 4, 18-21, 101-103, 107, 109-112, 117-118, 121n21, 130, 136, $167,181,189,204$

de-territorialisation of EU law 196-197

Deutsch, Karl 133

différance 18-19, 25, 31 see also Derrida, Jacques

diglossia 10, 12, 24, 36n2, 139, 141-142, 147, 151, 170n5, 205

Directorate-General for Translation (DG Translation) 91-92, 118, 161, 165, 168-169, 186, 190-192, 197-199, 207-213

diversity as juxtaposition and as mixing 118, 129, 138, 144, 165-166, 206

domestication of translations 100 , 106, 114

Eco, Umberto 13, 129, 136

ecology of language 58-59

ecology-of-languages-paradigm see ecology of language

economics of language 70

Energeia 14, 106

English as a lingua franca 23-24, 107, 149, 193; of the EU 3, 47, 59-61, 82n33, 112, 127, 139, 158-161, 166, 168-169, 187, 197, 205, 211, 213; as a mother tongue 33-34, 38n18, 139-143, 
147, 151, 196; paradigm in linguistics (ELF) 27-35, 62, 121n22, 143-144, 149, 160, 162, 193, 199 see also lingua franca

epistemicide 63, 114, 193, 205

equivalence 9 , 15, 90, 96-105, 107-108, 115, 117, 191, 206

Ergon 14, 106

Esperanto 28, 149-150, 162, 164, 169, 172n18, 172n19, 199

European Charter for Regional or Minority Languages (ECRML) 55, 56-57, 181, 194

European Citizens' Initiative (ECI) 93, 119n5, 134

European Union (EU): areas of competence 3-4, 51-52, 54, 57, 130-131, 133, 161, 182-183, 185, 188, 194, 198, 212; budget $53,79 \mathrm{n} 4,79 \mathrm{n} 9$, 93-94, 115-117, 119n6, 170n4, 183, 188, 190-191, 207-208; Charter of Fundamental Rights 49-50, 93, 95; citizenship 3, 35, 54, 130, 134-135, 196, 199n1 see also Balibar, Étienne; co-official languages 53, 67, 80n11, 157-158, 188; court cases 49, 91, 97, 115, 119n4, 212; Court of Justice 49, 60, 79n4, 91, 97, 115, 119n4, 119n5, 130, 209, 212; democratic deficit 92, 131-132, 134-135, 139, 191, 212 see also democracy; Eurobarometer 33, 62, 73, 82n29, 116, 135-136, 140, 166 see also statistics; foreign language teaching 73-78; institutions 79n4, 97, 115, 130-132, 209, 212; language families 162-167; linguistic hierarchy $63,94-95,97,108$, 112, 116, 132, 161, 167-168, 189, 199, 205, 208-209; migrant languages see minority languages; minority languages 35, 48, 53-59, 134, 141, 146, 186-187, 212 see also minority languages; nonterritorial languages see minority languages; official and working languages 2-3, 45-46, 48, 57, 81n21, 95, 158-159, 187, 206-209, 211; procedural languages 3, 51, 60, 81n21, 92; survey results see statistics; regional languages see minority languages; translation policy 90-95; translation (and language) regimes 93-95, 113, 115, 116, 130, 149-150, 159, 168-169, 205, 207, 211; treaties 48-52, 95-96, 128, 130-131, 157, 159, 185, 210

Europeanisation 137, 139, 169n3 expressive value of language 13-14, 23-24, 32-33, 35-36, 37n9, 59-61, 116, 135,211

Faye, Jean-Pierre 136

Ferguson, Charles A. 170n5

Fishkin, James 169n3

Fishman, Joshua A. 13-14, 57, 68, 72, 115, 170n5

foreignisation of translations 100, 114

Foucault, Michel 64-65, 103

Freud, Sigmund 103-104

Frost, Catherine 61-62

Gardner, Jeremy 172n22, 196-197, 201n12

Gasché, Rodolphe 111

German functional school 100, 103, 120n13

Giani, Eugenio 158, 162

global political economy 70

Goethe, Johann W. von 99-100

governmentality 65,77

Graddol, David 27, 149, 153-156, 169

Gravier, Magali 189

Grimm, Dieter 3, 133, 135-136

Grin, François 21, 70-71, 93-95, 113, $115,145,147-150,155,159-160,162$, 166-167

Habermas, Jürgen 17, 21, 38n16, 61, 79, 130, 133, 135-137, 161, 200n3

Habermasian see Habermas, Jürgen

Haugen, Einar 22, 58

Heidegger, Martin 105, 107, 120n15, $169 \mathrm{n} 2$

Herder, Johann G. 13-15, 35, 47, 51, 59, 61-62, 78, 205

Herderian see Herder, Johann G.

Hermans, Theo 96-98

Horace 99

Hornberger, Nancy 66-67, 69

House, Juliane 28-29, 62

Humboldt, Wilhelm von 14-15, 35, 36n5, 59, 61, 106, 165, 205, 211

Humboldtian see Humboldt, Wilhelm von

identity $4,7-8,15,20,23-24,31-36,50-51$, 59, 63, 78-79, 95, 110, 116, 121n21, 127, 131, 134-138, 144, 154-155, 160, 185, 197, 205-206 see also nation

ideology 19-20, 23, 31-36, 63-64, 144, 153, 166-167, 205

impossible, the 52, 62, 78, 101, 109-111, 113, 115, 133, 142, 171n10, 190, 198 
instrumental value of (or approach to) language 9-10, 12-13, 17-18, 23-25, 28-31, 33-35, 37n9, 59-62, 78, 116, 135, 139, 141, 153-154, 156, 205 intercomprehension 113, 118, 128, 149-150, 161-168, 181-184, 194-195, 212-213 see also transcultural competence and transcultural turn intraduisible see translatability invisibility of translations and translators 112-114, 118, 183, 189-193

Irish (language) 46-47, 54, 61, 67, 80n15, 158-160, 186-187, 209

Ives, Peter 5, 61, 139, 169

Jenkins, Jennifer 27, 33-35, 37n15, 162 Johnson, David C. 20, 24, 64-67, 72 Juncker, Jean-Claude 91, 158-159, 209

Kachru, Braj 2, 26-27, 29

Killilea Resolution 56

Klein, Horst G. 163-164

Koskinen, Kaisa 192, 197

Kraus, Peter A. 11, 21, 24, 59, 61, 77, 95, 130-131, 135-136, 138-139, 141-142, 144, 147, 158-159, 162, 165, 168, 169n3, 195

Kristeva, Julia 103

Kymlicka, Will 57, 128-129, 170n8

Lambert, Richard D. 68

language-as-problem 66, 69-70, 72, 77, 184 language-as-resource $66,68,71-72,77,184$ language-as-right $66,72,184$

language policy $3-4,24,49-53,57,64-72$, 119n5, 138-139, 141, 158, 161-162, 168, 181-199, 200n3, 205, 211-212; bottom-up 36n3, 65, 72, 77-78, 188, 194, 199; covert 65,72 ; critical 64, 68; education $71-78,82 \mathrm{n} 33,116,168$, 181-199, 205; grassroots see bottomup; overt $65,70-72$; and planning 65-68, 182-183, 186-187, 194, 196; top-down $65,72,188,194$

language turn 36, 112, 118, 161, 164, 181-199, 205

Laponce, Jean 143, 170n6, 171n10

Letta, Enrico 129

life chances 141-142, 145

ligatures see options and ligatures lingua franca $12,21-26,63,127,142$, 145-147, 150-153, 195 see also English as a lingua franca

lingua nullius 143 linguicism 37n10, 58

linguistic (in)justice $37 \mathrm{n} 9,70,127$, 144-151, 160-162, 167-169, 185, 188, 199, 210, 212-213

linguistic determinism 15, 19, 117

linguistic diversity see multilingualism

linguistic genocide 58, 68

linguistic imperialism 58, 68

linguistic turn in philosophy of language $16,18,36,184,189$

Locke, John 12-13, 24, 35, 47, 59, 61-62

Lockean see Locke, John

logocentrism see logos

logos 8-9, 12-13, 18, 20, 35, 61, 101-102, 107-109, 112, 117, 206

Lundquist, Lita 189

Luther, Martin 99

Luxembourgish 45-46, 187

Mac Giolla Chríost, Diarmait 160-162

machine translation $16,35,38 \mathrm{n} 19,107$, 152-153, 190-191, 197, 207-208

Macron, Emmanuel 158, 170n4

Maltese (language) 45-47, 54, 159-160, 187, 209

Mamadouh, Virginie 193-194

maxi-min principle 146-147, 165, 167 see also Van Parijs, Philippe

Mélenchon, Jean-Luc 158, 162

Mill, John Stuart 133

minority languages $24,64,66-71,77$, 81n24, 119n5, 146, 161 see also European Union, minority languages

mistranslation 106-107, 120n17

Modiano, Marko 34, 160, 162, 172n22

Monnet, Jean 129

Monti, Mario 60, 158

mother-tongue tuition 73, 75-76, 82n31, 195

multilingual judicial reasoning 97, 112

multilingualism 35, 47-50, 61-64, 69-73, 77-79, 91, 93, 108, 113, 116, 118, 136, 139, 142, 144-147, 149-150, 164-166, 168, 181-199, 205-213

multiplicity and unity see unity and multiplicity

Muschg, Adolf 130-131, 199

nation $11-12,14,20,22,35,36 \mathrm{n} 3,130$, 135-136, 138; national identity 11-12, $15,20,22-24,62,67,127,131$, 137-138, 167, 206; national language $11,23-24,35,57,59,67,78,144-147$ see also identity 
Nida, Eugene 99, 120n16

Nietzsche, Friedrich 103

Norris, Christopher 36n7, 102

Oettinger, Günther 158

options and ligatures 139, 141-145, 147, 153, 171n9, 195

Orban, Leonard 186

O'Regan, John 33, 107

Organization for Security and Co-Operation in Europe (OSCE) 71, 96

Oslo Recommendations Regarding the Linguistic Rights of National Minorities 71

Ostler, Nicholas 23, 26-27, 149-154, 156, 169

pandemic of 2020 see coronavirus pandemic of 2020

Pennycook, Alastair 19-20, 65, 69-70, $81 \mathrm{n} 24$

Phillipson, Robert 24, 31, 53, 58-59, 141, 143, 153, 162, 168, 181, 186

Plato 9-10, 12, 16, 61, 104, 205

probability-driven language learning 145-146 see also Van Parijs, Philippe

Protagoras 107

public sphere 17, 133, 135, 137-138, 165, 169n3

Q-value 146 see also De Swaan, Abram

Reiß, Katharina 100

Reissner, Christina 162-163, 165

reversibility principle 111-112, 144, 184, 204, 206

Ricento, Thomas 27, 37n8, 63, 81n24

Ricoeur, Paul 13, 15, 20, 35, 101-102, 121n21, 191, 206

Rorty, Richard 199

Ruiz, Richard 66

Sapir-Whorf hypothesis 14-15

Saussure, Ferdinand de 10, 18, 102

Schleiermacher, Friedrich 99-100

Seidlhofer, Barbara 27-33

shared destiny or fate 128-131, 133, 137, 169n2, 206

Shohamy, Elana 22, 37n8, 65, 166

Shuibhne, Niamh Nic 186

sieben Siebe 163-164

Skutnabb-Kangas, Tove 58, 68, 141 social justice $33,68-71,73,78,82 \mathrm{n} 28,153$

sous rature 107

Spolsky, Bernard 64, 68-69, 140-141

statistics 1-3, 27, 33, 45, 60-62, 70, 74-76, 91-94, 116-117, 132, 135-136, 139-140, 149, 157, 162-164, 195, 208

Stegmann, Tilbert D. 163-164

Steiner, George 7-8, 14-16, 19, 98, 100

territoriality principle $68,141,144$, 146-147, 151, 199

Tollefson, James W. 64, 71, 81n24

transcultural competence $69,113,118$, 128, 161-168, 172n23, 181-199, 212-213 see also intercomprehension and transcultural turn

transcultural turn 128, 139, 161-168, 181-199, 205 see also intercomprehension and transcultural competence

translanguage 113

translatability 19, 90, 98-109, 117, 120n14, 120n15, 189, 206

translation turn 112, 115, 118, 167, 181-199, 205

transnationalism 61, 127, 133, 135-137, 147, 169n3, 181, 206

Tsuda, Yukio 58

Turkish (language) 2, 23, 45, 54, 79n3, 80n14, 187, 200n7

unity and multiplicity 108-109, 112, 116-118, 127, 129, 133, 135-136, 138, 167, 184, 204-206

universal linguistic human rights paradigm 58-59, 66

untranslatability see translatability

Ursprache 13, 35, 101

Ushioda, Ema 154

van Gunsteren, Herman 131, 169n2

Van Parijs, Philippe 23, 60, 141, 143-147, 150, 160-161, 165, 167, $171 \mathrm{n} 12$

Vattimo, Gianni 136

Venuti, Lawrence 100, 106-108

Vermeer, Hans J. 100, 103, 120n13

von Busekist, Astrid 138, 144

Weber, Max 141

Williams, Melissa 131, 137

World Englishes 25-27, 30, 34, 151, 160

Wright, Sue 37n13, 93-94, 132, 184, 192 